\title{
REVISTA
}

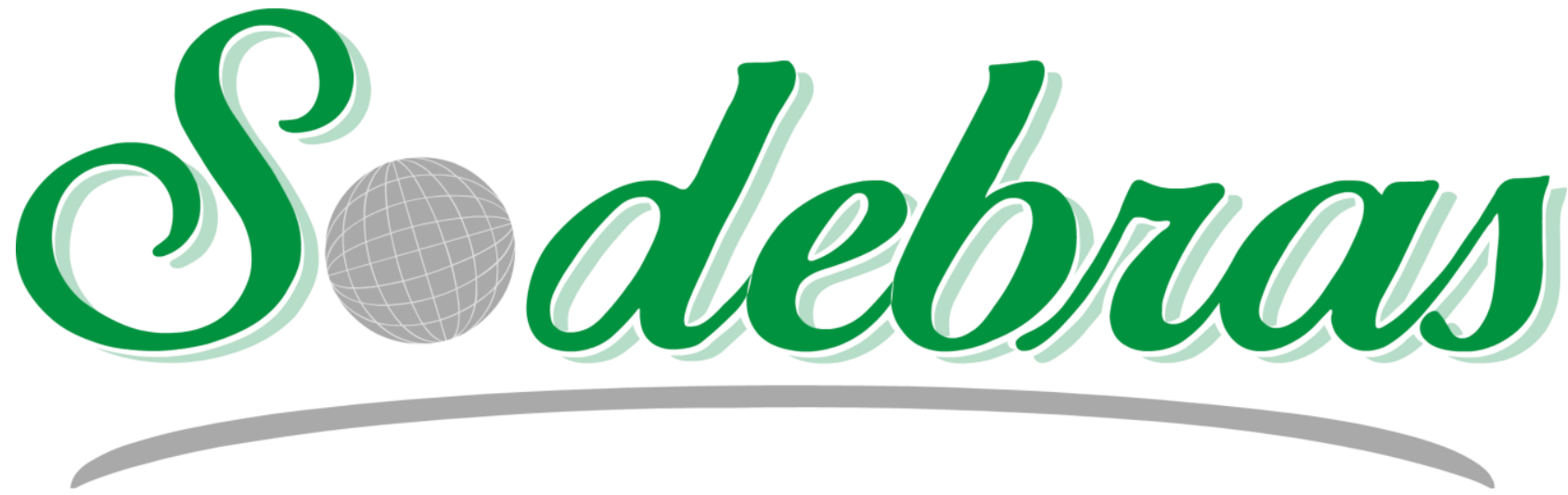

SOLUÇÕES PARA O DESENVOLVIMENTO DO PAÍS 


\title{
ARTIGOS PUBLICADOS
}

\author{
PUBLICAÇÃO MENSAL \\ Nesta edição
}

\begin{abstract}
ANÁLISE TÉCNICO-ECONÔMICA DA EFICIÊNCIA ENERGÉTICA DE UM PRÉDIO PÚBLICO - UM ESTUDO DE CASO
\end{abstract}

TECHNICAL-ECONOMIC ANALYSIS OF THE ENERGY EFFICIENCY OF A PUBLIC BUILDING - A CASE STUDY - Nayra G. Neves; Phellipe T. Dinardi; Vinicius C. De Serra; Walter A. V. Valenzuela

ANÁLISE DE REQUISITOS PARA VIABILIZAR A GESTÃO DE CONHECIMENTO EM DISPOSITIVO MÓVEL

ANALYSIS OF REQUIREMENTS TO PROVIDE MOBILE KNOWLEDGE MANAGEMENT - Andre Henrique

Dos Santos; Flávio Henrique Alves; Eduardo Heinemann; Eduardo Filgueiras Damasceno

AVALIAÇÃO EXPERIMENTAL DA TECNOLOGIA LORA EM CONDIÇÕES REAIS PARA O CLIMA TROPICAL

EXPERIMENTAL EVALUATION OF LORA TECHNOLOGY IN REAL CONDITIONS FOR TROPICAL CLIMATE - Wesen, Ednelson; Almeida, Thiago; Dinardi, Phelippe; Pereira, Luis; Vermehren, Victor; Valenzuela, Walter

DESENVOLVIMENTO DE UM ROBÔ GUIA REATIVO PARA ESCOLA SUPERIOR DE TECNOLOGIA

DEVELOPING A ROBOT REACTIVE GUIDE FOR A COLLEGE OF TECHNOLOGY - Adolpho Nilton Gloria; Moisés Pereira Bastos; Luís Eduardo Mena Barreto Pereira; Daniel De Souza Carolino; Almir Kimura Junior ...

IMPLEMENTAÇÃO DE NAVEGAÇÃO AUTÔNOMA E QRCODE NO ROBÔ GUIA REATIVO DA ESCOLA SUPERIOR DE TECNOLOGIA

IMPLEMENTATION OF AUTONOMOUS NAVIGATION AND QRCODE IN ROBOT REACTIVE GUIDE OF THE TECHNOLOGY'S COLLEGE - Kaique Correa Da Mota; Moisés Pereira Bastos; Mateus De Sousa Pantoja; Luís Eduardo Mena Barreto Pereira; Almir Kimura Junior

OPERAÇÕES CRUD UTILIZANDO BANCOS DE DADOS RELACIONAIS E NÃO RELACIONAIS

CRUD OPERATIONS USING RELATIONAL AND NON-RELATIONAL DATABASES - Nepomuceno, César; Lopes, Diego; Bastos, Moisés; Soares, André; Valenzuela, Walter

SE PUEDE PATENTAR EL SOFTWARE, UN ACERCAMIENTO A ESTA IDEA

SOFTWARE CAN BE PATENTED, A APPROACH TO THIS IDEA - Jorge Nerandy Escorcia Subiroz; Luana

Esteche Nunes Korocoski

UM ALGORITMO PARA GERAÇÃO DE ROTAS PARA COLETA DE RESÍDUOS SÓLIDOS NA CIDADE DE MANAUS UTILIZANDO DADOS IOT

AN ALGORITHM FOR THE GENERATION OF ROUTES FOR THE COLLECTION OF SOLID WASTE IN THE CITY OF MANAUS USING IOT DATA - Lopes, Diego; Neves, Nayra; Soares, André; Bastos, Moises;

Valenzuela, Walter

UMA APLICAÇÃO IOT COM PROTOCOLO MQTT PERSISTINDO EM MONGODB

AN IOT APPLICATION WITH MQTT PROTOCOL PERSISTING IN MONGODB - Albuquerque, Jesus; Chen, Daniel; Bastos, Moisés; Soares, André; Valenzuela, Walter 


\section{A (IN)COMPATIBILIDADE DO DIREITO DE DESCONEXÃO COM O TELETRABALHO}

THE (IN)COMPATIBILITY OF THE RIGHT OF DISCONNECTION WITH TELEWORK - Amanda Ferreir Primo; Luana Esteche Nunes Korocoski; Luiz Eduardo Dos Santos Pereira Gomes; Thiago Andre Fonseca Dos Santos

A MANIFESTAÇÃO DE VONTADE CONTRATUAL NOS APLICATIVOS, FRENTE AO CÓDIGO DE DEFESA DO CONSUMIDOR

THE EXPRESSION OF CONTRACTUAL WILL IN APPLICATIONS AND CONSUMER DEFENSE CODE Luana Esteche Nunes Korocoski; Thiago Andre Fonseca Santos; Luiz Eduardo Dos Santos Pereira Gomes; Amanda Ferreira Primo

VALIDADE DO RECONHECIMENTO POR FOTOGRAFIA COMO MEIO DE PROVA NO PROCESSO PENAL VALIDITY OF RECOGNITION BY PHOTOGRAPH AS A MEANS OF PROOF IN CRIMINAL PROCEEDINGS - Luana Esteche Nunes Korocoski; Thiago Andre Fonseca Santos; Luiz Eduardo Dos Santos Pereira Gomes; Amanda Ferreira Primo

INOVAÇÃO ABERTA NA GESTÃO PÚBLICA: O PAPEL DAS UNIVERSIDADES PÚBLICAS PARA UMA MELHOR EFICIÊNCIA DO ESTADO

OPEN INNOVATION IN PUBLIC MANAGEMENT: THE ROLE OF PUBLIC UNIVERSITIES FOR BETTER EFFICIENCY IN THE STATE - Daiane Tieme Kawahara Paiva; Ronie Galeano

SISTEMAS DE IRRIGAÇÃO AUTOMATIZADO: REVISÃO

AUTOMATED IRRIGATION SYSTEMS: REVIEW - Jampierre V. Rocha

SECAGEM DE AMOSTRAS DE BANANA: EFEITO DA GEOMETRIA DA AMOSTRA E DA TEMPERATURA DE SECAGEM

DRYING OF BANANAS SAMPLES - EFFECT OF SAMPLE GEOMETRY AND DRYING TEMPERATURE Kelly Hofsetz; Carolina Baraldi E Silva

PREVISÃO DE PRECIPITAÇÃO DE CHUVA USANDO SÉRIES TEMPORAIS E NEURO-FUZZY

FORECAST OF RAIN PRECIPITATION USING TIME SERIES AND NEURO-FUZZY - Jampierre V. Rocha;

Marcelo Da C. Ferreira; Taís B. Ferreira

AVALIAÇÃO DA INCERTEZA DE MEDIÇÃO NA CALIBRAÇÃO DE MEDIDOR DE VAZÃO DE LÍQUIDOS PELO MÉTODO GRAVIMÉTRICO

MEASUREMENT UNCERTAINTY IN THE CALIBRATION OF FLUID FLOW METER BY THE GRAVIMETRIC METHOD - Idrissa Deme

CARACTERIZAÇÃO DE FILME DE DIAMANTE CVD POLICRISTALINO DEPOSITADO EM SILÍCIO COM DIFERENTES ORIENTAÇÕES CRISTALINAS

CHARACTERIZATION OF POLYCRYSTALLINE CVD DIAMOND FILM DEPOSITED ON INTRINSIC SILICON WITH DIFFERENT CRYSTALLINE ORIENTATIONS - Alexandre Marcello Cavalca De Almeida; Evaldo Chagas Gouvêa; Teófilo Miguel De Souza

PLANEJAMENTO ELÉTRICO CIMATEC PARK: ESTUDO DE FLUXO DE POTÊNCIA, CURTO-CIRCUITO E PERDAS DA ATUAL REDE DE DISTRIBUIÇÃO DE ENERGIA ELÉTRICA DO COMPLEXO.

ELECTRICAL PLANNING CIMATEC PARK: STUDY OF POWER FLOW, SHORT-CIRCUIT AND LOSSES OF THE CURRENT NETWORK OF DISTRIBUTION OF ELECTRIC ENERGY OF THE COMPLEX. - Lucas Do Espirito Santo Fernandes; Tales Silva De Santana; Ana Tereza Andrade Borba; Luiz Fernando Taboada Gomes Amaral 
ANÁLISE ABRANGENTE DE SISTEMA HIDROSTÁTICO E DE TURBINA EÓLICA COM BASE BIBLIOMÉTRICA, 1983 - 2019

A COMPREHENSIVE ANALYSIS OF HYDROSTATIC SYSTEM AND WIND TURBINE WITH BIBLIOMETRIC BASE, 1983 - 2019 - Thamyres Machado David; Luciano Lizardo De Souza Guimarães; Vanessa Aparecidade De Sá Machado; Diego Menegusso Pires

ANÁLISE DA INFLUÊNCIA DO COMPORTAMENTO DO VENTO NA EFICIÊNCIA DE TURBINAS EÓLICAS DE EIXO VERTICAL UTILIZANDO CFD

ANALYSIS OF THE INFLUENCE OF WIND BEHAVIOR ON THE EFFICIENCY OF VERTICAL AXIS WIND TURBINES USING CFD - Alex R. A. Rodrigues; Claudinei R. Calado; Enzo R. R. Dos Santos

APLICAÇÃO DE FERRAMENTAS DA QUALIDADE NA ANÁLISE DE FALHAS EM MANGUEIRAS HIDRÁULICAS APLICADAS A ROV

APPLICATION OF QUALITY TOOLS IN FAILURE ANALYSIS IN HYDRAULIC HOSES APPLIED TO ROV Vanessa Aparecida De Sá Machado; Luciano Lizardo De Souza Guimarães; Wallice Medeiros De Souza;

Eyko Medeiros Rios

AUTOMATIZAÇÃO DE UMA BANCADA DE CALIBRAÇÃO DE MEDIDORES DE VAZÃO DE LÍQUIDOS

AUTOMATION OF A LIQUID FLOW METER CALIBRATION SYSTEM - Idrissa Deme

ESTUDO E DESENVOLVIMENTO DE UM MODELO MATEMÁTICO PARA UM MONOTRILHO ELÉTRICO DE ALTA VELOCIDADE MOVIDO A ENERGIA SUSTENTÁVEL, VISANDO A DIMINUIÇÃO DA EMISSÃO DE DIÓXIDO DE CARBONO NO DESLOCAMENTO ENTRE AS CIDADES DE SÃO PAULO E RIO DE JANEIRO

STUDY AND DEVELOPMENT OF A MATHEMATICAL MODEL FOR A ELECTRIC HIGH SPEED MONORAIL POWERED BY RENEWABLE ENERGY, LOOKING TO DECREASE THE DISPLACEMENT OF CARBON DIOXIDE IN THE DISPLACEMENT BETWEEN THE CITIES OF SÃO PAULO AND RIO DE JANEIRO Carlos Augusto Marcondes Dos Santos; Teófilo Miguel De Souza 


\section{Área: Interdisciplinar}

\begin{tabular}{|c|c|}
\hline $9-00$ & $\begin{array}{l}\text { ANÁLISE TEECNICO-ECONÔMICA DA EFICIÉNCIA ENERGETICA DE UM PRÉDIO } \\
\text { PÚBLICO - UM ESTUDO DE CASO } \\
\text { TECHNICAL-ECONOMIC ANALYSIS OF THE ENERGY EFFICIENCY OF A } \\
\text { PUBLIC BUILDING - A CASE STUDY } \\
\text { Nayra G. Neves; Phellipe T. Dinardi; Vinicius C. De Serra; Walter A. V. Valenzuela }\end{array}$ \\
\hline $9-00$ & $\begin{array}{l}\text { ANÁLISE DE REQUISITOS PARA VIABILIZAR A GESTÃO DE CONHECIMENTO } \\
\text { EM DISPOSITIVO MÓVEL } \\
\text { ANALYSIS OF REQUIREMENTS TO PROVIDE MOBILE KNOWLEDGE } \\
\text { MANAGEMENT } \\
\begin{array}{l}\text { Andre Henrique Dos Santos; Flávio Henrique Alves; Eduardo Heinemann; Eduardo } \\
\text { Filgueiras Damasceno }\end{array}\end{array}$ \\
\hline $9-00$ & $\begin{array}{l}\text { AVALIAÇÃO EXPERIMENTAL DA TECNOLOGIA LORA EM CONDIÇÕES REAIS } \\
\text { PARA O CLIMA TROPICAL } \\
\text { EXPERIMENTAL EVALUATION OF LORA TECHNOLOGY IN REAL CONDITIONS } \\
\text { FOR TROPICAL CLIMATE } \\
\text { Wesen, Ednelson; Almeida, Thiago; Dinardi, Phelippe; Pereira, Luis; Vermehren, } \\
\text { Victor; Valenzuela, Walter }\end{array}$ \\
\hline $9-00$ & $\begin{array}{l}\text { DESENVOLVIMENTO DE UM ROBÔ GUIA REATIVO PARA ESCOLA SUPERIOR } \\
\text { DE TECNOLOGIA } \\
\text { DEVELOPING A ROBOT REACTIVE GUIDE FOR A COLLEGE OF TECHNOLOGY } \\
\text { Adolpho Nilton Gloria; Moisés Pereira Bastos; Luís Eduardo Mena Barreto Pereira; } \\
\text { Daniel De Souza Carolino; Almir Kimura Junior }\end{array}$ \\
\hline $9-00$ & $\begin{array}{l}\text { IMPLEMENTAÇÃO DE NAVEGAÇÃO AUTÔNOMA E QRCODE NO ROBÔ GUIA } \\
\text { REATIVO DA ESCOLA SUPERIOR DE TECNOLOGIA } \\
\text { IMPLEMENTATION OF AUTONOMOUS NAVIGATION AND QRCODE IN ROBOT } \\
\text { REACTIVE GUIDE OF THE TECHNOLOGY'S COLLEGE } \\
\text { Kaique Correa Da Mota; Moisés Pereira Bastos; Mateus De Sousa Pantoja; Luís } \\
\text { Eduardo Mena Barreto Pereira; Almir Kimura Junior }\end{array}$ \\
\hline $9-00$ & $\begin{array}{l}\text { OPERAÇÕES CRUD UTILIZANDO BANCOS DE DADOS RELACIONAIS E NÃO } \\
\text { RELACIONAIS } \\
\text { CRUD OPERATIONS USING RELATIONAL AND NON-RELATIONAL } \\
\text { DATABASES } \\
\begin{array}{l}\text { Nepomuceno, César; Lopes, Diego; Bastos, Moisés; Soares, André; Valenzuela, } \\
\text { Walter }\end{array}\end{array}$ \\
\hline $9-00$ & $\begin{array}{l}\text { SE PUEDE PATENTAR EL SOFTWARE, UN ACERCAMIENTO A ESTA IDEA } \\
\text { SOFTWARE CAN BE PATENTED, A APPROACH TO THIS IDEA } \\
\text { Jorge Nerandy Escorcia Subiroz; Luana Esteche Nunes Korocoski }\end{array}$ \\
\hline
\end{tabular}




\begin{tabular}{|l|l|}
\hline 9-00 & $\begin{array}{l}\text { UM ALGORITMO PARA GERAÇÃO DE ROTAS PARA COLETA DE RESÍDUOS } \\
\text { SÓLIDOS NA CIDADE DE MANAUS UTILIZANDO DADOS IOT }\end{array}$ \\
& $\begin{array}{l}\text { AN ALGORITHM FOR THE GENERATION OF ROUTES FOR THE COLLECTION } \\
\text { OF SOLID WASTE IN THE CITY OF MANAUS USING IOT DATA } \\
\text { Lopes, Diego; Neves, Nayra; Soares, André; Bastos, Moises; Valenzuela, Walter }\end{array}$ \\
\hline 9-00 & UMA APLICAÇÃO IOT COM PROTOCOLO MQTT PERSISTINDO EM MONGODB \\
& $\begin{array}{l}\text { AN IOT APPLICATION WITH MQTT PROTOCOL PERSISTING IN MONGODB } \\
\text { Albuquerque, Jesus; Chen, Daniel; Bastos, Moisés; Soares, André; Valenzuela, } \\
\text { Walter }\end{array}$ \\
\hline
\end{tabular}




\author{
Volume $16-\mathrm{N}^{\mathrm{o}} 174$ - Junho / 2020 \\ XLII International Sodebras Congress \\ 28 a 30 de maio de 2020 - Web Conference.
}

\title{
ANÁLISE TÉCNICO-ECONÔMICA DA EFICIÊNCIA ENERGÉTICA DE UM PRÉDIO PÚBLICO - UM ESTUDO DE CASO
}

\section{TECHNICAL-ECONOMIC ANALYSIS OF THE ENERGY EFFICIENCY OF A PUBLIC BUILDING - A CASE STUDY}

\author{
NAYRA G. NEVES; PHELLIPE T. DINARDI; VINICIUS C. DE SERRA; WALTER A. V. VALENZUELA \\ UNIVERSIDADE DO ESTADO DO AMAZONAS
}

ngn.eng16@uea.edu.br; ptd.eng16@uea.edu.br; viniciusserra89@gmail.com,wvalenzuela@uea.edu.br

\begin{abstract}
Resumo - Realizou-se uma análise nos sistemas energéticos da Universidade do Estado do Amazonas (UEA) para propor melhorias em relação ao consumo de energia em prédios públicos pertencente a instituição. Para avaliar as possíveis melhorias realizou-se inicialmente uma análise quantitativa e da potência atual dos sistemas de iluminação e climatização da Universidade e para avaliar o impacto da substituição por equipamentos mais eficientes utilizou-se os indices financeiros específicos (Payback composto, Taxa Interna de Retorno, Valor Presente Líquido) como pré-diagnóstico energético. Os resultados energéticos no sistema de iluminação apresentaram uma redução de cerca de $47 \%$ da potência consumida enquanto que no sistema de climatização teve uma redução de $44 \%$.

Palavras-chave: Eficiência Energética 1. Iluminação 2. Ar condicionado 3.
\end{abstract}

\begin{abstract}
An analysis was carried out in the energy systems of the Amazonas State University (UEA) to propose improvements in relation to energy consumption in public buildings belonging to the institution. In order to evaluate the possible improvements, a quantitative analysis and of the present power of the lighting and air conditioning systems of the University were initially carried out and to evaluate the impact of substitution by more efficient equipment, specific financial indexes (Composite Payback, Internal Rate of Return, Net Present Value) were used as energy pre-diagnosis. The energy results in the lighting system showed a reduction of about $47 \%$ of the power consumed while in the air-conditioning system there was a reduction of $44 \%$.
\end{abstract} Keywords: Energy Efficiency 1. Lighting 2. Air conditioning 3.

\section{INTRODUÇÃO}

Na década de 70 , surgiram as primeiras ideias de conservação de energia oriunda, principalmente, da crise do petróleo de 1973 a 1979. Mais tarde, em 1997, com o protocolo de Kyoto a ideia de conservação de energia se consolidou principalmente com a criação de instituições que estabeleceram programas que visam promover a eficietização energética nos mais diversos setores do processo produtivo, residenciais e governamentais (MOREIRA \& GIOMETTI, 2010).

No Brasil, surgiram programas de eficiência Energética voltados para o uso racional de recursos naturais, por exemplo, o Programa Nacional de Conservação de Energia Elétrica (PROCEL), o Programa Nacional de Racionalização do Uso dos Derivados do Petróleo e Gás Natural (CONPET) e o Programa Brasileiro de Etiquetagem
(PBE), com a finalidade de promover a sustentabilidade ambiental e socioeconômica.

Além de germinar a ideia de conservação ambiental muitos consumidores e gestores veem a ideia de conservação de energia como uma maneira de poupar gastos, por meio de projetos de eficiência energética mediante execução de medidas embasadas em conhecimentos aplicados, empregando conceitos de engenharia, economia e administração aos sistemas energéticos (MILTON et al, 2007).

No entanto antes de executar medidas que tornam sistemas mais eficientes é necessário conhecer e diagnosticar a realidade energética do mesmo para estabelecer prioridades e implementar projetos de melhoria e redução de perdas. De acordo com o Centro de Pesquisas de Energia Elétrica (CEPEL) em seu Guia para eficietização energética nas edificações públicas os subsistemas de iluminação e climatização estão dentre os responsáveis que mais consomem energia elétrica em edifícios públicos. Por esse motivo a prioridade estabelecida a este estudo de caso serão os subsistemas mencionados em CEPEL (2014).

Nesse contexto, projetos de eficiência energética devem ser medidos de forma a encontrar justificativas econômicas que permitam sua implementação. Não é razoável adotar procedimentos para eficientizar um sistema a qualquer custo, por isso em projetos como esse é necessário constituir uma análise econômica através de indicadores de viabilidade financeira.

Este trabalho descreve os dispositivos e parâmetros utilizados para implementar melhorias em relação ao consumo de energia em prédios públicos pertencente a Universidade do Estado do Amazonas, bem como instituir uma análise quantitativa da viabilidade das medidas realizadas por intermédio de índices financeiros específicos.

\section{METODOLOGIA}

O estudo de caso, de caráter descritivo e exploratório de abordagem quantitativa desenvolveu-se nos edifícios situados em Manaus da Universidade do Estado do Amazonas (UEA). O estudo foi realizado em quatro escolas de ensino superior, Escola Superior de ciências da Saúde (ESA), Escola Superior de Artes e Turismo (ESAT), Escola Normal Superior (ENS) e Escola Superior de Ciências Sociais (ESO) além da Policlínica de Odontologia, do 
Núcleo de Práticas Jurídicas (NPJ) e do Núcleo de Atendimento a Pacientes Especiais (NAOPE).

Todos os locais alvos do estudo pertencem ao grupo A da classe de poder público dos grupos tarifários da 1 .
Amazonas Energia S/A (Ame) com exceção do NAOPE e NPJ, pertencente ao grupo B de mesma classe. Os dados com as características dos consumidores constam na tabela 1.

Tabela 1- Características dos consumidores

\begin{tabular}{ccccc}
\hline & Grupo & Horário & Energia consumida* (kWh) & Faturas mensais* \\
\hline ESA & A & Verde & 112200,00 & $\mathrm{R} \$ 62.359,76$ \\
ENS & A & Verde & 42835,55 & $\mathrm{R} \$ 22.161,39$ \\
ESO & A & Convencional & 61544,00 & $\mathrm{R} \$ 31.035,13$ \\
ESAT & A & Verde & 58400,00 & $\mathrm{R} \$ 31.737,25$ \\
POLICLINICA & A & Verde & 57860,00 & $\mathrm{R} \$ 34.254,65$ \\
NAOPE & B & - & 4819,60 & $\mathrm{R} \$ 3.080,31$ \\
NPJ & $\mathrm{B}$ & - & 3440,00 & $\mathrm{R} \$ 2.031,65$ \\
\hline
\end{tabular}

* Valor médio mensal do consumo, constantes das 12 últimas faturas.

Fonte: Levantamento dos Autores.

Buscando implementar medidas de eficiência energética para reduzir custos das faturas de energia, realizou-se um estudo de caso para os sistemas de iluminação e climatização nas respectivas escolas, pois ambos são os principais responsáveis pelo consumo de energia (CEPEL, 2014) em torno de 80\%. Diante de pesquisas realizadas para alternativas mais eficientes disponíveis no mercado para a substituição dos sistemas da universidade optou-se em substituir lâmpadas fluorescentes por lâmpada com tecnologia LED de fluxo luminoso equivalente e substituir os condicionados de ar convencionais para os de tecnologia inverter de mesma capacidade de refrigeração.

O gráfico 1 ilustra o percentual de condicionadores de ar do tipo HI-Wall em função de suas classes após testes de eficiência do INMETRO.

Gráfico 1 - Ar condicionados por classe de eficiência

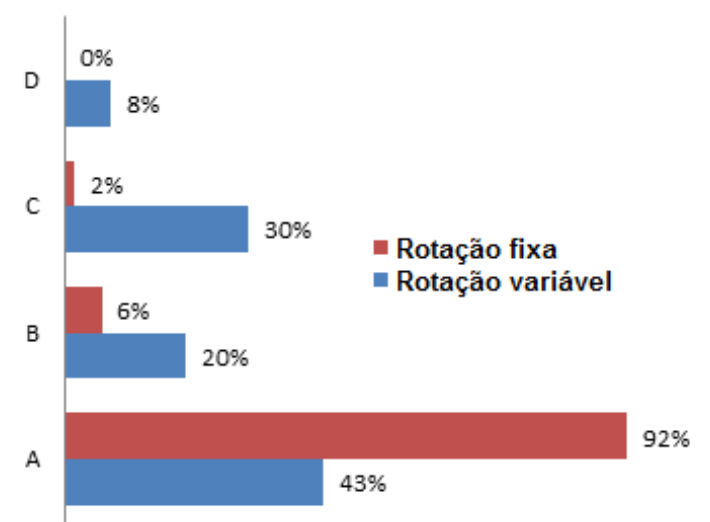

Fonte: Elaborado a partir Inmetro (2018).

Do gráfico 1 é possível constatar que os aparelhos de climatização com compressor de rotação variável assume um papel importante na classificação de eficiência A, 92\% dos Split $H i$-wall inverter testado apresentam a maior classificação energética, logo para operar nas mesmas condições que o outro modelo os climatizadores com tecnologia inverter consomem menor potência.

A tabela 2 mostra o comparativo de eficiência entre a lâmpada LED e a fluorescente. A partir dos índices da tabela 2 , é concebível a proporcionalidade entre o fluxo luminoso e a potência na fluorescente, visto que para produzir um fluxo luminoso alto requer uma potência diretamente maior, fazendo com que a eficiência energética, dada em $1 \mathrm{~m} / \mathrm{W}$, seja baixa comparada a eficiência da lâmpada em LED.

Tabela 2 - Eficiência energética por tipo de lâmpada

\begin{tabular}{cccc}
\hline Tipo & $\begin{array}{c}\text { Potência } \\
(\mathbf{W})\end{array}$ & $\begin{array}{c}\text { Fluxo } \\
\text { luminoso } \\
(\mathbf{l m})\end{array}$ & $\begin{array}{c}\text { Eficiência } \\
\text { energética } \\
(\mathbf{l m} / \mathbf{W})\end{array}$ \\
\hline $\begin{array}{c}\text { Fluorescente } \\
\text { LED }\end{array}$ & 36 & 2500 & 69,444 \\
& 18 & 2000 & 111,111 \\
\hline
\end{tabular}

Fonte: LEDVANCE (2019).

Os valores apresentados na Tabela 2 estabelecem uma diferença evidente entre parâmetros de eficiência. A relação entre a potência e o fluxo luminoso torna possível substituir os modelos convencionais por suas equivalentes em modelos de tecnologia mais eficientes sem a necessidade de trocar a luminária e do uso de reatores eletromagnéticos.

A partir da implementação dessas medidas explorou-se em conjunto o método quantitativo e qualitativo de engenharia econômica e decisões de projeto, descritas e detalhadas por Avila (2013). Foram aplicados indicadores financeiros, Valor Presente Líquido (VPL), payback descontado e a Taxa Interna de Retorno (TIR). Tais indicadores têm por objetivo retornar o tempo de retorno do investimento inicial a ser feito na troca dos sistemas, correspondente ao payback e o ganho total com o investimento, através do VPL no qual é associado ao que denominamos de Taxa Mínima de Atratividade (TMA) e corresponde a taxa mínima estabelecida que o investimento deverá produzir para ser atraente. Já o TIR é a taxa de retorno anual composta que a empresa obterá, se investir no projeto e receber as entradas de caixas previstas, e geralmente nas decisões de projetos é comparado a TMA estabelecida.

A Taxa Mínima de Atratividade estabelecida foi a taxa de juros do Sistema Especial de Liquidação e Custódia (SELIC), pois é a taxa básica de juros da economia no Brasil, utilizada no mercado interbancário para financiamento e serve de referência para outras taxas da economia (ANZANELLO \& WENER, 2018).

Por meio das faturas de energia elétrica dos prédios de agosto de 2017 a julho de 2018 obtivemos as características do sistema elétrico de cada escola e demais edifícios. A coleta de dados foi realizada a partir do levantamento de carga do sistema de iluminação e climatização por intermédio de inspeção nos edifícios de modo a obter a quantidade, tipo, potência e tempo mensal de utilização das lâmpadas e condicionadores de ar. 
Os dados coletados das características do sistema foram analisados de forma quantitativa onde pode-se dimensionar a participação dos sistemas de refrigeração e iluminação na potência total consumida no qual proporcionam o embasamento para estabelecer os índices financeiros do investimento no projeto de eficiência energética estabelecido mediante substituições de parâmetros por alternativas mais eficientes.

\section{RESULTADOS}

As despesas com Energia Elétrica de todos os imóveis da Universidade do Estado do Amazonas, situados em Manaus, somam trezentos mil reais em média, de modo que $79 \%$ desse total são faturados do consumo de energia elétrica, gráfico 2 .

Gráfico 2 - Fatura detalhada para consumidores do grupo A

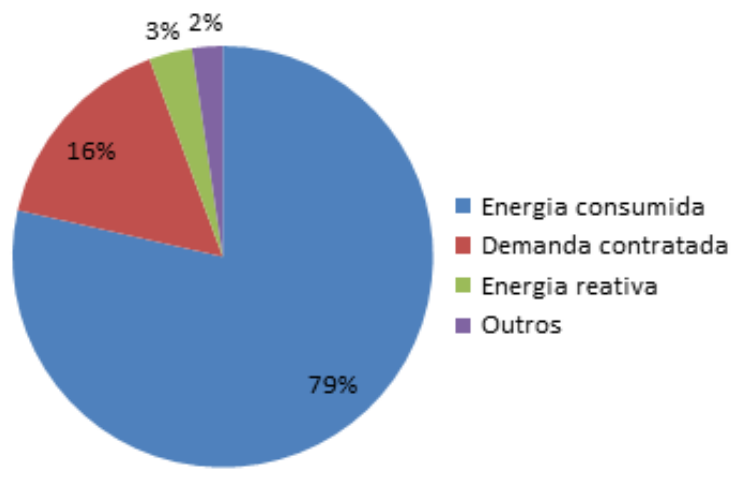

Fonte: Faturas período de agosto de 2017 a julho de 2018 - Ame.

O gráfico 2 indica os principais responsáveis pelas despesas de faturamento em energia elétrica dos locais pesquisados, onde a demanda contratada corresponde a um percentual significativo de $16 \%$, esse valor trata-se da demanda de potência ativa a ser continuamente disponibilizada pela concessionária e que deverá ser integralmente paga. A NAOPE e o NPJ enquadram-se no grupo B e por consequência não pagam demanda contratada nem energia reativa assim seu faturamento é proveniente apenas da quantidade de energia consumida. Por outro lado, a ESA e a POLICLÍNICA pagam em energia reativa, respectivamente, $\mathrm{R} \$ 4.735,44$ e $\mathrm{R} \$ 1.547,76$, em média, correspondente a $8 \%$ e $5 \%$ de suas faturas. Por sua vez, a ESAT chega a $4 \%$ e a ENS com $2 \%$.

A partir do levantamento quantitativo nos subsistemas foi dimensionado suas respectivas participações na energia total consumida das escolas. Nesse âmbito as lâmpadas fluorescentes de $40 \mathrm{~W}$ são as mais utilizadas na instituição, por conseguinte elas impactam diretamente o consumo de energia. Além de sua própria potência há também o consumo dos reatores magnéticos ou eletromagnéticos, que tanto acrescem no consumo de energia ativa como também geram energia reativa no sistema.

De mesmo modo, no sistema de climatização utilização de ar condicionados do tipo convencional, de rotação fixa, é maioria absoluta. A grande quantidade desses eletrodomésticos na instituição assim como sua alta potência de operação contribui para assumir a maior parte do consumo de energia, conforme o gráfico 3 que mostra uma média do percentual de cooperação de cada subsistema no consumo total de energia elétrica da universidade.
Gráfico 3 - Parcela dos subsistemas na energia consumida.

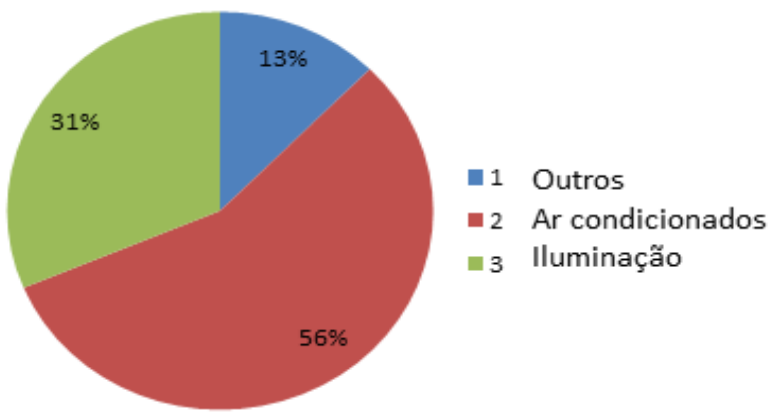

Fonte: Compilação dos autores.

Analisando o Gráfico 3, verifica-se que $56 \%$, correspondem ao consumo de energia do sistema de climatização médio nos locais pesquisados. Os aparelhos condicionadores de ar da instituição possuem uma carga térmica elevada por se tratar de um ambiente escolar onde o número de pessoas em um mesmo ambiente é grande. Uma alta carga térmica corresponde a uma potência elétrica de operação maior que juntando as altas temperaturas da cidade de Manaus, cerca de $42{ }^{\circ} \mathrm{C}$ em dias mais quentes, consomem mais energia.

Diante dos parâmetros estabelecidos para tornar eficiente o sistema, os valores calculados para a substituição sugerida, constam na Tabela 3, com a energia consumida em $\mathrm{kWh}$ das escolas e prédios administrativos.

Tabela 3 - Consumo Atual e Proposto em kWh

\begin{tabular}{ccccc}
\hline & \multicolumn{2}{c}{ Iluminação } & \multicolumn{2}{c}{ Climatização } \\
\hline & Atual & Proposto & Atual & Proposto \\
ESA & 13342,59 & 8697,42 & 51400,80 & 28784,45 \\
ENS & 5973,62 & 2699,32 & 26458,93 & 14817,00 \\
ESO & 8122,93 & 4557,71 & 34996,69 & 19598,14 \\
ESAT & 9049,81 & 5959,03 & 33333,49 & 18666,76 \\
POLICLINICA & 7759,46 & 3853,66 & 40597,20 & 22734,43 \\
NAOPE & 842,24 & 379,01 & 2624,47 & 1469,71 \\
NPJ & 187,12 & 84,20 & 2215,95 & 1240,93 \\
\hline \multicolumn{5}{c}{ Fonte: Elaboração dos Autores } \\
\hline
\end{tabular}

Analisando os resultados obtidos, Tabela 3, verificase a redução nos subsistemas após as mudanças de eficiência propostas por meio dos cálculos do consumo de energia levando em consideração o mesmo tempo para as mesmas características de ambientes, no sistema de iluminação ocorreu uma redução de cerca de $47 \%$ da potência consumida enquanto que no sistema de refrigeração teve uma redução de $44 \%$, conforme o dimensionado da carga.

NPJ foi o que mais reduziram seus consumos de energia, de um total de $2403,7 \mathrm{kWh}$ para $1325,136 \mathrm{kWh}$, porque não possuíam nenhuma lâmpada em LED em seu subsistema de iluminação, dando a possibilidade de reduzir em quase $50 \%$ da potência de seu sistema atual. Por outro lado, a ESAT e a ESA obtiveram as menores reduções, cerca de $34 \%$ e $35 \%$, respectivamente, pois seus subsistemas já possuíam um número significado de lâmpadas em LED de $20 \mathrm{~W}$ nos lugares das de $40 \mathrm{~W}$. O valor de $44 \%$ do sistema de climatização corresponde ao percentual médio fornecido pelos fabricantes, podendo variar de acordo com a temperatura e outros critérios técnicos que tanto podem 
aumentar a economia quanto diminuir dependendo do tipo de consumidor (LG, 2018).

Para a troca dos equipamentos foi realizado um levantamento de preços e feito uma média não probabilística dos dados coletados. Nas tabelas 4 e 5 estão os preços médios das lâmpadas e condicionadores de ar bem como o preço médio para suas instalações.

Tabela 4 - Preço médio Ar condicionado inverter

\begin{tabular}{ccc}
\hline BTU & Preço & Instalação \\
\hline 12000 & $\mathrm{R} \$ 2.136,75$ & $\mathrm{R} \$ 769,00$ \\
18000 & $\mathrm{R} \$ 3.001,50$ & $\mathrm{R} \$ 825,00$ \\
22000 & $\mathrm{R} \$ 3.328,75$ & $\mathrm{R} \$ 989,00$ \\
24000 & $\mathrm{R} \$ 3.733,89$ & $\mathrm{R} \$ 989,00$ \\
30000 & $\mathrm{R} \$ 6.074,14$ & $\mathrm{R} \$ 1.039,00$ \\
36000 & $\mathrm{R} \$ 7.927,67$ & $\mathrm{R} \$ 1.099,00$ \\
48000 & $\mathrm{R} \$ 10.306,50$ & $\mathrm{R} \$ 1.259,00$ \\
60000 & $\mathrm{R} \$ 13.068,00$ & $\mathrm{R} \$ 1.259,00$ \\
\hline
\end{tabular}

Fonte: Levantamento dos autores, dados coletados em dez/2018.

Tabela 5 - Preço médio lâmpadas LED

\begin{tabular}{ccc}
\hline Tipo & Preço & Instalação \\
\hline TUBULAR 18 W & $\mathrm{R} \$ 21,20$ & \\
$120 \mathrm{~cm}$ & & \\
TUBULAR 9 W & $\mathrm{R} \$ 13,26$ & $\mathrm{R} \$ 18,00$ \\
$60 \mathrm{~cm}$ & $\mathrm{R} \$ 30,40$ & \\
Compacta $15 \mathrm{w}$ & $\mathrm{R} \$ 27,00$ & \\
Compacta 5 w & \\
\hline
\end{tabular}

Fonte: Levantamento dos autores, dados coletados em dez/2018.
A partir do levantamento de preços definidos é possível realizar uma análise econômica entre a troca dos sistemas convencionais para os sistemas energeticamente mais eficientes.

$\mathrm{Na}$ Tabela 6 estão os valores calculados dos indicadores financeiros para trocar uma lâmpada fluorescente de $40 \mathrm{~W}$ por uma lâmpada de $18 \mathrm{~W}$ com uso de 240 hora/mês para um consumidor do grupo A com base na tarifação da AmE-2017 Resolução homologatória No 2.337 de ANEEL (2017). A taxa mínima de atratividade (TMA) utilizada no cálculo do valor presente líquido (VPL) foi a do SELIC de 6,5\% anual correspondente ao mês de maio do ano de 2019 (RECEITA FEDERAL, 2019). O consumo do sistema atual e do proposto são de respectivamente, em reais, 6,27 e 2,82. A vida útil da lâmpada levada em consideração no cálculo foi de 25.000 horas resultando em um tempo de vida útil do sistema de 120,77 meses a partir de um investimento inicial de $\mathrm{R} \$ 21,20$ com instalação de $\mathrm{R} \$ 18,00$ com base nas pesquisas de mercado realizadas.

Analogamente, na Tabela 7 estão os valores calculados para a substituição dos equipamentos do sistema de climatização de tecnologia convencional por um de tecnologia inverter com uso de $240 \mathrm{~h} / \mathrm{mês}$. A taxa mínima de atratividade (TMA) utilizada também foi a do SELIC em maio/2019. O consumo do sistema atual e do proposto são de respectivamente, em reais, 252,56 e 141,43 . A vida útil da lâmpada levada em consideração no cálculo foi de 10 anos resultando em um tempo de vida útil do sistema de 120 meses a partir de um investimento inicial de $\mathrm{R} \$ 3.001,50$ com instalação de $\mathrm{R} \$ 825,00 \mathrm{com}$ base nas pesquisas de mercado realizadas.

Tabela 6 - Indicadores para troca de uma lâmpada LED

\section{Características do Sistema de Iluminação}

\begin{tabular}{ccccccc}
\hline \multicolumn{7}{c}{ Características do Sistema de Iluminação } \\
\hline $\begin{array}{c}\text { Indicadores financeiros } \\
\text { Período }\end{array}$ & 0 & 1 & 2 & $\ldots$ & 119 & 120 \\
$\begin{array}{c}\text { Economia do } \\
\text { período }\end{array}$ & $-\mathrm{R} \$ 39,20$ & $\mathrm{R} \$ 3,45$ & $\mathrm{R} \$ 3,45$ & $\ldots$ & $\mathrm{R} \$ 3,45$ & $\mathrm{R} \$ 3,45$ \\
Valor presente & $-\mathrm{R} \$ 39,20$ & $\mathrm{R} \$ 3,43$ & $\mathrm{R} \$ 3,41$ & $\ldots$ & $\mathrm{R} \$ 1,85$ & $\mathrm{R} \$ 1,84$ \\
Fluxo de caixa & $-\mathrm{R} \$ 39,20$ & $-\mathrm{R} \$ 35,77$ & $-\mathrm{R} \$ 32,36$ & $\ldots$ & $\mathrm{R} \$ 265,09$ & $\mathrm{R} \$ 266,93$ \\
VPL & $\mathrm{R} \$ 266,93$ & & & & & \\
$\begin{array}{c}\text { Payback } \\
\text { descontado }\end{array}$ & 11,75841 & 0,979867515 & & & & \\
TIR descontado & $8,22 \%$ & & & & &
\end{tabular}

Fonte: Elaboração dos Autores.

Tabela 7 - Indicadores para ar condicionado inverter

\begin{tabular}{ccccccc}
\hline \multicolumn{7}{c}{ Características do sistema de climatização } \\
\hline \multicolumn{7}{c}{ Indicadores financeiros } \\
Período & 0 & 1 & 2 & $\ldots$ & 119 & 120 \\
Economia do & $-\mathrm{R} \$ 3.826,50$ & $\mathrm{R} \$$ & $\mathrm{R} \$$ & $\ldots$ & $\mathrm{R} \$$ & $\mathrm{R} \$$ \\
período & & 11,13 & 111,13 & $\ldots$ & 111,13 & 111,13 \\
VP & $-\mathrm{R} \$ 3.826,50$ & 110,54 & 109,97 & $\ldots$ & 59,52 & 59,21 \\
& & $-\mathrm{R} \$$ & $-\mathrm{R} \$$ & & $\mathrm{R} \$$ & $\mathrm{R} \$$ \\
Fluxo de caixa & $-\mathrm{R} \$ 3.826,50$ & $3.715,96$ & $3.605,99$ & $\ldots$ & $5.983,93$ & $6.043,14$ \\
VPL & $\mathrm{R} \$ 6.043,14$ & & & & & \\
Payback & 38,088708 & 3,17405903 & & & & \\
descontado & $2,26 \%$ & & & &
\end{tabular}


A troca de uma única lâmpada gera uma economia mensal de $\mathrm{R} \$ 3,45$ que ao longo de um período estimado de vida do sistema de 120 meses gerará um lucro, Valor presente líquido, de $\mathrm{R} \$ 266,93$ de tal modo que o investimento será pago em 11,75 meses correspondendo a uma Taxa Interna de Retorno de 8,22\%, ou seja, muito maior que a Taxa Mínima de Atratividade estabelecida tornando, a troca de apenas uma lâmpada em LED economicamente e energeticamente executável.

A taxa interna de retorno do condicionador de ar também foi maior que a Taxa mínima de atratividade.
Embora menor que o TIR da LED ainda é um investimento economicamente e energicamente possível. A taxa inferior é consequência do alto valor de aquisição do aparelho de tecnologia inverter no qual levara mais tempo para ser pago tornando o payback maior e o TIR menor.

Nas Tabelas 8 e 9 estão os valores encontrados dos indicadores financeiros dos sistemas de iluminação e de climatização, respectivamente, das escolas e prédios administrativos da Universidade do Estado do Amazonas.

Tabela 8 - Indicadores financeiros troca pelo sistema mais eficiente de iluminação

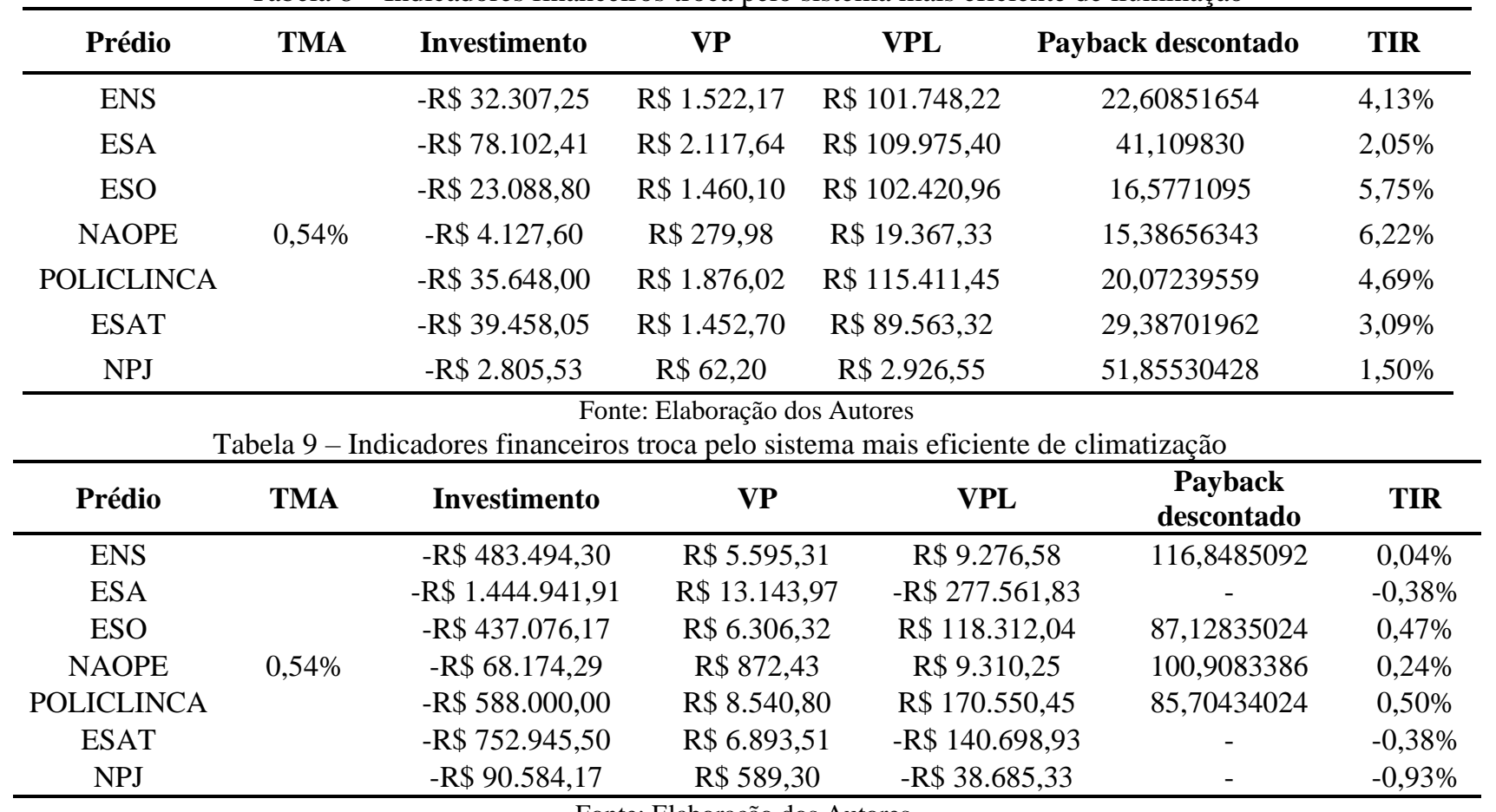

Fonte: Elaboração dos Autores.

Os indicadores financeiros, Valor Presente Líquido, ou ganho, e Taxa Interna de Retorno, resultaram valores positivos para as propostas de intervenção no sistema de iluminação, a TIR de todas as escolas e prédios foram superiores à Taxa Mínima de Atratividade, onde a NAOPE ficou com a maior taxa, $6,22 \%$ e com o menor payback de 15,38 meses. O ganho final, VPL, apresentou-se no total de $\mathrm{R} \$ 19.367,33$ com um investimento inicial de apenas $\mathrm{R} \$$ 4.127,60. O maior faturamento, ocorreu na policlínica e na ESA onde o tempo para pagar o investimento foi os dois maiores em comparação aos outros, com 20,07 e 41,10 meses.

Os índices financeiros da substituição dos equipamentos de climatização apresentaram TIR ruins em comparação a SELIC estando contemplados numa faixa de $0,93 \%$ até $0,5 \%$. A obtenção negativa inviabiliza a realização das trocas como proposta de eficietização do sistema de prédios, pois o valor total a ser investido supera grandemente a economia proporcionada. No período estabelecido dos equipamentos corroboram para a ineficácia econômica deste projeto. Os prédios da ESA, NPJ e ESAT não retornaram saldo positivo no Valor Presente Líquido em função da economia oferecida não quitar o valor total investido ao longo do período de vida útil deste estudo. A substituição não se apresenta atrativa nesse cenário, mas com a popularização da tecnologia os preços tendem a baixar e o investimento pode vir a ser viável.

\section{CONCLUSÃO}

Neste estudo, a porcentagem de consumo dos sistemas de climatização e iluminação foram estimados por visitas técnicas e seu resultado impacta diretamente na precisão dos índices econômicos obtidos evidenciando que o dimensionamento correto é vital e crítico para o desenvolvimento da pesquisa. Além disso, a economia gerada pelo ar-condicionado de tecnologia inverter varia de acordo com o fabricante.

A substituição imediata de um sistema de iluminação convencional mostrou-se favorável em todos os casos estudados tendo sua menor taxa de retorno calculada em $1,5 \%$ ao mês apresentando-se três vezes maior que a taxa mínima mensal de atratividade estabelecida pelo Banco Central Brasileiro no qual foi utilizado para esse estudo.

A troca para o sistema de climatização não foi viável em nenhum dos prédios estudados, a maior taxa interna de retorno apresentada foi de $0,5 \%$ não superando a escolhida como mínima no projeto, isso se deve ao fato do alto investimento para aquisição de um número elevado de aparelhos de condicionadores de ar na instituição de ensino em que o estudo foi realizado. No entanto a substituição unitária do condicionador de ar do tipo tradicional pelo inverter é favorável e apresenta ganhos de investimento positivos assim como uma Taxa Interna de Retorno acima 
da Taxa Mínima de Atratividade tornando a substituição gradativa uma opção de investimento lucrativa e viável.

\section{REFERÊNCIAS BIBLIOGRÁFICAS}

AGÊNCIA NACIONAL DE ENERGIA ELÉTRICA. Resolução Normativa n. 414. ANEEL, 2010.

AGÊNCIA NACIONAL DE ENERGIA ELÉTRICA. Resolução Normativa n. 800. ANEEL, 2017.

ANEEL. Agência Nacional de Energia Elétrica. Resolução Homologatória No2.337. ANEEL, 2017. Disponível em:<http://www.eletrobrasamazonas.com/cms/wpcontent/uploads/2017/02/RESOLU\%C3\%87\%C3\%83OHOMOLOGAT\%C3\%93RIA-N\%C2\%BA-2.337-DE-31DE-OUTUBRO-DE-2017..pdf> Acesso em 30 abril 2019.

ANZANELlO, Jose David. WERNER, Liane. Análise de viabilidade econômica da implantação de sistemas de geração de energia solar fotovoltaica na cidade de Porto Alegre. VII Congresso Brasileiro de Engenharia de Produção. Ponta Grossa, PR, 2018.

AVILA, Antonio Victorino. Matemática financeira e engenharia econômica / Antonio Victorino Avila; Florianópolis. "Programa de Educação Tutorial da Engenharia Civil - UFSC", 2013.

CENTRO DE PESQUISAS DE ENERGIA ELÉTRICA CEPEL. Guia para eficientização energética nas edificações públicas. Versão 1.0. Coordenador Ministério de Minas e Energia - MME. Rio de Janeiro: CEPEL, 2014.

INMETRO. Instituto Nacional de Metrologia, Normalização e Qualidade Industrial. Gráfico 1. Condicionadores de ar split hi-wall 2018. Disponível em: :<http://www.inmetro.gov.br/consumidor/pbe/condicionador es_ar_split_hiwall_indicenovo.pdf $>$ Acesso em 20 maio 2019.

LEDVANCE. Catálogo LED 2019. Tabela 2. Lâmpadas Osram e Luminárias Ledvance. Disponível em: <https://www.voltimum.com.br/files/pdflibrary/00_ledvance _catalogo_led_2018_-_dezembro.pdf> Acesso em 20 maio 2019.

LG. Catálogo Ar condicionados 2018. Disponível em: <https://www.lg.com/br/ar-condicionado/conteudoextra/20917_LG_Take_One_Line_Up_Cond_de_Ar_2303.pdf> Acesso em 03 fev. 2019.

LIMA. Lucas F. Estudo de eficiência energética em aparelhos de condicionadores de ar e técnicas para redução de carga térmica nas edificações. Trabalho de Conclusão de Curso (Graduação) - Universidade Estadual de Londrina, Londrina, 2017.

MAMEDE FILHO, João. Instalações Elétricas Industriais. 9.Ed. Rio DE Janeiro. Editora LTC. 2017.

MILTON, Cesar Silva. et al. Eficiência energética: teoria \& prática. 1.Ed. Minas Gerais. FUPAI, 2007.

MOREIRA, Helena Margarido. GIOMETTI, Ana Lúcia Bueno. O Protocolo de Quioto e as Possibilidades de Inserção do Brasil no Mecanismo de Desenvolvimento Limpo por meio de Projetos em Energia Limpa. Rio de Janeiro, 2008.
RECEITA FEDERAL. Ministério da Economia. Taxa de juros SELIC. Disponível em: < http://receita.economia.gov.br/orientacao/tributaria/pagamen tos-e-parcelamentos/taxa-de-juros-selic > Acesso em $12 \mathrm{fev}$. 2020.

SANTOS, Talía Simões dos et al. Análise da eficiência energética, ambiental e econômica entre lâmpadas de LED e convencionais. Eng. Sanit. Ambient., Rio de Janeiro , v. 20, n. 4, p. 595-602, dez. 2015 . Disponível em:

<http://www.scielo.br/scielo.php?script=sci_arttext\&pid=S1 413-41522015000400595\&lng=pt\&nrm=iso $>$. Acesso em 02 mar. 2020.

VASCONCELOS e LIMBERGER. Iluminação eficiente: iniciativas da Eletrobrás PROCEL e parceiros. Rio de Janeiro: Eletrobrás PROCEL, 2013.

\section{AGADECIMENTOS}

Os autores agradecem à Pró-reitoria de Extensão e Assuntos Comunitários (PROEX/UEA), pelo suporte financeiro e ao apoio técnico e profissional dos funcionários e professores da Universidade do Estado do Amazonas. 


\author{
Volume $16-\mathrm{N}^{\mathrm{o}} 174$ - junho / 2020 \\ XLII International Sodebras Congress \\ 28 a 30 de maio de 2020 - Web Conference.
}

\title{
ANÁLISE DE REQUISITOS PARA VIABILIZAR A GESTÃO DE CONHECIMENTO EM DISPOSITIVO MÓVEL
}

\section{ANALYSIS OF REQUIREMENTS TO PROVIDE MOBILE KNOWLEDGE MANAGEMENT}

\author{
ANDRE HENRIQUE DOS SANTOS; FLÁVIO HENRIQUE ALVES, \\ EDUARDO HEINEMANN, EDUARDO FILGUEIRAS DAMASCENO; \\ UNIVERSIDADE TECNOLÓGICA FEDERAL DO PARANÁ
}

andrehs@outlook.com; fhalves@live.com, \{ heinemann,damasceno \}@utfpr.edu.br

\begin{abstract}
Resumo - A Gestão do Conhecimento (GC) é frequentemente relacionada a obtenção de vantagem competitiva, a inovação e ao desempenho organizacional, mas sua aplicação é complexa, exige investimentos volumosos e seus resultados práticos são de difícil mensuração. Neste contexto, surge a Gestão de Conhecimento Móvel, ou Mobile Knowledge Management (mKM), que emprega dispositivos móveis nos processos de GC a fim de alavancar os resultados e reduzir os custos. Esta pesquisa buscou a compreensão e levantamento dos requisitos de um aplicativo móvel para mKM. Os resultados obtidos foram comparados com softwares open source, e foi constatado que o Moodle é o melhor candidato para servir de plataforma para mKM. Por fim, foram elaborados diagrama em UML e protótipos do tipo wireframe sugerindo as alterações necessárias ao sistema para que ele atenda às necessidades da $\mathrm{mKM}$.
\end{abstract}

Palavras-chave: Gestão de Conhecimento. Gestão de Conhecimento Móvel. Análise de Requisitos.

Abstract - Knowledge Management (KM) is often related to
obtaining competitive advantage, innovation and organizational
performance, but its application is complex, requires massive
investments and its practical results are difficult to measure. In
this context, comes the Mobile Knowledge Management (mKM),
which uses mobile devices in the KM processes in order to
improve the results and reduce costs. This research sought to
understand and survey the requirements of a mobile application
for mKM. The results obtained were compared with open source
software, and it was found that Moodle is the best candidate to
serve as a platform for mKM. Finally, UML diagram and
wireframe prototypes were developed suggesting the necessary
changes to the system so that it meets the needs of mKM. Keywords: Knowledge Management. Mobile Knowledge Management. Requirements Analysis.

\section{INTRODUÇÃO}

O estudo bibliométrico realizado por Castro et al. (2019) sobre o assunto Gestão do Conhecimento (GC) no recorte temporal entre 2012 e 2018 identificou que os principais artigos produzidos buscam relacionar a $\mathrm{GC}$ ao desempenho organizacional, inovação e obtenção de vantagem competitiva.

Dentre os artigos pesquisados, destacam-se os de Andreeva e Kianto (2012), que concluem que a GC é um facilitador do alto desempenho organizacional, capaz de influenciar a competitividade empresarial e os resultados econômicos e financeiros; Lee, Kim e Kim (2012), que apontam a Tecnologia da Informação (TI) como principal infraestrutura para as práticas de GC; e Massingham e Massingham (2014), que explicam que os resultados da GC influenciam o desempenho organizacional de forma indireta e, por isso, não podem ser projetados ou mensurados através de técnicas tradicionais, que são predominantemente baseadas nos resultados financeiros.

Porém, apesar de seus benefícios, os investimentos necessários em infraestrutura para GC são elevados e seus resultados demoram para serem percebidos, pois dependem da plena utilização dos sistemas propostos (ANDREEVA e KIANTO, 2012).

Neste contexto, surge uma abordagem conhecida como Mobile Knowledge Management (mKM), ou Gestão de Conhecimento Móvel em tradução livre, que utiliza dispositivos móveis nos processos de GC, explorando suas capacidades técnicas e tirando proveito de sua popularização.

A mKM viabiliza a entrega de conteúdo a qualquer hora e em qualquer lugar, além de possibilitar melhor contextualização dos materiais produzidos através dos recursos multimidia destes dispositivos, potencializando os resultados da GC (DERBALLA e POUSTTCHI, 2004; ZUGA et al. 2006; PIMMER et al., 2018).

Considerando a ampla adesão da população mundial aos smartphones, a mKM viabiliza a redução dos custos de infraestrutura de GC de três formas: possibilita o aproveitamento de recursos disponíveis; possibilita a aquisição de equipamentos de melhor qualidade a preços acessíveis; reduz a necessidade de treinamento em função da familiaridade dos usuários com este tipo de equipamento (MEIRELLES, 2019; KROGH, 2012).

Porém, a literatura corrente carece de estudos sobre quais requisitos devem ser atendidos pelos aplicativos mobile (APP) desenvolvidos para este fim. Portanto, é objetivo deste trabalho levantar os requisitos de um APP para GC.

Ressalta-se que, de forma geral, o tema mKM é apresentado como desdobramento ou complemento ao assunto GC, e não como alternativa. Portanto, faz-se necessário que, primeiramente, os requisitos de um Sistema de Gestão do Conhecimento (SGC) sejam levantados, e, posteriormente, os requisitos de seu APP sejam analisados.

Além disso, convêm que apenas requisitos de alto nível e essenciais aos processos de GC sejam elicitados. 
Especificações detalhadas de aspectos estruturais e técnicos dependem de fatores que fogem ao escopo deste trabalho.

E para que os resultados se tornem ainda mais relevantes, é possível comparar os requisitos levantados com as características de softwares open source que apresentem potencial para serem utilizados como SGC.

Desta forma, torna-se possível confirmar a existência, ou não, de uma alternativa de baixo custo que, no âmbito acadêmico, viabilize estudos práticos sobre a mKM e, no ambiente empresarial, possibilite a implantação de projetos piloto para análise de viabilidade baseada em resultados reais.

\section{METODOLOGIA}

Esta é uma pesquisa aplicada, por buscar a obtenção de conhecimento para solução de um problema específico; exploratória, por possibilitar a formulação de hipóteses e contribuir para melhor entendimento do assunto; e bibliográfica, por ser predominantemente fundamentada em material previamente elaborado (GERHARDT e SILVEIRA, 2009; GIL, 2002).

Com base na literatura corrente, foram identificadas as principais dificuldades enfrentadas pela GC e as possibilidades de utilização de dispositivos móveis em seus processos. A partir destes resultados, foram levantadas hipóteses para a superação destas dificuldades.

As hipóteses levantadas foram transcritas em formato de requisitos de um sistema computacional e foram comparadas a sistemas open source para a identificação de plataforma livre capaz de viabilizar a gestão de conhecimento em dispositivos móveis.

A biblioteca Bitnami (bitnami.com), que dispõe de pacotes padronizados em diversos formatos e integração com serviços de hospedagem em nuvem, foi utilizada como fonte para os softwares testados, que foram selecionados conforme os seguintes critérios:

1. Ser capaz de gerenciar conteúdo;

2. Ser um software open source;

3. Ser um projeto ativo (última versão estável lançada a menos de 6 meses);

4. Possuir APP próprio;

A comparação dos requisitos elicitados se deu através de testes de usabilidade dos softwares e consultas às documentações oficiais.

Os testes foram realizados sob as perspectivas do administrador e do usuário comum, na tentativa de criar um ambiente compatível com as práticas de GC, buscando coletar evidências da compatibilidade com os requisitos elicitados.

A compatibilidade foi classificada em quatro níveis:

1. Atende totalmente: o software atende ao requisito de forma completa, sem necessidade de adaptações;

2. Atende parcialmente: o software atende parte do requisito, apresentando restrições ou limitações;

3. Não atende: o software não atende ao requisito;

4. Não verificado: não foram coletadas evidencias conclusivas para a verificação.

Como resultado, foram elaborados diagrama de caso de uso, conforme padrão UML, e protótipos do tipo wireframes para a complementação dos argumentos expostos.

\section{RESULTADOS}

\section{1 - Requisitos Elicitados}

Os requisitos elicitados foram subdivididos em Requisitos do SGC e Requisitos do APP, conforme Quadros 1 e 2 :

\begin{tabular}{|c|c|}
\hline \multicolumn{2}{|r|}{ Quadro 1 - Requisitos do SGC } \\
\hline Requisito & Descrição \\
\hline SGC-01 & Suportar múltiplos formatos de conteúdo \\
\hline SGC-02 & Oferecer diferentes formas de interação \\
\hline SGC-03 & Possibilitar a comunicação entre os usuários \\
\hline SGC-04 & $\begin{array}{c}\text { Permitir a produção de conteúdo por todos os } \\
\text { usuários }\end{array}$ \\
\hline SGC-05 & Possibilitar a produção colaborativa de conteúdo \\
\hline SGC-06 & $\begin{array}{l}\text { Oferecer ferramenta de edição de texto com } \\
\text { recursos de correção ortográfica e gramatical }\end{array}$ \\
\hline SGC-07 & $\begin{array}{c}\text { Possibilitar a contextualização do conteúdo através } \\
\text { de recursos multimídia }\end{array}$ \\
\hline SGC-08 & $\begin{array}{c}\text { Apresentar interfaces simplificadas, oferecendo } \\
\text { somente as ferramentas necessárias para cada } \\
\text { tarefa }\end{array}$ \\
\hline SGC-09 & $\begin{array}{l}\text { Fornecer os dados estatísticos da produção de } \\
\text { conhecimento }\end{array}$ \\
\hline SGC-10 & $\begin{array}{l}\text { Fornecer os dados estatísticos do consumo de } \\
\text { conhecimento }\end{array}$ \\
\hline SGC-11 & Exigir autenticação dos usuários \\
\hline SGC-12 & $\begin{array}{r}\text { Permitir a criação de gru } \\
\text { suas permiss }\end{array}$ \\
\hline SGC-13 & $\begin{array}{c}\text { Garantir que restrições aos conteúdos sejam } \\
\text { impostas conforme as permissões de cada grupo }\end{array}$ \\
\hline SGC-14 & $\begin{array}{l}\text { Alertar o gestor quando um usuário for incluído em } \\
\text { mais de um grupo }\end{array}$ \\
\hline SGC-15 & $\begin{array}{c}\text { Permitir a criação de perfis de usuários conforme } \\
\text { suas atribuições }\end{array}$ \\
\hline SGC-16 & $\begin{array}{c}\text { Enviar novos conteúdos para a validação do perfil } \\
\text { responsável antes de disponibilizá-los aos demais } \\
\text { usuários }\end{array}$ \\
\hline SGC-17 & $\begin{array}{l}\text { Oferecer, na interface de consumo de conteúdo, } \\
\text { opções para envio de dúvidas ou comentários }\end{array}$ \\
\hline SGC-18 & $\begin{array}{c}\text { Oferecer, na interface de consumo de conteúdo, } \\
\text { canais diretos de comunicação com o responsável } \\
\text { pelo material }\end{array}$ \\
\hline
\end{tabular}

Fonte: Autores, 2020.

Quadro 2-Requisitos do APP

\begin{tabular}{|c|c|}
\hline \multicolumn{2}{|c|}{ Requisito Descrição } \\
\hline APP-01 & Permitir o consumo do conteúdo do SGC \\
\hline APP-02 & $\begin{array}{c}\text { Apresentar os conteúdos de forma equivalente ao } \\
\text { SGC, ou seja, sem perdas de informação ou } \\
\text { impactos na visualização }\end{array}$ \\
\hline APP-03 & $\begin{array}{c}\text { Permitir o download do conteúdo para consumo } \\
\text { offline }\end{array}$ \\
\hline APP-04 & Permitir a produção de conteúdo \\
\hline APP-05 & $\begin{array}{l}\text { Ser capaz de utilizar os recursos de produção } \\
\text { multimídia do dispositivo (câmera e microfone) }\end{array}$ \\
\hline APP-06 & $\begin{array}{l}\text { Na interface de produção de conteúdo, permitir a } \\
\text { inclusão de material multimídia, podendo o } \\
\text { material ser produzido diretamente pelo } \\
\text { aplicativo, estar armazenado no dispositivo ou } \\
\text { disponibilizado na internet }\end{array}$ \\
\hline
\end{tabular}

Fonte: Autores, 2020. 
Os requisitos SGC-01, SGC-02, representam a preocupação em centralizar os conteúdos em uma plataforma única, para que os usuários saibam onde devem busca-los. Esta abordagem evita que o conhecimento deixe de ser acessado por falta de informação sobre sua disponibilização (TESSIER e DALKIR, 2016).

Por isso, o SGC deve ser capaz de manipular múltiplos tipos de conteúdo (e.g. texto puro, arquivo multimídia, pacotes SCORM, pacotes H5P, conteúdo incorporado), funcionando como um repositório. Ele também deve oferecer diferentes formas de interação com e entre os usuários (e.g. chat, questionário, pesquisa, quiz, wiki, fórum).

Para Pimmer et al. (2018) e Emerson e Berge (2018), além de funcionar como um repositório de conteúdo, o SGC deve possibilitar a comunicação entre os usuários e o acesso a suporte especializado quando necessário. Estas necessidades foram transcritas nos requisitos SGC-03, SGC-17 e SGC-18.

Quanto aos requisitos SGC-04, SGC-05 e APP-04, a interação entre os usuários é apresentada como uma das principais formas de transferência de conhecimento. Portanto, convêm que todos os usuários possam participar do processo criativo e que a produção colaborativa seja viabilizada (ZIVIANI, 2019; ROBLEK et al., 2013).

Considerando os requisitos anteriores e seguindo a orientação de Pimmer et al. (2018), é necessário que os matérias produzidos passem por algum processo de verificação e validação para que sua qualidade seja assegurada. Para isso, os requisitos SGC-06, SGC-15 e SGC-16 foram especificados.

Os requisitos SGC-07, APP-05 e APP-06 representam uma das principais vantagens da utilização dos dispositivos móveis nos processos de GC. Os recursos de produção multimídia dos dispositivos móveis permitem a contextualização do conhecimento de forma muito mais eficiente do que através de descrições textuais, facilitando sua absorção (PIMMER et al., 2018; DERBALLA e POUSTTCHI, 2004).

O engajamento dos funcionários nos processos de conhecimento e a devida utilização dos sistemas disponibilizados são dificuldades enfrentadas constantemente pela GC. Isso se deve à constatação de que o compartilhamento de conhecimento é um comportamento contrário ao padrão humano e deve ser promovido através de práticas de Gestão de Recursos Humanos para que aconteça (e.g. planos de cargos e salários, incentivos, premiações, cultura organizacional) (ANDREEVA e KIANTO, 2012; LEE, KIM e KIM, 2012). Para tanto, é necessário controlar a produção e consumo de conhecimento, por isso os requisitos SGC-09 e SGC-10.

Além disso, os sistemas precisam ser projetados para que apresentem interfaces simples e intuitivas a fim de evitar barreiras a sua utilização, resultando no requisito SGC-08, (ANDREEVA e KIANTO, 2012; KROGH, 2012).

Com relação a segurança da informação, os requisitos SGC-11, SGC-12, SGC-13 e SGC-14 traduzem as preocupações de Krogh (2012) sobre formas de restringir o acesso a determinados públicos como medida de proteção.

Por fim, os requisitos APP-01, APP-02 e APP-03 representam a facilidade de entrega de conteúdo a qualquer hora e em qualquer lugar. Esta é a principal justificativa para a adoção de dispositivos móveis nos processos de GC (DERBALLA e POUSTTCHI, 2004).

\section{2 - Resultados dos Testes}

Após o trabalho de levantamento de requisitos, iniciouse a etapa de teste com softwares capazes de gerenciar conteúdo.

O Quadro 3 apresenta a lista de softwares inicialmente considerados como candidatos aos testes:

Quadro 3 - Lista de softwares potenciais

\begin{tabular}{|c|c|c|}
\hline Nome & Site & Categoria \\
\hline CMS Made Simple & www.cmsmadesimple.org & CMS \\
\hline Composr & compo.sr & CMS \\
\hline concrete5 & $\underline{\text { concrete5.org }}$ & CMS \\
\hline Drupal & drupal.org & CMS \\
\hline Joomla! & www.joomla.org & CMS \\
\hline MODX & www.modx.com & CMS \\
\hline Neos & www.neos.io & CMS \\
\hline Open Atrium & openatrium.com & CMS \\
\hline Pimcore & $\underline{\text { www.pimcore.org }}$ & CMS \\
\hline Plone & plone.org & CMS \\
\hline ProcessWire & www.processwire.com & CMS \\
\hline SilverStripe & www.silverstripe.org & CMS \\
\hline TYPO3 & $\underline{\text { www.typo3.org }}$ & CMS \\
\hline WordPress & $\underline{\text { www.wordpress.org }}$ & CMS \\
\hline XOOPS & $\underline{\text { xoops.org }}$ & CMS \\
\hline eXo Platform & www.exoplatform.com & DMS \\
\hline Alfresco Community & www.alfresco.com & ECM \\
\hline Mahara & $\underline{\text { www.mahara.org }}$ & ePortfolio \\
\hline Canvas LMS & www.canvaslms.com & LMS \\
\hline Moodle & $\underline{\text { moodle.org }}$ & LMS \\
\hline Open edX & $\underline{\text { open.edx.org }}$ & LMS \\
\hline
\end{tabular}

Fonte: Autores, 2020

Legenda: CMS - Content Management System; EMS - Document Management Systems; ECM - Enterprise Content Management; ePortfolio - Portfólio Eletrônico;

LMS - Learning Management System.

Foram realizadas consultas aos sites oficiais de cada um dos softwares listados a fim de identificar o propósito geral de cada projeto e foi percebido que, nesta pesquisa, os softwares classificados puramente como CMS não deveriam ser utilizados como plataforma de GC.

Apesar de oferecem grande variedade de recursos e concederem liberdade para a criação de diversos tipos de sites, para que suas capacidades possam ser plenamente exploradas seu usuário precisa dominar diversos conhecimentos técnicos. Por isso, os CMS são mais indicados para editores, designers e desenvolvedores.

Usuários comuns também podem fazer utilização destes softwares, mas estarão restritos a modelos prédefinidos, o que não atenderia as necessidades complexas da GC e da mKM.

Sendo assim, os CMS de propósito geral foram excluídos da lista, restando os itens constantes no Quadro 4 , que também apresenta os resultados dos testes:

Quadro 4-Resultados dos Testes

\begin{tabular}{|c|c|c|c|c|c|}
\cline { 2 - 6 } \multicolumn{1}{c|}{} & \multicolumn{5}{c|}{ Software } \\
\hline Requisito & $\begin{array}{c}\text { Canvas } \\
\text { LMS }\end{array}$ & $\begin{array}{c}\text { eXo } \\
\text { Platform }\end{array}$ & Mahara & Moodle & $\begin{array}{c}\text { Open } \\
\text { edX }\end{array}$ \\
\hline SGC-01 & $\mathrm{T}$ & $\mathrm{T}$ & $\mathrm{T}$ & $\mathrm{T}$ & $\mathrm{T}$ \\
\hline SGC-02 & $\mathrm{T}$ & $\mathrm{T}$ & $\mathrm{T}$ & $\mathrm{T}$ & $\mathrm{T}$ \\
\hline SGC-03 & $\mathrm{T}$ & $\mathrm{T}$ & $\mathrm{T}$ & $\mathrm{T}$ & $\mathrm{P}$ \\
\hline SGC-04 & $\mathrm{P}$ & $\mathrm{T}$ & $\mathrm{T}$ & $\mathrm{T}$ & $\mathrm{T}$ \\
\hline
\end{tabular}




\begin{tabular}{|c|c|c|c|c|c|}
\cline { 2 - 6 } \multicolumn{1}{c|}{} & \multicolumn{5}{c|}{ Software } \\
\hline Requisito & $\begin{array}{c}\text { Canvas } \\
\text { LMS }\end{array}$ & $\begin{array}{c}\text { eXo } \\
\text { Platform }\end{array}$ & Mahara & Moodle & $\begin{array}{c}\text { Open } \\
\text { edX }\end{array}$ \\
\hline SGC-05 & P & T & T & T & T \\
\hline SGC-06 & N & N & N & N & N \\
\hline SGC-07 & T & P & T & T & T \\
\hline SGC-08 & T & T & N & T & N \\
\hline SGC-09 & N & N & N & T & N \\
\hline SGC-10 & T & N & N & T & T \\
\hline SGC-11 & T & T & T & T & T \\
\hline SGC-12 & N & N & T & T & N \\
\hline SGC-13 & N & N & T & T & N \\
\hline SGC-14 & N & N & N & N & N \\
\hline SGC-15 & P & T & T & T & P \\
\hline SGC-16 & N & N & T & T & N \\
\hline SGC-17 & P & N & T & T & P \\
\hline SGC-18 & P & N & T & T & N \\
\hline APP-01 & $?$ & T & N & T & $?$ \\
\hline APP-02 & $?$ & T & N & P & $?$ \\
\hline APP-03 & $?$ & N & N & T & $?$ \\
\hline APP-04 & $?$ & N & P & T & $?$ \\
\hline APP-05 & $?$ & N & P & P & $?$ \\
\hline APP-06 & $?$ & N & P & P & $?$ \\
\hline
\end{tabular}

Legenda: $\mathrm{T}$ - Atende totalmente; $\mathrm{P}$ - Atende parcialmente; $\mathrm{N}$ - Não atende; ? - Não verificado.

Dentre os softwares analisados, o que atendeu o maior número de requisitos foi o Moodle. Além de ter atendido 16 dos 18 requisitos elicitados para o SGC, ele ainda oferece a atividade denominada base de dados, que funciona como um repositório de conhecimento e apresenta as seguintes características:

- O administrador define os campos que irão compor os modelos das páginas de produção, consulta e visualização de conteúdo;

- Os modelos podem ser criados em código HTML, CSS e JavaScript, porém sua estilização é complexa e trabalhosa, pois não existe documentação detalhada do padrão gráfico da aplicação;

- Os campos podem ser dos tipos: área de texto (com conteúdo rico), arquivo, botão de rádio, caixa de seleção, data, foto, inserção de texto (texto simples), latitude e longitude, menu, multimenu, número e URL;

- Os campos do tipo área de texto disponibilizam editor com funcionalidades de inserção de conteúdo rico e incorporado, mas este recurso não está disponível no APP;

- Todos os usuários podem incluir conteúdos;

- Os conteúdos produzidos pelos usuários devem ser validados pelo professor, caso essa configuração seja habilitada, e é possível alterar os nomes dos papeis dos usuários (e.g. professor para gerente, aluno para funcionário).

Este recurso é o que melhor atendeu as necessidades gerais da GC identificadas nos trabalhos consultados, pois funciona como um repositório de conhecimento, permite que todos os usuários produzam conteúdo, permite a inclusão de material multimidia e oferece recursos de controle do material produzido.

Porém, foram registrados os seguintes apontamentos sobre seu APP:
1. Para que possa ser utilizado por qualquer instância do Moodle, o aplicativo solicita o endereço do site da aplicação principal. Esta configuração representa uma tarefa adicional para o usuário e pode gerar dúvidas;

2. A disposição dos elementos nas interfaces de listagem, visualização e criação de itens é ruim:

2.1. A área disponível é mal aproveitada. Existem muitos espaços em branco e quebras de linha que reduzem a quantidade de itens exibidos;

2.2. Os botões de acesso, edição e exclusão são mal posicionados, consumindo muito espaço em tela;

2.3. Não existe divisão clara entre os itens listados;

2.4. Existe uma barra sobre a área principal contendo as abas denominadas Conteúdos, Participantes e Competências, mas somente a primeira foi utilizada.

3. A interface de criação e edição de conteúdo não disponibiliza o editor WYSIWYG (acrônimo para "O que você vê é o que você obtém” em tradução livre), que permite a inserção de conteúdo rico e incorporado.

4. O campo do tipo arquivo suporta a inclusão de apenas um arquivo;

5. Não é possível editar ou excluir conteúdo criado por outro usuário. Esta funcionalidade também não está disponível na versão para navegador.

Considerando os requisitos elicitados, tais apontamentos precisam ser superados para que o aplicativo possa ser considerado como ferramenta relevante para a GC.

Para tanto, foram elaborados diagrama UML e protótipos das telas sugerindo as correções necessárias.

\section{3 - Correções Propostas}

A correção do primeiro apontamento é a mais simples e bastaria que o APP viesse configurado com os dados do endereço da aplicação principal.

Quanto aos demais apontamentos, as telas propostas foram baseadas no diagrama de caso de uso representado na Figura 1.

Figura 1 - Diagrama de Caso de Uso: Principais funcionalidades

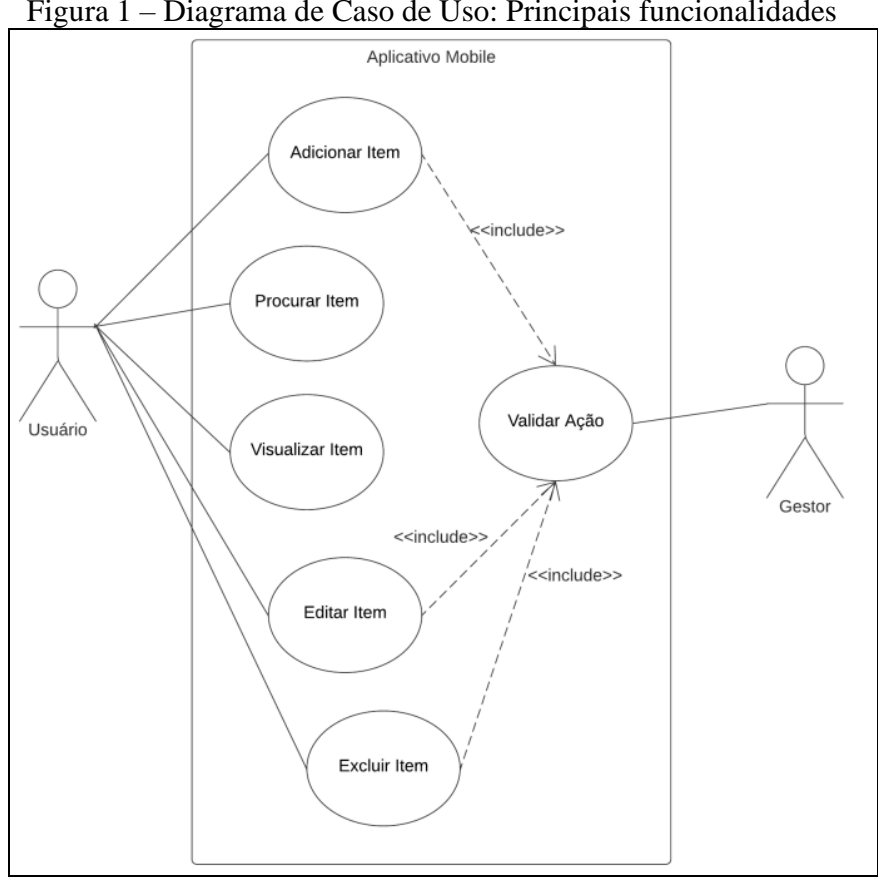

Fonte: Autores, 2020. 
A interface de consulta foi pensada para oferecer as principais funcionalidades do aplicativo em uma única tela. Nela, é possível procurar um item, adicionar um item e visualizar uma lista contendo o nome e uma breve descrição dos itens disponíveis.

Além disso, os itens foram apresentados como cartões para que seus elementos e botões pudessem ser melhor contextualizados. Os cartões em vermelho representam itens pendentes de validação, disponíveis apenas para quem o criou/editou e para o gestor responsável até sua aprovação. Tais sugestões são apresentadas na Figura 2.

Em função do botão excluir (ícone lixeira), estar muito próximo ao botão editar (ícone lápis), e por se tratar de ação definitiva, foi proposta interação de confirmação nos casos em que esta funcionalidade é oferecida. O protótipo da tela é apresentado na Figura 3.

Uma interação semelhante seria apresentada na interface de criação/edição para os botões excluir e cancelar.

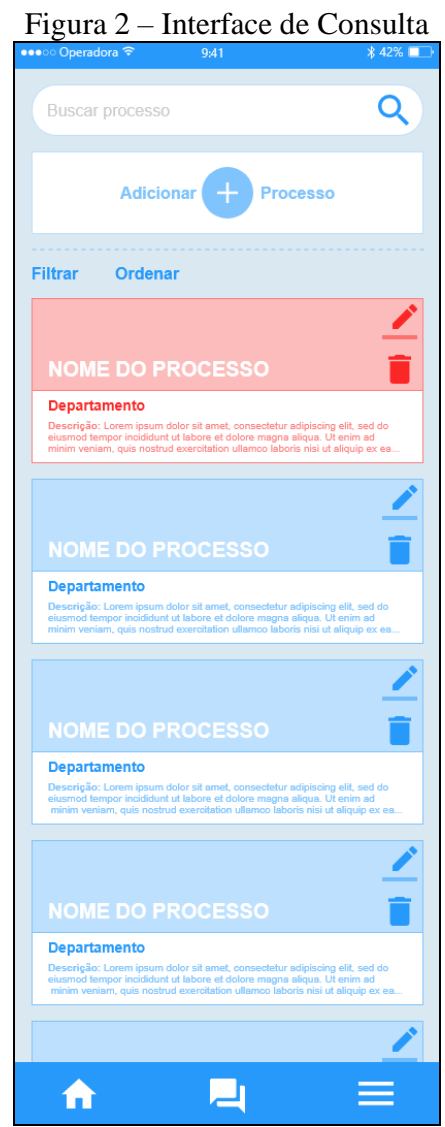

Fonte: Autores, 2020.
Figura 3 - Confirmação

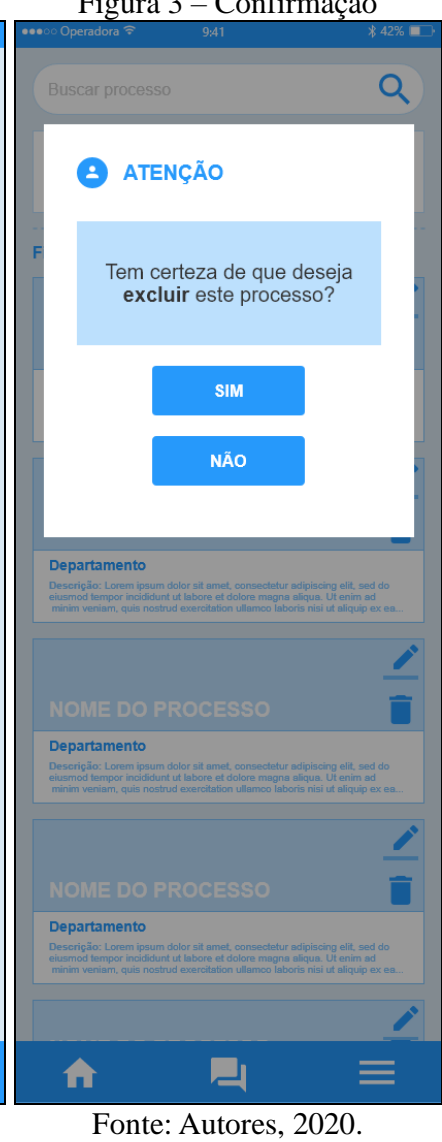

A interface de criação/edição de conteúdo foi projetada para disponibilizar o editor WYSIWYG. A má distribuição dos elementos também foi corrigida, conforme Figura 4.

Por fim, a Figura 5 apresenta a interface de visualização do conteúdo, que foi desenhada para oferecer os botões de edição e download (para todos os usuários) e aprovação (apenas para o perfil de gestor, por isso o ícone na cor vermelha).

$\mathrm{Na}$ mesma tela, foram adicionados data de publicação do material; nome do autor com botões para contato; e campo para envio de dúvidas.
Figura 4 - Interface de Criação/Edição

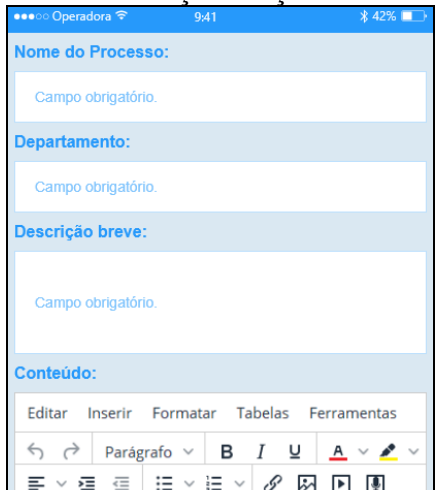

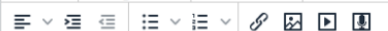

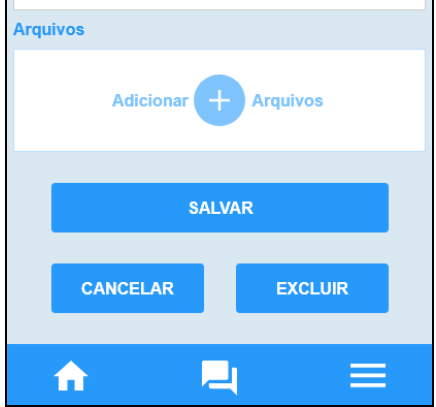

Fonte: Autores, 2020.
Figura 5 - Interface de

Visualização

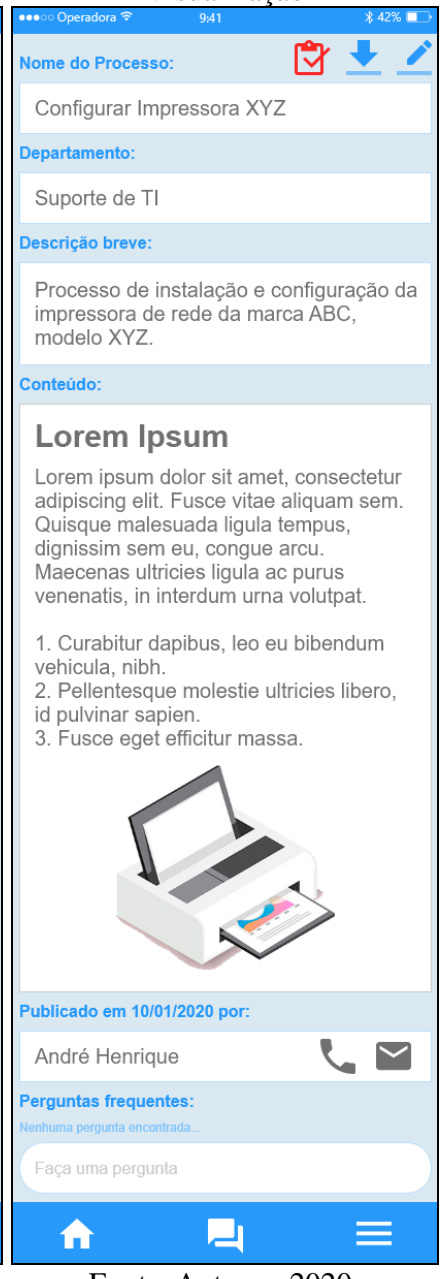

Fonte: Autores, 2020.

Neste protótipo, funcionalidades adicionais como consulta e alteração de informações de perfil e configurações do aplicativo seriam acessadas através do ícone de menu, disponível no canto inferior direto.

$\mathrm{O}$ ícone casa daria acesso a interface de consulta, que seria a tela principal do APP, e as funcionalidades de chat seriam acessadas através do ícone de balões sobrepostos.

\section{CONSIDERAÇÕES FINAIS}

Os resultados desta pesquisa foram os seguintes:

- Com base na literatura corrente, os requisitos de um SGC e de um APP para mKM foram elicitados e sintetizados nos Quadros 1 e 2, respectivamente;

- Softwares open source foram testados a fim de identificar quais destes requisitos eram capazes de atender. Os resultados dos testes podem ser conferidos no Quadro 3;

- Dentre os softwares testados, o Moodle foi considerado como o melhor candidato para servir de plataforma de GC para a aplicação da mKM;

- Suas limitações e as limitações de seu APP foram analisadas e resultaram em um diagrama de caso de uso, conforme padrão UML, e protótipos do tipo wireframes.

Desta forma, esta pesquisa contribuiu para a elucidação dos problemas enfrentados pela mKM e sugeriu uma alternativa de baixo custo para novos estudos. 
As indicações deste trabalho também podem ser aplicadas em ambiente empresarial, mas em caráter experimental, visto que as principais limitações do Moodle (e de seu APP) são inerentes ao seu design e a ausência de funcionalidades chave, fatores que podem criar barreiras para sua utilização.

\section{REFERÊNCIAS BIBLIOGRÁFICAS}

ANDREEVA, Tatiana e KIANTO, Aino. Does knowledge management really matter? Linking knowledge management practices, competitiveness and economic performance. Journal of Knowledge Management, v. 16, n. 4, p. 617-636, 13 jul. 2012. Disponível em: https://www.emerald.com/insight/content/doi/10.1108/1367 3271211246185/full/html. Acesso em: 25 jan. 2020.

CASTRO, Ahiram Brunni Cartaxo De e colab. Gestão do Conhecimento: Um Mapeamento das Principais Publicações Sobre o Assunto para o Levantamento de Temáticas Emergentes. Revista Gestão da Produção Operações e Sistemas, v. 14, n. 3, p. 86-97, 1 jul. 2019. Disponível em: https://revista.feb.unesp.br/index.php/gepros/article/view/26 07. Acesso em: 10 jan. 2020.

DERBALLA, V. e POUSTTCHI, K. Extending Knowledge Management to Mobile Workplaces. p. 583-590. 2004. Disponível em: https://mpra.ub.uni-muenchen.de/3616/. Acesso em: 22 jan. 2020.

EMERSON, Lynn C. e BERGE, Zane L. Microlearning: Knowledge management applications and competencybased training in the workplace. Knowledge Management \& E-Learning: An International Journal, v. 10, n. 2, p. 125132, 15 jun. 2018. Disponível em: http://www.kmeljournal.org/ojs/index.php/online-publication/article/view/17. Acesso em: 28 jan. 2020.

GERHARDT, Tatiana Engel e SILVEIRA, Denise Tolfo. Métodos de Pesquisa. 1. ed. Porto Alegre: Editora da UFRGS, 2009.

GIL, Antonio Carlos. Como Elaborar Projetos de Pesquisa. 4. ed. São Paulo: Editora Atlas, 2002.

KROGH, Georg Von. How does social software change knowledge management? Toward a strategic research agenda. Journal of Strategic Information Systems, v. 21, n. 2, p. 154-164, 2012. Disponível em: https://www.sciencedirect.com/science/article/abs/pii/S0963 868712000157?via\%3Dihub. Acesso em: 25 jan. 2020.

LEE, Sangjae e GON KIM, Byung e KIM, Hoyal. An integrated view of knowledge management for performance. Journal of Knowledge Management, v. 16, n. 2, p. 183-203, 30 mar. 2012. Disponível em: https://www.emerald.com/insight/content/doi/10.1108/1367 3271211218807/full/html. Acesso em: 25 jan. 2020.

MASSINGHAM, Peter Rex e MASSINGHAM, Rada K. Does knowledge management produce practical outcomes? Journal of Knowledge Management, v. 18, n. 2, p. 221-254, 7 abr. 2014. Disponível em: https://www.emerald.com/insight/content/doi/10.1108/JKM10-2013-0390/full/html. Acesso em: 25 jan. 2020.
MEIRELLES, Fernando de Souza. Pesquisa Anual do Uso de TI nas Empresas, FGVcia: Centro e Tecnologia de Informação Aplicada da EAESP, 30a edição, FGV, 2019.

PIMMER, Christoph e colab. Mobile and ubiquitous knowledge management: Lessons from the transportation sector. Proceedings of the European Conference on Knowledge Management, ECKM, v. 2, p. 693-699, 2018. Disponível em: https://www.researchgate.net/publication/328829473_Mobil e_and_Ubiquitous_Knowledge_Management_Lessons_from _the_Transportation_Sector. Acesso em: 28 jan. 2020.

ROBLEK, Vasja e colab. Factors of knowledge management and the impact of employee turnover in activity and performance in Scientific and technological parks in Slovenia. Journal of Information and Organizational Sciences, v. 37, n. 1, p. 63-72, 2013. Disponível em: https://jios.foi.hr/index.php/jios/article/view/831. Acesso em: 01 abr. 2020.

TESSIER, Dana e DALKIR, Kimiz. Implementing Moodle for e-learning for a successful knowledge management strategy. Knowledge Management \& E-Learning: An International Journal, v. 8, n. 3, p. 414-429, 15 set. 2016. Disponível em: http://www.kmeljournal.org/ojs/index.php/online-

publication/article/view/344. Acesso em: 28 jan. 2020.

ZIVIANI, Fabricio e colab. O impacto das práticas de gestão do conhecimento no desempenho organizacional: um estudo em empresas de base tecnológica. Perspectivas em Ciência da Informação, v. 24, n. 1, p. 61-83, mar. 2019. Disponível em: http://www.scielo.br/scielo.php?script=sci_arttext\&pid=S14 13-99362019000100061\&tlng=pt. Acesso em: 28 jan. 2020.

ZUGA, Bruno e colab. M-learning and Mobile Knowledge Management: Similarities and Differences. International Journal of Computing \& Information Sciences, v. 4, n. 2, p. 58-62, 2006. Disponível em: https://www.researchgate.net/publication/228818376_Mlearning_and_mobile_knowledge_management_similarities _and_differences. Acesso em: 22 jan. 2020.

\section{COPYRIGHT}

Direitos autorais: Os autores são os únicos responsáveis pelo material incluído no artigo. 


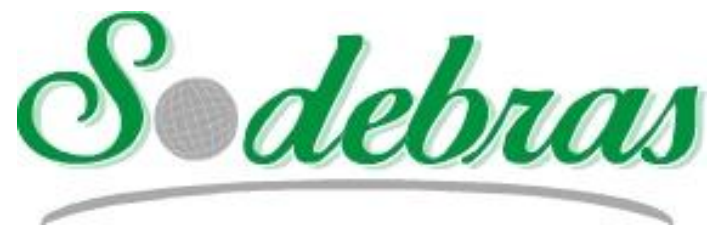

\author{
Volume $16-\mathrm{N}^{\mathrm{o}} 174$ - Junho / 2020 \\ XLII International Sodebras Congress \\ 28 a 30 de maio de 2020 - Web Conference.
}

\title{
AVALIAÇÃO EXPERIMENTAL DA TECNOLOGIA LORA EM CONDIÇÕES REAIS PARA O CLIMA TROPICAL
}

\section{EXPERIMENTAL EVALUATION OF LORA TECHNOLOGY IN REAL CONDITIONS FOR TROPICAL CLIMATE}

\author{
WESEN, Ednelson; ALMEIDA, Thiago; DINARDI, Phelippe; PEREIRA, Luis; VERMEHREN, Victor; \\ VALENZUELA, Walter \\ UNIVERSIDADE DO ESTADO DO AMAZONAS
}

ednelson.wesen@gmail.com; tga.eng17@uea.edu.br; lembpr.eng16@uea.edu.br; ptd.eng16@uea.edu.br;
vvalenzuela@uea.edu.br;wvalenzuela@uea.edu.br

\begin{abstract}
Resumo - Este artigo apresenta uma avaliação da tecnologia LoRa com o objetivo de fornecer suporte a sua implantação, pelo laboratório INOVATEC, para uma solução em sistema de tecnologia de comunicação em cidades inteligentes. Os cenários de comunicação esperados no emergente ambiente da Internet das Coisas (IoT) apontam para um grande crescimento de dispositivos inteligentes conectados em uma mesma rede. As tecnologias de comunicação de maior interesse para a IoT são conhecidas como redes de longa distância de baixa potência (LPWANs). O sistema de comunicação LoRa desponta como uma excelente opção capaz de fornecer comunicação eficiente em termos de energia $e$ cobertura. Este artigo realiza a avaliação experimental da tecnologia LoRa na faixa de $915 \mathrm{MHz}$ quanto ao seu alcance em condições reais de propagação no clima tropical da cidade de Manaus-Brasil.

Palavras-chave: LoRa. LPWAN. IoT. Cidades Inteligentes.
\end{abstract}

\begin{abstract}
This article presents an evaluation of LoRa technology in order to provide support for its implementation, by the INOVATEC laboratory, for a solution in communication technology system in smart cities. The communication scenarios expected in the emerging Internet of Things (IoT) environment point to a great growth in smart devices connected to the same network. The communication technologies of greatest interest to IoT are known as low power wide area networks (LPWANs). Currently, Lora technology is emerging as an excellent option capable of providing efficient communication in terms of energy and coverage. This article performs the experimental evaluation of LoRa technology in the $915 \mathrm{MHz}$ band as to its range in real conditions of propagation in the tropical climate of the city of Manaus-Brazil.
\end{abstract}

Keywords: LoRa. LPWAN. IoT. Smart Cities.

\section{INTRODUÇÃO}

LoRa (Long Range) é uma tecnologia de rede de área ampla de baixa potência (LPWAN). Foi desenvolvido por Cycleo de Grenoble, França e adquirido pela Semtech, o membro fundador da LoRa Alliance e promovida através da LoRa ${ }^{\circledR}$ Alliance. A criação desta aliança foi iniciada pelos líderes industriais do mercado da tecnologia destacando as áreas da tecnologia da informação, automação industrial, e telecomunicações. Essas instituições têm como missão padronizar as redes de comunicação de grandes áreas e baixa potência (LPWAN) para implantar as tecnologias IoT, M2M em cidades inteligentes, além de aplicações industriais em todos os países.
É importante fazer uma distinção entre LoRa e LoRaWAN. Enquanto LoRaWAN descreve um mapeamento completo do protocolo de comunicação para a segunda e terceira camadas do modelo OSI, LoRa é uma especificação de camada física (PHY) proprietária da Semtech [LoRaTMAlliance, 2016], desenhada para redes de longo alcance e baixa potência. Assim, esta tecnologia está projetada para permitir a conectividade de objetos inteligentes em distâncias da ordem dos quilômetros, com baixo consumo de energia, requerimento essencial das redes da Internet das Coisas.

Com relação à modulação, o LoRa é um esquema de modulação proprietário de espalhamento de espectro derivado da modulação Chirp Spread Spectrum (CSS) (CHIANI, 2019) focada em fornecer robustez a transmissões de longo alcance.

Embora o aparecimento e a difusão de LoRaWAN seja recente, grande número de trabalhos tem sido publicado auxiliando na análise ou avaliação de sua performance em diferentes cenários ou propondo melhorias nas versões de prateleira conforme HERRERA-TAPIA (2017) e PETÄJÄJÄRVI (2017). Sob o ponto de vista teórico, o estudo em BANKOV (2016) analisou a capacidade do LoRaWAN em termos de escalabilidade e taxa de transferência de nó.

Todos esses trabalhos concluíram que sistemas LoRaWAN devem ser cuidadosamente configurados e dimensionados hospedando um grande número nós. Concretamente, em GEORGIOU (2017), foi estudado o impacto negativo de interferências dentro de células LoRaWAN de alta densidade populacional. Os autores encontraram algumas interferências relacionadas a certas sequências de espalhamento, que chegavam a prejudicar a escalabilidade do sistema LoRaWAN.

No que se refere ao aspecto de cobertura, alguns estudos forneceram contribuições significativas. Em JÖRKE (2017), os autores instalaram terminais em diferentes locais na cidade de Dortmund, Alemanha. O grupo de pesquisa utilizou o transceptor Pycom LoPy para um teste na faixa de $433 \mathrm{MHz}$ e de $868 \mathrm{MHz}$. Foram instalados um gateway com uma antena a $30 \mathrm{~m}$ do solo e oito nós, espalhados por toda a cidade. Quatro nós foram instalados indoor, enquanto os outros quatro foram instalados ao ar livre. Todos os nós usaram um fator de espalhamento SF12 e uma taxa de codificação de 4/8. Além disso, foi realizado um teste com um transceptor móvel montado no teto de um veículo a uma altura de 1,7 m. Após a análise de desempenho verificou-se a possibilidade de 
recepção do sinal em até $5,8 \mathrm{~km}$, mas com a existência de pontos cegos sem recepção a partir de $2 \mathrm{~km}$. Em PETÄJÄJÄRVI² (2015), os autores realizam um teste com um receptor fixo instalado a $24 \mathrm{~m}$ do nível do mar e dois transmissores LoRa móveis, sendo um transmissor instalado sobre o teto de um automóvel na cidade de Oulu, Finlândia e um segundo transmissor montado em um barco para fornecer dados de medição adicionais. Os resultados mostraram que, no solo, pacotes foram recebidos com um sucesso superior a $80 \%$ nas distancias de até $5 \mathrm{~km}$. Na água, cerca de $70 \%$ dos pacotes foram entregues com sucesso a distâncias inferiores a $15 \mathrm{~km}$. Embora interessantes, em ambos trabalhos a avaliação foi realizada para a comunicação no sentido da estação base para o terminal móvel (downlink), sendo a antena transmissão posicionada no topo das edificações e o clima europeu.

Embora interessantes, em ambos os trabalhos não foi considerada a comunicação no sentido do terminal móvel para a estação base, o posicionamento da antena da estação base próximo ao solo e as condições reais de propagação para o clima tropical, sendo estas considerações o propósito deste trabalho.

\section{PARÂMETROS E FÓRMULAS}

A comunicação entre os terminais e o gateway é definida pelos parâmetros de configuração da camada física do LoRa, pois seus ajustes influenciam diretamente nos resultados obtidos quanto à taxa de transmissão, máximo alcance, consumo energético e robustez diante de interferências e ruídos. A tecnologia LoRa provê quatro parâmetros de ajustes: a frequência da portadora, a largura de banda, a taxa de código (Code Rate - CR) e o fator de espalhamento (Spreading Factor-SF) (BOR, 2016).

\section{1 - Frequência da Portadora e Largura de Banda}

A frequência da portadora varia de acordo com as regiões e frequências disponíveis em cada localidade. O Plano de Atribuição, Destinação e Distribuição de Frequências no Brasil estabelecido pela Anatel (DE TELECOMUNICAÇÕES, 2019) prevê que a faixa de frequência de 902-928 MHz, com frequência central em 915 $\mathrm{MHz}$, seja destinada para aplicações industriais, científicas e médicas (ISM). É esta a faixa de frequência empregada para a tecnologia LoRa no Brasil.

Para a tecnologia LoRa, três larguras de banda são definidas: $125 \mathrm{kHz}, 250 \mathrm{kHz}$, e $500 \mathrm{kHz}$. O LoRa substitui um bit por múltiplos chips de informação, Estes múltiplos chips de informação precisam ser transmitidos na mesma velocidade que a taxa de bits original. Assim, os dados são enviados com uma taxa de chip (chips por segundo - cps) igual à largura de banda $(250 \mathrm{kHz}=250 \mathrm{kcps})$. Se a largura de banda for baixa, a sensibilidade será alta, mas a taxa de transmissão será baixa; quer dizer que a potência do sinal que o receptor vai detectar pode estar abaixo do nível de ruído, requerendo um maior ganho de processamento na recepção para a decodificação do sinal (RAZA, 2017). Por outro lado, uma largura de banda alta leva a uma alta taxa de transferência, mas com maior tempo de transmissão e menor sensibilidade. Com a largura de banda maior, mais sinais ortogonais serão usados, resultando em uma capacidade da rede mais alta, porém a potência do sinal terá uma sensibilidade mais baixa por conta da agregação adicional de ruído (BOR, 2016).

\section{2 - Taxa de código, Fator de espalhamento e Taxa de erro}

A taxa de código, em inglês Code Rate - $\mathrm{CR}$, está diretamente relacionada à técnica FEC, Foward Error Correction, que representa a quantidade de bits usados para redundância na mensagem enviada, para que erros na transmissão possam ser corrigidos e a mensagem original recuperada. São implementados valores de CR variando de $4 / 5$, redundância mínima, até $4 / 8$, maior valor de redundância possível. Um pacote que usa o CR 4/8 passa um tempo maior no ar e menor carga útil, em contrapartida tem maior chance de chegar corretamente ao receptor.

Sequências ortogonais são empregadas para proporcionar o uso eficiente do espectro decorrente da subutilização da banda provocada pelo espalhamento espectral. Na especificação do LoRa, o espalhamento espectral relaciona-se ao parâmetro denominado fator de espalhamento (Spreading Factor - SF). É prevista a configuração de seis valores diferentes para o SF (SF7, SF8, SF9, SF10, SF11 e SF12). Cada valor de SF é ortogonal um do outro, permitindo a transmissão e recepção simultânea. Quanto maior o fator, maior é a energia por bit transmitido, o que possibilita um maior alcance entre o receptor e o transmissor, porém tem como consequência a redução da taxa de transmissão de bits (SCHAFFERS, 2011). O tempo de transmissão também aumenta com o aumento do SF, por este motivo, o SF12 não é permitido no Brasil, pois seu time on air é demasiadamente grande, a ponto de violar a regulamentação imposta pela agência reguladora, Anatel. Para cada fator de espalhamento existe um compromisso entre a robustez da modulação a interferências e a taxa de transmissão de bits.

A comunicação entre o terminal e o gateway não será possível se a potência do sinal recebido for muito baixa, de modo que não possa ser distinguida do ruído presente no receptor. Essa relação é conhecida como relação sinal-ruído (SNR). Assim, para uma dada taxa de bits de modulação há uma SNR mínima exigida pelo receptor para atingir uma taxa de erro de bit desejada (BER) ou taxa de erro de pacote (PER). Essa SNR mínima necessária é geralmente definida em termos da sensibilidade do receptor, que é o nível absoluto de potência de entrada necessário para não exceder $1 \%$ de BER ou PER no receptor. Assim, a sensibilidade do receptor, especificada na folha de dados do receptor, é o nível de energia de entrada que fornece o SNR mínimo necessário para o estabelecimento da comunicação sem fio. Para a banda de 125 $\mathrm{kHz}$ o LoRa requer uma SNR teórica mínima de $-7,5 \mathrm{~dB}$ quando empregado o SF7 e de -20 dB para o SF12.

\section{3 - Fatores que influenciam na cobertura de um sistema sem fio}

Existem muitos fatores que afetam a cobertura de uma rede sem fio que vão desde a tecnologia dos dispositivos envolvidos na comunicação, como os rádios, cabos e antenas, assim como a física envolvida na transmissão sem fio. No entanto, a maior influência na cobertura de um sistema sem fio é o ambiente de propagação no qual os sinais trafegam. Destacam-se neste ambiente os seguintes fatores:

\subsection{1 - Distância entre dispositivos}

Quanto mais distantes os dispositivos da rede envolvidos na comunicação, mais a intensidade do sinal diminui. Isso se deve ao modo como os sinais sem fio se propagam cobrindo uma área mais ampla à medida que avançam e, por isso, à medida que o sinal se espalha mais, 
mais fraco se torna. A intensidade do sinal diminui, em uma relação exponencial negativa em função da distância entre os dois dispositivos.

\subsection{2-Obstruções físicas}

Os sinais sem fio podem ter dificuldade em penetrar objetos sólidos, como morros, prédios, paredes simples ou até pessoas. Quanto mais obstruções houver entre o transmissor e o receptor, maior a chance de que a intensidade do sinal seja afetada. Uma maneira de minimizar este efeito é utilizar frequências específicas disponíveis. Como regra, quanto menor a frequência, melhores características de penetração as ondas têm. No entanto, quanto maior a frequência, melhor a capacidade de reflexão da onda, portanto, em alguns casos, refletir um sinal para o receptor pode funcionar melhor do que tentar enviá-lo através de objetos, isto é, paredes.

\subsection{3 - Interferência de rede sem fio}

As redes de comunicação sem fio estão se tornando cada vez mais comuns e, portanto, mais transmissões sem fio estão sendo enviadas pelo ar. Sinais que operam em frequências semelhantes podem causar interferência entre si e ter um efeito significativamente negativo no desempenho da rede e, como consequência, na sua cobertura. Isso significa que as bandas de frequência mais usadas popularmente, como as bandas não licenciadas, podem ser seriamente afetadas pela superlotação dos sinais sem fio até um ponto em que um dispositivo não funcionará em um nível aceitável. Outras tecnologias sem fio podem causar interferências idênticas, como telefones celulares que operam dentro dos mesmos intervalos.

\subsection{4 - O desvanecimento por multipercurso}

A reflexão do sinal é a causa do fenômeno conhecido tecnicamente como desvanecimento por multipercurso que ocorre normalmente devida à presença de edifícios com estruturas complexas e intricadas. Os diferentes caminhos que os sinais tomam ao serem transmitidos podem causar diferenças nos comprimentos gerais das distâncias do caminho a caminho do receptor. Quando esses sinais variáveis chegam ao receptor, eles podem estar fora de fase entre si e isso pode fazer com que as ondas sobrepostas em questão aumentem a amplificação do sinal ou cancelem-se completamente. Além disso, os instantes em que os sinais refletidos atingem o receptor são diferentes devido às diferentes distâncias nos caminhos de RF que eles viajaram para chegar lá. A propagação no atraso entre os sinais cria a interferência inter-simbólica - ISI (Intersymbol Interference), que é uma situação em que os sinais atrasados começam a corromper os símbolos que viajam em um caminho de RF mais curto.

Alguns destes fatores não podem ser evitados e devem ser tomadas medidas para tentar minimizar seus efeitos negativos no desempenho da rede, mas outros podem ser resolvidos completamente através da atualização de equipamentos ou de um bom planejamento do sistema sem fio.

\section{METODOLOGIA}

Ao longo do período de 30 dias foram conduzidos testes de validação de um sistema de comunicação LoRa composto por um receptor fixo e um emissor com 1,5 metro de altura do nível do chão instalado no teto de um automóvel, que se deslocou ao longo da cidade de Manaus, contemplando um cenário de testes total de sete bairros. Foram conduzidos quatro experimentos:

i. Cenário 1. Ambiente densamente urbano com muitas obstruções e localizado em um vale com sistema de recepção fixo montado com uma antena a $6 \mathrm{~m}$ do solo na Escola Superior de Tecnologia da Universidade do Estado do Amazonas;

ii. Cenário 2. Ambiente suburbano com poucas obstruções e localizado em um pico e sistema de recepção fixo montado com uma antena a $2 \mathrm{~m}$ do solo em uma via suburbana;

iii. Cenário 3. Ambiente urbano - ao longo de uma importante artéria da cidade de Manaus, com intenso tráfego de veículos. O sistema de recepção fixo montado com uma antena a $6 \mathrm{~m}$ do solo; e,

iv. Cenário 4. Ambiente urbano - ao longo da mesma via do item anterior, porém com o sistema de recepção fixo montado com uma antena a $2 \mathrm{~m}$ do solo.

A Tabela 1 apresenta as principais características dos quatro cenários empregados nos testes experimentais. As condições climáticas variaram de parcialmente nublado com chuva até ensolarada, com temperatura mínima de $24{ }^{\circ} \mathrm{C}$ e máxima de $37{ }^{\circ} \mathrm{C}$ e umidade relativa do ar de $51 \%$ até $95 \%$.

Tabela 1 - Características dos cenários envolvidos nos experimentos da tecnologia LoRa em Manaus.

\begin{tabular}{|c|c|c|c|c|c|}
\hline Cenário & Lat & Lon & $\begin{array}{c}\text { Altititude } \\
(\mathbf{m})\end{array}$ & $\begin{array}{l}\text { Altura } \\
\text { Ant(m) }\end{array}$ & Ambiente \\
\hline 1 & -3.09219 & -60.01827 & 36 & 6 & Urb Denso \\
\hline 2 & -3.06491 & -60.05258 & 87 & 2 & Suburbano \\
\hline 3 & $-3,06100$ & $-60,02510$ & 59 & 6 & Urb Denso \\
\hline 4 & $-3,04299$ & $-60,02483$ & 75 & 2 & Urb Denso \\
\hline
\end{tabular}

Os testes foram realizados para validar um enlace uplink ponto a ponto, com informações de sensores de temperatura e umidade além de informações do geoposicionamento através do sistema global de posicionamento, em inglês global positioning system - GPS. O indicador de intensidade do sinal recebido (RSSI) e a relação sinal-ruído (SNR) foram analisados em função da distância e da característica urbanística dos cenários testados. Utilizou-se uma antena do modelo Delock 88451 LTE antenna, com ganho de 2,8 dBi do lado da recepção fixa e uma antena com ganho e 2,0 dBi na unidade transmissora veicular.

Em uma cobertura outdoor, levantou-se a melhor configuração de modulação do LoRa para uma cidade com clima tropical úmido, segundo classificação climática de Köppen, adotando-se após validação fator de espalhamento SF7, largura de banda de $125 \mathrm{kHz}$ e taxa de codificação de 4/8 de bits de redundância. $\mathrm{O}$ menor cenário de teste foi de área total de $0,785 \mathrm{~km}^{2}$, majoritariamente suburbana e o maior cenário foi de área total de $12,566 \mathrm{~km}^{2}$ majoritariamente urbano densamente ocupada, mas com incidência de regiões de floresta. As áreas foram estimadas por meio das informações do GPS, e validadas pelo programa computacional Google Earth, disponível em versão gratuita.

\section{RESULTADOS}

A Tabela 2 ilustra a forma como foram tabuladas as informações detalhadas sobre os parâmetros da comunicação obtidos do dispositivo de medição instalado na unidade móvel 
ao transferir dados para o receptor fixo LoRa, para alguns pontos selecionados. A título de exemplo, a Tabela 2 apresentada os valores para alguns pontos do Cenário 4 do teste. Com base em todas as medições realizadas, o nível de sinal do RSSI variou de $-46 \mathrm{dBm}$ a $-119 \mathrm{dBm}$. Como a sensibilidade teórica do módulo LoRa configurada com SF 7 é de cerca de $-123 \mathrm{dBm}$, os resultados estão alinhados com as expectativas teóricas.

Tabela 2 - Valores de medição para alguns pontos selecionados nos quais foi possível estabelecer a comunicação entre o terminal móvel e o receptor fixo LoRa para o Cenário 4.

\begin{tabular}{cccccccc}
\hline Item & $\begin{array}{c}\text { Dist } \\
\text { RSm }\end{array}$ & RSSI & SNR & $(\mathbf{d B})$ & Lat & Lon & \multicolumn{2}{c}{ Temp } & Umid \\
& $\mathbf{(} \mathbf{C})$ & $(\boldsymbol{\%})$ \\
\hline 1 & 0,027 & -69 & 9,50 & $-3,04323$ & $-60,02477$ & 36,8 & 54,4 \\
2 & 0,027 & -68 & 9,50 & $-3,04323$ & $-60,02476$ & 36,8 & 54,4 \\
3 & 0,027 & -78 & 9,75 & $-3,04323$ & $-60,02476$ & 36,8 & 54,1 \\
4 & 0,028 & -62 & 9,50 & $-3,04324$ & $-60,02476$ & 36,8 & 53,9 \\
5 & 0,025 & -75 & 9,75 & $-3,04322$ & $-60,02480$ & 36,8 & 53,9 \\
6 & 0,031 & -104 & 0,75 & $-3,04272$ & $-60,02488$ & 36,8 & 53,3 \\
7 & 0,160 & -108 & $-6,00$ & $-3,04157$ & $-60,02500$ & 36,8 & 52,8 \\
8 & 0,563 & -111 & $-8,25$ & $-3,03794$ & $-60,02452$ & 36,6 & 52,5 \\
9 & 0,410 & -97 & 7,75 & $-3,03932$ & $-60,02509$ & 36,5 & 52,2 \\
10 & 0,232 & -83 & 9,25 & $-3,04094$ & $-60,02518$ & 36,6 & 52,5 \\
11 & 0,023 & -105 & 3,50 & $-3,04288$ & $-60,02501$ & 36,6 & 52,6 \\
12 & 2,000 & -108 & 1,50 & $-3,06098$ & $-60,02495$ & 36,2 & 53,8 \\
13 & 2,000 & -109 & $-8,75$ & $-3,06098$ & $-60,02504$ & 36,1 & 53,8 \\
14 & 2,000 & -108 & $-1,25$ & $-3,06098$ & $-60,02509$ & 36,2 & 54,0 \\
15 & 2,001 & -107 & $-2,25$ & $-3,06099$ & $-60,02509$ & 36,2 & 53,6 \\
16 & 1,404 & -111 & $-7,50$ & $-3,05562$ & $-60,02508$ & 36,3 & 51,3 \\
17 & 1,404 & -108 & $-8,00$ & $-3,05562$ & $-60,02518$ & 36,2 & 51,2 \\
18 & 1,404 & -109 & $-5,75$ & $-3,05562$ & $-60,02524$ & 36,2 & 51,6 \\
19 & 1,404 & -107 & $-5,00$ & $-3,05562$ & $-60,02524$ & 36,2 & 51,6 \\
20 & 1,404 & -109 & 1,75 & $-3,05562$ & $-60,02523$ & 36,2 & 51,8 \\
21 & 1,406 & -109 & $-1,25$ & $-3,05564$ & $-60,02515$ & 36,2 & 52,0 \\
22 & 1,183 & -113 & $-5,00$ & $-3,05363$ & $-60,02512$ & 36,0 & 54,1 \\
23 & 0,502 & -99 & 7,00 & $-3,04751$ & $-60,02486$ & 35,1 & 52,1 \\
24 & 0,382 & -92 & 9,00 & $-3,04643$ & $-60,02486$ & 34,9 & 53,0 \\
25 & 0,248 & -84 & 9,25 & $-3,04523$ & $-60,02481$ & 34,7 & 53,5 \\
26 & 0,105 & -66 & 9,50 & $-3,04394$ & $-60,02479$ & 34,6 & 53,7 \\
\hline & 0,010 & -46 & 9,50 & $-3,04308$ & $-60,02480$ & 34,4 & 53,6 \\
\hline
\end{tabular}

As Figuras de 1 a 4 mostram o mapa de nível de sinal obtido a partir do valor da RSSI de cada ponto em que foram realizadas a medições para cada um dos quatro cenários. $\mathrm{O}$ ponto fixo, com o módulo receptor, está localizado no centro da circunferência cujo raio representa a cobertura obtida para o cenário em questão. Os pontos de medição são diferenciados por cores, sendo que os pontos em verde representam os locais onde o nível de RSSI foi superior a $-100 \mathrm{dBm}$, que fornece um sinal forte com uma alta confiabilidade antecipada para efeitos de desvanecimento e interferência. Os pontos em amarelo mostram os locais onde os valores de ficaram entre $-100 \mathrm{dBm}$ e $-116 \mathrm{dBm}$. De acordo com (HÄGERLING, 2014) este segmento fornece uma intensidade de sinal suficiente para alcançar os transceptores LoRa instalados em ambientes internos e até instalados em porões. Ainda assim, observou-se algumas perdas de pacotes. Os pontos em vermelho representam os locais em que a medição de RSSI foi inferior a $-116 \mathrm{dBm}$ e nestas proximidades ocorreram algumas perdas de pacote, que não constam nas figuras.

Figura 1 - Mapa de cobertura com os pontos de medição bem-

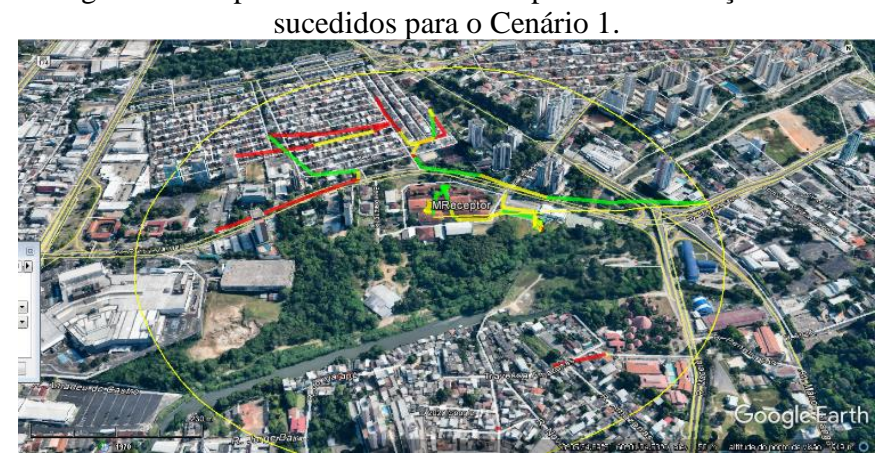

Figura 2 - Mapa de cobertura com os pontos de medição bemsucedidos para o Cenário 2.

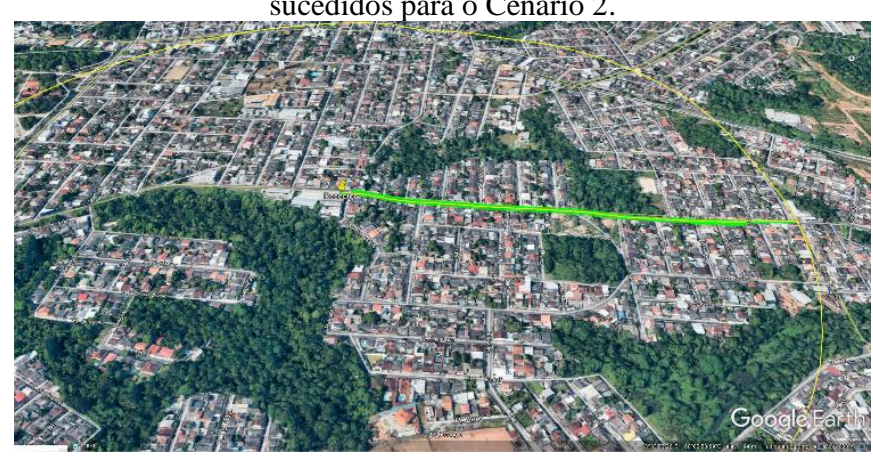

Figura 3 - Mapa de cobertura com os pontos de medição bemsucedidos para o Cenário 3 .

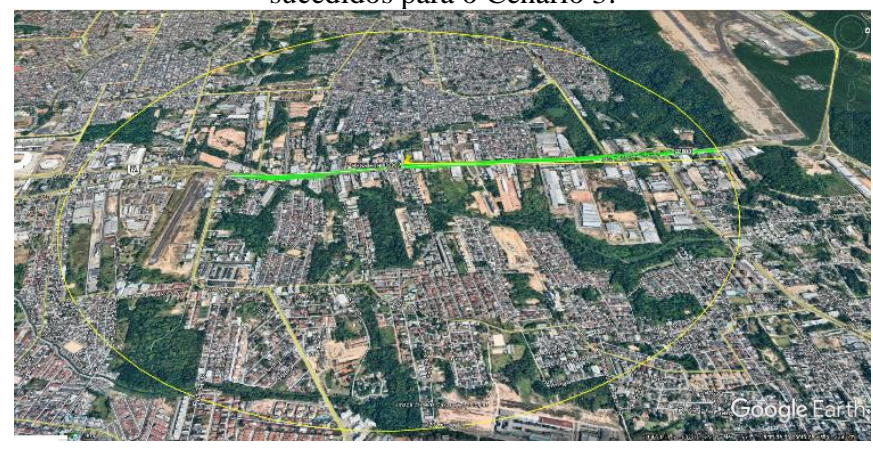

Figura 4 - Mapa de cobertura com os pontos de medição bemsucedidos para o Cenário 4.

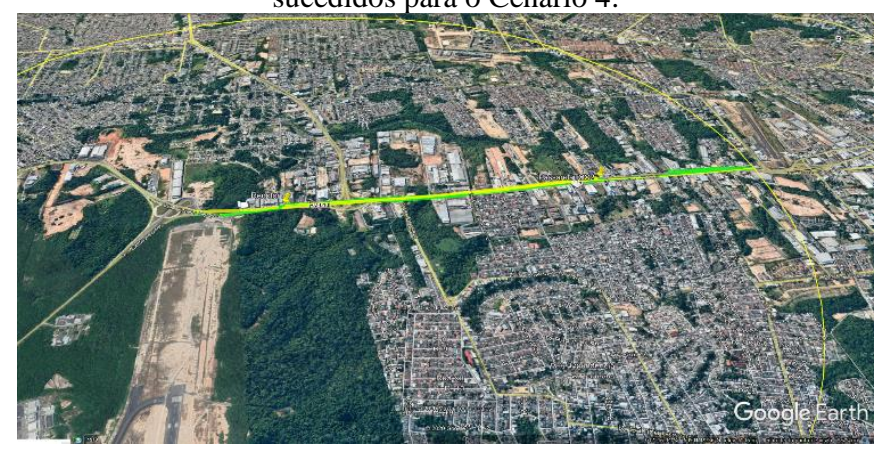

A Tabela 3 apresenta um resumo dos dados obtidos para os pontos de medição nos quais os dispositivos finais foram capazes de se comunicar. Nota-se claramente que o cenário 1, 
por localizar-se em um vale, foi o que apresentou os piores resultados quanto ao nível de sinal recebido, raio de cobertura e de taxa de pacotes entregues - PDR (Packet Delivery Rate).

As Figuras de 5 a 8 exibem o perfil de elevação para os cenários do teste. Através destas, fica evidente que a intensidade do sinal e a disponibilidade da rede dependem muito da posição real em que se localiza o ponto. $\mathrm{O}$ surgimento dos primeiros pontos cegos é causado mais devido às elevações e sombras de obstáculos do que por outros fatores. Levando em consideração os perfis de elevação nas figuras, a propagação consiste em menos folga, quando os edifícios existentes são considerados, resultando em perda adicional de trajetória. Na figura 5, que apresenta o perfil referente ao Cenário 1 , a antena receptora encontra-se obstruída pelas edificações próximas proporcionando más condições de propagação, especialmente para pontos situados além do vale, nas porções esquerda e direita da figura. $\mathrm{Na}$ Figura 6, as condições de propagação são boas para os pontos situados à direita e por isso obteve-se a melhor taxa de pacotes entregues - PDR. As Figuras 7 e 8 apresentam o mesmo perfil de elevação, mas posicionamentos e alturas das antenas receptoras diferentes. A antena receptora presente na Figura 7, apesar de situar-se em uma cota $16 \mathrm{~m}$ inferior à antena da Figura 8, apresentou melhores resultados devido a sua localização próxima do centro da região de cobertura do teste e por ser $4 \mathrm{~m}$ mais elevada.

Figura 5 - Perfil de elevação para o Cenário 1, mostrando a localização do ponto fixo de recepção.

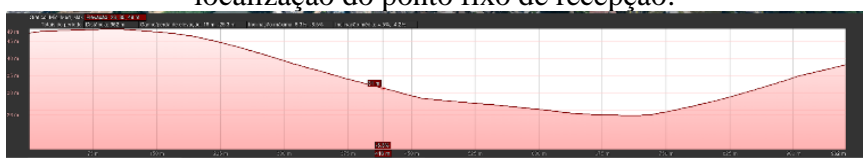

Figura 6 - Perfil de elevação para o Cenário 2, mostrando a localização do ponto fixo de recepção.

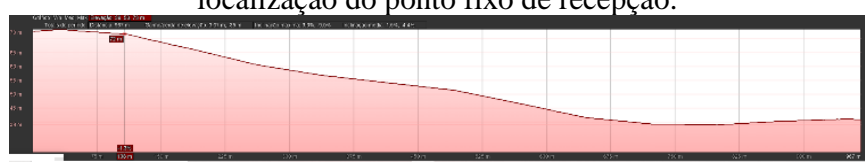

Figura 7 - Perfil de elevação para o Cenário 3, mostrando a localização do ponto fixo de recepção.

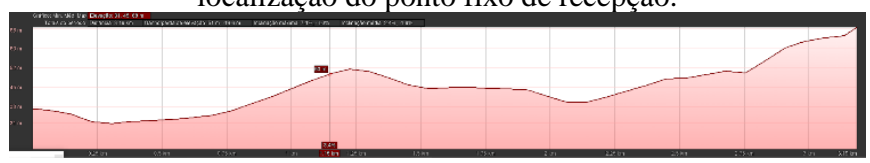

Figura 8 - Perfil de elevação para o Cenário 4, mostrando a localização do ponto fixo de recepção

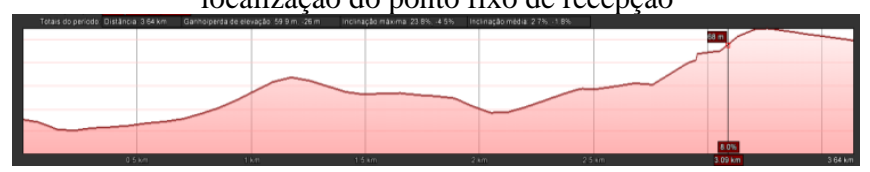

A primeira preocupação a ser destacada aqui é que levamos em consideração apenas medições usando largura de banda de $125 \mathrm{kHz}$ com o SF 7. Apesar de os resultados obtidos fornecerem algum grau sobre as capacidades de comunicação da tecnologia em uso, seria definitivamente benéfico explorar mais detalhadamente as medições que abrangem diferentes parâmetros de comunicação da tecnologia LoRa, como largura de banda, fator de espalhamento, taxa de código, modulações e ambiente de uso (áreas com intensa vegetação, áreas com pouca urbanização, entre outras).
Tabela 3 - Resumo dos valores de medição para todos os pontos nos quais foi possível estabelecer a comunicação entre o terminal móvel e o receptor fixo LoRa.

\begin{tabular}{ccccc}
\hline Cenário & $\begin{array}{c}\text { RSSIMáx } \\
(\mathbf{d B m})\end{array}$ & $\begin{array}{c}\text { RSSIḾn } \\
(\mathbf{d B m})\end{array}$ & $\begin{array}{c}\text { Raio } \\
(\mathbf{m})\end{array}$ & $\begin{array}{c}\text { PDR } \\
\text { \% }\end{array}$ \\
\hline 1 & -78 & -119 & 522 & 68 \\
2 & -59 & -102 & 860 & 95 \\
3 & -69 & -100 & 2001 & 93 \\
4 & -46 & -113 & 2000 & 89 \\
\hline
\end{tabular}

É importante salientar que os resultados apresentados foram obtidos para o sinal de uplink, isto é, para a transferência de dados de um nó móvel para a estação fixa.

\section{CONCLUSÃO}

Neste artigo, foi apresentada uma avaliação de alcance e desempenho de uma rede IoT Smart City baseada em LoRa na cidade de Manaus-Brasil. São apresentados e discutidos os resultados das medições do mundo real com um receptor LoRa instalado a $6 \mathrm{~m}$ e a $2 \mathrm{~m}$ de altura acima do solo. Uma análise de disponibilidade mostra que a recepção do sinal é possível em áreas de cobertura com alcance de até $2,0 \mathrm{~km}$, considerando pontos cegos sem recepção a partir de intervalos de $500 \mathrm{~m}$, causados por elevações e sombreamento por obstáculos.

Embora os resultados apresentados indiquem as possibilidades de comunicação da tecnologia LoRa, os resultados obtidos trouxeram à tona as limitações da tecnologia em questão.

No futuro, outros fatores de dispersão, níveis de largura de banda e esquemas de modulação podem ser levados em consideração.

\section{REFERÊNCIAS BIBLIOGRÁFICAS}

BANKOV, D. et all "On the limits of LoRaWANchannel access". In Proceedings of the International Conference on Engineering and Telecommunication (EnT),Moscow, Russia, 2016.

BOR, M. et all. "LoRa for the Internet of Things". In: Proceedings of the 2016 International Conference on Embedded Wireless Systems and Networks, EWSN '16, pp. 361-366, USA, 2016.

$\mathrm{BOR}^{2}$, M. et all. "Do LoRa Low-Power Wide-Area Networks Scale?" In: Proceedings of the 19th ACM International Conference on Modeling, Analysis and Simulation of Wireless and Mobile Systems, MSWiM '16, doi: 10.1145/2988287.2989163. New York, NY, USA, 2016.

CHIANI, M et all "Sobre a modulação LoRa para IoT: propriedades de forma de onda e análise espectral". Jornal IEEE Internet das Coisas - doi: 10.1109 / JIOT.2019.2919151 . hdl : 10754/655888. ISSN 2327-4662 em 2019.

DE TELECOMUNICAÇÕES, A. N. "Plano de Atribuição, Destinação e Distribuição de Frequências no Brasil", Acessado em março de 2020, https://www.anatel.gov.br/Portal/verificaDocumentos/docum ento.asp?numeroPublicacao=349400, 2019. 
GEORGIOU, O.; RAZA, U. "Low PowerWide Area Network Analysis: Can LoRa Scale?" IEEEWirel. Commun. Lett. 2017.

HÄGERLING, C. IDE, C. e WIETFELD, C. "Coverage and capacity analysis of wireless M2M technologies for smart distribution grid services," in International Conference on Smart Grid Communications (SmartGridComm), IEEE, 2014, pp. 368-373.

HERRERA-TAPIA, J et all. "Evaluating the use of subgigahertz wireless technologies to improve message delivery in opportunistic networks". In Proceedings of the 14th IEEE International Conference on Networking, Sensing and Control, (ICNSC 2017), Calabria, Italy, 2017.

JÖRKE et al., "Urban channel models for smart city IOTnetworks based on empirical measurements of LoRa-links at 433 and $868 \mathrm{MHz}$," in 2017 IEEE 28th Annual International Symposium on Personal, Indoor, and Mobile Radio Communications (PIMRC), Oct 2017, pp. 1-6.

LoRaTM-Aliance "LoRa Modulation Basics" (PDF), 2016 Arquivado a partir do original (PDF) em 18 de julho de 2019.

PETÄJÄJÄRVI et all. "Performance of a low-power widearea network based on LoRa technology: Doppler robustness, scalability, and coverage”. Int. J. Distrib. Sens. Netw. 2017.

PETÄJÄJÄRVI² et al., "On the coverage of LPWANs: range evaluation and channel attenuation model for LoRa technology, " in 2015 14th International Conference on ITS Telecommunications (ITST), Dec 2015, pp.55-59.

RAZA, U. et all. "Low Power Wide Area Networks: An Overview", IEEE Communications Surveys Tutorials, v. 19, n. 2, pp. 855-873, ISSN: 1553-877X. doi: 10.1109/COMST.2017.2652320, Secondquarter em 2017.

SCHAFFERS, H. et all. "Smart Cities and the Future Internet: Towards Cooperation Frameworks for Open Innovation". In: The Future Internet: Future Internet Assembly 2011: Achievements and Technological Promises, doi: 10.1007/978-3-642-20898-0 31. Springer Berlin Heidelberg, 2011.

\section{AGRADECIMENTOS}

Este trabalho conta com o apoio da Samsung Eletrônica da Amazônia Ltda. e AGIN - Agência de Inovação da UEA.

\section{COPYRIGHT}

Direitos autorais: $\mathrm{O}(\mathrm{s})$ autor(es) é(são) o(s) único(s) responsável(is) pelo material incluído no artigo. 


\author{
Volume 16 - $\mathrm{N}^{\mathrm{o}} 174$ - Junho / 2020 \\ XLII International Sodebras Congress \\ 28 a 30 de maio de 2020 - Web Conference.
}

\title{
DESENVOLVIMENTO DE UM ROBÔ GUIA REATIVO PARA ESCOLA SUPERIOR DE TECNOLOGIA
}

\section{DEVELOPING A ROBOT REACTIVE GUIDE FOR A COLLEGE OF TECHNOLOGY}

\author{
ADOLPHO NILTON GLORIA ${ }^{1}$; MOISÉS PEREIRA BASTOS ${ }^{2}$; LUÍS EDUARDO MENA BARRETO \\ PEREIRA $^{3}$; DANIEL DE SOUZA CAROLINO ${ }^{4}$; ALMIR KIMURA JUNIOR ${ }^{5}$
}

\author{
1,2,3,4,5 - Universidade do Estado do Amazonas
}

\section{5 - Samsung OCEAN Manaus}

a.niltonferreira@hotmail.com; mpbastos@uea.edu.br;lembpr.eng16@uea.edu.br;dsc.eng17@uea.edu.br; akimura@uea.edu.br;

\begin{abstract}
Resumo - Este artigo tem como objetivo apresentar a implementação de um robô móvel reativo que guie e informe os visitantes, sendo este um seguidor de linha composto de sensores para se locomover, contendo também dispositivos para Interação Humano Máquina e de um sistema global de posicionamento, para a sua localização. Para tal foi utilizada a ferramenta computacional Autodesk Inventor para desenho $e$ testes mecânicos $e$ o desenvolvimento do software em linguagem baseada em $\mathrm{C} / \mathrm{C}++$, chamada de Wiring. Os resultados obtidos nos experimentos feitos durante a pesquisa mostraram que o sistema realizou a localização com precisão, realizando a movimentação de forma estável e correta, ou seja, seguindo a linha até encontrar a posição solicitada, e a Interação Humano Máquina realizou a comunicação de forma sucinta e eficaz.

Palavras-chave: Robô Móvel. Interação Humano-Máquina. Robótica.
\end{abstract}

\begin{abstract}
This article aims to present the implementation of a reactive mobile robot that guides and informs visitors, being a line follower composed of sensors for locomotion, also including devices for Human Machine Interaction and a global positioning system, for its location. For that, a computational tool from Autodesk Inventor was used for design and mechanical tests and software development in a specific language in $C / C++$, called wiring. The results obtained in the experiments carried out during a research that shows the system executed in precision, performing a movement in a stable and correct way, that is, following a line until finding the requested position, and the Human Machine Interaction Executed in the Succinct Communication and effective.
\end{abstract}

Keywords: Mobile Robot. Human-machine interaction. Robotics.

\section{INTRODUÇÃO}

A interação humano-máquina, em meio à realidade e ao cotidiano da sociedade traz uma discussão sobre o que nos reserva o futuro trazido por essas novas obras. As mudanças tecnológicas acontecem de forma dinâmica e tecnologia como as máquinas de escrever, de fax e televisões de tubo foram rapidamente ultrapassadas (PENAFIEL; PEREIRA, 2014).

Nesse contexto de novas obras/tecnologias, o robô móvel autônomo tem uma linha de aplicações para o futuro , hoje a sua utilização é mais concentrada na execução de tarefas cotidianas em ambientes internos, devido a isso , as plataformas devem ser capazes de navegar e evitar obstáculos. Relacionando aos robôs seguidores de linha, pode-se inferir que um sistema robótico requer um mapa, devendo acrescentar a linha no ambiente real, então definida sua trajetória e em seguida realizar a navegação (KWANG-HYUNK et al., 2008). Com base nessas aplicações, a ideia do robô reativo é de ser uma máquina que necessita de acionamentos humanos para fazer qualquer ação pré-programada, sendo composto por dispositivos periféricos que recebem os mesmos e os transferem para a máquina executar da forma correspondente. Sendo assim as suas ações necessitam de humanos para serem executadas.

O presente projeto tem como objetivo projetar um robô móvel reativo que guie e informe os visitantes na Escola Superior de Tecnologia, sendo um seguidor de linha composto de sensores para locomoção, tendo dispositivos para interação humano-máquina, com desenvolvimento utilizando uma plataforma de desenho e simulação Autodesk Inventor ${ }^{\circledR}$ e o desenvolvimento do software em uma linguagem baseada em $\mathrm{C} / \mathrm{C}++$, chamada de Wiring, utilizando normas técnicas de segurança em cada desenho mecânico, técnicas em movimentação de robôs móveis e interações humano-máquina.

\section{REFERENCIAL TEÓRICO}

\subsection{Robótica}

A robótica possui a capacidade de atuação em vários campos que vão desde o uso industrial com os AGV's e manipuladores até os robôs utilizados na medicina em cirurgias. É tratada com o conjunto de teorias aplicadas , que compreende vários ramos da engenharia, como a mecânica, elétrica e eletrônica, a computação e as ciências cognitivas, como a biologia. Porém, robôs sozinhos constituem apenas uma parte de um sistema robótico (NIKU, 2013). De acordo com (SOUZA, 2016) os robôs atualmente são comumente utilizados em linhas industriais para realização de atividades repetitivas, visando diminuir o perigo e esforço para os seres humanos, mas a sua aplicabilidade está alterando, recentemente observa-se a popularização de robôs 
comerciais que podem facilitar as atividades cotidianas (tarefas domésticas) como cortar grama e limpar o piso.

\subsubsection{Robô Seguidor de Linha}

Um veículo guiado automaticamente (AGV) é um robô móvel contendo uma série de sensores e circuitos de comunicação que o tornam autônomo, ou seja, independente do ser humano. Sistemas baseados em AGVs podem ser utilizados para várias finalidades, tanto na execução de tarefas industriais quanto domésticas. Estes sistemas são mais utilizados em depósitos e plantas industriais, mas podem ser encontrados em sistemas para transporte de cargas, como em portos, ou mesmo no transporte pessoal (ANDRADE , 2013).

\subsection{Controlador}

Controle liga-desliga, é quando o controlador compara o sinal de entrada, que indica o valor atual da grandeza(PV), como valor determinado como ponto de controle, conhecido como Set Point (SP), se caso o:

- $\mathrm{PV}>\mathrm{SP}=$ desliga o atuador;

- $\mathrm{PV}<\mathrm{SP}=$ liga o atuador;

As vantagens deste controlador são a simplicidade e o baixo custo, a desvantagem é a oscilação da saída em torno do Set Point do controlador, a chamada histerese, não garantindo precisão, apenas uma proximidade do valor do processo ao valor programado, o que pode causar desgaste do atuador, devido aos acionamentos frequentes.

\subsection{1 controlador $P D$}

A combinação do parâmetros do controlador Derivativo somada ao Proporcional resulta em uma resposta rápida no momento do surgimento do erro, sendo um valor alto de execução ao processo, mas à medida que o erro reduz o valor de execução reduz, ou seja, o valor de execução se aproxima do Set Point. Tendo justamente a função de "antecipar" a ação de controle, tendo o processo agindo mais rápido. Diante disso o sinal de controle a ser aplicado é proporcional a uma predição da saída do processo. Se este controle PD for aplicado a um processo que a resposta natural é rápida, esse sistema poderá deixa-lo instável, por exemplo, quando a resposta de ação do atuador deve ser rápida como nos sistemas de controle de pressão (AMORIM, 2011).

\subsection{Interação Humano Máquina}

Segundo Penafiel e PEREIRA (2014), na necessidade da interação entre o humano e as máquinas tem-se de fundamental a construção de uma interface amigável ao usuário. A comunicação entre o humano e a máquina, é um canal no qual são feitas as interações que visam atingir um objetivo comum. Sendo que o que determina como as pessoas operam e controlam a máquina é a interface que faz parte de um sistema computacional. Com uma interface bem projetada, os usuários se sentem satisfeitos e seguros ao realizar suas ações.

Desta forma as atividades básicas do Design de Interação, o funcionamento de Usabilidade e Avaliação de Interface são primordiais na comunicação. Para ajudar nessa comunicação humano e máquina existe a tela touchscreen, que é a tela sensível ao toque, sendo um display eletrônico visual que pode detectar a presença e localização de um toque dentro da área de exibição, por meio de pressão. Essas telas sensíveis ao toque estão se tornando cada vez mais comuns. Hoje já é comum encontrarmos essa tecnologia em telefones celulares, tablets, caixas eletrônicos, videogames, entre outros. As telas sensíveis ao toque dispensam o uso de botões (TECMUNDO, 2008).

\section{METODOLOGIA}

Se valendo de pesquisas com embasamento teórico em artigos e revistas científicas, disciplinas cursadas na faculdade e experiências realizadas em laboratório para execução e implementação deste projeto. Foi elaborado a seguinte divisão do projeto: Arquitetura do Sistema; Projeto Mecânico; e Projeto Eletrônico.

\section{1 - Arquitetura do Sistema Proposto}

O desenvolvimento do projeto mecânico do robô foi realizado no programa Autodesk Inventor $®$, visando a melhor alocação de seus componentes e performance. Os dispositivos utilizados foram: motores com drivers, sensores de linha e sensores ultrassônicos, para sua movimentação; o sensor RFID, para sua localização; a tela touchscreen e sistema sonoro, para a IHM; como também baterias e circuitos de controle e alimentação elétrica.

A concepção do chassi do robô se deu através de um estudo bibliográfico de projetos já existentes, observando primordialmente a organização de sua estrutura com a finalidade de desenvolver a melhor forma eletromecânica e que se encaixasse com o projeto de desenho $3 \mathrm{D}$ do robô.

A estrutura do robô foi ilustrada na Figura $1 \mathrm{com}$ a visão posterior e na Figura $2 \mathrm{com}$ a visão frontal, representando a visão geral do desenho mecânico e dos seus principais componentes, enfocando em sua funcionalidade.

Figura 1 - Vista posterior do Robô

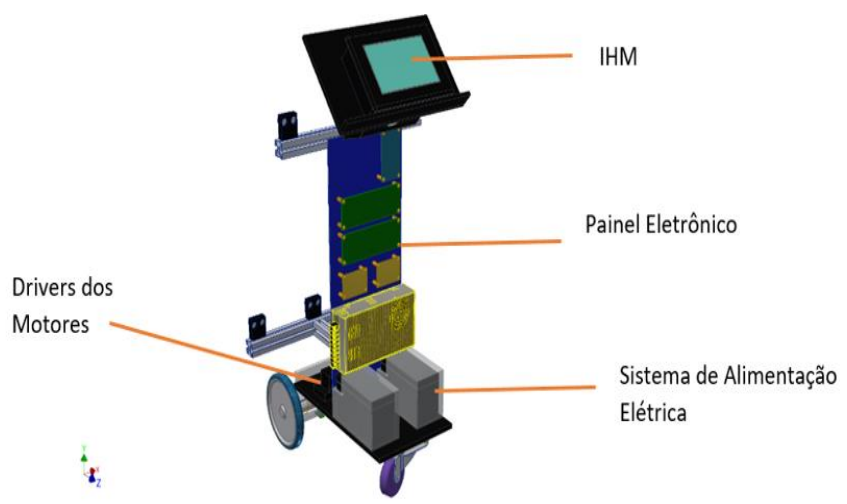

Fonte: Autor 
Figura 2 - Vista frontal do Robô

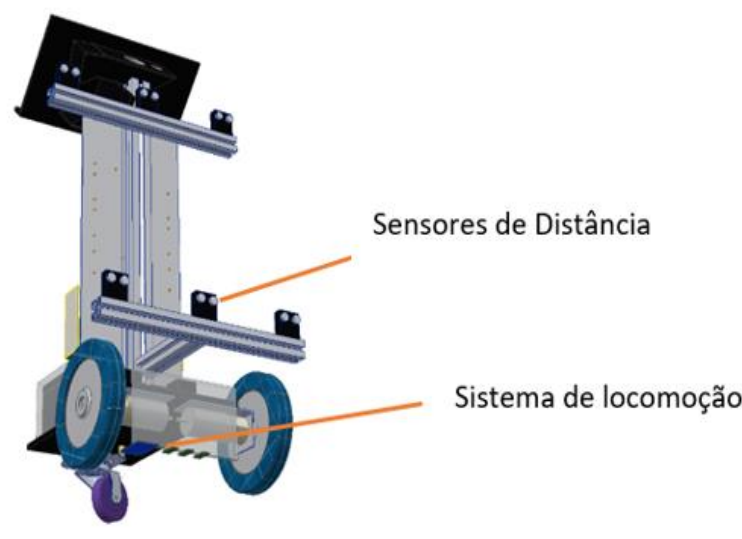

Fonte: Autor

\section{2 - Projeto Mecânico}

A montagem do robô teve início no estudo de sua base mecânica de alocação das rodas, tendo como enfoque o robô tipo uniciclo, contendo uma estrutura formada por duas rodas fixas convencionais sobre um mesmo eixo, controladas de maneira independente, e por uma roda boba que lhe confere estabilidade, ilustrada na Figura 3.

Figura 3 - Estrutura da Base Uniciclo

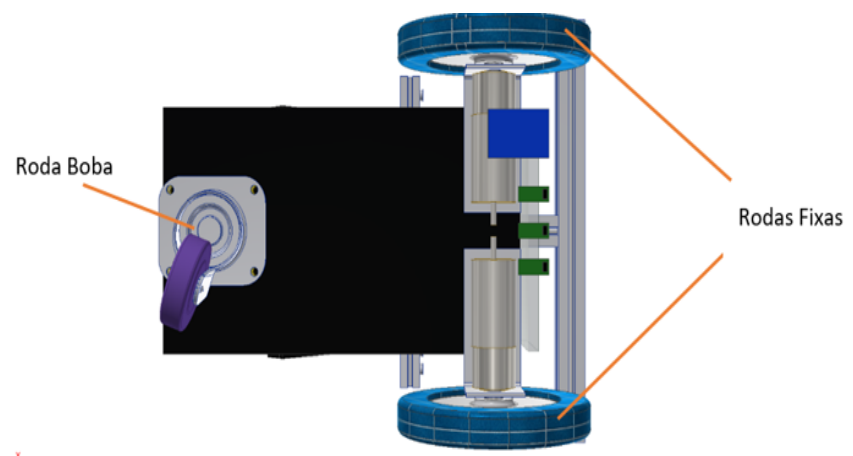

Fonte: Autor

A montagem da base mecânica dos componentes de movimentação, conforme definido os motores DC, estabelece o sistema de tração-direção associado ao sistema mecânico, por ter o controle das duas rodas de forma independente em suas velocidades. Após isso, definir rodas fixas conforme o ambiente de funcionalidade do robô, por fim a definição da roda boba e acordo com o peso da estrutura.

\subsection{1 - Rodas}

Devido às dependências da Escola Superior de Tecnologia possuírem superfície lisa, as rodas devem ter o máximo de atrito possível com o chão, por isso foram escolhidas as rodas fixas com câmara (pneu) como ilustrada na Figura 4 com pressão de 36 PSI, diâmetro de $150 \mathrm{~mm}$ e suporta até $80 \mathrm{~kg}$.
Figura 4 - Imagem ilustrativa da Roda

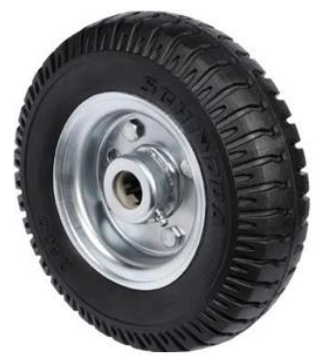

Fonte: Autor

A escolha da roda boba se deve a não poder ter atrito com o chão e sim resistência a carga empregada sobre ela, para assim ter uma estrutura que aloque o peso sobre a mesma, com alocação do peso não centralizado na estrutura, por sua estabilidade e pela alocação das rodas, na Figura 5 o desenho 3D ilustrativo, temos o rodízio industrial escolhido que é de placa polipropileno, sustentando até $90 \mathrm{~kg}$ com 100 $\mathrm{mm}$ de altura.

\subsection{2 - Estrutura do Robô}

O tamanho da base visto na figura 6 foi desenvolvida após a definição das rodas e motor do sistema. Essa base foi projetada no programa Autodesk Inventor, facilitando ao adicionar cálculos em suas medidas. Foi projetada uma base de 380x220 $\mathrm{mm}^{2}$. Definimos que o material de fabricação da base foi Poliacetal.

Figura 6 - Projeto da Base

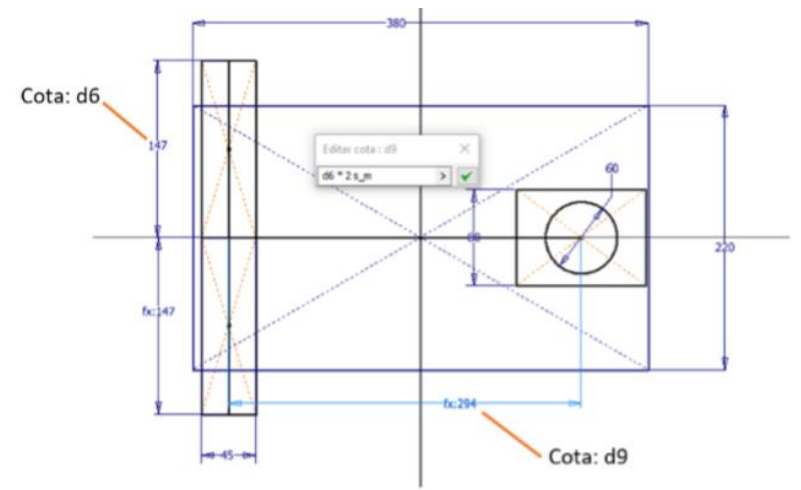

Fonte: Autor

\section{3 - Projeto Eletrônico}

O projeto eletrônico foi dividido em seis sub tópicos:

\subsection{1 - Sistema de Controle}

O sistema de controle tem como objetivo a administração dos sensores, comunicação com IHM e acionamento dos atuadores com base nos algoritmos de Controle Proporcional e localização. Este é composto por: microcontrolador, placa de acionamento e os demais componentes conectados. 
Figura 7 - Visão Geral Sistema de Controle

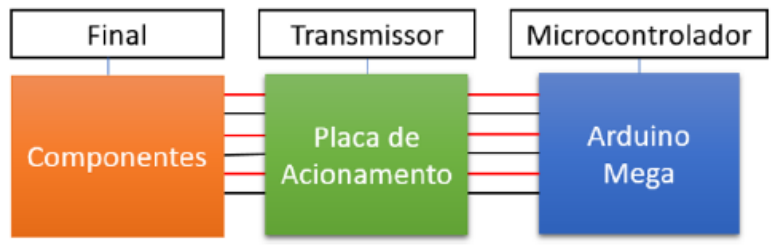

Fonte: Autor

O sistema de controle visto na Figura 7 tem como objeto central o microcontrolador, que no caso desse projeto, o utilizado foi o da Plataforma Arduino Mega, a escolha deste se deu pelas características: Quantidade de Portas - Digitais (algumas com Funções PWM - usadas para controle dos
Drives de Motores) e analógicas; Facilidade de Programação, usando sua interface nativa com linguagem baseada em $\mathrm{C} / \mathrm{C}++$; Baixo custo e facilidade de compra. Além disso a placa de acionamento serve como uma ponte que organiza a comunicação do Arduino com os seguintes componentes: driver de motores DC, sensores de distância, sensores de linha e leitor de RFID.

\subsection{2 - Sistema de Alimentação e Armazenamento Elétrico}

O objetivo desse sistema é o gerenciamento das baterias (carregamento e regulação para outros componentes). Constituído por Sistema de carregamento, baterías de $12 \mathrm{~V}$, regulador de $5 \mathrm{~V}$ e placa de alimentação. A visão geral do Sistema pode ser observado na Figura 8.

Figura 8 - Visão Geral Sistema de Alimentação e Armazenamento Elétrico.

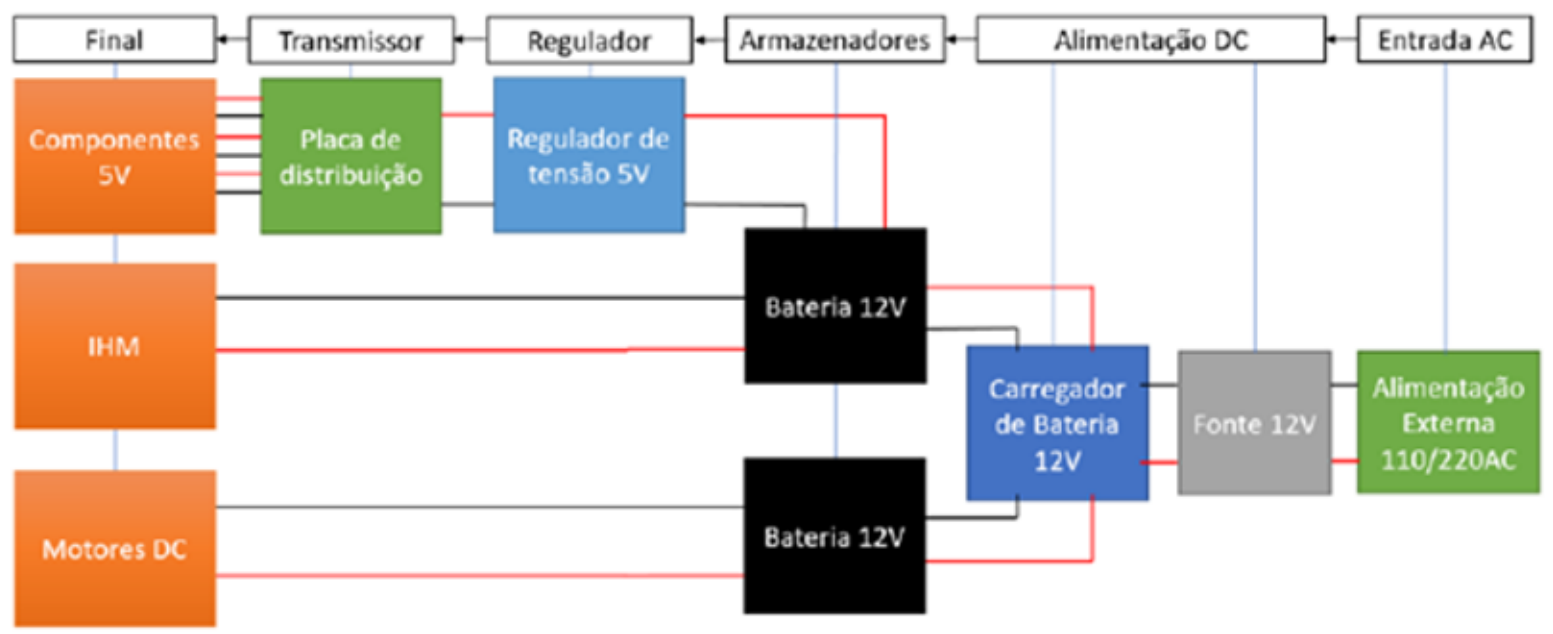

Fonte: Autor

O Sistema de carregamento utiliza uma fonte steady power $12 \mathrm{~V} / 100 \mathrm{~W}$ conectada ao um módulo carregador de bateria. Ele realiza a medição e controle do carregamento das baterias de chumbo ácido, estas são seladas e reguladas por válvula. $\mathrm{O}$ uso desse tipo bateria visa suprir tempo de recarga e as mesmas são livres de manutenção. O regulador de tensão é utilizado para alimentar de forma adequada o sistema de controle (microcontrolador e sensores) cuja a tensão dos componentes é padronizada em $5 \mathrm{~V}$. A placa de alimentação tem o papel de ramificar de forma organizada as tensões disponíveis de $12 \mathrm{~V}$ e $5 \mathrm{~V}$, facilitando as conexões dos dispositivos.

\subsection{3 - Sensores}

O sensoriamento do Robô é constituído basicamente por dois tipos diferentes: sensor de linha e sensor de distância. O sensor de linha definido para o projeto é Módulo Sensor Ótico TCRT500. Ele funciona com base no reflexo do infravermelho nas superfícies onde se encontra a linha. Foi inserido no robô 3 sensores deste tipo visando a implementação do seguidor de linha.

O sensor de distância utilizado foi Sensor Ultrassônico HC-SR04, o seu princípio de funcionamento baseia-se na utilização do ultrassom para medir distância, conforme Figura 9. No projeto foi utilizado 6 sensores, com um range máximo de $20 \mathrm{~cm}$ (distância que o robô deve ficar de qualquer objeto ou pessoa).

Figura 9 - Funcionamento do Sensor Ultrassônico.

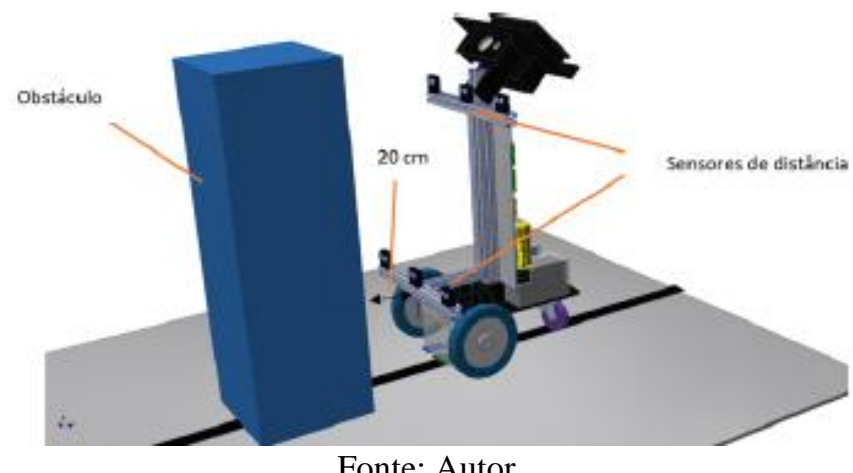

\subsection{4 - Sistema de Atuação}

O objetivo desse sistema é atuação móvel do robô, ele é constituído por: motores DC e Driver Motor DC. O motor Escolhido foi Gear Motor PG45775, que possui as seguintes características: alimentação de 12V, RPM máximo de 500, redutor acoplado, torque de $32 \mathrm{~kg} / \mathrm{cm}$. Já o driver Motor Dc 
foi o speed Controller-Victor888 com alimentação de $12 \mathrm{~V}$ e corrente máxima de saída de $5^{\mathrm{a}}$, com entradas de controle via PWM (saídas do Arduino).

\subsection{5 - Sistema de Localização}

É um sistema que cujo objetivo é fornecer ao robô a sua localização e a informação acerca daquele lugar. O método é utilizar tag's RFID's fixas nos pontos principais da Universidades e usar leitores embutidos no Robô para obter as informações nas tag's. Com essas informações o robô verificará se o local informado na tag é o mesmo selecionado na IHM, conforme apresentado na Figura 10.

Figura 10 - Funcionamento do Sensor Ultrassônico.

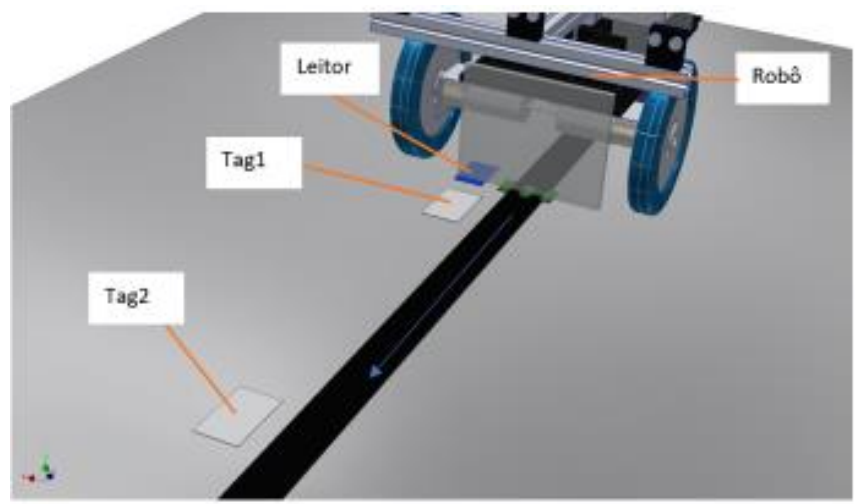

Fonte: Autor.

O Sensor utilizado foi o leitor RFID - MFRC522 que possui frequência de $13,56 \mathrm{Mhz}$.

\subsection{6 - Interação Humano Máquina}

Este sistema é constituído por uma tela touchscreen cujo modelo é Touch Controller CUWIN, apresentada na Figura 11. O papel desse sistema é fornecer interatividade (mapas e aplicações) com o usuário e comunicação com o sistema de controle (Serial com Arduino).

Figura 11 - Touch Controller CUWIN.

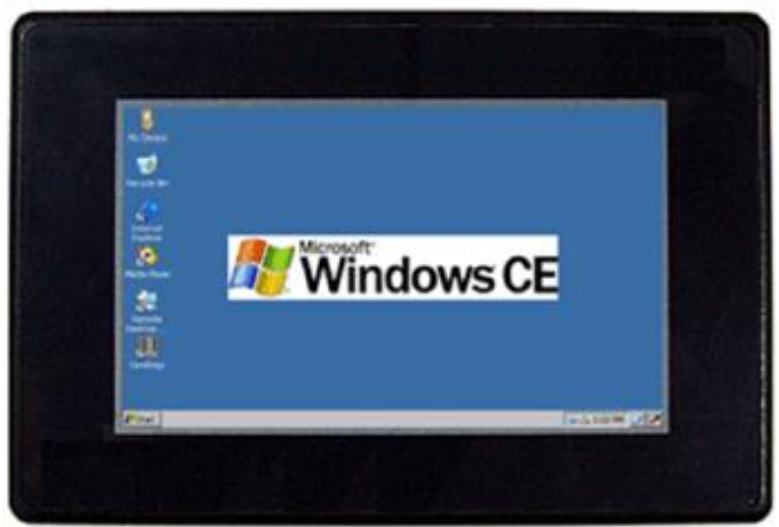

Fonte: Autor.

\section{RESULTADOS}

A seguir apresentamos os tipos de testes realizados e seus resultados.

\subsection{Testes de Locomoção}

O seguidor de linha tem um comportamento simples, mas importante, que permite o uso de robôs móveis em ambientes estruturados como indústria. Por percorrer caminhos pré-estabelecidos, marcados no chão por uma linha, tornando diversos processos práticos para serem automatizados.

Figura 12 - Pista de Testes

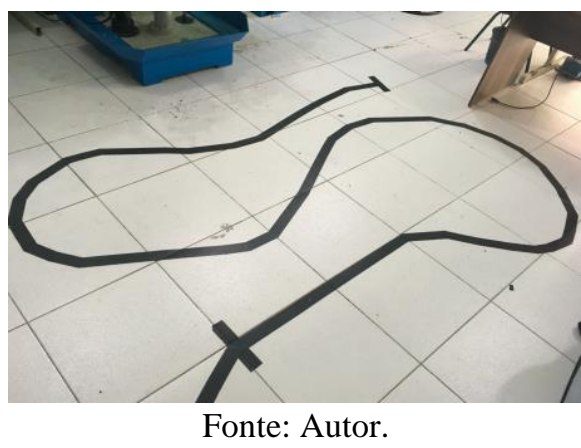

No primeiro teste do seguidor de linha visto na Figura 12 , tem-se a construção do circuito no chão, com curvas em um ângulo de 20 graus de acordo com a pista, como ilustrado na figura 12 .

A responsabilidade de uma movimentação correta e eficaz está diretamente interligada ao controlador, por suas variáveis do controle PD. Então realizou-se testes de melhoria no controle, ajustando o valor da constante do Proporcional (Kp) até chegar ao resultado da constante de 100. Depois encontrando o valor do Derivativo (Kd) da constante de 30, como ilustrado na Figura 13 as variáveis de PD do programa.

Figura 13 - Variáveis do Cálculo do PD

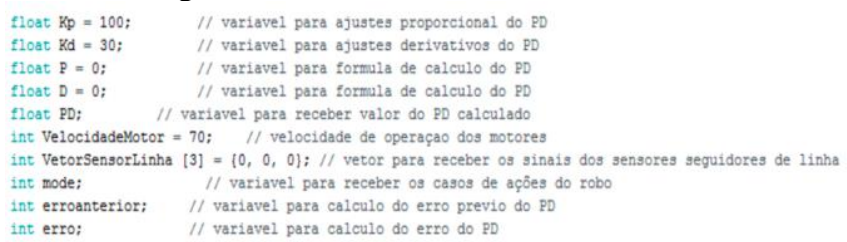

Fonte: Autor.

Para se chegar a esses valores, teve-se que testar muitas vezes só o controlador Proporcional, como resultado dos testes, os valores abaixo de 100 tiveram respostas lentas ao erro, e os valores acima desse ganho mostraram respostas muito rápidas e assim oscilavam muito o sistema, sendo perfeito em linha reta.

Logo após, teve-se que testar inúmeras vezes o controlador Derivativo, como anulamos a constante Proporcional no sistema, pode-se ter uma resposta só dessa constante que resultou no valor 30 , por demonstra que valores acima desse o sistema oscilou bastante mas com valores abaixo de 30 teve-se respostas lentas em curvas, com isso não prevendo o erro a tempo. Fazendo o robô conseguir fazer as curvas das linhas demarcadas.

\subsection{Testes no Sistema de Localização \& Interação Humano Máquina}

O sistema de localização é um dos sistemas principais, por definir como o robô vai localizar os destinos selecionados no mapa da IHM. Realizados testes do módulo RFID em relação a resposta de sua comunicação de leitor e Tag, 
mostrando que é de forma instantânea, sem precisar parar e processar para saber se o robô está na posição certa ou não, ilustrado os ambientes de testes do robô na Figura 14 e 15.

A figura 14 apresenta uma pista com muitas curvas e com duas tags para fazer o teste de que o robô para na posição desejada. Na figura 15 temos a foto da pista reta para teste de controle em locomoção sem curvas, visando manter a estabilidade do sistema.

Figura 14 - Pista Demarcada com Tags

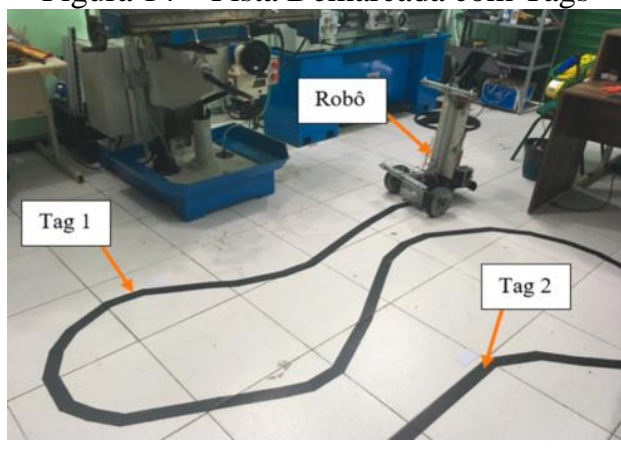

Fonte: Autor.

Os testes foram realizados em conjunto com a IHM, para viabilizar o funcionamento de localizar e informar na tela, então na Figura 16 tem se a tela touchscreen que é entrada de informação para o robô. Nela contêm o mapa para escolha do local desejado, contendo apenas dois locais de escolha na tela para teste.

Figura 15 - Pista Demarcada com Tags

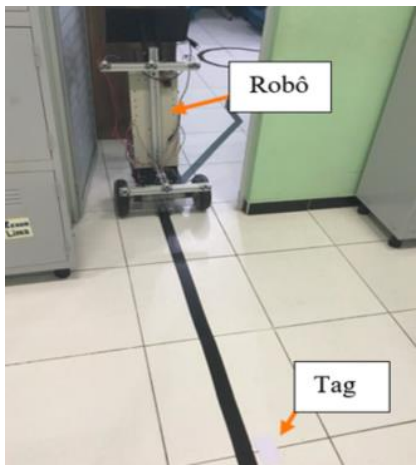

Fonte: Autor.

Figura 16 - Escolha do Local no Mapa da IHM

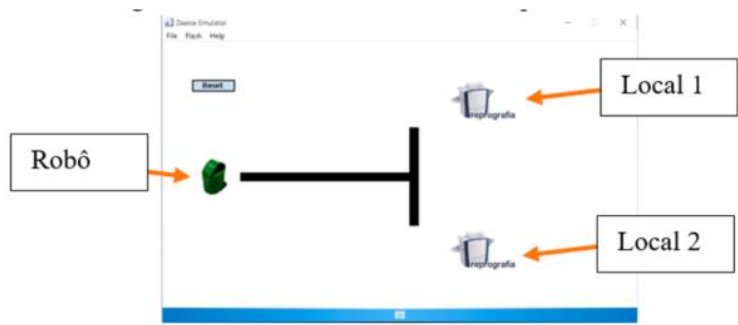

Fonte: Autor.

Após essa escolha do local que o robô deve conduzir a pessoa, tendo uma voz computacional chamando a pessoa para acompanhar o robô, então o autômato segue a linha demarcada até encontrar um obstáculo humano em sua frente, parando como ilustrado na Figura 17.
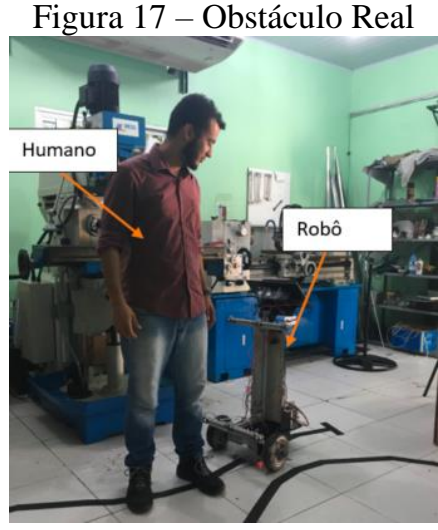

Fonte: Autor.

Com a saída da pessoa de sua frente, o robô percorre o restante do caminho até chegar ao local determinado e sinaliza na IHM que chegaram na posição destinada, tendo uma voz computacional confirmando a chegada ao local .

\section{CONCLUSÃO}

Este trabalho teve o objetivo de desenvolver um robô guia reativo para a Escola Superior de Tecnologia da Universidade do Estado do Amazonas, visando criar um agente de interação entre a comunidade em geral e a instituição de ensino.

De acordo com o método proposto foi realizado o desenho mecânico para garantir os requisitos de funcionalidades e especificar as dimensões da estrutura. Em seguida passou-se para a organização de uma estrutura eletromecânica de modo que garantisse que todos os acionamentos mecânicos e atuadores executassem suas funções como necessário. Tendo em vista os resultados dos testes de viabilidade dos métodos propostos tanto para a locomoção quanto para o sistema de localização foi necessário utilizar um controlador PD para que os erros de movimentação em linha reta e curvas ficassem mais suaves.

No sistema de localização, conclui-se que o módulo RFID utilizado para ter o feedback de posicionamento nas localidades foi satisfatório, uma vez que o tempo de resposta apresentado pelo sistema foi adequado necessidade de operação instantânea a informação obtida pelos leitores de tag.

Por fim quando o sistema chega na posição solicitada a IHM informa ao usuário que se encontra no local desejado através de comunicação por voz e mensagem na tela touchscreen do sistema.

Esse artigo é resultado de um trabalho de fim de curso desenvolvido na UEA-EST (Farreira, 2017)

\section{REFERÊNCIAS BIBLIOGRÁFICAS}

AMORIM, A. F. Robô Seguidor de Linha Autônomo Utilizando o Controlador Proporcional-Derivativo em uma plataforma de Hardware/Software Livre. Tese (Doutorado) — Universidade Estadual do Sudeste da Bahia - UESB, 2011.

ANDRADE, D. S. Robô seguidor de linha. Tese (Doutorado) — Universidade Federal de Santa Catarina, 2013 
ARDUINO. Arduino. 2016. Data de acesso: 15 outubros de $2016 . \quad$ Disponível em: <http://www.arduinoportugal.pt/arduino/>.

COMOFAZERASCOISAS. Regulador de tensão, uma visão geral sobre esse importante componente. 2014. Disponível em: <http://www.comofazerascoisas.com.br/ regulador-detensao-introducao.html $>$.

FARREIRA, Adolpho. Desenvolvimento de um Robô Guia Reativo Para Escola Superior de Tecnologia. Manaus, TCC UEA, Junho de 2017

KWANG-HYUNK, P. K.-H. P. et al. A steward robot for humanfriendly human-machine interaction in a smart house environment. IEEE Transactions on Automation Science and Engineering, v. 5, p. 2125, 2008.

MARSHALL. Como funcionam os microcontroladores. 2000. Disponível em:<<http://informatica.hsw.com.br/microcontroladores.ht $\mathrm{m}>$.

NIKU, S. B. Introdução à Robótica: analise, aplicações e controle. [S.1.]: LTC: Livros Técnicos e Científicos, 2013

PENAFIEL, D. S. A.; PEREIRA, G. A. S. Geração de mapas para localização e navegação de um manipulador móvel usando múltiplos sensores. Tese (Doutorado) Universidade Federal de Minas Gerais, 2014.

SOUZA, F. J. A. M. Introdução aos Robôs. 2016. Disponível em: <Introduç aoaosRobôs>.

TECMUNDO. O que é touch screen? 2008. Disponível em: <ttp://www.tecmundo.com.br/multitouch/177-o-que-etouch-screen-.htm>.

\section{AGRADECIMENTOS}

Este trabalho conta com o apoio da Samsung Eletrônica da Amazônia Ltda e Samsung Ocean Manaus.

\section{COPYRIGHT}

Direitos autorais: Os autores são os únicos responsáveis pelo material incluído no artigo. 


\author{
Volume $16-\mathrm{N}^{\circ} 174$ - Junho / 2020 \\ XLII International Sodebras Congress \\ 28 a 30 de maio de 2020 - Web Conference.
}

\title{
IMPLEMENTAÇÃO DE NAVEGAÇÃO AUTÔNOMA E QRCODE NO ROBÔ GUIA REATIVO DA ESCOLA SUPERIOR DE TECNOLOGIA
IMPLEMENTATION OF AUTONOMOUS NAVIGATION AND QRCODE IN ROBOT REACTIVE GUIDE OF THE TECHNOLOGY'S COLLEGE

\author{
KAIQUE CORREA DA MOTA ${ }^{1}$; MOISÉS PEREIRA BASTOS²; MATEUS DE SOUSA PANTOJA ${ }^{3}$; LUÍS \\ EDUARDO MENA BARRETO PEREIRA ${ }^{4}$; ALMIR KIMURA JUNIOR ${ }^{5}$
}

\author{
1,2,3,4 - Universidade do Estado do Amazonas \\ 5 - Samsung OCEAN Manaus
}

kaiquec.mota@gmail.com;mpbastos@uea.edu.br;msp.ele17@uea.edu.br;lembpr.eng16@uea.edu.br; akimura@uea.edu.br

\begin{abstract}
Resumo - O desenvolvimento da tecnologia robótica é um grande marco na história da humanidade onde a criação de robôs para a realização do trabalho humano era algo totalmente fictício. $E$ possível perceber o uso da robótica em diversos lugares, como por exemplo, indústrias, mercados e escolas. O objetivo deste trabalho é o desenvolvimento de um novo sistema de navegação $e$ posicionamento para o robô guia reativo da Escola Superior de Tecnologia do estado do Amazonas, com o intuito de projetar $e$ implementar um novo sistema capaz de guiar e orientar os visitantes da instituição. O novo sistema é baseado em uma navegação autônoma através da tecnologia de GPS e um posicionamento mais preciso com leituras de código de barra estilo QRcode. Em adição, também, realizou-se o desenvolvimento das estruturas mecânica, elétrica e eletrônica do robô. No desenvolvimento deste projeto levou-se em consideração a análise e o estudo dos seguintes componentes: sensor GPS GY-Neo6mV2, sensor MPU9250, Raspberry Pi 2 e Arduino Mega 2560. Como resultado, foi analisado que o sistema mostrou um desempenho adequado, tendo uma boa aplicabilidade ao robô e uma ótima interatividade para guiar e orientar os visitantes da instituição quando for acionado.
\end{abstract}

Palavras-chaves: Navegação Autônoma. GPS. QRcode. Raspberry Pi 2. Arduino Mega.

\begin{abstract}
The development of robotic technology is a major milestone in the history of mankind where the creation of robots to perform human work was something totally fictitious. It is possible to perceive the use of robotics in several places, such as industries, markets and schools. The objective of this work is the development of a new navigation and positioning system for the reactive guide robot of the Escola Superior de Tecnologia of the state of Amazonas, in order to design and implement a new system capable of guiding and guiding the institution's visitors. The system is based on autonomous navigation using GPS technology and more precise positioning with QRcode-style barcode readings. In addition, it was develop the mechanical, electrical and electronic structures of the robot. In the development of this project, the analysis and study of the following components was taken into account: GPS sensor GY-Neo6mV2, sensor MPU9250, Raspberry Pi 2 and Arduino Mega 2560. As a result, it was analyzed that the system showed an adequate performance, having good applicability to the robot and great interactivity to guide and orient the institution's visitors when triggered.
\end{abstract}

Keywords: Autonomous Navigation. GPS. QRcode. Raspberry Pi 2. Arduino Mega.

\section{INTRODUÇÃO}

O mundo tem evoluído bastante e neste sentido de acordo com Pacheco (1999) os avanços alcançados são importantes para o desenvolvimento tecnológico. A evolução é marcada pelo rompimento do processo comum e passa a ser reconhecido pelos especialistas (CARUSO, 2007).

Para Ribeiro, Miyadaira e Ferruzzi (2016) os crescentes avanços científicos nos dias atuais têm possibilitado a criação de projetos de engenharia que facilitam a realização de trabalhos complexos e robustos demais para os humanos executarem, devido às limitações físicas e mentais. Logo, a criação de robôs de alta performance e precisão passou a ser considerado não mais uma visão futurista e sim uma realidade que está presente em feiras, simpósios e congressos tecnológicos realizados ao redor do mundo (DIANA; GUILHERME, 2014). Nesse estudo será abordado um tipo específico de Robô, que para Secchi (2008) surgiram da necessidade de transporte de recursos nas grandes linhas de produção existentes nas indústrias.

O presente trabalho visa implementar um sistema de navegação e posicionamento para um robô guia reativo, nas instalações da Escola Superior de Tecnologia - UEA com o intuito de guiar e informar novos professores e alunos da instituição. Realizamos um protótipo inicial baseado em sensores óticos (seguidor de linha) e identificação por radiofrequência (RFID). Após esse primeiro protótipo melhoramos os resultados com base de pesquisas no uso de GPS - Global Positioning System e a tecnologia QRCode que atuaram juntas para fornecer precisão e autonomia para a movimentação do robô.

Os problemas que este estudo visa prover soluções relacionados a navegação e o posicionamento do robô construído. Para o sistema de navegação foi usado no primeiro protótipo sensores óticos que faziam a detecção de linhas fixas no chão, no entanto essas linhas ficam sujeitas a ações de agentes naturais e/ou humanos que podem desgastálas e dificultar a leitura dos sensores. Assim como o sistema 
de posicionamento do robô que prove o uso de tags RFID's fixas no chão que podem sofrer alterações nas suas posições, assim como interferência nas leituras se algum corpo estranho estiver sobre ela.

Assim, no projeto final foi desenvolvido um sistema de navegação e posicionamento inteligente para o robô guia interativo da Escola Superior de tecnologia (EST), com a capacidade para uma locomoção mais autônoma e precisa dentro da instituição de ensino. Como também projetar e desenvolver o sensoriamento e atuação do robô para locomoção e posicionamento adequados, com uma estrutura eletromecânica que comporte os novos elementos eletrônicos necessários para o funcionamento total do robô. Além disso realizar testes em laboratório e na instituição para validar o funcionamento do sistema de navegação e posicionamento do robô.

\section{REFERENCIAL TEÓRICO}

\subsection{1 - Robótica móvel}

Segundo Souza (2016) os robôs têm papel fundamental no ramo industrial, onde são empregados principalmente nas linhas de produção, pois o seu uso possui os melhores custos benefícios. Sechi (2008) afirma que a robótica surgiu da expansão das linhas de produção, nas quais veículos guiados automaticamente (AGV's) foram desenvolvidos para apoiar a realimentação de insumos nessas linhas. Logo, Sechi (2018) define robôs móveis como plataformas mecânicas habilitados a navegar em ambientes usando um sistema de locomoção. Neste contexto, Leite (2013) afirma que a robótica móvel possui três questões que devem ser resolvidas para o robô ter um bom desempenho, sendo: "Onde Estou?", "Aonde vou?" e "Como devo chegar lá?". Logo, a solução para cada uma destas questões depende basicamente dos tipos de sensores que o equipamento recebe os dados.

Portanto com o avanço tecnológico, sensores mais modernos foram capazes de realizar tarefas mais complexas, desenvolvendo ainda mais os sistemas de percepção e navegação dos robôs móveis (ALMEIDA; NASCIMENTO; FILHO, 2014).

\subsection{2 - Navegação Autônoma}

A navegação na robótica pode ser classificada em três categorias: a navegação global, a navegação local e a navegação híbrida (HEINEN, 2000). Onde a navegação global ocorre quando o robô cria e segue sua rota a partir do seu posicionamento relativo a um mapa ambiente. Já a navegação local faz o uso de sinalização no local do trajeto para definir a posição do robô. Logo a navegação híbrida prove uma mistura entre navegação global e local visando movimentação e tomadas de decisões mais autônomas.

Contudo a navegação indoor, como é conhecida os deslocamentos percorridos em ambientes internos como casas e edifícios (OLIVEIRA; SANTOS; CINELLI, 2017). Vem se tornando desafiadora, pois se faz necessário técnicas mais precisas para o sistema de percepção do robô, o qual têm que ser capaz de conhecer sua posição e orientação dentro do ambiente interno onde ele trabalha. Assim, cresce o uso de técnicas de navegação autônoma baseadas em aquisição de imagens e posicionamento relativo em mapas locais (PINAGÉ; PINHEIRO; QUEIROZ-NETO, 2010). Como mostrado na Figura 1 o projeto do robô Pionner 2DX que está equipado com vários sensores e câmeras para uma navegação em ambientes internos calculado tanto em simulação como em testes práticos.

Figura 1 - Chave Seletora alimentando os ports do Microcontrolador

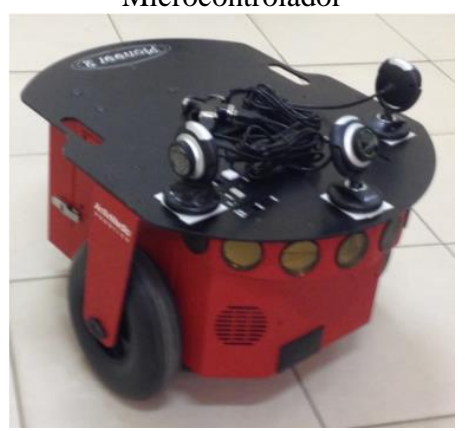

Fonte: PINAGÉ; PINHEIRO; QUEIROZ-NETO, 2010.

\section{METODOLOGIA}

Como pode ser visto no decorrer desse artigo, será mostrado de forma mais específica como ocorreu o desenvolvimento do sistema de orientação e navegação para o robô guia reativo da Escola Superior de Tecnologia desenvolvido a partir do primeiro protótipo pelo ex-discente Adolfo Nilton Gloria Ferreira (FERREIRA, 2017), visando melhorias na questão da sua antiga estrutura mecânica, elétrica, eletrônica e de software. Deste modo, foi elaborado a seguinte divisão do projeto: Arquitetura do Sistema; Remodelação do Projeto Mecânico; e Remodelação do Projeto Elétrico e Eletrônico.

\section{1 - Arquitetura do sistema proposto}

O desenvolvimento do projeto envolve a utilização do minicomputador Raspberry Pi 2 e a plataforma Arduino Mega como controladores de todos os sensores e componentes necessários para a captura de informação no ambiente da instituição, possibilitando a locomoção e orientação programada para o robô. As melhorias envolvendo a estrutura mecânica do robô foram desenhadas e projetadas para a melhor realocação de alguns componentes e o melhor posicionamento dos novos.

Os componentes reutilizados no projeto foram: plataforma Arduino Mega, sensores ultrassônicos, motores DC, placa reguladora de tensão, fonte de alimentação com saída 12 volts, placa carregável controlável e baterias 12 volts. Os novos dispositivos implantados são: o minicomputador Raspberry Pi 2, o monitor 15 polegadas, o teclado, o mouse, a webcam Logitech, o sensor GPS GYNeo06Mv2, o sensor MPU 9250, o sensor amperímetro ACS712 e dois drivers Pololu controladores de motores DC.

O sistema final de orientação do robô envolve um sistema supervisório criado a partir de uma aplicação no sistema operacional do Raspberry Pi 2, conforme a Figura 2. $\mathrm{O}$ visitante da instituição se depararia com uma tela inicial podendo escolher entre conhecer um pouco sobre a história da Universidade do Estado do Amazonas ou conhecer os principais cursos ministrados na sede da Escola Superior de Tecnologia ou escolher um mapa para ativar a orientação guiada pelo robô. 
Figura 2 - Arquitetura do Sistema Proposto

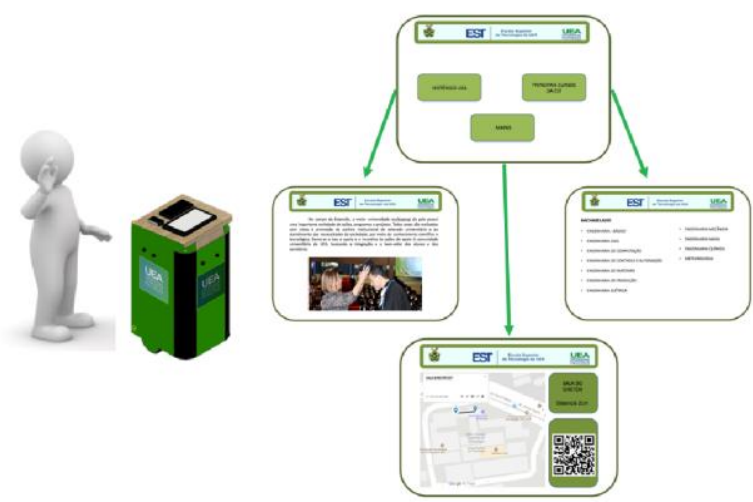

Fonte: Autor.

As melhorias na estrutura mecânica do robô partiram do estudo bibliográfico sobre robótica móvel, buscando a melhor alocação dos componentes, distribuição de peso e dimensionamento para locomoção. Na figura 3 está ilustrado a visão interna do robô com as divisões dos componentes em camadas, partindo da base onde se encontram o sistema de energização e de atuação do robô, seguindo para a primeira camada, onde localiza-se o sistema de recarregamento das baterias. Logo após, temos a segunda camada, com o sistema de controle sensorial, seguindo para a terceira camada, onde está presente o sistema de projeção da interface gráfica.

Figura 3 - Visão Interna do Robô

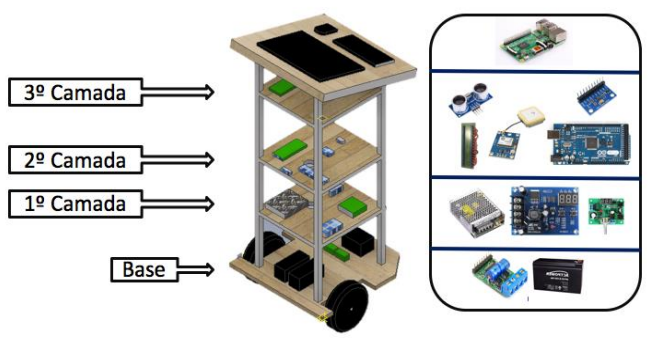

Fonte: Autor.

Na figura 4 está ilustrado a visão externa do robô com o devido enclausuramento e locação dos sensores ultrassônicos. Em adição, podemos observar no topo do robô o painel principal onde se encontram o monitor, mouse, teclado e webcam Logitech para a interação humanomáquina.

Figura 4 - Visão Externa do Robô

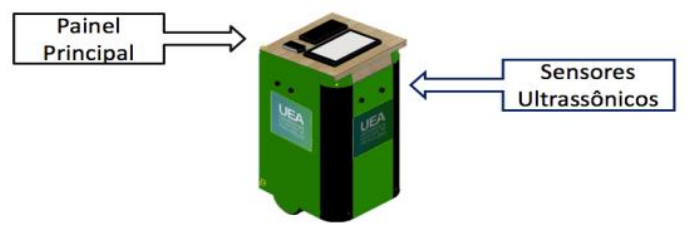

Fonte: Autor.

\section{2 - Remodelação do Projeto Mecânico}

A remodelação do projeto mecânico do robô teve início com a estruturação da base para alocação das rodas, motores e drivers, estabelecendo o sistema de energização e atuação. Seguindo a mesma linha da estrutura anterior, o robô possui na parte inferior da base, duas rodas fixas convencionais controladas independentemente e uma roda boba, todas em disposição triangular, conforme ilustrado na figura 5 . Observa-se também, o sistema de atuação dado pelos motores DC fixados em uma barra de perfil Bosch devidamente acoplada a base na parte inferior. Em adição os eixos dos motores foram fixados nas rodas, criando a tração necessária para a locomoção do robô.

Figura 5 - Base Lado Inferior.

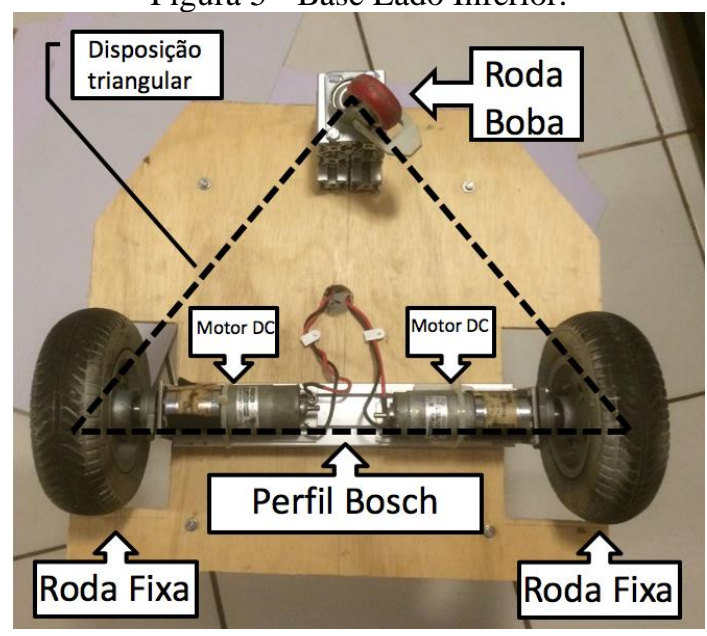

Fonte: Autor.

$\mathrm{Na}$ parte superior da base temos o sistema de energização do robô onde podemos encontrar as três baterias de 12 volts, gerando 7,2 amperes/hora cada uma. Cada bateria possui uma determinada função onde duas delas alimentam os dois motores separadamente e outra alimenta os dispositivos eletrônicos presentes no robô, como ilustra a imagem 6.

Figura 6 - Base Lado Superior.

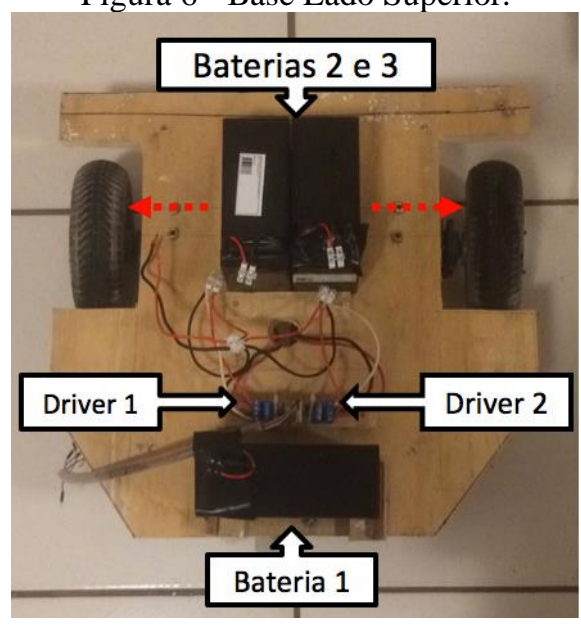

Fonte: Autor.

Após o desenvolvimento da base, foi fixado uma estrutura com pequenas barras retangulares de alumínio formando uma gaiola para a fixação de prateleiras configurando a estrutura de camada como desejado, como está ilustrado na figura 7. 
Figura 7 - Divisão Interna do Robô.

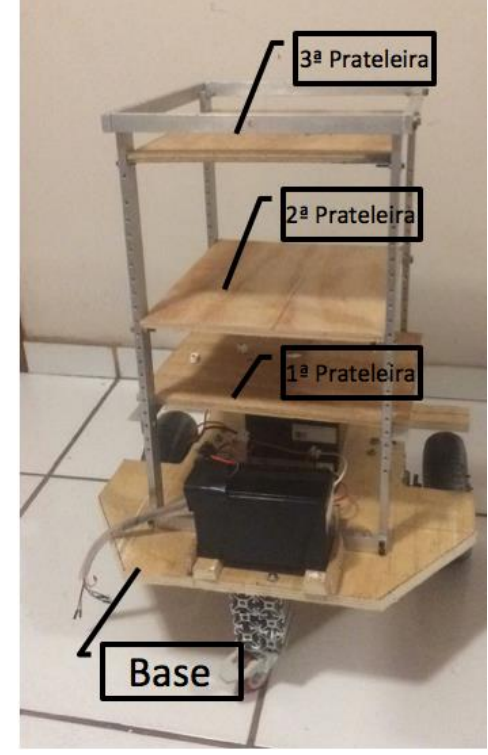

Fonte: Autor.

Por fim, temos o painel principal do robô, localizado no topo da estrutura mecânica, onde foi fixado o sistema de interação humano-máquina constituído pelo monitor, teclado, mouse e webcam como demonstra a figura 8 .

Figura 8 - Painel principal.

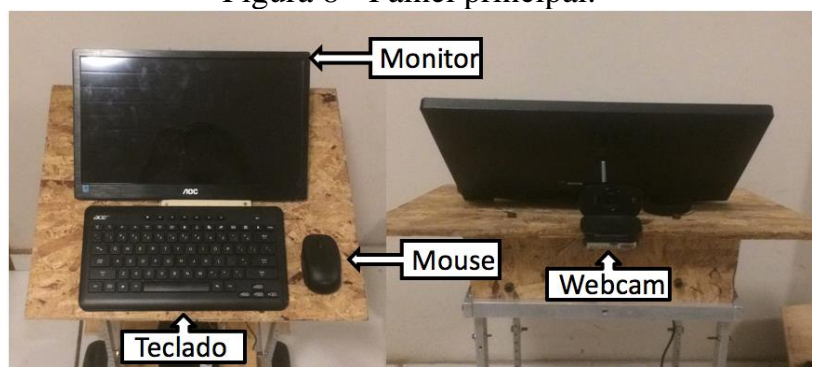

Fonte: Autor.

\section{3 - Remodelação do Projeto Elétrico e Eletrônico}

A remodelação do projeto elétrico e eletrônico do robô teve início com a implementação de alguns novos componentes dos quais seriam necessários para o novo sistema de orientação. Desse modo, o robô foi dividido em cinco camadas, constituindo todo o sistema elétrico e eletrônico necessário para sua atuação. As camadas foram tituladas na seguinte ordem: base, camada de recarregamento, camada de controle sensorial, camada de projeção da interface gráfica e painel principal.

\subsection{1 - Base}

A base do robô, na sua parte superior possui o sistema de alimentação e o sistema de controle dos motores. Nela está presente, três baterias seladas, compostas por chumbo ácido regulado por válvulas e com cerca de $1,8 \mathrm{~kg}$ cada bateria. No projeto anterior, o robô possuía apenas duas baterias que distribuem energia para os dois motores e os demais sensores. Neste projeto foi sensato a implementação de uma nova bateria devido o uso de novos componentes que demandam mais energia.
Figura 9 - Esquema de energização do robô.

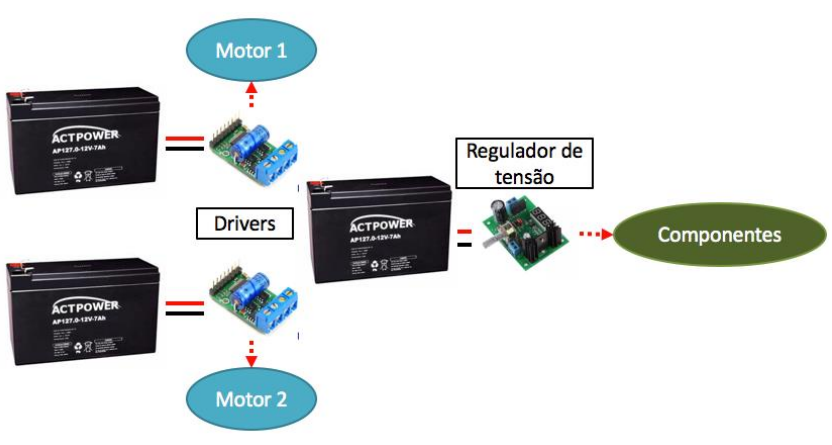

Fonte: Autor.

Assim, a distribuição de energia é dada pela carga dos motores onde cada um é conectado a um driver controlador energizado por uma bateria individualmente e a carga dos demais componentes que são energizados por outra bateria conectada a um regulador de tensão. Em outras palavras, cada motor possui uma bateria que o energiza individualmente $\mathrm{e}$ os demais componentes são energizados por uma outra bateria como ilustrado na figura 9 .

\subsection{2 - Camada de Recarregamento}

A camada de recarregamento do robô tem como principal função o recarregamento das baterias através da fonte de alimentação CGC com tensão de entrada de 115 ou 230 VAC e tensão de saída de 12 VDC. Contudo, nesta camada também ocorrem outras funções como a regulagem de tensão realizada pela placa reguladora LM317, o controle de carregamento realizado pelo módulo carregador de bateria XH-M603 e a leitura de corrente contínua realizada pelo sensor ACS712, ilustrados na figura 10.

Figura 10 - Camada de Recarregamento.

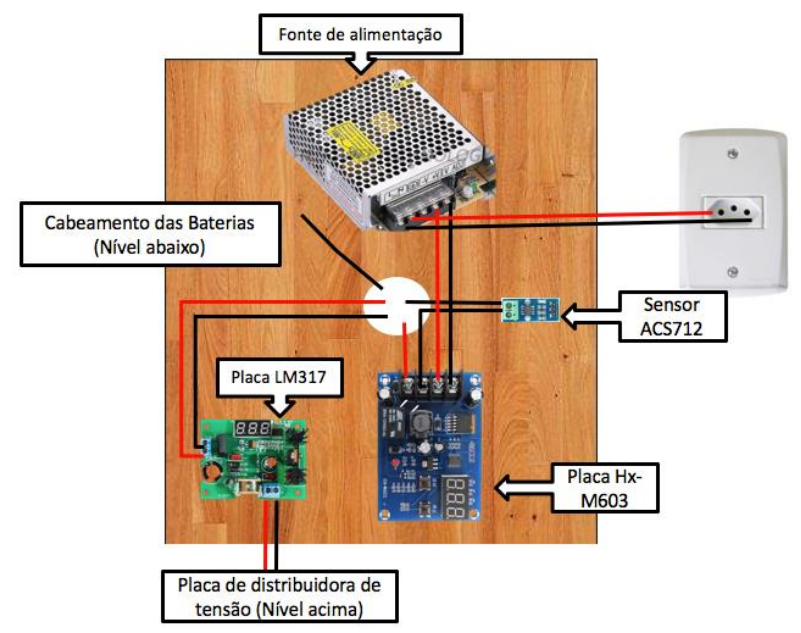

Fonte: Autor.

\subsection{3 - Módulo Carregador de bateria XH-M603}

O módulo para o controle de recarregamento das baterias foi o XH-M603. Ele possui uma tensão de entrada de 10-30 VDC de modo que através de seus botões é programado a tensão final de recarregamento. Para a realização de sua função de maneira adequada, esse módulo necessita estar conectado com a fonte de alimentação e as baterias das quais deve recarregar, como ilustrado na figura 11 . 
Figura 11- Conexões placa de carregamento baterias.

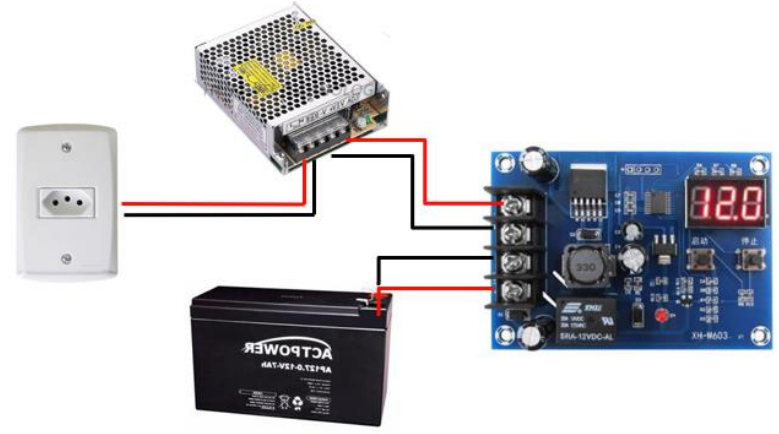

Fonte: Autor.

\subsection{4 - Camada de Controle Sensorial}

A camada de controle sensorial do robô tem como principal função a leitura e controle dos sensores presentes no robô. Nesta camada estão presentes o Arduino Mega, plataforma que realizará todo o controle e leitura dos sensores conectados a ele, o sensor GPS GY-Neo06Mv2, responsável pela leitura das coordenadas geográficas do robô, o sensor MPU 9250, que tem a funcionalidade de uma bússola eletrônica, capaz de dar informações sobre o sentido o qual o robô está percorrendo, a placa de distribuidora de tensão, que alimentará todos os sensores e os sensores ultrassônicos dos quais tem a função de evitar qualquer impacto do robô com pessoas ou objetos em seu caminho. Na figura 12, podemos visualizar como os componentes estão distribuídos na camada, ressaltando que os sensores ultrassônicos se encontram conectados ao enclausuramento do robô para obtenção de dados.

Figura 12 - Camada de Controle Sensorial.

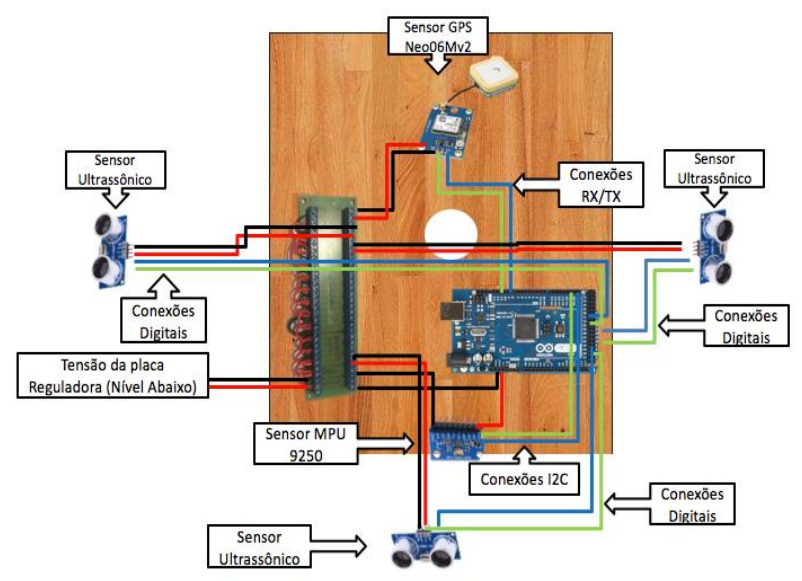

Fonte: Autor.

\section{RESULTADOS}

Os resultados obtidos através dos testes práticos mostraram que o novo sistema proposto possui aplicabilidade $\mathrm{e}$ interatividade adequadas, garantindo a autonomia desejada para o robô. Em questão de desempenho, a orientação guiada do robô obteve melhorias tanto em relação a sua forma posicionamento quanto na sua forma navegação. Assim, na análise geral do projeto vimos, que os objetivos planejados foram alcançados e que grandes melhorias foram implementadas no robô. A figura 13 demonstra a comparação efetiva entre os dois projetos e as melhorias alcançadas através dos resultados obtidos.

Durante os testes tanto em laboratório quanto na instituição ocorreram as seguintes dificuldades:

1. Interferências na recepção dos dados de navegação em coordenadas geográficas pela antena do sensor GPS GYNeo06Mv2.

2. Falta de atuação do robô perante ao encontro de objetos fixos que bloqueiam a sua trajetória.

3. Pouca sensibilidade do robô para evitar fatores diversificados que podem se encontrar na universidade, como por exemplo, rotas bloqueadas por multidões e presença de animais nos corredores.

Dessa forma, para trabalhos futuros é possível a implementação de um novo receptor ou sensor para a captação de dados mais preciso em ambientes fechados da instituição. Em adição, é possível também o desenvolvimento de um novo sistema de orientação e navegação fundamentado na transmissão e recepção de sinais de radiofrequência, por exemplo, a triangulação de sinais produzidos por dispositivos RFID ou a triangulação de sinais produzidos por roteadores de Wi-Fi.

Seria importante também adicionar ao sistema de controle sensorial uma forma de atuação perante ao bloqueio de objetos fixos no caminho do robô. Além de estabelecer uma ação com relação às situações diversificadas encontras na instituição, mencionadas das dificuldades dos testes. 


\begin{tabular}{|c|c|c|}
\hline Sistema Analisado V & Projeto Anterior (FERREIRA, 2017) & Projeto Atual (MOTA, 2018) \\
\hline Sistema de Navegaçăo & $\begin{array}{l}\text { Navegação com base na coleta de informaçōes de } \\
\text { sensores opticos para o robô seguir uma linha como } \\
\text { trajetória dentro da instituição }\end{array}$ & $\begin{array}{c}\text { Navegação com base na coleta de dados de } \\
\text { coordenadas geograficas dentro da instituiç̧ão } \\
\text { criando rotas pré-estabelecidas para a navegaç̧ão do } \\
\text { robô }\end{array}$ \\
\hline Sistema de Posicionamento & $\begin{array}{l}\text { Posicionamento realizado a partir da leitura de Tag's } \\
\text { com sistema de radio frenquência RFID } \\
\text { posicionandos no chão da instituiç̧ão }\end{array}$ & $\begin{array}{c}\text { Posicionamento realizado a partir da decodificação } \\
\text { de Qrcodes posicionados nas portas do destino } \\
\text { desejado. }\end{array}$ \\
\hline Sistema de Alimentaçăo & $\begin{array}{l}\text { Utilização de apenas duas baterias de } 12 \text { volts e } \\
\text { tempo de atividade não especificado. }\end{array}$ & $\begin{array}{l}\text { Utilização de três baterias de } 12 \text { volts tempo de } \\
\text { atução media do robô especificada em } 2 \text { horas e } \\
\text { meia. }\end{array}$ \\
\hline Sistema de IHM & $\begin{array}{l}\text { Simples sem definiçăo de rotas especificas } \\
\text { programadas em Windowns CE }\end{array}$ & $\begin{array}{l}\text { Mais interativo com diversas janelas contendo } \\
\text { informaçăo tanto do histórico da UEA, cursos } \\
\text { ministrados e as } 6 \text { rotas de navegaçăo dentro da } \\
\text { instituiç̧ão. Programada em uma aplicabilidade do } \\
\text { sistema operacional UBUNTU MATE. }\end{array}$ \\
\hline Custo na Construç̧ăo do Robô & Informação não espeficada & Informaç̧ão espeficidade e detalhada \\
\hline $\begin{array}{c}\text { Regulagem da Velocidade de } \\
\text { atuçẵo }\end{array}$ & Informação năo espeficada & $\begin{array}{l}\text { Informação espeficidade e projetada para adequação } \\
\text { da situçăo real de atução do robô que seria } \\
\text { acompanhar a caminhada de uma pessoa adulta. }\end{array}$ \\
\hline $\begin{array}{c}\text { Sistema de processamento de } \\
\text { informaçăo }\end{array}$ & $\begin{array}{c}\text { Processamento de dados e coleta de informaçōes } \\
\text { realizada apenas por uma plataforma lógica } \\
\text { programavél, Arduino Mega. }\end{array}$ & $\begin{array}{l}\text { Processamento de dados e coleta de informaçōes } \\
\text { realizadas por duas plataformas lógicas } \\
\text { programavéis, Arduino Mega e o Raspberry Pi } 2 .\end{array}$ \\
\hline
\end{tabular}

Fonte - Próprio Autor

\section{CONCLUSÃO}

Neste projeto foi desenvolvido e implementado um novo sistema de navegação e posicionamento no robô guia da Escola Superior de Tecnologia com base na recepção de dados obtidos de diversos sensores.

O novo sistema de navegação e posicionamento fez o uso de GPS e leitura de QRcode, além da criação de um novo sistema de interação Homem-Máquina que foi embarcado no computador de placa única Raspberry PI 2. Tal sistema demandou um novo desenho mecânico que passou a ser dividido em camadas para adequação dos novos componentes do robô. Além disso o controle do robô foi realizado entre a interação entre um Arduino Mega 2560 e do Computador de placa única Raspberry PI 2 que é responsável pelo gerenciamento da IHM.

\section{REFERÊNCIAS BIBLIOGRÁFICAS}

ALMEIDA, J.S; NASCIMENTO, R.S.; FILHO, P.P.R. "Desenvolvimento de um sistema de navegação para um 
robô móvel autônomo via construção de um mapa local”, 2014.

DIANA, S. A. P., GUILHERME, A. S. P. "Geração de mapas para localização e navegação de um manipulador móvel usando múltiplos sensores". Universidade Federal de Minas Gerais, Brasil, 2014.

FERREIRA, Desenvolvimento de um Robô Guia Reativo para Escola Superior de Tecnologia, Universidade do Estado do Amazonas (UEA), Manaus, Brasil, 2017.

HEINEN, F.J. "Robótica Autônoma: Interação entre Planificação e Comportamento Reativo", Série Produção Discente, Editora Unisinos, 2000. Disponível em: . Data de acesso: 20 de outubro de 2017

LEITE, D. S. Controle autônomo de robô móvel baseado em logica fuzzy, 2013

OLIVEIRA, T. A. B.; SANTOS, F. A. N. V.; CINELLI, M. J. Sistemas de navegação indoor e sistema de compras para pessoas com deficiência visual: potenciais no uso em supermercado, 2017.

PACHECO, Marco Aurélio C. Algoritmos Genéticos: Princípios e Aplicações. 1999. Disponível em: http://www.ica.ele.puc-rio.br/Downloads/38/CE-ApostilaComp-Evol.pdf. Acesso em 04 dez 2010.

PINAGÉ, F.A.; PINHEIRO, H.S.; QUEIROZ-NETO, J.P. Sistema de navegação autônoma de robôs moveis em ambientes com obstáculos em movimento. 2010.

RIBEIRO, W. C.; MIYADAIRA, A. N.; FERRUZZI, Y. Desenvolvimento de mão de robótica de baixo custo. Universidade Tecnológica Federal do Paraná, 2016.

SECCHI, Humberto. "Uma Introdução aos Robôs Móveis“. San Juan, Argentina, 2008.

SOUZA, J.A.M. Robótica: Introdução aos robôs, 2016. Disponível em: . Data de acesso: 22 de outubro de 2017.

\section{AGRADECIMENTOS}

Este trabalho conta com o apoio da Samsung Eletrônica da Amazônia Ltda, Samsung Ocean Manaus e Universidade do Estado do Amazonas.

\section{COPYRIGHT}

Direitos autorais: Os autores são os únicos responsáveis pelo material incluído no artigo. 


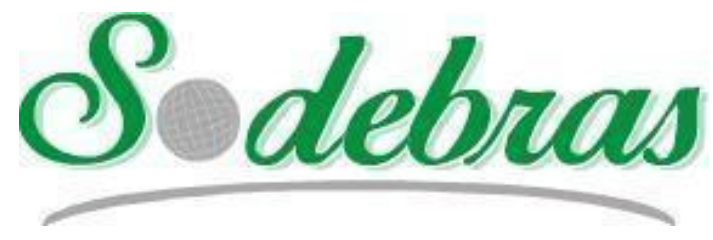

\author{
Volume $16-\mathrm{N}^{\mathrm{o}} 174$ - Junho / 2020 \\ XLII International Sodebras Congress \\ 28 a 30 de maio de 2020 - Web Conference.
}

\title{
OPERAÇÕES CRUD UTILIZANDO BANCOS DE DADOS RELACIONAIS E NÃO RELACIONAIS
}

\author{
CRUD OPERATIONS USING RELATIONALAND NON-RELATIONAL \\ DATABASES
}

\author{
NEPOMUCENO, César; LOPES, Diego; BASTOS, Moisés; SOARES, André; VALENZUELA, Walter \\ UNIVERSIDADE DO ESTADO DO AMAZONAS
}

camn.lic@uea.edu.br;diml.eng@uea.edu.br; mpbastos@uea.edu.br; alsoares@uea.edu.br;wvalenzuela@uea.edu.br

\begin{abstract}
Resumo - Bancos de dados são parte crucial de uma aplicação que utiliza permanência de informações, na atual fase da tecnologia computacional existe uma ampla possibilidade de escolha entre bancos de dados disponíveis para atender as necessidades de um software. Este trabalho apresenta a implementação da persistência de dados utilizando operações CRUD em um banco SQL e um banco NoSQL. Os SGBD escolhidos foram o MongoDB e o MySQL que possuem ampla adesão mundial e para realizar as operações CRUD foi implementada uma interface com Angular que possibilita o cadastro de localizações geográficas em um mapa da cidade de Manaus-AM. Essas localizações serão calculadas por uma API utilizando dados de latitude e longitude. O trabalho inclui uma explicação das estruturas básicas e os processos iniciais da sua implementação do MongoDB e do MySQL. Com o intuito de ampliar as informações acerca do assunto abordado, também demonstra uma análise qualitativa entre o MongoDB e o MySQL, destacando características relevantes acerca desses SGBDs. Palavras-chaves: Persistência, SQL, NoSQL
\end{abstract}

Abstract - Databases are a crucial part of an application that uses information permanence, in the current phase of computational technology there is a wide choice between databases available to meet the needs of a software. This work presents the implementation of data persistence using CRUD operations in an SQL and a NoSQL database. The DBMS chosen were MongoDB and MySQL, which have wide worldwide adhesion and to carry out CRUD operations, an interface with Angular was implemented, which allows the registration of geographic locations on a map of the city of Manaus-AM. These locations will be calculated by an API using latitude and longitude data. The work includes an explanation of the basic structures and the initial processes of its implementation of MongoDB and $M y S Q L$. In order to expand the information on the subject addressed, it also demonstrates a qualitative analysis between MongoDB and MySQL, highlighting relevant characteristics about these DBMSs.

Keywords: Persistence, SQL, NoSQL

\section{INTRODUÇÃO}

No ramo da tecnologia os bancos de dados e seus sistemas de gerenciamento desempenham papel inquestionável, sendo a base para o funcionamento de qualquer sistema que necessite de armazenamento ou manipulação de dados. Nesse contexto, os avanços da tecnologia e de suas possibilidades de utilização exigem que gerenciamento das estruturas de dados seja feito da maneira mais eficiente possível. (RAMEZ, 2005)

Essa eficiência inicia pela escolha correta entre bancos de dados relacionais (Structured Query Language, SQL) e os não relacionais (No Structured Query Language, NoSQL) para a utilização em conjunto com uma aplicação web. Esses dois tipos de estruturas de dados possuem características, estruturação e manipulação distintas, mas visam o mesmo objetivo de gerenciar dados. (RAMEZ, 2005)

Além da escolha mais assertiva de um tipo de banco de dados, existe também a necessidade de uma interface de manipulação de dados onde o usuário poderá realizar operações de inserção, edição, consulta e exclusão de registros. Uma interface implementada com boas práticas, alinhada com um banco de dados bem estruturado são o ponto de partida para uma aplicação funcional. (Ramez, 2005)

Neste trabalho serão apresentadas operações básicas implementadas para uma interface CRUD (acrônimo do inglês Create, Read, Update and Delete) persistindo registros de localização no mapa da cidade de Manaus em um banco de dado relacional, utilizando o MySQL, e não relacional, utilizando o MongoDB. O estudo também apresenta uma análise qualitativa entre os bancos de dados utilizados.

\section{REFERÊNCIA TEÓRICA}

\subsection{Bancos de dados relacionais}

O SQL foi a primeira solução adotada em larga escala para a estruturação de registros em um banco de dados e por um longo período permaneceu como a única opção viável. Criado em 1974, pela IBM, buscava utilizar o modelo relacional criado por Edgar Frank Codd. O SQL recebeu revisões e consequentemente novas versões para garantir e melhorar o desempenho da sua implementação. $\mathrm{O}$ esquema de organização no modelo relacional organiza os registros de dados em tabelas, onde as linhas são registros e as colunas são uma característica daquele registro. Essas características são determinadas por quem realizar a implementação. O 
quadro 1 apresenta um exemplo da organização dessas tabelas.

Quadro 1 - Exemplo de Organização de registro em tabela

\begin{tabular}{|c|c|c|c|c|}
\cline { 1 - 3 } Funcionários & \multicolumn{5}{|c|}{ SQL } \\
\cline { 1 - 4 } ID & Nome & Sobrenome & Cargo & Depto \\
\hline 1 & Carlos & Sanchez & Gerente & Vendas \\
\hline 2 & João & Batista & Porteiro & Adm \\
\hline 3 & Carla & Guimarães & Faxineira & Serviços \\
\hline
\end{tabular}

No exemplo apresentado no quadro 1, os registros de dados na tabela possuem as seguintes características: ID, Nome, Sobrenome, Cargo e Depto. Toda tabela SQL precisa ser identificada por um nome que será definido pelo programador e que visa indicar quais registros serão destinados àquela estrutura, na Tabela 1 o nome escolhido foi Funcionários indicando que esta tabela irá possuir os registros dos funcionários de uma empresa. Cada campo armazena uma informação importante do registro (linha), entretanto a primeira linha da tabela indica o tipo computacional de cada campo (DONAHOO, 2005).

Como exemplo de sistema de gerenciamento de banco de dados (SGBD) para bancos relacionais é possível citar o MySQL, que é open source e possui um vasto número de desenvolvedores.

\subsection{Bancos de dados não relacionais}

Com a ampliação do uso das tecnologias nos ramos industrial e comercial, os tamanhos do fluxo e da quantidade de dados a serem manipulados por sistemas de gerenciamento de banco de dados (SGBD), os bancos que utilizavam SQL demonstraram um aumento do custo computacional em seu funcionamento, bem como aumento da complexidade de suas estruturas. Diante disso, uma nova solução foi implementada, a estrutura NoSQL, ou bancos não relacionais, com o objetivo de suprir a necessidade de gerenciamento de grandes quantidades de dados sem que a complexidade das estruturas aumente de forma proporcional. O termo NoSQL foi utilizado pela primeira vez por Carlo Strozzi em 1998 para designar um banco de dados de sua autoria, que não utilizava uma interface SQL. Apesar desse primeiro momento, os bancos não relacionais só ganharam notoriedade quando grandes empresas da Internet, como Google e Amazon, divulgaram informações sobre seus projetos de armazenamento de dados que buscavam suprir as necessidades e reduzir a complexidade que eram apresentadas nos bancos SQL (DIANA, 2010).

Os registros em uma estrutura não relacional não são organizados em tabelas e não necessitam de interligações entre os tipos existentes para possibilitar consultas múltiplas. $\mathrm{Na}$ figura 1 temos um exemplo da organização dos dados em documentos livres, um exemplo de dados não relacionais.
Figura 1 - Persistência de dados NoSQL

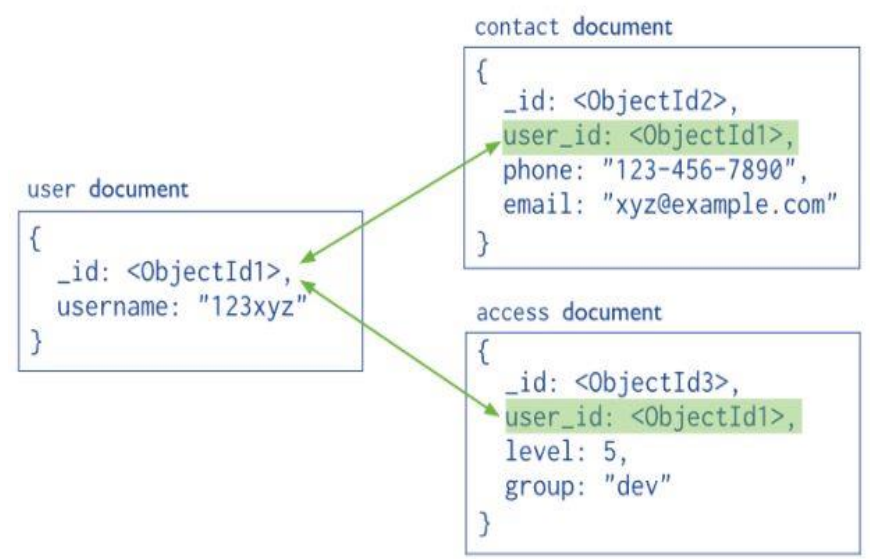

Fonte: https://www.mongodb.com/

O MongoDB é um exemplo de banco de dados NoSQL, sendo uma opção multiplataforma e de código aberto. Sua implementação é orientada a documentos livres e visa possibilitar um mundo onde a velocidade e a escalabilidade funcionam; onde não existe a necessidade de configurações ou instalações complicadas (PLUGGE; HAWKINS; MEMBREY, 2010)

\subsection{CRUD - Create, Read, Update and Delete}

A realização de operações de gerenciamento básicas em um banco de dados pode ocorrer em interfaces conhecidas como CRUD, que é uma sigla para as operações Create, Read, Update and Delete. Tais operações possibilitam ao usuário uma manipulação completa dos dados armazenados em um banco de dados.

\section{IIL. METODOLOGIA}

Neste estudo foi desenvolvida uma interface CRUD visando realizar a persistência de dados obtidos via formulário web em banco de dados relacional e não relacional. Tal sistema permite um estudo prático e comparativo entre os tipos de bancos de dados supracitados. Como banco de dados relacional foi utilizado o MySQL e não relacional o MongoDB.

\subsection{Interface CRUD}

Para obter os dados a serem persistidos nos bancos de dados foi necessário o desenvolvimento de uma interface CRUD, isto é, um meio de interação com o usuário visando apenas cadastrar e listar os dados. Tal interface foi desenvolvida em TypeScript com o uso do framework Angular. Antes de conceituar ambos, é necessário um entendimento do que é JavaScript ou JS que representa uma linguagem de programação multiparadigma, com script de alto nível, interpretada e estruturada. Agora em uma rápida apresentação, podemos conceituar o TypeScript como uma ferramenta adicional ao JavaScript sendo capaz de adicionar uma tipagem estática ao mesmo, que originalmente possui tipagem dinâmica. Essa conversão ocorre apenas no ambiente de desenvolvimento, ao passo que no processo conhecido como build de produção, toda a linguagem implementada em TypeScript será convertida em JavaScript. Em relação ao Angular, é um framework destinado a criar interfaces utilizando linguagens de programação $w e b$, com ferramentas nativas que permitem implementar o que são chamadas de 
Single-page Application, que basicamente são páginas web que funcionam como uma aplicação completa, um conceito parecido com as aplicações mobile. A interface desenvolvida é apresentada na figura 2 .

Figura 2 - Interface de cadastro dos pontos no mapa

\begin{tabular}{l} 
Cadastrar Pontos \\
Nome* \\
NOME \\
\hline Latitude* \\
LATITUDE \\
\hline Longitude* \\
LONGITUDE \\
\hline Endereço \\
ENDEREÇO \\
\hline Informą̧̋́es adicionais \\
INFORMAÇÕES ADICIONAIS \\
\hline \\
\hline Campos com * são obrigatórios \\
\hline
\end{tabular}

Fonte: Autores

Como pode ser visto na figura 2 temos os seguintes campos:

- Campo "Nome": destinado a uma identificação textual personalizada ao ponto do mapa a ser registrado

- Campo "Latitude": recebe um valor real presente entre o intervalo -90 e 90, que são os valores mínimo e máximo na latitude do globo.

- Campo "Longitude": recebe um valor real presente entre o intervalo -180 e 180, que são os valores mínimo e máximo de longitude do globo.

- Campo "Endereço": destinado a informações geográficas acerca do ponto a ser registrado, essas informações serão geradas automaticamente pela Application Programming Interface (API) do GoogleMaps utilizando os valores dos campos Latitude e Longitude.

- Campo "Informações Adicionais": recebe as características personalizadas sobre o ponto a ser registrado, sendo o único campo no formulário que não possui preenchimento obrigatório.

No desenvolvimento de uma aplicação que possui persistência em banco de dados é importante utilizar medidas que garantam a integridade das informações fornecidas pela interface CRUD e uma dessas medidas é implementar validações para os campos a serem preenchidos pelo usuário. O Angular possui ferramentas nativas que atuam na validação de dados ainda no front-end, antes mesmo de enviar os dados ao banco.

Na figura 3 é apresentado um exemplo da validação com Angular implementada. Ao ocorrer o preenchimento dos campos Nome, Latitude e Longitude com caracteres ou valores que não são aceitos pelo banco de dados, os campos da interface alteram sua coloração para vermelho, visualmente indicando ao usuário que a informação fornecida no campo é inválida e dessa forma impossibilitando a realização do envio do formulário ao banco de dados. Também é possível implementar no Angular métodos de validações personalizadas caso as ferramentas nativas não atendam aos requisitos da aplicação.

Figura 3 - Validação de campos via Angular

Cadastrar Pontos

Casa da Esquina

90

Fonte: Autores

\subsection{Persistência com o banco de dados não relacional}

O exemplar de banco de dados NoSQL escolhido para este trabalho foi o MongoDB, uma aplicação lançada em 2009 e que dispensa várias estruturas obrigatórias no esquema SQL e que é utilizado por grandes empresas que manipulam grandes quantidades de informação tais como Facebook, Google, Ebay. O MongoDB conta ainda com features direcionadas a facilitar sua utilização como um servidor mantido pela empresa e administrado pela comunidade de usuários, que já está pronto para a integração com aplicações e pode ser baixado do site oficial, além da grande adesão de usuários em ambientes como o GitHub e universidades.

O MongoDB é um banco de dados com armazenamento de registros orientado a documentos com estrutura baseada em JSON (JavaScript Object Notation) (TRUICA, 2013) e com modelagem direcionada aos objetos no código da aplicação a ser integrado, sendo esses documentos armazenados em Coleções, que são equivalentes as tabelas SQL. Possui uma versão online e uma versão de funcionamento local, a escolha entre as duas é pessoal e deve levar em conta qual opção atenderá as necessidades da sua aplicação. A organização de dados via documento em JavaScript pode ser representada da seguinte maneira:

\{

nome: "Carlos",

sobrenome: "Sanchez", cargo : "Gerente", depto : "Vendas"

\}

O MongoDB é case sensitive, o que significa ser capaz de diferenciar letras maiúsculas e minúsculas, detalhe importantíssimo ao realizar qualquer operação com o mesmo. O único pré-requisito para iniciar a utilização do software após a sua instalação é verificar se o MongoDB já está em funcionamento. Isso pode ser feito acessando a pasta bin dentro da pasta de instalação do MongoDB com o terminal (prompt de comando do sistema operacional utilizado). É importante frisar que adicionar a pasta de instalação do MongoDB à variável de ambiente $P A T H$ permite executar os comandos a partir de qualquer diretório. 
Através do comando mongo o MongoDB estabelecerá uma conexão com o seu principal serviço, o mongo shell, que poderá ser uma conexão local, via Host Remoto (passível de ser com ou sem autenticação), via TLS/SSL ou com uma Réplica MongoDB. Também é possível, designar a porta pela qual a conexão irá ocorrer, conforme a figura 4.

Figura 4 - Inicializando o serviço do MongoDB

mongo - -port 28015

Fonte: Autores

A próxima ação é criar um banco de dados, que pode ser realizada através do comando use NomeDoBanco, que também funciona como comando para alternar entre bancos de dados já existentes, seguindo a figura 5 .

Figura 5 - Criando um banco de dados no MongoDB
$\begin{aligned} & \text { >> use localizacoes } \\ & \text { switched to db localizacoes }\end{aligned}$

Fonte: Autores

Para verificar qual banco de dados está em uso basta executar o comando $d b$, como indicado na figura 6 , e na linha seguinte será impresso o nome do banco de dados:

Figura 6 - Verificando qual banco de dados está em uso

$l>>d b$
localizacoes

Fonte: Autores

A operação de inserção de dados em um banco gerenciado pelo MongoDB pode ser realizada utilizando o simples comando db.NomeDaColeção.insert(\{\}), como demonstrado na figura 7.

Figura 7 - Inserção de dados em uma coleção

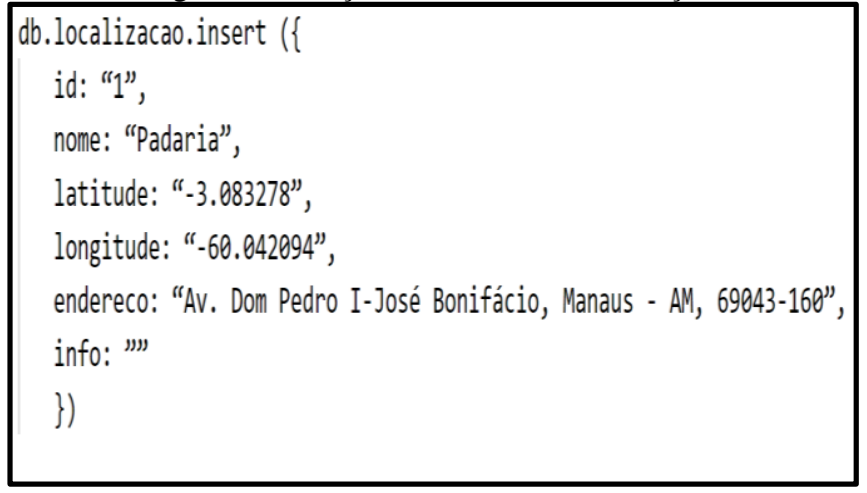

Fonte: Autores

Caso a coleção "Funcionários" ainda não exista no banco de dados, o comando utilizado para inserir o JSON também criará a coleção automaticamente. Apesar de funcionarem de maneira semelhante às tabelas SQL, as coleções no MongoDB não se limitam em armazenar apenas um tipo de dado, mas possibilitando que registros com estrutura similar possam ser armazenados em uma mesma coleção.

Uma característica importante sobre o MongoDB é que cada registro nas coleções possui um id único que é gerado automaticamente pelo software que pode ser utilizado para referenciar o registro ao qual está atrelado, mas diferente do MySQL que possui funções para atribuir um identificador único autoincrementavel conforme solicitação do usuário, o MongoDB não possui uma função nativa para essa ação, ficando a cargo do usuário implementá-la, se necessário, de maneira que requisitos de sua aplicação sejam atendidos.

\subsection{Persistência com o banco de dados relacional}

O MySQL é o SGDB baseado no sistema SQL com código livre e com maior adesão mundial, sendo por muito tempo considerado melhor ferramenta para aplicações que utilizam bancos de dados. Foi o escolhido porque possibilita efetuar simulações em uma base de dados paralela, definida de acordo com as necessidades, detectar e resolver problemas na configuração incorreta das variáveis em sua base real, fornecendo a configuração do storage engine InnoDB e possui ferramentas de otimização como o Query Cache que armazena os comandos SQL que foram usados recentemente. (SILVA; ALVES, 2012). O MySQL é um dos principais banco de dados relacionais. Sua arquitetura é composta por três camadas: conexão com o cliente, análise da instrução SQL e execução da instrução (SCHWARTZ, 2012).

A estrutura básica do MySQL é composta por um servidor e uma aplicação cliente onde a comunicação ocorre por meio do SQL. O software possui uma interface gráfica que atua como cliente conhecida por MySQL Workbench, por meio da qual são implementadas as entidades, seus atributos e os relacionamentos. A interface é apresentada na figura 8 .

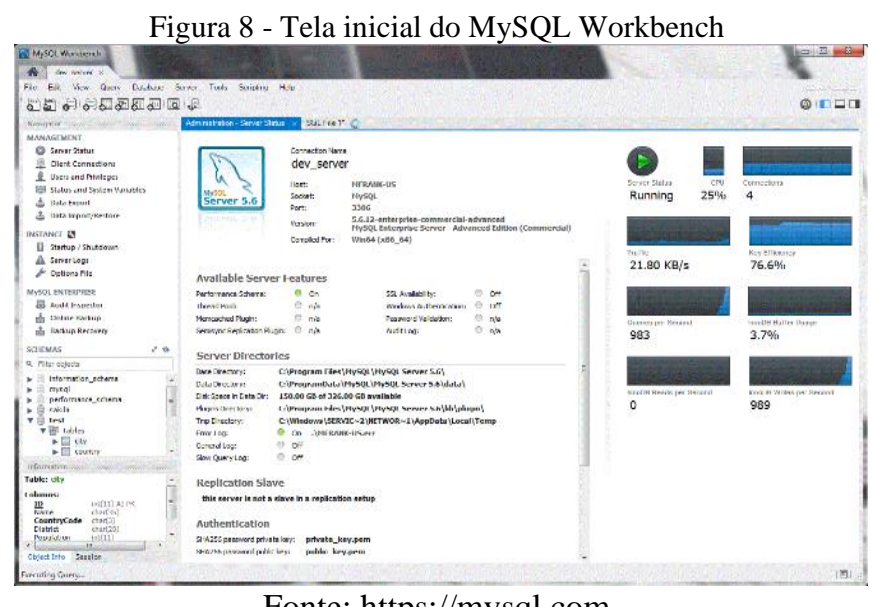

Fonte: https://mysql.com

O MySQL necessita que toda a sua estrutura esteja bem definida e criada previamente para que suas operações possam ser realizadas. Na figura 9 mostra-se a criação de um banco MySQL utilizando o comando CREATE.

\section{Figura 9 - Criando um banco de dados no MySQL \\ mysql> create database mapa;}

\section{Fonte: Autores}

Após criado o banco é necessário acessá-lo, utilizando o comando USE, da maneira feita na figura 10 .

Figura 10 - Acessando um banco de dados MySQL

mysql> use mapa;

Fonte: Autores 
A partir daí, já é possível criar uma tabela SQL com um nome, todos os seus dados e respectivos tipos (para o cenário em questão foram utilizados os tipos: INT, VARCHAR e REAL), e que é demonstrado na figura 11.

Figura 11 - Criando uma tabela no MySQL

create table events (
id INT AUTO_INCREMENT,
nome VARCHAR(255) NOT NULL,
latitude REAL,
longitude REAL,
PRIMARY KEY (id),
);

Fonte: Autores

É obrigatório que toda tabela SQL possua uma chave primária única. O comando AUTO_INCREMENT indica que o valor do campo id será gerado automaticamente e será incremental, o comando NOT NULL indica que o valor do campo nome não poderá ser vazio.

Para executar qualquer operação em um banco MySQL é necessário estar conectado a ele por meio da função de CONNECT, conforme a figura 12, onde são passados: host, nome de usuário, senha e banco de dados ao qual se deseja ter acesso. A seguir, é possível verificar um trecho de código onde a operação de conexão é feita utilizando a linguagem JavaScript e o servidor Node Express em sua versão 4.17.1.

Figura 12 - Utilizando o comando CONNECT

const connection = mysql.createConnection $(\{$
host : 'localhost',
user : 'mapa',
password: 'password',
database : 'mapa'
\}$)$;
connection. connect ()$;$

\section{Fonte: Autores}

A linguagem SQL possui uma operação de inserção de dados em uma tabela, o INSERT. Na figura 13, é apresentado um trecho de código que demonstra a operação de inserção, onde são passados: a tabela em que se deseja incluir uma nova linha, os campos que estão sendo passados e, por fim, seus respectivos valores.

Figura 13 - Utilizando o comando INSERT

router.post('/mapa', (req, res, next) $\Rightarrow\{$
$\quad$ db.query (
'INSERT INTO mapa
(nome, latitude, longitude)
VALUES (?,?, ?)',
[req.body.nome,
req.body. latitude,
req.body. longitude],
\});

Fonte: Autores
É possível também utilizar a operação de listagem de dados utilizando o SELECT. A figura 14, está um trecho de código mostrando como utilizar tal operação, onde são passados os campos a serem buscados e a tabela que se deseja acessar.

Figura 14 - Utilizando o comando SELECT

router.get('/mapa, function (req, res, next) \{
db.query(
'SELECT id,
nome,
latitude,
longitude
FROM mapa,
);
\});

Fonte: Autores

Na operação de listagem é possível utilizar alguns filtros por meio da cláusula WHERE (por exemplo, SELECT FROM * mapa WHERE latitude > 0 AND longitude > 0), além disso, também é possível ordenar dados utilizando o comando ORDER BY (por exemplo, SELECT FROM * mapa ORDER BY nome), os dois comandos também podem ser utilizados juntos (por exemplo, SELECT FROM * mapa WHERE latitude $>0$ AND longitude $>0$ ORDER BY nome).

A linguagem SQL possui outros comandos conhecidos como CRUD, são eles: DELETE e UPDATE. O comando DELETE exclui uma ou mais linhas de uma determinada tabela dependendo das condições passadas. Já o comando UPDATE, assim como o DELETE, necessita de uma ou mais condições para atualizar uma ou mais linhas de uma tabela de banco de dados.

\section{RESULTADOS}

O principal objetivo desse trabalho é apresentar a implementação prática de operações CRUD utilizando banco de dados NoSQL e SQL, conforme demonstrado ao longo deste artigo. Contudo visando ampliar os resultados do estudo foi desenvolvida uma análise qualitativa entre MySQL e MongoDB. Tal análise é apresentada no quadro 2.

Quadro 2 - Análise qualitativa entre MySQL e MongoDB

\begin{tabular}{|c|c|c|}
\hline Banco de Dados & MySQL & MongoDB \\
\hline Estrutura & Relacional & Não-relacional \\
\hline $\begin{array}{l}\text { Linguagem de } \\
\text { programação }\end{array}$ & $\mathrm{C} / \mathrm{C}++$ & $\mathrm{C}, \mathrm{C}++$ e JavaScript \\
\hline Escalabilidade & $\begin{array}{c}\text { Afeta a } \\
\text { complexidade e o } \\
\text { desempenho }\end{array}$ & $\begin{array}{c}\text { Escalabilidade } \\
\text { horizontal, pronta } \\
\text { para grandes fluxos } \\
\text { de dados }\end{array}$ \\
\hline Flexibilidade & $\begin{array}{l}\text { Mudanças na } \\
\text { estrutura das } \\
\text { tabelas podem } \\
\text { afetar toda a base } \\
\text { de dados }\end{array}$ & $\begin{array}{c}\text { Estrutura dinâmica } \\
\text { e adaptável à } \\
\text { alterações após } \\
\text { implementação }\end{array}$ \\
\hline Features & - Triggers; & -Alta Performance; \\
\hline
\end{tabular}




\begin{tabular}{|c|c|c|}
\hline Importantes & $\begin{array}{c}\text { - Query Cache; } \\
- \text { SubSelects; }\end{array}$ & $\begin{array}{c}\text { - Operações } \\
\text { CRUD; } \\
\text { - Data Aggregation; }\end{array}$ \\
\hline Compatibilidade & $\begin{array}{c}\text { Disponível para os } \\
\text { principais Sistemas } \\
\text { Operacionais e } \\
\text { variáveis do } \\
\text { Sistema Ubuntu }\end{array}$ & $\begin{array}{c}\text { Disponível para os } \\
\text { principais Sistemas } \\
\text { Operacionais }\end{array}$ \\
\hline
\end{tabular}

Fonte: Autores

A implementação da interface para dois tipos de bancos de dados diferentes também possibilitou uma comparação entre os processos que envolvem a preparação do ambiente computacional onde ocorrerá a manutenção do banco de dados.

\section{CONCLUSÃO}

O planejamento da arquitetura de uma aplicação que utilize persistência de informações em um banco de dados deve envolver uma análise atenciosa das opções de SGDB disponíveis com o intuito de implementar uma estrutura que atenda os requisitos da aplicação.

Bancos de dados relacionais como o MySQL possuem estruturas com maior complexidade e custo computacional, mas oferecem ferramentas consolidadas que são altamente integradas com suas estruturas e que proporcionam ao usuário um ambiente familiar à outras etapas de um processo de desenvolvimento de software. Em contraste com o ambiente relacional, e ainda de certa forma representante de um novo processo que envolve a implementação de um banco de dados não-relacional, como o MongoDB, provém uma estrutura concisa para atender as necessidades da persistência de dados. A escalabilidade de bancos de dados desse tipo são um atrativo para empresas que lidam com grandes fluxos de informação, que na atual fase da tecnologia tornou-se o principal item com potencial de mercado.

Com este trabalho foi possível perceber as diferentes implementações com bancos de dados relacionais e não relacionais ao persistirem os mesmos dados, no caso provenientes de uma mesma interface CRUD.

Por fim, após uma análise qualitativa entre os bancos de dados utilizados neste trabalho, MongoDB e MySQL, é perceptível que a utilização de cada ferramenta pode ser definida de acordo com a aplicação e seus respectivos requisitos.

\section{REFERÊNCIAS BIBLIOGRÁFICAS}

C.-O. TRUICA, A. BOICEA, AND I. TRIFAN, "CRUD Operations in MongoDB," no. Icacsei, pp. 347-350, 2013.

E. PLUGGE, P. MEMBREY, AND T. HAWKINS, The

Definitive Guide to MongoDB. Apress, 2010.

M. DE DIANA AND M. A. GEROSA, "Nosql na Web 2.0: Um estudo comparativo de bancos Não-Relacionais para Armazenamento de Dados na Web 2.0," IX Work. Teses e Diss. em Banco Dados - WTDBD, p. 8, 2010.

M. DONAHOO AND G. SPEEGLE, Critical Acclaim for SQL: Practical Guide for Developers.

MongoDB official webpage. [Online]. Available:

https://www.mongodb.com/. Acessado em 15/03/2020
MySQL official webpage. [Online]. Available: https://www.mysql.com/. Acessado em 15/03/2020

N. S. B. ELMASRI, Ramez, Sistema de Banco de Dados, vol. 4. 2005 .

SCHWARTZ, B.; ZAITSEV, P.; TKACHENKO, V. High performance MySQL: optimization, backups, and replication. Sebastopol, USA: O’Reilly Media, Inc, 2012.

SILVA, G. F. A. AND ALVES, A. G. (2012) "Simulador de análise e desempenho para banco de dados MySQL", Anais... Congresso Nacional de Extensão Universitária, 6., Encontro de Atividades Científicas da UNOPAR, 15., 2012. Londrina: UNOPAR.

\section{AGRADECIMENTOS}

Este trabalho conta com o apoio da Samsung Eletrônica da Amazônia Ltda. através da Lei de Informática, AGIN Agência de Inovação da UEA e FUEA - Fundação Universitas de Estudos Amazônicos.

\section{COPYRIGHT}

Direitos autorais: Os autores são os únicos responsáveis pelo material incluído no artigo. 


\author{
Volume $16-\mathrm{N}^{\mathrm{o}} 174$ - Junho / 2020 \\ XLII International Sodebras Congress \\ 28 a 30 de maio de 2020 - Web Conference.
}

\title{
SE PUEDE PATENTAR EL SOFTWARE, UN ACERCAMIENTO A ESTA IDEA
}

\author{
SOFTWARE CAN BE PATENTED, A APPROACH TO THIS IDEA \\ JORGE NERANDY ESCORCIA SUBIROZ ${ }^{1}$; LUANA ESTECHE NUNES KOROCOSKI ${ }^{2}$ \\ 1 - UNIVERSIDADE EXTERNADO DE COLOMBIA; 2 - UNIVERSIDADE ESTADUAL DO CENTRO \\ OESTE.
}

jorgenescorcia@gmail.com.co; luanaesteche@yahoo.com.br

\begin{abstract}
Resumo. Como regla, el software está protegido como copyright, ya que el código fuente de la creación surge de la actividad creativa intelectual y no está cubierto por la concesión de patentes. Sin embargo, hay críticas a este modo de protección, ya que puede no ser la forma más eficiente de salvaguardar el derecho del creador, ya que omite las técnicas utilizadas para crear un programa. En el análisis, verificamos que la protección del software no se ajusta exclusivamente como un derecho de autor puro ni como un producto exclusivamente patentable. Esto se logra después del reconocimiento de que hay partes del bien intelectual que corresponden a una u otra rama, como el hecho de que existe un lenguaje propio, pero que sin duda es un bien de naturaleza técnica, acordando ser patentable a la luz de cualquier legislación.

Palavras-chave: Software. Derecho del autor. Patenteabilidade del Software.
\end{abstract}

\begin{abstract}
As a rule, software is protected as copyright, since the source code of creation arises from intellectual creative activity and is not covered by the grant of patents. However, there are criticisms of this mode of protection, as it may not be the most efficient way to safeguard the creator's right, as it omits the techniques used to create a program. In the analysis, we verified that the protection of the software does not fit exclusively as a pure copyright nor as an exclusively patentable product. This is achieved after the recognition that there are parts of the intellectual property that correspond to one or the other branch, such as the fact that there is a language of its own, but which is undoubtedly a property of a technical nature, agreeing to be patentable in light of any legislation.
\end{abstract}

Keyword: Software. Copyright.. Software Patent.

\section{INTRODUCCION}

Si el sueño de Steve Jobs en "Apple" era que sus productos fueran un todo y así lo demuestran sus diferentes productos (ISAACSON, 2011), pues sus diseños y contenidos, son estéticamente llamativos y funcionales, no es fácil hoy en día separar lo físico y lógico en los deferentes artilugios electrónicos de allí que se empiece a entender al software apesar de su protección en el derecho de la propiedad intelectual através de los derechos de autor, hace parte de un todo con el hardware y por ello es un interés jurídico sui generis que necesita ser protegido de forma independiente a las obras del espíritu.

Es decir no debiera ser tratado como una obra literaria, sino como una combinación de invención y obras, para así llegar a lo que propone este documento, que no es otra cosa que se siga el debate del por qué debería patentarse esta creación del ingenio.

\section{METODOLOGIA}

El inicio del estudio se realizó con capacitación teórica sobre el tema, comenzando con una investigación bibliográfica y un análisis preliminar sobre el tema de investigación, utilizando el método exploratorio con análisis bibliográfico y documental. Se expusieron algunos métodos de protección del software, así como teorías a favor y en contra de la patentabilidad del programa desarrollado a través de derechos de autor exclusivos. Finalmente, se analizó la jurisprudencia sobre el tema, a través de estudios de casos, que respaldan la teoría aplicada por los autores del escrito.

\section{RESULTADOS}

Para abordar el tema defínase al programa de computador como aquel conjunto de instrucciones que permiten el funcionamiento de algo llamado computador o procesador, la legislación comunitaria andina, Decisión 351 de 1993 la cual regula lo correspondiente y conceptúa al software en su artículo 3 como:
La expresión de un conjunto de instrucciones mediante palabras, códigos, planes o en cualquier otra forma que, al ser incorporadas en un dispositivo de lectura automatizada, es capaz de hacer que un ordenador o aparato electrónico sea capaz de elaborar informaciones y ejecute determinado resultado.

Por su parte la doctrina especializada explica a esta creación a partir de las actividades que ejecuta, entendiendo por ello que él se constituye del sistema operativo y el aplicativo.(HARVARD,1968). Además de un código fuente y código objeto que permiten el funcionamiento de la máquina, transforman el leguaje humano, en el lenguaje del ordenador que le permite hacer lo que está destinado.(BENDER, 1968)

Con lo anterior se puede obtener con absoluta claridad las características de la creación del ingenio llamado software y que permite agruparlo sin equívocos dentro de 
los conjuntos de intangibles propios del derecho de autor y de la propiedad industrial, ya que como veremos más adelante, puede participar de las dos categorías, cuanto más si hoy a él se le analiza bajo la "experiencia de los usuarios y del servicios que provee" (GOMULKIEWICZ, 2002).

Gustavo Adolfo García Arango ${ }^{1}$ con respecto a la calidad jurídica del software dice que: "El software puede ser protegido jurídicamente desde la propiedad intelectual, industrial (patente) o los derechos de autor."

Desde la academia se han descrito las principales semejanzas y diferencias entre el derecho de autor y la propiedad industrial, tal como lo hace (OMNPI, 2006):

Existe una semejanza entre los dos regímenes, esta es el bien jurídico protegido, que en este escenario es el aporte intelectual, así una creación intelectual, puede ser protegida por ambos regímenes desde un punto diverso, como una obra artística que también puede ser protegida desde el campo de la propiedad industrial como diseño industrial. Sin embargo no puede dejarse de lado las claras diferencias que a su vez también tienen estos campos de derecho, pues con solo mencionar que los derechos humanos tienen protección en la declaración de derechos humanos, le carga de esa indivisibilidad que tienes con la esencia de la persona y por tanto no puede ser desconocido ni vulnerado.

Por otro lado la propiedad industrial otorga protección a ciertos bienes intangible por su aplicación en la industria, sin reconocerle de esta manera alguna consideración al autor.

En lo que respecta a la amparo constitucional del software como una obra literaria, la Organización Mundial de la Propiedad Intelectual -OMPI- ha considerado que la complejidad de encuadrar el software dentro de las obras espituriales protegidas por el derecho de autor radica en los elementos no literales contenidos en el mismo:

El problema que plantea la clasificación estricta del software como obra literaria surge cuando se considera que los programas de computadora tienen otros elementos que normalmente no están protegidos mediante el derecho de autor. El software no es solamente una expresión literaria; las líneas del código tienen una función que no depende de su construcción gramatical. El código fuente de un programa de computadora puede ser completamente diferente del de otro programa $\mathrm{y}$, con todo, cumplir la misma función a la hora de dar lugar a un conjunto similar de instrucciones que producen un resultado similar. Este es el fondo de la dicotomía entre la idea y la expresión que a menudo está en la primera línea del debate en torno a la protección del software.

\footnotetext{
${ }^{1}$ GARCIA G. (2007). Aspectos jurídicos del software libre en Colombia. Revista Digital de la Universidad Catolica del norte, extraído de http://revistavirtual.ucn.edu.co/index.php/RevistaUCN/article/view File/158/303
}

Está claro que copiar partes importantes del código fuente de un programa para incorporarlas a otro programa constituye una infracción del derecho de autor. Sin embargo, este tipo de infracción es relativamente raro, y el problema real se ha convertido en la protección de los elementos no literales contenidos en el software. ${ }^{2}$ (OMPI, 2006)

El Consejo de Estado, máxima autoridad en materias de patentes en Colombia, en sentencia del catorce (14) de diciembre de mil novecientos noventa (1990), Bogotá D.C, Sala de lo Contencioso Administrativo, Sección Primera, se pronunció al respecto al decir que:

Las necesidades planteadas por los diversos productores del software en el país, quienes día a día venían reclamando un marco de protección para sus programas ante la reiterada reproducción ilícita de los mismos, se empezó a evidenciar la importancia de contar con una reglamentación en este sentido" y que "para ello fueron estudiadas las diversas posiciones doctrinales y legislativas del mundo, siendo evidente que en la actualidad la tendencia casi unánime es la de considerar el soporte lógico como una creación propia del dominio literario, sujeta a disposiciones del derecho de autor.

Hace luego un recorrido por las posiciones legales y jurisprudenciales de otros países en cuanto tienden actualmente y en forma generalizada a la protección del software.

Por otra parte Jamarillo (2010) argumenta

La característica dominante en los países desarrollados también es la de enmarcar la protección del software por esta vía. Por supuesto en la definición del tema jugaron un papel importante motivaciones de política internacional así como las obligaciones emergentes de los acuerdos internacionales en materia de derechos de autor y la presión de los países productores del software, en especial de los Estados Unidos.

Aceptar la tesis del libelista con respecto al software, sería negarle la posibilidad de protección a cualquier obra que en el futuro pueda desarrollarse o definirse por cualquier medio conocido o por conocer, pues sería necesario entonces, según el libelista, que cada vez se requiera una ley que de manera expresa definiera el ámbito de protección a esa nueva obra, con los perjuicios que ocasionaría a los autores o titulares al ser utilizadas sus obras sin autorización, pero sin poder defenderse al no encontrar un mecanismo legal eficaz en inmediato para defender sus intereses.

${ }^{2}$ Organización Mundial de la Propiedad Intelectual- OMPI-.(2006).
Propiedad Intelectual y Software. Revista No. 06 de la OMPI.
Extraido http://www.wipo.int/wipo magazine/es/2008/06/article 0006.html 
Ahora bien, en el futuro las comunicaciones entre los individuos y el cambio de informaciones entre los mismos tendrá una demanda mucho más pronunciada que en la actualidad. En esa medida, es inaceptable que se limiten los avances tecnológicos por no encuadrar en el legalismo pretendido y lo que es peor, que estos se invaliden arguyendo la ausencia de legislación.

Por tanto, es necesario que el legislador le haga frente a estos avances, construyendo un concepto documental que acorte la distancias que hoy en día exige la funcionalidad Estatal, sin olvidar que la comunicación cada vez se vuelve más sofisticada e innovadora, y por tanto la legislación actual se queda corta en su intento de regular sin tener la capacidad de avance y actualización al ritmo en que evoluciona la tecnología.

Tal como se extrae de lo dicho en los párrafos anteriores, es evidente que las características del software no se ajustan totalmente a las características del derecho de autor o de la propiedad industrial y que encuadrarlo forzosamente a cualquiera de estos tipos podría traer serias implicaciones prácticas desde el punto de vista de su aplicación jurídica, por tanto es pertinente que desde la academia se planteen nuevas soluciones como la posibilidad de que también se patente apesar que en ocasiones positivamente se haya consagrado en norma que no es una reivindicación patentable y así el ingenio se proteja. Lo expresado con anterioridad encuentra sustento en que:

La protección de la propiedad intelectual es una tarea de importancia crucial para el fomento de la creatividad y el talento nacionales, en la medida en que garantiza que el trabajo creador del artista o del científico no será objeto de apropiación ni aprovechamiento indebidos por parte de terceros."

\section{1 - Cuando se puede patentar el software.}

Ante la pregunta de cuándo se puede patentar el programa de computador, hay que reconocer que la mayoría de legislaciones se niegan acceder a ello y han sido los tribunales judiciales en casos concretos que han traído el tema a debate y que han permitido bajo ciertas condiciones que el software se haya patentado y se pueda patentar. Por cierto aun hoy no es pacificó el asunto, pues no se ha dejado contentos a los bandos que defienden la idea de una patente a pesar que ya se hizo y los que no, quienes se mantienen en el concepto de clásico que ya hemos mencionados, pero con todo se han dado las bases para que hoy lleguemos a una doble protección, pues las autoridades administrativas encargadas de conceder el privilegio atendiendo las providencias de los jueces, han accedido en ocasiones a patentar un software, gracias al concepto del "efecto técnico" del mismo, que párrafos siguientes explicaremos.

\footnotetext{
${ }^{3}$ Sentencia C-924 de 2000. En esa oportunidad la Corte declaró exequible el Convenio entre el Gobierno de la República de Colombia y el Gobierno de la Federación de Rusia sobre cooperación cultural y científica, suscrito en Santa Fe de Bogotá el 26 de noviembre de 1997, y la Ley 566 del 2 de febrero de 2000 que lo aprueba.
}

Es que a la luz del sistema anglosajón Estado Unidense, el software se protege por el "copyright" o derechos de autor y así lo consagra, en el "CopyrigthAct, título 17 sección 101". De igual manera la Unión Europea hace lo propio, en la Directiva del 14 de mayo de 1991. Ambos regímenes tratan a la creación estudiada, como una obra literaria de la que habla el Convenio de Berna, al considerar que en su elaboración hay un lenguaje que se tiene que redactar, similar al que hace el escritor en su obra.(HANSEN, 2004).

Por su parte la Organización Mundial del Comercio "OMC" en los acuerdos sobre la propiedad intelectual“ADPIC" se consagró en su artículo 101 que:

Programas de ordenador y compilaciones de datos. I. Los programas de ordenador, sean programa fuentes o programas objeto, serán protegidos como obras literarias en virtud del Convenio de Berna de 1971.

Los sistemas normativos latinoamericanos no han escapado a lo dicho anteriormente y por ello en la Decisión 351 de 1993, de la que participa Colombia, como miembro de la Comunidad Andina de Naciones, se tiene el mismo concepto

Se tiene que decir que la idea de patentar el software nace de las críticas al sistema de protección que bridan los derechos de autor y muy a pesar de lo dice Pollaud-Dulian (2011), en la "La propietéindustrielle" quien considera inadecuado ala patente como instrumento de cabal protección del interés, pues el sistema de patentes es oneroso y hay dificultades en la concesión del mismo y es que se tiene, con algo de razón que el copyright, solo puede proteger la parte literal del software como son los códigos, dejando por fuera las técnicas empleadas para la creación del programa,(Harvard, 1968) que es sin duda un procedimiento para crear un producto y como tal es patentable, así como también el hecho que en razón al régimen de limitaciones y excepciones a los derechos de autor, los programas se podrán conocerse de manera gratuito, permitiendo la variación de los pasos en la programación, para llegar un programa parecido haciendo que las copias ilegales pasen a disimulables y que sin miramiento afecta el derecho de los autores.

Por último y la más importante de las críticas a cerrar la posibilidad de patentar los programas de computador, es olvidar la esencia misma de la creación pues ella tiene de por si un objetivo funcional que lo hace ser un todo con la máquina, es decir que es connatural que sin el uno no exista lo otro.

Ante lo anterior, en los estrados judiciales en los dos regímenes existentes como "comomlaw" y el derecho continental europeo, que de por sí influencia al latinoamericano se han concedido el privilegio de la patente a unos programas de computadores, gracias a lo que han llamado el "efecto técnico" del mismo.

\section{2 - El efecto técnico del software, criterio para patentar el software.}

La jurisprudencia en este tema ha considerado que lo prohibido por la Ley es la patente del programa de computador "per se" o "como tal", significando que no se puede patentar un software cuando este se refiere a la parte literal o escrita, es decir al algoritmo que se redacta para crearlo o en mejores palabras lo que se refiere al código 
fuente y al código objeto, pues ello corresponden a la parte abstracta de la creación o la expresión de la idea del autor, pero si este haciendo referencia al programa se crea para el funcionamiento de una maquinaria $o$ hace parte del procedimiento o proceso, es decir tiene u componente técnico que se aprecie como un todo para la fabricación de un producto, estaremos en presencia de lo que se conoce como el "efecto técnico del software" y que si podría generar una reivindicación.

En los Estados Unidos si bien se persiste en mantener el esquema de protección del software por medio del copyright, gracias a litigios como el de "ALICE CORPORATIÓN vs CLS BANK", se planteó el debate de lo que es patentable o no dentro del programa de computador, especialmente su relación directa con el hardware, La Corte Suprema de Justicia en dicho fallo aclaró que el computador no es una máquina, pero a pesar de ello "no se convierte en impatentable cuando incorpore ideas abstracta, si no que se podrá patentar cuando traiga una mejora funcional al computador" sumado a que deberá atender además los requisitos de patentabilidad como son la novedad, la no obviedad y la utilidad. (SUPREMECOURT OF THEE UNITED STATES, 2014)

Desde la óptica continental europea, también fueron los litigios quienes dieron vida al debate de la patente del software y es así que la Oficina Europea de Patentes, consideró en razón a los fallos que se venían profiriendo tales como el de VICOM de 1986; IBM de 1998 y MICROSOFT de 2006, "que el programa de computador es una serie de instrucciones que constituyen un método y para que sea patentable debe aportar un efecto técnico."(DRILLON, 2013)

En el primero de los procesos la sala técnica de la oficina europea dijo:

Una invención que sería patentable conforme los criterios clásicos de patentabilidad no debe ser excluida de la protección por el solo hecho de que su implementación implique la utilización de medios técnicos modernos, estos es, bajo la forma y empleo de un programa de computador; el criterio determinante es la contribución que aporta al estado de la técnica dela técnica la invención en atención a la reivindicación, la cual deberá ser considerada como un todo. (GALLOUX, 2012)

Del segundo de los procesos se destaca que la Sala, explicó que los programas de computadores son patentables cuando tenga un carácter técnico, explicando que ello se logra cuando "sea capaz de realizar un efecto técnico suplementario o adicional” (DRILLON, 2013)

El último de los litigios, es decir el MICROSOFT del años 2006, la corporación adujó que si el programa debe entenderse como un conjunto de etapas, "debe entenderse como un método operado por un sistemas informático y presenta un efecto técnico si se almacenan en el mismo" (DRILLON, 2013)

Se colige entonces que en criterio de la jurisprudencia europea también se puede patentar el programa de computador al participar de los conceptos aqui expuestos, es decir el de "software como tal" que no puede ser patentado y el de "efecto técnico del software" el cual permite su reconcomiendo a través de la concesión del privilegio, pues la invención presenta un componente técnico, que escapa a la sola interacción del programa con el hardware.

\section{3 que benedicios trae la reivindicación del software a} traves de la patente.

Estas líneas deben empezar planteando um problama real y se tiene que la Suprema Corte de los Estados Unidos está conociendo desde el pasado 10 de enero de 2020, las peticiónes o "amicus curiae" para que decida, si GOOGLE debe pagar regalías por el uso de un software necesario y utilizado por la mayoría de teléfonos celulares del mundo, conforme Herrera (2020) permite conocer que ventajas traeria La petente del sowfware para resolver este litiligio

El problema jurídico del caso radica, según unos de lo quejosos "en el carácter anticompetitivo de la protección por derechos de autor de las interfaces de los programas de computador". (GHOSH, 2020)

Si definimos a las interfaces de programación o (las application programming interfaces- API) en instrucciones de código que facilitan que diversos programas de computador puedan ser interoperables. Herrera, (2020) hace alusion a ideas y como las ideas no se pueden proteger por los derechos de autor, la demandada no tendría por que reponder, pero si patanetaramos el procedimento em el que hacer parte la interfas, sin duda se le diera la proteccion que requiere la creacion intelectual, pues el sistemas y el mismo aparato tennologico el smartphone donde funciona es uno solo.

Recuerdese que en mataria de derechos de autor existe la teoria la fusion de la idea co la expesion material, es decir la protección del derecho de autor abarca solo las expresiones, pero no las ideas, em campbio el derecho de las patentes si cubre los procedimientos, métodos de operación , sin dejar por fuera a la interfase, que em palabea de la misma OMPI, "es un derecho exclusivo que se concede sobre un producto o un proceso que, por lo general, ofrece una nueva manera de hacer algo o una nueva solución técnica a un que creemos segun los supuestos facticos del caso lo que pudo haber hecho GOOGLE y que lo llevo al litigio que se citado.

Partiendo de la base que esencia el software incluso el "per se" o "de por si" del cual ya se habló, se puede patentear de acuerdo a que los requisitos para lograrlo sin dificultad alguna estan implícito en él, como creación del intelecto destinada a satisfacer una necesidad y no procurar la cultura, pues cada legislación reconoce como requisitos de patentabilidad, lo de novedoso, no evidente y útil si estamos em el sistema anglosajon, o el de novedad, nível inventivo y aplicación industrial propios de los sitemas continenatales europeos de los cuales participan los países latino americanos, las ventajas de patentear el software radica Para ratificar la hipotesis que se planteó em los parrafos anteriores y que se sustenta em el software patentable segun ANA JEDRUSIK, y PHIL WADSWORTH consultores en propiedad intelectual, quienes estribeiron em la revista de la OMPI del 2017,

1.Ofrece una rentabilidad razonable del éxito comercial de sus invenciones;2. facilita a las pequeñas empresas y a las empresas emergentes, cuya actividad es la innovación, el establecimiento de colaboraciones empresariales fructíferas;3.promueve la difusión sistemática de conocimientos a partir 
de la publicación de la patente, lo que supone un importante motor para la innovación; y 4. ayuda a atraer a socios de inversión y a apoyar la expansión empresarial. (JEDRUSIK, WADSWORTH 2017)

\section{CONCLUSION}

Huelga preguntarse si hay necesidad de cerrar las puertas de la patente a los programas de computadores, cuando hemos visto que se trata de un interés jurídico de la propiedad intelectual de carácter particular y único que puede fácilmente participar de las dos ramas de este derecho como son el de los derechos de autor o de la propiedad industrial.

A lo anterior se llega luego de reconocer que hay partes del bien intelectual que corresponde a una y a otra rama como sería el hecho que hay un lenguaje propio, pero que sin duda se trata de un bien de carácter técnico y que fácilmente fuera de los dogmático cumple con los presupuesto para ser patentable a la luz de cualquier legislación, pues cada programa que nace hoy en día es novedoso, tiene nivel inventivo y sin duda una aplicación en la industria, bajo el entendido que el primero de estos requisitos se refiere a la modificación del estado de la técnica, es decir la creación o modificación de la que se sabe al respecto al software, el segundo del mérito inventivo que tiene la creación del programa aun si parte de algo ya creado y por ultimo su rol como participe de la actividad industrial ya sea para su comercialización como producto o como parte del procedimiento que sirve para producir.

No hay que olvidar lo rápido y cambiante que es el mumdo de la tecnoligia y de no protegerse el software por patente "podría obstaculizar el desarrollo tecnológico, dar lugar a soluciones técnicas poco eficientes y reducir así las oportunidades de colaboración y transferencia tecnológica." (JEDRUSIK, WADSWORTH, 2017)

Es que claro es que el programa de computador ya no es escindible del cuerpo físico que le permite funcionar y que hoy en nuestro comercio actual se trata de un producto más que el consumidor adquiere.

No se trata de defender alguna de las posiciones que aquí se expusieron, recordando que la mas compartida es la europea quien ha generado un dualismo de protección que redunda en beneficio de la actividad creadora, pero que aún resulta ineficaz, más bien se propondría crear un derecho propio que grita hacer parte de lo que hoy se habla como derecho informático, como el marco jurídico encargado de brindar protección a eso llamado software cada días más está presente en la vida del ser humano y que en un momento dado se transformará como es hoy en parte integrante de su ser.

\section{REFERENCIAS BIBLIOGRAFICAS}

ADPIC. El Acuerdo de la OMC sobre los Aspectos de los Derechos de Propiedad Intelectual relacionados con el Comercio. Información sobre los ADPIC disponible en el sitio Web de la OMC.

BENDER, David. Computer Programs: Should they Be Patentable?.Columbia La Review, vol 68, nº 2, feb.1968.

DRILLON, Sebastien. La Protecion des logictels par brevel d'invention. Lexis Nex ris Classeur Brevets Propriete industrialle, $\mathrm{n}^{\circ} 4.2013$.
GALlOUX, Jean Chistophe. La Propriete industrielle, Paris, Dalloz, 2012.

GARCÍA G. Aspectos jurídicos del software libre en Colombia. Revista Digital de la Universidad Catolica del norte, 2007. extraído de http://revistavirtual.ucn.edu.co/index.php/RevistaUCN/articl e/viewFile/158/303.

GOMULKIEWICZ, Robert W. Legal Protection for Software: Still a Work in Progress. Tex Wesleyan L. Ver. 445-54, 2002.

HANSEN, Kim G. Software Patents in Europe. Scandinavian Stud, L.174. 2004.

HARVARD, LawReview 81, n. 7, 1968.

HERRERA, Luisa. ¿Cómo alcanzar el anhelado balance entre la sana competencia y la innovación?: un breve estudio del caso de GOOGLE VS. ORACLE. 2020. Disponível em: https://propintel.uexternado.edu.co/comoalcanzar-el-anhelado-balance-entre-la-sana-competencia-yla-innovacion-un-breve-estudio-desde-el-caso-de-googlevs-oracle/. Acesso em: 27 jan. 2020.

ISAACSON, Walter. Steve Jobs.Bogotá: Ed. Penguin Randon, 2015.

JAMARILLO, Alfredo Vega. Manual de Derecho de Autor. Direccion Nacional de Derecho de Autor. Bogotá, 2010.

JEDRUSIK, Ania; WADSWORTH, Phil. La protección por patente de las invenciones implementadas por ordenador. Ompi Revista, Espanha, p. 01-01, fev. 2017. Disponível

em:

https://www.wipo.int/wipo_magazine/es/2017/01/article_00 02.html. Acesso em: 08 maio 2020.

LEGISLACION COMUNITARIA ANDINA. Decision 351 de 1993.

OFICINA EUROPEIA DE PATENTES, Sala de Recursos.

OMPI. Derecho de autor: ¿Qué es el derecho de autor?. 2020. Disponível em: https://www.wipo.int/copyright/es/. Acesso em: 08 maio 2020.

ORGANIZACIÓN MUNDIAL DE LA PROPIEDAD INTELECTUAL- OMPI-.(2006). Propiedad Intelectual y Software. Revista No. 06 de la OMPI. Extraido de http://www.wipo.int/wipo_magazine/es/2008/06/article 000 6.html.

POULLAUN-DULLIAN, Frederic.La Propriete Industrielle, Paris, econômica, 2011.

SUPREMECOURT OF THE UNITED STATES. Alice Corporatión vs Cls Bank, 2014.

STRICKLETT, Sue Ghosh. Google v. Oracle: An Expansive Fair Use Defense Deters Investment In Original Content. 2020. Disponível em: https://www.ipwatchdog.com/2020/01/19/google-v-oracleexpansive-fair-use-defense-deters-investment-originalcontent/id=117951/. Acesso em: 19 jan. 2020.

\section{COPYRIGHT}

Direitos autorais: Os autores são os únicos responsáveis pelo material incluído no artigo. 


\title{
Volume $16-\mathrm{N}^{\mathrm{o}} 174$ - Junho / 2020 \\ XLII International Sodebras Congress \\ 28 a 30 de maio de 2020 - Web Conference.
}

\section{UM ALGORITMO PARA GERAÇÃO DE ROTAS PARA COLETA DE RESÍDUOS SÓLIDOS NA CIDADE DE MANAUS UTILIZANDO DADOS IOT}

\author{
AN ALGORITHM FOR THE GENERATION OF ROUTES FOR THE \\ COLLECTION OF SOLID WASTE IN THE CITY OF MANAUS USING IOT DATA
}

\author{
LOPES, DIEGO; NEVES, NAYRA; SOARES, ANDRÉ; BASTOS, MOISES; VALENZUELA, WALTER \\ UNIVERSIDADE DO ESTADO DO AMAZONAS
}

diml.eng@uea.edu.br,ngn.eng16@uea.edu.br,alsoares@uea.edu.br,mpbastos@uea.edu.br, wvalenzuela@uea.edu.br

\begin{abstract}
Resumo - A Internet das Coisas (IoT) atualmente vem sendo amplamente estudada na área de cidades inteligentes para sensoriamento, localização, rastreamento e gerência de coisas inteligentes. A geração de rotas para caminhões coletores de resíduos sólidos da cidade de Manaus pode ser inserida em uma aplicação de Iot. O problema de roteamento de veículos trata de um conjunto de rotas de veículos de custo mínimo, originando e terminando em um depósito central e possui heurísticas de desenvolvimento. Este trabalho propõe um algoritmo para geração de múltiplas rotas, utilizando a heurística orientada ao tempo e ao vizinho mais próximo, com uma origem e um destino especificados para o recolhimento de resíduos nos pontos coletáveis com volumes diversos, em seguida apresenta os resultados de simulações quantitativas feitas a partir dos parâmetros propostos, além das rotas a distância percorrida e o tempo necessário para cada trajeto.

Palavras-chave: Iot. VRP. Vizinho mais próximo.
\end{abstract}

\begin{abstract}
The Internet of Things (IoT) is currently being widely studied in the area of smart cities for sensing, locating, tracking and managing smartthings. The generation of routes for trucks collecting solid waste from the city of Manaus can be inserted in an Iot application. The vehicle routing problem deals with a set of minimum cost vehicle routes, originating and ending in a central warehouse and has development heuristics. This work proposes an algorithm for the generation of multiple routes, using the timeoriented heuristic and the closest neighbor, with a specified origin and destination for the collection of waste at the collectable points with different volumes, then presents the results of simulations. measurements made from the proposed parameters, in addition to the routes the distance traveled and the time required for each route.
\end{abstract}

Keywords: Iot. VRP. Nearest neighbor.

\section{INTRODUÇÃO}

A Internet das coisas, do inglês The Internet Of Things (IoT) é um dos termos mais utilizados quando se fala na atual fase da industrialização. A IoT é o modo como todas as coisas estão conectadas à internet e se comunicando entre si, através de dispositivos de sensoriamento inteligentes e softwares que transmitem dados para uma rede. Ela alcança o objetivo de identificar, localizar, rastrear, monitorar e gerenciar coisas inteligentes, (Solomon, 1987).

A internet das coisas nos possibilita integrar praticamente tudo que está ao nosso redor. As informações compartilhadas permitem que sejam feitas inúmeras aplicações de inovações que variam das mais diversas áreas da sociedade, como meio ambiente, indústria, comércio e smart cities e tem por objetivo melhorar a qualidade de vida das pessoas.

O planejamento de roteirização de caminhões coletores de lixo da cidade de Manaus é uma das aplicações na qual a IoT pode otimizar com auxílio de sistemas de sensoriamento inteligente. Em geral, as gerações de itinerários precisam diminuir os custos e maximizar a produtividade. Por esse motivo existem soluções relacionadas ao Problema de Roteamento de Veículos, do inglês Vehicle Routing Problem (VRP), que diz respeito a um problema de otimização combinatória, que envolve o projeto de um conjunto de rotas de veículos de custo mínimo, originando e terminando em um depósito central, para uma frota de veículos que atende um conjunto de clientes com demandas conhecidas.

O VRP diz respeito ao serviço de logística. As mercadorias de $\mathrm{n}$ clientes possuem uma demanda de mercadorias e estas são entregues por uma frota de veículos homogêneos. Os veículos precisam realizar um percurso saindo do local do depósito e entregando as mercadorias para um subconjunto de clientes, levando em consideração a demanda e o retorno ao local inicial. As rotas de cada veículo não podem ultrapassar a capacidade do veículo e o tempo máximo para finalizar a rota. Todos os requisitos e restrições operacionais dos clientes precisam ser atendidos e o custo de transporte global minimizado. Esse custo pode ser monetário, de distância, de tempo ou de outra forma. (Arakaki, 1998).

Formalmente, o VRP é definido em um grafo direcionado $\mathrm{G}=(\mathrm{V}, \mathrm{A})$ com o conjunto de vértices $\mathrm{V}$ e o conjunto de $\operatorname{arcos} \mathrm{A}$. $\mathrm{O}$ conjunto de vértices $\mathrm{V}$ consiste no conjunto de clientes $N=\{1, \ldots, n\}$ e os vértices 0 e $n+1$ que representam o depósito no início e no final. Cada cliente $\mathrm{i} \in$ $\mathrm{N}$ está associado a uma janela de tempo [ai, bi], um tempo de serviço não negativo si, um intervalo de demanda [qmin i, qmax i] e um lucro ei $\geq 0$ por unidade de demanda entregue. Além disso, uma janela de tempo $[\mathrm{a} 0, \mathrm{~b} 0]=[\mathrm{an}+1, \mathrm{bn}+1]$ é associada aos depósitos para modelar o horizonte de planejamento (Tilk et al, 2019).

Dentre os vários tipos de algoritmos de roteamento, Solomon (1987) aborda em seu estudo sobre algoritmos para roteamento de veículos e problemas de agendamento com restrições de janela de tempo. Nele os algoritmos são 
divididos em métodos sequenciais e paralelos. Onde procedimentos sequenciais constroem uma rota de cada vez até que todos os clientes sejam agendados. E os paralelos são caracterizados pela construção de uma série de rotas simultaneamente.

Esse trabalho, de caráter exploratório e de abordagem quali-quanti, descreve o desenvolvimento de um algoritmo para geração de múltiplas rotas para coleta de resíduos sólidos na cidade de Manaus utilizando dados de um sistema IoT, com base nas heurísticas orientada para o tempo e do vizinho mais próximo abordado por Solomon (1987), onde todas as rotas são iniciadas encontrando-se o cliente não roteado "mais próximo" ao depósito.

A métrica utilizada nesta abordagem tenta explicar a proximidade geográfica e temporal dos clientes. Deixe o último cliente na rota parcial atual ser cliente $i$, e deixe $j$ denotar qualquer cliente não roteado que possa ser visitado em seguida. Em seguida, a métrica utilizada, $c_{i j}$, mede a distância direta entre os dois clientes, $\mathrm{d}_{i j}$, a diferença de tempo entre a conclusão do serviço em i e o início do serviço na $j$, $\mathrm{T}_{i j}$, e a urgência de entrega ao cliente $\mathrm{j}, \mathrm{v}_{i j}$, como expressa pelo tempo restante até o último possível início de serviço do veículo (Solomon, 1987).

\section{REFERENCIAL TEÓRICO}

\section{1 - Iot (Internet of Things)}

Iot é uma grande rede de equipamentos (coisas) ligados entre si capazes de gerar uma grande quantidade de dados que podem ser utilizados em diversas aplicações. Em seu artigo, Talari et al (2017), afirma que a IoT é capacitada pela expansão de várias coisas e equipamentos de comunicação e envolvem equipamentos inteligentes, como, celulares, eletrodomésticos ou sensores que colaboram para um objetivo comum.

\section{2 - Vehicle Rounting Problem (VRP)}

Segundo Barrier (2003), o problema de roteamento de veículo consiste em vários clientes, cada um exigindo que um peso específico das mercadorias seja entregue. Os veículos despachados de um único depósito devem entregar as mercadorias necessárias e retornar ao depósito. Cada veículo pode ter um peso limitado e também pode ser restringido na distância total que pode percorrer. Apenas um veículo pode visitar cada cliente. O problema é definir um conjunto de rotas de entrega que atenda a esses requisitos e ofereça um custo total mínimo. Na prática, isso geralmente é considerado equivalente a minimizar a distância total percorrida ou a minimizar o número de veículos utilizados e, em seguida, minimizar a distância total para esse número de veículos. Uma das abordagens para solucionar este problema utiliza a heurística do vizinho mais próximo.

\section{3 - Vizinho mais Próximo}

O algoritmo de vizinho mais próximo é eficaz na solução de problemas altamente complexos, como o VRP. Estes são principalmente problemas de otimização. A técnica do vizinho mais próximo $\mathrm{K}$ geralmente usando a distância euclidiana ou a comparabilidade cosseno entre as tuplas (Mohammed et al, 2017). Na heurística do vizinho mais próximo é adicionado, a cada iteração, o vértice mais próximo do último já inserido. Quando todos os vértices são visitados, o procedimento é terminado.

\section{METODOLOGIA}

O estudo proposto, de caráter descritivo e exploratório, com abordagem quantitativa e qualitativa da implementação de um algoritmo de geração de rotas para caminhões coletores de resíduos sólidos dentro da cidade de Manaus. Para a sua implementação foi utilizada uma heurística orientada a tempo e vizinho mais próximo, apresentada por Solomon(1987).

Cada ponto coletável dentro da cidade foi considerado como um nó de um grafo. Por necessidades de execução das atividades de coleta, cada ponto coletável (ou nó do grafo) foi associado a uma região geográfica. Para cada região é gerado um grafo contendo seus pontos coletáveis.

Os pontos coletáveis possuem um peso que é calculado a partir dos dados obtidos pelo sensoriamento e armazenado em servidores na nuvem e é definido por uma equação condicional que leva em conta o seu nível de enchimento, a quantidade de dias que não é coletado e o nível de gás presente em seu interior. Para a execução do algoritmo só serão considerados os pontos que satisfizeram a condição da equação (1) a seguir.

(Nivel $>80 \%$ ) ou

(Nível $>20 \%$ e Dias $>2)=$ verdadeiro

Nesta etapa, o resultado são grafos, por regiões geográficas, totalmente desconectados, possuindo apenas pontos coletáveis aptos, como apresentado na figura 1.

Figura 1 - Exemplo de grafo desconectado por região contendo os pontos coletáveis aptos

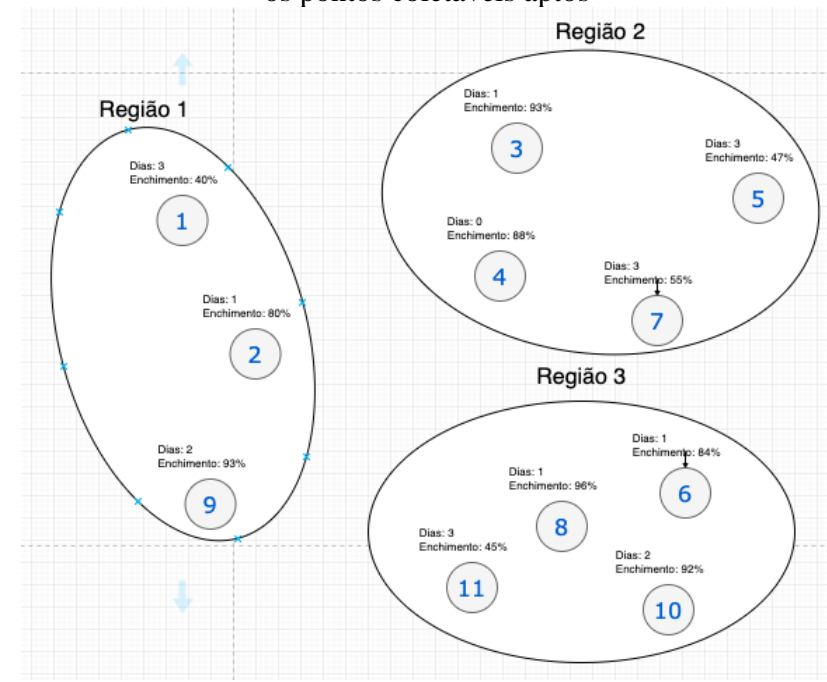

Fonte: Elaboração dos autores.

Para que o algoritmo possa ser executado, é necessário um grafo não direcionado e totalmente conectado. Para isso, a cada nó foram criadas arestas para todos os demais nós do grafo da região, como mostrado na figura 2. Tais arestas possuem pesos que são calculados de acordo com a distância em metros e o tempo em segundos entre cada ponto. 
Figura 2 - Exemplo de grafos por região com arestas entre todos os pontos coletáveis

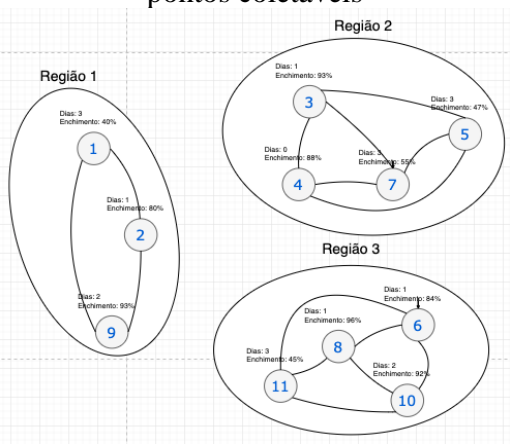

Fonte: Elaboração dos autores.

Como entrada do algoritmo, estão: origem, destino, tempo máximo de coleta para cada caminhão, uma lista de caminhões contendo sua capacidade e uma lista de grafos por região não direcionados e totalmente conectados, contendo os pontos de coleta (nós do grafo) e suas arestas encontradas na etapa anterior. Apresentamos a seguir um pseudocódigo do algoritmo gerado:

geradorRotas(origem, destino, Tmax, Capacidade, caminhões, grafos)

noAtual $=$ origem

listaRotas $=[[$ noAtual $]]$

para i em grafos faca:

enquanto grafo[i].vertices.tamanho $>0$ faca:

rota $=$ listaRotas.tamanho

se Tmax > listaRotas[rota].tempo e Capacidade >

listaRotas[rota].capacidade:

listaRotas[rota].add(vizinhoMaisProximo(noAtual, grafo[i]))

As etapas de preparação para que se possa entrar com os dados necessários para o gerador de rotas, incluem:

I. Análise dos pontos coletáveis aptos a serem coletados,

II. Divisão dos pontos coletáveis em regiões geográficas da cidade de Manaus (norte, sul, leste, oeste, centro-oeste e centro-sul), para isso foi utilizado a Application Programming Interface (API) do Google Maps,

III. geração do grafo, onde seus nós são os pontos coletáveis e as arestas são as distância (calculada pela API do Google) entre cada nó e os demais pontos.

\section{RESULTADOS}

Os resultados abaixo foram obtidos por meio de simulação de dados, onde foram gerados aleatoriamente os dados dos pontos de coleta (capacidade, nível de enchimento e dias sem coleta).

\section{1 - Resultados da Simulação}

Foram utilizados dados de pontos coletáveis (coordenadas no mapa de Manaus, nível de enchimento e dias sem coleta) gerados aleatoriamente e um computador MacBook Air 2005, com memória RAM de 4 gigabytes, 1600 megahertz, DDR3 e um processador Intel Core I5 Dual-Core, de 1,6 gigahertz. Os pontos coletáveis utilizados para a simulação são apresentados na tabela 1 .
Tabela 1 - Pontos coletáveis utilizados para a simulação

\begin{tabular}{|c|c|c|c|c|}
\hline $\begin{array}{c}\mathrm{Nr} \\
\mathrm{o}\end{array}$ & $\begin{array}{c}\text { Latitude/Longi } \\
\text { tude }\end{array}$ & Região & $\begin{array}{c}\text { Enchi } \\
\text { ment } \\
\text { o (l) } \\
\end{array}$ & $\begin{array}{c}\text { Dias sem } \\
\text { Coleta }\end{array}$ \\
\hline 1 & $\begin{array}{l}-3.000140 / \\
-60.002441\end{array}$ & zona-norte & 150 & 1 \\
\hline 2 & $\begin{array}{c}-3.004274 / \text { - } \\
59.980428 \\
\end{array}$ & zona-norte & 180 & 1 \\
\hline 3 & $\begin{array}{c}-3.000118 /- \\
59.972010\end{array}$ & zona-norte & 120 & 2 \\
\hline 4 & $\begin{array}{c}-3.013564 / \text { - } \\
59.939042 \\
\end{array}$ & zona-norte & 200 & 1 \\
\hline 5 & $\begin{array}{c}-3.014602 /- \\
59.938829 \\
\end{array}$ & zona-norte & 180 & 1 \\
\hline 6 & $\begin{array}{c}-3.031978 /- \\
59.989389\end{array}$ & zona-norte & 140 & 2 \\
\hline 7 & $\begin{array}{c}-3.032043 /- \\
59.985927 \\
\end{array}$ & zona-norte & 100 & 2 \\
\hline 8 & $\begin{array}{c}-3.031977 / \text { - } \\
59.989465 \\
\end{array}$ & zona-norte & 160 & 1 \\
\hline 9 & $\begin{array}{c}-3.035027 / \text { - } \\
59.939318 \\
\end{array}$ & zona-leste & 192 & 1 \\
\hline 10 & $\begin{array}{c}-3.044733 /- \\
59.944959 \\
\end{array}$ & zona-norte & 100 & 1 \\
\hline 11 & $\begin{array}{c}-3.050639 /- \\
59.944833 \\
\end{array}$ & zona-leste & 70 & 2 \\
\hline 12 & $\begin{array}{c}-3.062960 / \text { - } \\
59.950434 \\
\end{array}$ & zona-leste & 150 & 2 \\
\hline 13 & $\begin{array}{c}-3.075378 /- \\
59.955009 \\
\end{array}$ & zona-leste & 180 & 1 \\
\hline 14 & $\begin{array}{c}-3.075872 /- \\
59.957190 \\
\end{array}$ & zona-leste & 160 & 1 \\
\hline 15 & $\begin{array}{c}-3.058301- \\
60.006438 \\
\end{array}$ & zona-centro-sul & 170 & 1 \\
\hline 16 & $\begin{array}{c}-3.066278 / \text { - } \\
59.990212 \\
\end{array}$ & zona-centro-sul & 140 & 2 \\
\hline 17 & $\begin{array}{c}-3.081527 / \text { - } \\
60.024595 \\
\end{array}$ & zona-centro-sul & 160 & 1 \\
\hline 18 & $\begin{array}{c}-3.091780 / \text { - } \\
60.017621 \\
\end{array}$ & zona-centro-sul & 160 & 1 \\
\hline 19 & $\begin{array}{c}-3.093316 /- \\
60.021974 \\
\end{array}$ & zona-centro-sul & 160 & 1 \\
\hline 20 & $\begin{array}{c}-3.091220 /- \\
60.017978 \\
\end{array}$ & zona-oeste & 120 & 1 \\
\hline 21 & $\begin{array}{c}-3.094113 /- \\
60.009411 \\
\end{array}$ & zona-centro-sul & 100 & 2 \\
\hline 22 & $\begin{array}{c}-3.104551 /- \\
60.026484 \\
\end{array}$ & zona-centro-sul & 120 & 2 \\
\hline 23 & $\begin{array}{c}-3.104443 /- \\
60.012300 \\
\end{array}$ & zona-centro-sul & 160 & 2 \\
\hline 24 & $\begin{array}{c}-3.101366 /- \\
60.056590 \\
\end{array}$ & zona-oeste & 140 & 2 \\
\hline 25 & $\begin{array}{c}-3.101133 /- \\
60.053886\end{array}$ & zona-oeste & 160 & 2 \\
\hline 26 & $\begin{array}{c}-3.107280 /- \\
60.053046 \\
\end{array}$ & zona-oeste & 160 & 1 \\
\hline 27 & $\begin{array}{c}-3.125645 /- \\
60.026459 \\
\end{array}$ & zona-centro-sul & 160 & 1 \\
\hline 28 & $\begin{array}{c}-3.129877 / \text { - } \\
60.023451 \\
\end{array}$ & zona-sul & 180 & 1 \\
\hline 29 & $\begin{array}{c}-3.127342 /- \\
60.006121 \\
\end{array}$ & zona-sul & 120 & 2 \\
\hline 30 & $\begin{array}{c}-3.128988 / \text { - } \\
59.997934 \\
\end{array}$ & zona-sul & 90 & 2 \\
\hline
\end{tabular}

Os pontos coletáveis, descritos na tabela 1, foram inseridos utilizando latitude e longitude de suas coordenadas geográficas e foram separados em regiões, sendo estas 
denominadas: norte, leste, centro-sul, oeste e sul dentro da cidade de Manaus. A figura 3 mostra os pontos dispostos no mapa.

Figura 3 - Pontos coletáveis exibidos no mapa de Manaus

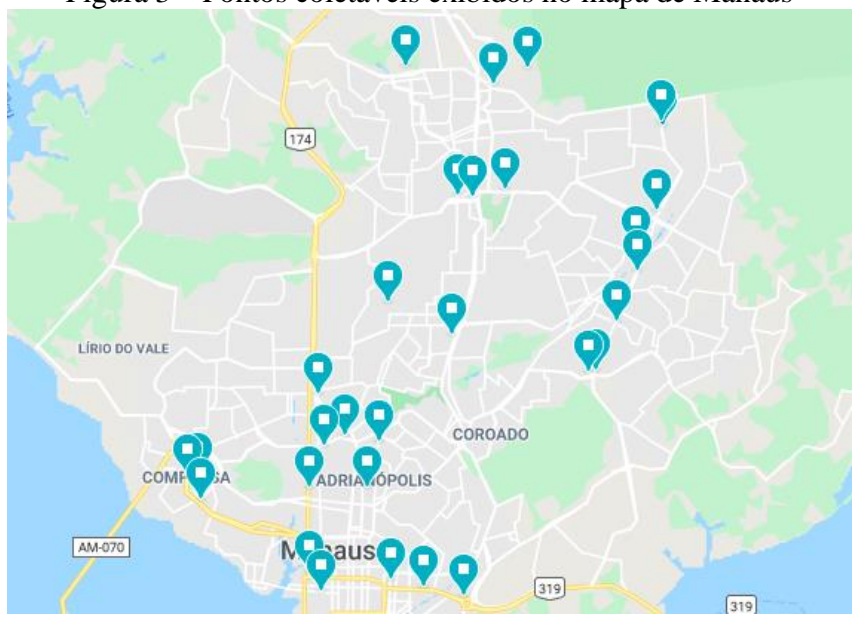

Fonte: Elaboração dos autores.

O algoritmo foi implementado utilizando linguagem JavaScript por meio do framework Node.js em sua versão 10.16.3.

A tabela 2 mostra quais pontos coletáveis pertencem a cada rota, as distâncias necessárias para completar a rota em metros e o tempo total em minutos de cada trajeto com base nas características dos pontos coletáveis da tabela 1 .

Tabela 2 - Rotas geradas pelo algoritmo.

\begin{tabular}{cccc}
\hline Rota & $\begin{array}{c}\text { Pontos } \\
\text { Coletáveis (Nro) }\end{array}$ & $\begin{array}{c}\text { Distância } \\
\text { Total }(\mathbf{m})\end{array}$ & $\begin{array}{c}\text { Tempo Total } \\
\text { Aproximado } \\
(\mathbf{m i n})\end{array}$ \\
\hline 1 & $3,7,6$ & 34000 & 59 \\
2 & $8,4,5,10,2$ & 52200 & 87 \\
\hline 3 & $11,12,14$ & 26000 & 53 \\
\hline 4 & 13,9 & 29000 & 54 \\
\hline 5 & $16,21,23$ & 22900 & 41 \\
\hline 6 & $17,19,22,18$ & 16600 & 38 \\
\hline 7 & 27,15 & 25700 & 51 \\
\hline 8 & $26,25,24,20$ & 18600 & 39 \\
\hline 9 & $29,30,28$ & 17600 & 47 \\
\hline
\end{tabular}

A distância total e o tempo total aproximado mostrados na tabela 2 foram obtidos utilizando a API de mapas do Google para direções, que permite entrar com uma origem e um destino e uma lista de paradas em formato de latitude e longitude. $\mathrm{O}$ tempo mostrado não leva em consideração o período em que o caminhão coletor ficará estacionado para realizar o recolhimento dos resíduos dos pontos coletáveis.

\section{CONCLUSÃO}

Algoritmos envolvendo Problema de Roteamento de Veículos são frequentemente usados em aplicações voltados para otimização de rotas e para o desenvolvimento de inovações voltados para sistemas IoT. O algoritmo implementado propõe uma solução para traçar rotas que recebe como entrada a origem, o destino, uma lista de caminhões contendo sua capacidade e uma lista de grafos por região contendo os pontos de coleta (nós do grafo) que combina as heurísticas: orientada a tempo e do vizinho mais próximo.
Para o cenário proposto foi feita a análise dos pontos aptos para coleta, a divisão desses pontos em regiões geográficas, geração do grafo, onde seus nós são os pontos coletáveis e as arestas são as distância entre cada nó e os demais pontos. $\mathrm{O}$ algoritmo dividiu os 30 pontos em 5 regiões geográficas e traçou 9 rotas com caminhões com capacidade de 500 litros para recolher 4382 litros de resíduos em um tempo que varia de 38 a 87 minutos.

Para trabalhos futuros, pretende-se incluir para a soma do tempo total em que o caminhão ficará parado em cada ponto, o que pode ser feito através de uma média probabilística que dependerá de aspectos físicos de como será feita a coleta nos pontos coletáveis, além da utilização de algoritmo genético para a solução do problema de roteamento.

\section{REFERÊNCIAS BIBLIOGRÁFICAS}

CHEN, Shanzhi, et al. A Vision of IoT: Applications, Challenges, and Opportunities With China Perspective. IEEE, 2004.

ARAKAKI, Reinald. Monografia O PROBLEMA DE ROTEAMENTO DE VEÍCULOS E ALGUMAS METAHEURÍSTICAS. Exame de Qualificação do Curso de Computação Aplicada - CAP. 1998.

TILK, Christian et al. Nested branch-and-price-and-cut for vehicle routing problems with multiple resource interdependencies. European Journal of Operational Research, 2019.

TALARI, Saber, et al. A Review of Smart Cities Based on the Internet of Things Concept. Portugal, 2017.

SOLOMON, Marius. Algorithms for the Vehicle Rounting and Scheduling Problems with Time Window Constraints. Massachusetts, 1987.

BAKER, Barrie. A Genetic Algorithm for the Vehicle Routing Problem. Reino Unido, 2003.

MOHAMMED, Mazin. Solving Vehicle Routing Problem by Using Improved K-Nearest Neighbor Algorithm for Best Solution. Journal of Computational Science, 21, 232-240. 2017.

SILVA, Gabriel et al. Algoritmos Heurísticos Construtivos Aplicados ao Problema do Caixeiro Viajante Para Definição de Rotas Otimizadas, 2013.

\section{AGRADECIMENTOS}

Este trabalho conta com o apoio da Samsung Eletrônica da Amazônia Ltda. através da Lei de Informática, AGIN Agência de Inovação da UEA e FUEA - Fundação Universitas de Estudos Amazônicos.

\section{COPYRIGHT}

Direitos autorais: Os autores são os únicos responsáveis pelo material incluído no artigo. 


\title{
Volume $16-\mathrm{N}^{\mathrm{o}} 174$ - Junho / 2020 \\ XLII International Sodebras Congress \\ 28 a 30 de maio de 2020 - Web Conference.
}

\section{UMA APLICAÇÃO IOT COM PROTOCOLO MQTT PERSISTINDO EM MONGODB}

\author{
AN IOT APPLICATION WITH MQTT PROTOCOL PERSISTING IN MONGODB \\ ALBUQUERQUE, Jesus; CHEN, Daniel; BASTOS, Moisés; SOARES, André; VALENZUELA, Walter \\ UNIVERSIDADE DO ESTADO DO AMAZONAS \\ jda.eng17@uea.edu.br;dac.eng17@uea.edu.br; \\ mpbastos@uea.edu.br;alsoares@uea.edu.br;wvalenzuela@uea.edu.br
}

\begin{abstract}
Resumo - O protocolo de mensagem MQTT é uma ótima maneira de realizar uma interconexão de dados entre sistemas, utilizandoo junto com um banco de dados e uma maneira de produzir informações, é possível criar facilmente uma aplicação de Internet das Coisas (IoT). Esse trabalho realizou testes e simulações qualitativas para certificar se esse conjunto de protocolos $e$ sistemas são uma boa opção para desenvolvimento de aplicações IoT. Como resultado, foi possível ratificar seu desempenho, concluindo que o uso do protocolo MQTT junto com o servidor de dados MongoDB constitui-se em um modo rápido e simples de desenvolver uma aplicação para emprego em IoT, parte da indústria 4.0. Além disso, concluiu-se que o uso de um banco de dados não estruturado como o MongoDB é mais vantajoso em um cenário de informações incertas, como o IoT $e$ seus microcontroladores, do que o banco de dados estruturado. Palavras-chave: MQTT. MongoDB. Internet of Things.
\end{abstract}

Abstract - The MQTT message protocol is a great way to perform data interconnection between systems, using it together with a database and a way to produce information, it is possible to easily create an easy Internet of Things (IoT) application. This article performs qualitative tests and simulations to see if this set of protocols and systems are a good option for IoT application development. As a result, it was possible to confirm its performance, concluding that MQTT together with MongoDB is a quick and simple way to develop an application for use in an IoT environment, part of industry 4.0. Furthermore, it was concluded that the use of an unstructured database as MongoDB is more advantageous in an uncertain information scenario, such as IoT and its micro controllers, than the structured database. Keywords: MQTT. MongoDB. Internet of Things.

\section{INTRODUÇÃO}

Desde o surgimento da Internet em 1969, tendo seu uso comercial autorizado em 1987 até meados dos anos 90, o seu crescimento foi dado de maneira estática. Com a evolução tecnológica no final do primeiro milênio, a Internet popularizou-se de forma exponencial (FAROOQ; et. al., 2015). Até então, como explica CARVALHO (2017), existia no mundo uma internet sem "coisas", não estávamos tão conectados, e certamente não éramos.

$\mathrm{O}$ conceito de Internet das Coisas (IoT) foi proposto pelo pesquisador do MIT Kevin Ashton, em 1999 (ASHTON, 2009). Como já mencionado, havia no mundo uma internet sem "coisas", ou seja, não havia interruptores de luz, sensores conectados à internet ou câmeras Wi-Fi. Como os seres humanos e o ambiente que os cercam são físicos, toda a sociedade é baseada em coisas. E foram essas coisas, no sentido abstrato propositalmente, segundo CAINÃ,
OLIVEIRA e MOTÁ (2018), designando qualquer entidade física que pode interagir pela Internet (MEDEIROS; et. al., 2018), que foram capazes de alimentar os computadores com os mais diversos tipos de informação a serem utilizadas posteriormente.

Para que essas informações sejam transmitidas entres as mais variadas entidades, protocolos foram desenvolvidos para atender a demanda de IoT. Um dos mais utilizados é o MQTT devido às suas características de fácil implementação, conexões entre os clientes assíncronas e por atender a dispositivos de baixa potência como sensores e microcontroladores, estes essenciais dentro da área de IoT, conforme observado por NEPOMUCENO (2020).

Há ainda neste contexto de manuseio de informações por computadores uma terceira preocupação: como são gerados muitos dados para processamento (SOLAGNA; LAZZARETTI, 2016), é necessário um local para armazenar adequadamente todo esse conjunto de registros e, posteriormente, acessá-los para tratá-los, recuperando-os.

As operações fundamentais de armazenamento e recuperação de informações são feitas em um Banco de Dados. Em IoT, por se tratar de ecossistemas digitais com diferentes entidades em que seus dados não necessariamente possuem relacionamentos e havendo a preocupação de que alguns registros são mais importantes que outros, o emprego de Banco de Dados Não Relacionais é mais vantajoso. Um deles é o MongoDB (FERREIRA, 2018), presente nesse trabalho.

O MongoDB é um software de Sistema de Gerenciamento de Banco de Dados (SGBD) criado em 2009 pela empresa de mesmo nome (MONGODB, 2020). O software utiliza conceitos de Banco de Dados Relacionais, como índices e consultas, e Não Relacionais como orientação a documentos livres e hierarquias complexas.

Neste trabalho, será realizada uma aplicação prática de um ambiente de Internet das Coisas, utilizando entidades que se comunicarão entre si pelo protocolo de mensagens MQTT. As informações produzidas por elas serão, por fim, armazenadas no Banco de Dados MongoDB adequadamente.

\section{REFERÊNCIA TEÓRICA}

\section{$2.1-M Q T T$}

Message Queuing Telemetry Transport é um protocolo de mensagens M2M (Machine-to-Machine) baseado em TCP/IP no qual tópicos são gerenciados por um broker, 
clientes publicadores enviam informações para eles e clientes inscritos as recebem. O MQTT se preocupa com a integridade de informações trocadas a partir da funcionalidade de Qualidade de Serviço (QoS). Também suporta encriptação fornecida pelo protocolo de segurança TLS nas comunicações sobre redes de computadores (KONESKI, 2018). Toda essa implementação é desenvolvida para atender baixas demandas de energia como dispositivos de pequeno porte tais como sensores e microcontroladores (GARCIA, P.; KLEINSCHMIDT, 2017), sem comprometer o desempenho desejado das aplicações que utilizam o MQTT como protocolo, analisado por TORRES, ROCHA e DE SOUZA (2016).

\section{2 - MongoDB}

O MongoDB é um Banco de Dados NoSQL, ou Não Relacional, de código aberto, orientado a documentos. Os documentos são baseados em JSON (JavaScript Object Notation) em modo binário. Essa característica possibilita armazenar os dados com hierarquias complexas e serem indexáveis, facilitando as operações de busca. Além disso, os dados dos documentos são desestruturados, o que seria um problema para os Bancos de Dados Relacionais, mas não para o MongoDB. Como explicam POLITOWSKI e MARAN (2014), os documentos podem ser armazenados em coleções (collections), onde serão efetuadas operações de busca (queries) e indexação (indexing). Queries são expressas na sintaxe JSON e enviadas ao MongoDB como objetos BSON pelo driver de conexão ao banco (BSON, 2020).

Com isso, o banco foi projetado para suportar a carga de informações de Big Data e, portanto, possui uma relação bem íntima com Internet das Coisas. Aplicações que trabalhem com JSON nativo como Node.js e outras tecnologias baseadas em JavaScript como softwares de celulares e ambientes Web são altamente recomendadas para utilizar MongoDB.

\section{3 - IoT (Internet of Things).}

Internet das Coisas designa os ecossistemas digitais compostos por máquinas, dispositivos e seres humanos que compartilham informações entre si e atuam para alcançarem objetivos individuais ou que interessem um grupo (MANO; et. al., 2016). Outros termos como Cidades Inteligentes (Smart Cities) e Sistemas Ciber-Físicos trabalham e até compartilham definições com IoT visto que todos estes possuem a filosofia de que há coisas que se comunicam utilizando o protocolo de Internet.

\section{METODOLOGIA}

Para o desenvolvimento deste estudo foi definida uma simulação de um sistema IoT de Monitoramento da temperatura ambiente de três cômodos de uma residência. Nesse sistema, os sensores enviam os dados via MQTT que são persistidos no MongoDB que está hospedado em um servidor em nuvem (cloud Server), caracterizando assim uma aplicação IoT. Utiliza-se um cenário simulado pois os sensores não foram implementados fisicamente. Com isso este sistema utiliza dados arbitrários/aleatórios simulando uma medição remota. $\mathrm{O}$ esquema do sistema é ilustrado pela figura 1 abaixo.
Figura 1 - Diagrama do cenário de testes MQTT

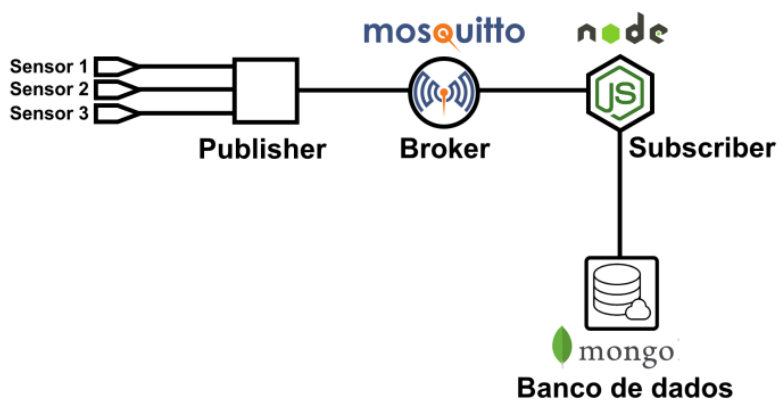

Fonte: Os autores

\section{1 - Sistema MQTT}

O sistema MQTT foi desenvolvido com base nos três componentes principais do protocolo: o assinante, o publicador e o broker (AL-FUQAHA, 2015). A primeira parte do sistema consiste em um cliente MQTT publisher denominado "Cômodos" e conectado ao broker central. O cliente "Cômodos", por sua vez, está recebendo informações de três sensores de temperatura ambiente de cômodos espalhados por uma residência. $\mathrm{O}$ publisher foi implementado utilizando o broker Mosquitto, desenvolvido pela Oracle. As informações dos cômodos estão organizadas em formato compacto JSON, conforme a seguir:

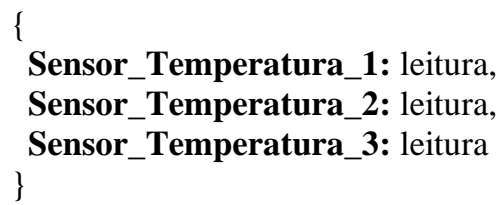

Os sensores de temperatura servem para simular os três cômodos da residência. No cenário do estudo proposto, também será simulada a ocorrência de algumas falhas na leitura dos sensores, condição essa melhor explicada posteriormente.

Além disso, o cliente "Cômodos" está inscrito no tópico "residencia1/comodos/temperatura" do broker. A utilização dos tópicos presentes no broker é bastante intuitiva. Neste caso, em umas das residências, no caso a residência 1, no tópico "cômodos", as temperaturas estão sendo enviadas para o broker. Essa relação do publisher e o broker está ilustrada na Figura 1.

O broker, também implementado utilizando o Mosquito através de um Terminal do Windows, funciona como o intermediador que recebe as informações de diversos clientes publishers, as organiza e transmite para todos os clientes subscribers que estão utilizando os mesmos tópicos. Outro ponto importante do broker é que ele possui a funcionalidade de Qualidade de Serviço (QoS) utilizada para assegurar a integridade dos dados que estão sendo enviados e recebidos. Neste caso de emprego em IoT, como existe um grande fluxo de informações, é comum algum atributo dentro dos pacotes trocados pelas entidades perder-se devido ao tráfego de informações. Por isso o QoS (Quality do Serviço) de todas as entidades do MQTT foram configurados para 0 , sendo essa a configuração mais baixa para a segurança da integridade dos dados.

Conforme a figura 1, a última entidade do Sistema MQTT presente no cenário IoT é o outro cliente 
Intermediário MQTT subscriber também conectado no broker. Ele está inscrito utilizando tópico do publisher "residencia1/comodos/\#”. O símbolo '\#' significa que ele receberá as informações de todos os sensores da casa, ou seja, de todos os subtópicos de "comodos/".

\section{2 - Cliente Intermediário}

Depois de receber os dados, o cliente Intermediário persistirá no MongoDB. Como ele ao mesmo tempo recebe informações do broker e envia para o banco de dados, o mesmo foi desenvolvido utilizando-se o framework NodeJs.

\subsection{1 - Recebendo as informações}

Observa-se o código-fonte em JavaScript responsável pela comunicação do cliente Intermediário com o broker do sistema na figura 2. Inicialmente é feito o requerimento dos módulos que implementam as funcionalidades necessárias para se trabalhar com MQTT e MongoDB. Em seguida, a conexão com o banco é realizada através do endereço disponibilizado pela MongoDB no Website. Por fim, a conexão com o broker também é estabelecida a partir do host e porta de acesso. No método 'subscribe' do cliente instanciado, o tópico "residencia1/comodos/\#” e o QoS do serviço são configurados.

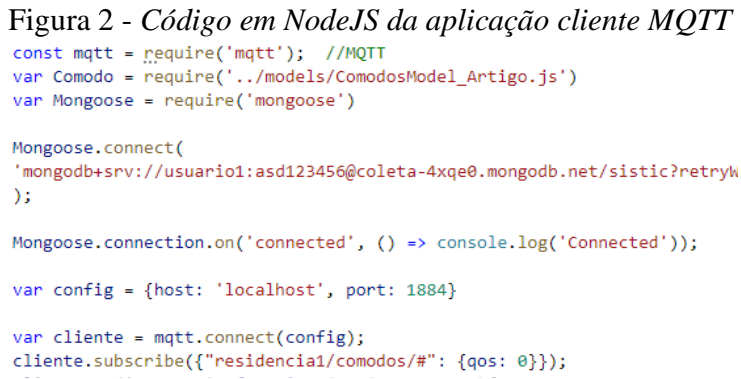

Fonte: Os autores

\subsection{2 - Armazenando as informações}

Nessa etapa, apresentada na figura 3, o cliente inscrito aguardará as informações vindas do broker. Ao serem recebidas, as mensagens serão convertidas primeiramente para formato String e depois para JSON. Após isso, a lógica para armazenamento no MongoDB foi implementada juntamente com algumas mensagens no console. Como o QoS foi configurado para 0 , pode ser que algum sensor não leia corretamente a temperatura ou no pior dos cenários não leia nada. Neste caso, como as informações do MongoDB são desestruturadas, não há problema em armazená-las nos documentos.

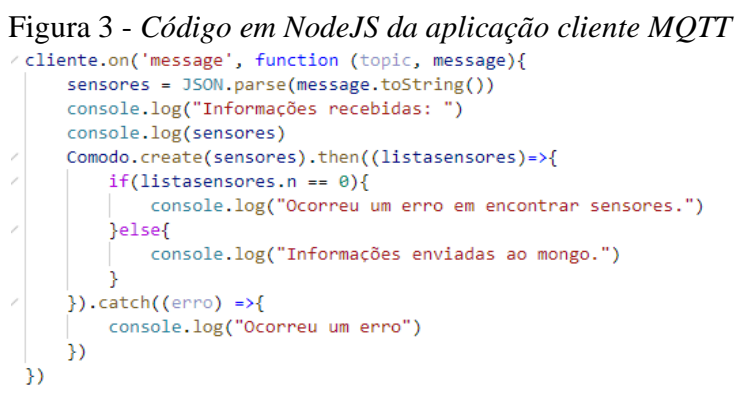

Fonte: Os autores
Para a implementação do banco de dados, foi utilizada uma instância do MongoDB através uma conta criada gratuitamente na sua plataforma Web Mongo Atlas.

\section{4 - Inicialização das entidades}

Primeiramente, foi criada uma simulação que reproduziu o diagrama da Figura 1. Portanto, dentro do Prompt de Comando, o Mosquitto Broker foi iniciado utilizando o comando mosquitto -v -p 1884 (-v inicia o broker com as configurações padrões; -p escolhe a porta do broker) conforme figura 4.

Figura 4 - Inicialização do Broker MQTT

C: \Users\Sword>mosquitto -p $1884-v$

1582908664: mosquitto version 1.6 .8 starting

1582908664: Using default config.

1582908664: Opening ipv6 listen socket on port 1884.

1582908664: Opening ipv4 listen socket on port 1884.

Fonte: Os autores

Em seguida, na figura 5, a aplicação NodeJS criada serve de subscriber para o ambiente de simulação. Para se inicializar, foi utilizado nodemon, uma biblioteca npm do NodeJS. Não entraremos em muitos detalhes, mas essa biblioteca facilita a simulação, pois permite iniciar o sistema sempre que este é salvo.

Figura 5 - Inicialização da aplicação NodeJS C: \Users \Sword \Documents $\backslash$ ProgramasApp \sistic_backe nd \app\controllers>nodemon ClienteMQTT_Artigo.js [nodemon] 2.0.2 [nodemon] to restart at any time, enter 'rs [nodemon] watching $\operatorname{dir}(s):{ }^{*} . *$ [nodemon] watching extensions: js,mjs,json [nodemon] starting "node ClienteMQTT_Artigo.js Connected

Fonte: Os autores

Assim que esses dois elementos supracitados foram inicializados, a simulação pode prosseguir com o envio de mensagens. Para enviar as mensagens, o MQTT junto com uma formatação em JSON foi utilizado: mosquitto_pub -h localhost -p 1884 -t residencia1/comodos/temperaturas $-q$ $0-\mathrm{m}$ “\{\"Sensor_Temperatura_XI": Y $\}$ "

Onde:

- Mosquitto_pub é o comando publicador

- -h indica o host a ser mandado, localhost no caso

- -p indica a porta de entrada

- -t indica o tópico e subtópicos

- -q indica o QoS usado

- -m indica a mensagem em si, ela foi propositalmente escrita para ser reconhecida como JSON.

A propósito de testes, o conteúdo das três mensagens foi diferente. Isto está representado na figura 6. No primeiro envio de leitura dos sensores, as três informações foram enviadas: 25, 28 e 30 do sensor 1, 2 e 3, respectivamente. Já no segundo, os dois primeiros enviaram informação de temperatura: 24 e 27 . No terceiro envio, somente o sensor 1 enviou a informação de 23. 
Figura 6 - Linhas de código utilizado para fazer uma publicação teste MQTT

C: $\backslash$ Users $\backslash$ Sword $\backslash$ Documents $\backslash$ ProgramasApp $\backslash$ sistic_backend \app\controllers>mosquitto_pub - $h$ localhost -p 1884 - $t$ residencia1/comodos/temperaturas - $q 0$-m " $\{\backslash$ "Sens or_Temperatura_1\": 25, \"Sensor_Temperatura_2\": 28 , \"Sensor_temperatura_3\": 30\}"

C: \Users \Sword \Documents $\backslash$ ProgramasApp $\backslash$ sistic backend \app\controllers>mosquitto_pub -h localhost -p 1884 - $t$ residencia1/comodos/temperaturas - q $0-m$ " $\{\backslash$ "Sens or Temperatura $1 \backslash ": 24$, \"Sensor_Temperatura_2\": 27 \}$^{\prime \prime}$

C: \Users \Sword \Documents \ProgramasApp \sistic_backend \app\controllers>mosquitto_pub - h localhost -p 1884 -t residencia1/comodos/temperaturas - $\mathrm{q} \theta-\mathrm{m} "\{\backslash$ "Sens or_Temperatura_1\": 23$\} "$

Fonte: Os autores

\section{RESULTADOS}

Após a inicialização do broker e da aplicação (figuras 4 e 5, respectivamente) é possível perceber por meio da figura 7 que houve uma alteração no broker. Tal alteração é apresentada pelo fato de que a aplicação se inscreveu no broker, causando o comportamento mostrado na figura 7 , confirmada pelo comando "New connection from 127.0.01 on port 1884.".

Figura 7 - Reação do broker ao ser inicializado e receber a inscrição

C: \Users \Sword>mosquitto -p 1884 -v

1582914543: mosquitto version 1.6 .8 starting

1582914543: Using default config.

1582914543: Opening ipv6 listen socket on port 1884.

1582914543: Opening ipv4 listen socket on port 1884.

1582914543: New connection from 127.0.0.1 on port 1884

1582914543: New client connected from 127.0.0.1 as mqt tjs_a072410c (p2, c1, k60).

1582914543: No will message specified.

1582914543: Sending CONNACK to mqttjs ae72410c $(\theta, \theta)$

1582914543: Received SUBSCRIBE from mqttjs_a072410c

1582914543: residencia1/comodos/\# (QOS $\theta$ )

1582914543: mqttjs a072410c $\theta$ residencia1/comodos/\#

1582914543: Sending SUBACK to mqttjs_a072410c

Fonte: Os autores

Em seguida, as mensagens da figura 6 foram enviadas, causando certas mudanças no Prompt de comando da aplicação. As mudanças, basicamente, são sinais que as mensagens foram bem-sucedidas. Tudo isso foi ilustrado na figura 8, que apresenta a mensagem "Informações recebidas". Em seguida, o sistema informa os dados recebidos e confirma o envio ao MongoDB.
Figura 8 - Resposta da aplicação ao receber a mensagem MQTT

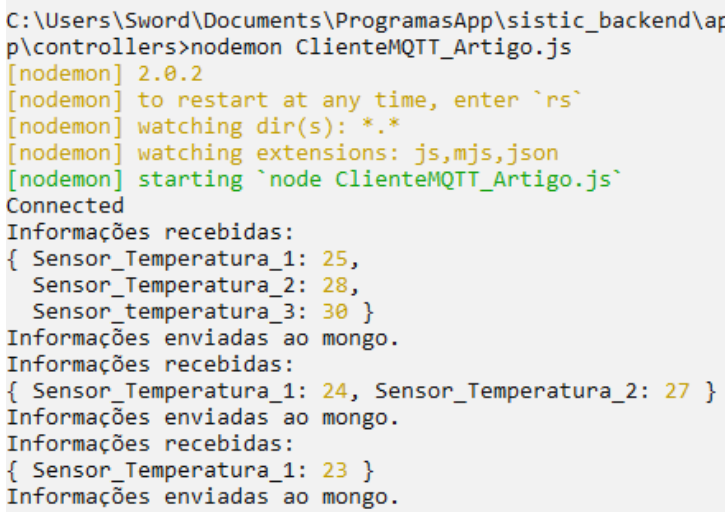

Fonte: Os autores

Por fim, entrou-se no site web do Mongo Atlas, onde podemos perceber que as mensagens e aplicações foram bemsucedidas nos testes: recebendo informações pelo broker, enviando-as até a aplicação (subscriber) e guardando-os no banco de dados. É possível visualizar este cenário por meio do banco de dados mongo na figura 9 .

Figura 9 - Imagem do banco MONGODB

\section{QUERY RESULTS 1-3 OF 3}

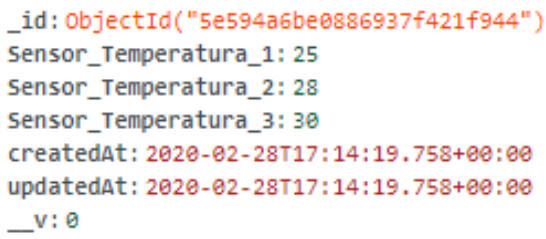

_id: ObjectId("5e594a82e0886937f421 f945") Sensor_Temperatura_1: 24

Sensor_Temperatura_2: 27

createdat: $2020-02-28 T 17: 14: 42.040+00: 00$ updatedat : 2020-02-28T17:14:42.040+e0:00 -v: $\theta$

\begin{abstract}
_id: ObjectId("5e594a92e0886937f421 f946") Sensor_Temperatura_1: 23

createdAt: $2020-02-28 T 17: 14: 58.241+00: 00$ updatedat: $2020-02-28 \mathrm{~T} 17: 14: 58.241+e 0: 00$ v: $\theta$
\end{abstract}

Fonte: Os autores

\section{CONCLUSÃO}

Pelos resultados obtidos, observamos que é possível criar aplicações para a indústria 4.0, utilizando poucos recursos. Usando um protocolo de informações como o MQTT e um banco de dados (MongoDB, no caso), neste trabalho conseguimos criar um simples processo de IoT, guardando informações externas para que elas possam ser utilizadas mais tarde. 
Além disso, através dos resultados, conclui-se que um banco de dados não estruturado é muito útil para IoT, pois se tivesse sido utilizado um banco de dados estruturado como um banco de dados relacional SQL, o sistema não reconheceria as várias nuances de possíveis mensagens que podem ocorrer. Por exemplo, durante a metodologia, foram enviadas três mensagens de conteúdos diferentes e elas foram todas aceitas. Se fosse utilizada linguagem SQL, as tratativas seriam mais complexas. Como outros sistemas irão tratar essas mensagens não está no escopo deste trabalho.

\section{REFERÊNCIAS BIBLIOGRÁFICAS}

Ala AL-FUQAHA, Senior Member, IEEE, et al. Internet of Things: A Survey on Enabling Technologies, Protocols, and Applications. IEEE COMMUNICATION SURVEYS \&amp; TUTORIALS, VOL. 17, NO. 4, FOURTH QUARTER 2015

Ashton, Kevin. That 'Internet of Things' thing. RFID Journal, 2009. Disponível em <http://www.rfidjournal.com/article/view/4986>. Acesso em 28 jun. 2020.

BSON Webpage. Disponível em <http://bsonspec.org/> Acesso em 20 jan. 2020.

CAINÃ, L.; OLIVEIRA, L.; MOTÁ, S. Internet das coisas (IOT): um estudo exploratório em agronegócios. VI Simpósio da Ciência do Agronegócio, 2018.

CARVALHO, M. ELFA MONITORING SYSTEMS: UM SISTEMA DE MONITORAMENTO DE PESSOAS IDOSAS POR MEIO DE SENSORES, UTILIZANDO INTERNET DAS COISAS. Universidade do Estado do Rio Grande do Norte. Programa de Pós-Graduação em Ciência da Computação, 2019.

FERREIRA, L. As diferenças entre SQL e NoSQL: MySQL x MongoDB. Medium, 2018. Disponível em <https://medium.com/devtranslate/diferencas-entre-sql-enosql-51311f9069bd>. Acesso em 20 jan. 2020.

GARCIA, P.; KLEINSCHMIDT, J. Tecnologias Emergentes de Conectividade na IoT: Estudo de Redes LPWAN. XXXV SIMPÓSIO BRASILEIRO DE TELECOMUNICAÇÕES E PROCESSAMENTO DE SINAIS, 2017.

KONESKI, E. Ambiente de comunicação segura de Internet das Coisas com a utilização do MQTT e TLS. Universidade Federal de Santa Catarina, 2018.

MANO, L.; VOLPANO, T.; FUNES, M.; NETO, J. Explorando tecnologias de IoT no contexto de Health Smart Home: uma abordagem para detecção de quedas em pessoas idosas. JADI - Marília - v. 2, 2016.

MEDEIROS, F.; COLPO, I.; SCHNEIDER, V.; CARVALHO, P. INTERNET OF THINGS: UMA INVESTIGAÇÃO DO CONHECIMENTO CIENTÍFICO EM ARTIGOS ACADÊMICOS NA ÚLTIMA DÉCADA. Revista Eletrônica de Administração e Turismo (ReAT), 2018.

MONGODB Official Webpage. Disponível em <https://www.mongodb.com/>. Acesso em 20 jan. 2020.
MQTT Official Webpage. Disponível em

<http://mqtt.org/faq>. Acessado em 11/09/2019

NEPOMUCENO, C., UMA ABORDAGEM TEÓRICA E PRÁTICA EM UM PROTOCOLO PARA IOT. XLI International Sodebras Congress, $\mathrm{N}^{\circ}$ 169, 2020.

POLITOWSKI, C.; MARAN, V. Comparação de Performance entre PostgreSQL e MongoDB. Departamento de Ciências Exatas e Engenharias Universidade Regional ^ do Noroeste do Estado do Rio Grande do Sul, 2014.

TORRES, A. B. B.; ROCHA, A. R.; DE SOUZA, J. N.

\section{ANÁLISE DE DESEMPENHO DE BROKERS MQTT} EM SISTEMA DE BAIXO CUSTO. In Anais do XXXVI congresso da sociedade brasileira de computação, 2016.

SOLAGNA, E.; LAZZARETTI A. UM ESTUDO COMPARATIVO ENTRE O MONGODB E O POSTGRESQL. Trabalho de Conclusão de Curso (TCC) Instituto Federal Sul-Rio-Grandense, 2016.

U.Farooq, M., Waseem, M., Mazhar, S., Khairi, A., \& Kamal, T. (2015). A Review on Internet of Things (IoT). International Journal of Computer Applications, 113(1), 1-7. https://doi.org/10.5120/19787-1571

\section{AGRADECIMENTOS}

Este trabalho conta com o apoio da Samsung Eletrônica da Amazônia Ltda. através da Lei de Informática, AGIN Agência de Inovação da UEA e FUEA - Fundação Universitas de Estudos Amazônicos.

\section{COPYRIGHT}

Direitos autorais: Os autores são os únicos responsáveis pelo material incluído no artigo. 


\section{Área: Ciências Humanas e Sociais}

\begin{tabular}{|c|c|}
\hline $6-1$ & $\begin{array}{l}\text { A (IN)COMPATIBILIDADE DO } \text { DIREITO DE DESCONEXÃO COM O } \\
\text { TELETRABALHO } \\
\text { THE (IN)COMPATIBILITY OF THE RIGHT OF DISCONNECTION WITH } \\
\text { TELEWORK } \\
\begin{array}{l}\text { Amanda Ferreir Primo; Luana Esteche Nunes Korocoski; Luiz Eduardo Dos Santos } \\
\text { Pereira Gomes; Thiago Andre Fonseca Dos Santos }\end{array}\end{array}$ \\
\hline 6-1 & $\begin{array}{l}\text { A MANIFESTAÇÃO DE VONTADE CONTRATUAL NOS APLICATIVOS, FRENTE } \\
\text { AO CÓDIGO DE DEFESA DO CONSUMIDOR } \\
\text { THE EXPRESSION OF CONTRACTUAL WILL IN APPLICATIONS AND } \\
\text { CONSUMER DEFENSE CODE } \\
\text { Luana Esteche Nunes Korocoski; Thiago Andre Fonseca Santos; Luiz Eduardo Dos } \\
\text { Santos Pereira Gomes; Amanda Ferreira Primo }\end{array}$ \\
\hline $6-1$ & $\begin{array}{l}\text { VALIDADE DO RECONHECIMENTO POR FOTOGRAFIA COMO MEIO DE PROVA } \\
\text { NO PROCESSO PENAL } \\
\text { VALIDITY OF RECOGNITION BY PHOTOGRAPH AS A MEANS OF PROOF IN } \\
\text { CRIMINAL PROCEEDINGS } \\
\text { Luana Esteche Nunes Korocoski; Thiago Andre Fonseca Santos; Luiz Eduardo Dos } \\
\text { Santos Pereira Gomes; Amanda Ferreira Primo }\end{array}$ \\
\hline $6-2$ & $\begin{array}{l}\text { INOVAÇÃO ABERTA NA GESTÃO PÚBLICA: O PAPEL DAS UNIVERSIDADES } \\
\text { PÚBLICAS PARA UMA MELHOR EFICIÉNCIA DO ESTADO } \\
\text { OPEN INNOVATION IN PUBLIC MANAGEMENT: THE ROLE OF PUBLIC } \\
\text { UNIVERSITIES FOR BETTER EFFICIENCY IN THE STATE } \\
\text { Daiane Tieme Kawahara Paiva; Ronie Galeano }\end{array}$ \\
\hline
\end{tabular}




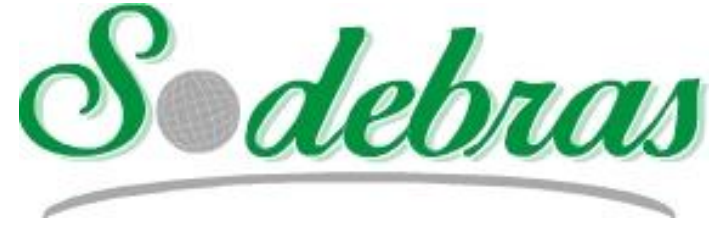

Volume $16-\mathrm{N}^{\circ} 174$ - Junho / 2020

XLII InternationalSodebrasCongress

28 a 30 de maio de 2020 - Web Conference.

\title{
A (IN)COMPATIBILIDADE DO DIREITO DE DESCONEXÃO COM O TELETRABALHO
}

\section{THE (IN)COMPATIBILITY OF THE RIGHT OF DISCONNECTION WITH TELEWORK}

\author{
AMANDA FERREIR PRIMO푼 LUANA ESTECHE NUNES KOROCOSKI²; LUIZ EDUARDO DOS \\ SANTOS PEREIRA GOMES ${ }^{3}$; THIAGO ANDRE FONSECA DOS SANTOS ${ }^{4}$

\section{1 - ESCOLA ASSOC. DOS MAGISTRADOS DO PR; 2 - UNIVERSIDADE ESTADUAL DO CENTRO- OESTE; 3 - CENTRO UNVERSITARIO DO LESTE MINEIRO; 4 - FACULDADE ESTACIO DE SÁ DE SERGIPE}

amandafprimo@hotmail.com; luanaesteche@yahoo.com.br; eduardo.ilheus@bol.com.br; thiagofonseca349@gmail.com

\begin{abstract}
Resumo - O presente artigo procura analisar a existência de compatibilidade ou não entre o direito de desconexão do empregado e a modalidade de prestação de teletrabalho, no direito brasileiro. A tecnologia foi incluída dentro da relação de trabalho como mecanismo de auxílio ao homem e sua mão de obra, o que por vezes facilita o exercício do labor, bem como a comunicação entre empregado e empregador. Entretanto, a internet também vem sendo utilizada como lazer fora de horário de trabalho, mantendo o trabalhador conectado, mesmo após sua desconexão física do ambiente em que presta seus serviços. A situação se agrava diante da implementação da modalidade de teletrabalho, onde o empregado necessita da internet para prestar seus serviços. Assim, este artigo aponta a limitação dos empregadores no uso da tecnologia para o trabalho, qual seja o respeito ao direito de desconexão do empregado.
\end{abstract}

Palavras-chave: Teletrabalho. Direito de desconexão. Tecnologia.

Abstract - This article seeks to analyze the compatibility or not between the employee's right to disconnect and the type of teleworking provision, under Brazilian law. Technology was included within the employment relationship as a mechanism to help man and his workforce, which sometimes facilitates the exercise of labor, as well as communication between employee and employer. However, the internet has also been used as leisure outside working hours, keeping workers connected, even after their physical disconnection from the environment in which they provide their services. The situation is aggravated by the implementation of the telework modality, where the employee needs the internet to provide his services. Thus, this article points out the employers' limitation in the use of technology for work, which is respect for the right of disconnection.

Keywords: Teleworking. Right of disconnection. Technology.

\section{INTRODUÇÃO}

Indiscutivelmente a tecnologia está cada vez mais presente em nossas vidas, não nos admira que ela venha a ser

${ }^{1}$ MELO, Sandro Nahmias. Teletrabalho, controle de jornada e direito à desconexão. adotada como forma do exercício do trabalho. Exemplo disso, é a reforma trabalhista $n^{\circ} 13.467 / 2017$ a qual incluiu como nova modalidade de exercício do labor, o teletrabalho, que se define pela prestação de serviços fora das dependências da empresa, através da utilização dos meios de tecnologia de comunicação e informação.

Ocorre que, apesar da necessidade da tecnologia é direito do empregado, fora do seu horário de trabalho, a desconexão, direito conceituado por Sandro Nahmias Melo (2019, p.90), como o desligamento físico e mental do trabalho. ${ }^{1}$ Todavia, este direito vem sendo cada vez menos observado pelos empregadores em razão da facilidade de comunicação pelas redes sociais.

Em razão deste fato, através de uma pesquisa hipotéticadedutiva, esclarecida por Antonio Carlos Gil como uma pesquisa que consiste na análise de situações hipotéticas e dedução das possíveis consequências ${ }^{2}$, estuda-se a possibilidade de compatibilidade do direito de desconexão com a prestação de serviços pela modalidade de teletrabalho, uma vez que pelo teletrabalho o empregado encontra-se conectado com a empresa através dos meios sociais, muitas vezes pessoais, dos quais não se tem controle da jornada de trabalho praticada bem como limitação entre vida profissional e vida privada.

\section{METODOLOGIA}

No artigo utilizou-se o método hipotético-dedutivo, levantadas conjecturas com base em hipóteses. Analisou-se a possibilidade de compatibilidade ou não entre a modalidade do "teletrabalho" e o direito de desconexão do empregado.

<http://www.mflip.com.br/pub/escolajudicial/?numero=75\&edicao $=11020$ \#page/80> Acesso em: 11 de fev. De 2020.

${ }^{2}$ GIL, Antonio Carlos. Métodos e técnicas de pesquisa social. São Paulo: Atlas, 1999. p. 30. 
De forma complementar, realizou-se pesquisa bibliográfica quanto aos conceitos dos direitos analisados "teletrabalho" e "direito de desconexão", com busca de artigos científicos e doutrina do tema.

\section{RESULTADOS}

A Constituição da República Federativa do Brasil, enumera em seu artigo $7^{\circ}$ os direitos e garantias do empregado, estando entre eles: o horário máximo de trabalho permitido diariamente e o direito ao descanso, conforme o inciso XIII: ${ }^{3}$

XIII - duração do trabalho normal não superior a oito horas diárias e quarenta e quatro semanais, facultada a compensação de horários e a redução da jornada, mediante acordo ou convenção coletiva de trabalho; (Vide Decreto-Lei ${ }^{\circ}$ 5.452, de 1943)

No mesmo sentido, a Consolidação das Leis Trabalhistas prevê os direitos de descanso do empregado, através do intervalo de 01 hora para a alimentação e, dos descansos entre jornadas, de 11 horas entre um dia e outro, bem como o descanso semanal remunerado, conforme artigos 66, 67 e 71, transcritos: ${ }^{4}$

Art. 66 - Entre 2 (duas) jornadas de trabalho haverá um período mínimo de 11 (onze) horas consecutivas para descanso.

Art. 67. É assegurado a todo empregado um repouso semanal remunerado de vinte e quatro horas consecutivas, preferencialmente aos domingos. (Redação dada pela Medida Provisória n ${ }^{\circ}$ 905, de 2019)

[...] Art. 71 - Em qualquer trabalho contínuo, cuja duração exceda de 6 (seis) horas, é obrigatória a concessão de um intervalo para repouso ou alimentação, o qual será, no mínimo, de 1 (uma) hora e, salvo acordo escrito ou contrato coletivo em contrário, não poderá exceder de 2 (duas) horas. $\S 1^{\circ}$ - Não excedendo de 6 (seis) horas o trabalho, será, entretanto, obrigatório um intervalo de 15 (quinze) minutos quando a duração ultrapassar 4 (quatro) horas.

As legislações acima transcritas preveem de forma implícita o direito de desconexão do empregado, o qual é conceituado por Sandro Nahmias Melo (2019, p.90) da seguinte forma: ${ }^{5}$

O direito à desconexão do ambiente de trabalho é inerente a todo e qualquer empregado e consiste no "desligamento", na desconexão, como o próprio nome sugere, tanto físico ou mental, do empregado ao ambiente em que trabalha.

O direito a desconexão é antes de tudo fator de resgate da natureza humana que na era da conexão em tempo integral encontra-se comprometida pelo

\footnotetext{
3 BRASIL. Constituição da RepúblicaFederativa do Brasil de 1988. Brasília, DF. $1988 . \quad$ Disponível em: <http://www.planalto.gov.br/ccivil_03/constituicao/constituicao.htm>Acess oem: 04 abr. 2020.

${ }^{4}$ BRASIL. Decreto Lei ${ }^{\circ}$ 5.452, de $1^{\circ}$ de maio de 1943. Brasília, DF.

1943. Disponívelem: <http://www.planalto.gov.br/ccivil_03/decretolei/del5452.htm>Acessoem: 05 abr. 2020.

${ }^{5}$ MELO, Sandro Nahmias. Teletrabalho, controle de jornada e direito à desconexão. Disponível
}

uso indiscriminado no ambiente laboral das ferramentas telemáticas.

O descanso e o direito a desligar-se do trabalho apresentam-se essenciais ao bem estar físico e mental do trabalhador, importando em sua qualidade de vida e saúde, sendo essencial até mesmo a sua produtividade, importando na defesa de vários direitos constitucionais conexos, como o direito à saúde, ao lazer e ao meio ambiente sadio.

A tecnologia surgiu como forma de facilitar e melhorar os meios de trabalho atuais, entretanto, esta facilidade existente traz como consequência, a possibilidade do contato com o empregado a qualquer momento, ainda que fora do ambiente de trabalho.

No Brasil, o direito à desconexão há muito vem sendo debatido e reconhecido pela jurisprudência, como garantia do empregado, direito esse que deve ter seu debate avivado em função da nova modalidade de labor, veja-se:

TRT-PR-26-10-2007 HORAS DE SOBREAVISO DURANTE OS DIAS DESTINADOS A REPOUSOS REMUNERADOS. DIREITO À DESCONEXÃO DO TRABALHO. Trabalhador que permanece em sobreaviso em dias destinados a repousos remunerados tem direito de receber, concomitantemente, as horas de sobreaviso e o valor correspondente ao repouso semanal remunerado pago de forma simples -, para completar a dobra, em razão do direito à desconexão do trabalho. $\mathrm{O}$ direito à desconexão ao trabalho é presença marcante na doutrina de Jorge Luiz Souto Maior, valendo referir o seguinte excerto: "Dizem que Deus criou o homem à sua imagem e semelhança. $\mathrm{O}$ homem, por sua vez, criou a máquina, mas esta, sem que se perceba, está recriando o homem à sua imagem e semelhança. $\mathrm{Na}$ era da informática, o homem está sendo transformado em sua essência: está se criando o homem cibernético. Se não for, portanto, por uma questão de responsabilidade social, que se pense no problema da desconexão do trabalho, então, como uma forma do homem (enquanto gênero humano) encontrar-se a si mesmo, para que consiga ser pai, mãe, filho, amigo; para que leia livros, assista filmes etc.; para que tenha tempo para rir, chorar, se emocionar... Não se adquire a plenitude do ser sem o sentimento. Este sentimento, aliás, é essencial até mesmo para que, ao retornar ao trabalho, o trabalhador consiga, enfim, enxergar as pessoas que estão à sua volta. A distância do trabalho permite até mesmo que a pessoa se veja no trabalho e consiga, então, avaliar criticamente sua postura, o que é essencial para, por mais paradoxal que pareça, atingir uma melhor eficiência no trabalho, mesmo que não seja este o propósito primordial da presente preocupação."

TRT-PR-04149-2006-663-09-00-4-ACO-31148-

2007 - 2A. TURMA Relator: PAULO RICARDO

POZZOLO Publicado no DJPR em 26-10-2007

<http://www.mflip.com.br/pub/escolajudicial/?numero=75\&edicao=11020 \#page/80> Acesso em: 11 de fev. De 2020

6 BRASIL. Tribunal Regional do Trabalho $9^{\mathrm{a}}$ Região (2 ${ }^{\mathrm{a}}$ Turma). RecursoOrdinário 04149-2006-663-09-00-4. Relator:Paulo Ricardo Pozzolo, 26 de outubro de 2007. Lex: jurisprudência do Tribunal Regional do Trabalho, Curitiba, PR, 2007. Disponívelem: <https://www.trt9.jus.br/basesjuridicas/jurisprudencia.xhtml>Acessoem: 13 abr. 2020 . 


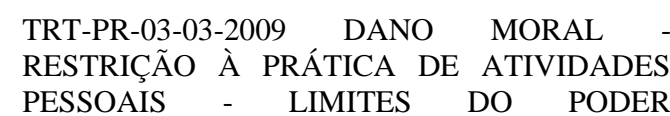
POTESTATIVO - DIREITO À DESCONEXÃO DO TRABALHO - Destaca-se não se olvidar que o cumprimento de metas em qualquer atividade laboral é lícita e imprescindível à organização do trabalho, porém, em nome dela, o empregador não pode ultrapassar os limites do seu poder potestativo, não permitindo ao empregado a desconexão do trabalho após o cumprimento da jornada.

TRT-PR-05990-2007-013-09-00-4-ACO-06812-

2009 - 4A. TURMA Relator: LUIZ CELSO NAPP Publicado no DJPR em 03-03-20097

Em contrapartida, a legislação brasileira, através da Lei $\mathrm{n}^{\circ} 13.467 / 2017$, estabeleceu a possibilidade do teletrabalho como uma modalidade de trabalho, incluindo o capítulo II-A da CLT, o qual conceitua o teletrabalho do artigo 75-B, transcrito: ${ }^{8}$

Art. 75-B. Considera-se teletrabalho a prestação de serviços preponderantemente fora das dependências do empregador, com a utilização de tecnologias de informação e de comunicação que, por sua natureza, não se constituam como trabalho externo. (Incluído pela Lei n ${ }^{\circ} 13.467$, de 2017)(Vigência) Parágrafo único. $\mathrm{O}$ comparecimento às dependências do empregador para a realização de atividades específicas que exijam a presença do empregado no estabelecimento não descaracteriza o regime de teletrabalho. n 13.467, de 2017)(Vigência)

A nível mundial, a Organização Internacional do Trabalho não estabelece uma norma específica sobre o teletrabalho, entretanto, prevê a possibilidade do trabalho a domicílio, conforme Convenção ${ }^{\circ} 177$, artigo $1^{\circ}:^{9}$

A los efectos Del presente Convenio:

(a) La expresión trabajo a domicilio significa El trabajo que una persona, designada como trabajador a domicilio, realiza:

(i) em su domicilio o e notros locales que escoja, distintos de los locales de trabajo de lempleador;

(ii) a cambio de una remuneración;

(iii) com El fin de elaborar um producto o prestar um servicio conforme a lãs especificaciones Del empleador, independientemente de quién proporcione el equipo, los materiales $\mathrm{u}$ otros elementos utilizados para ello,a menos que esa persona tengael grado de autonomía y de independencia económica necesario para ser considerada como trabajador Independiente em virtud de La legislación nacional o de decisiones judiciales;

(b) una persona que tenga La condición de asalariado no se considerará trabajador a domicilio a los efectos del presente Convenio por el mero

7 BRASIL. Tribunal Regional do Trabalho $9^{\mathrm{a}}$ Região (4 $4^{\mathrm{a}}$ Turma) RecursoOrdinário 05990-2007-013-09-00-4. Relator: Luiz Celso Napp, 03 demarço de 2009. Lex: jurisprudência do Tribunal Regional do Trabalho, Curitiba, PR, 2009.2 Disponívelem: <https://www.trt9.jus.br/basesjuridicas/jurisprudencia.xhtml>Acessoem: 13 abr. 2020.

${ }^{8}$ BRASIL. Decreto Lei ${ }^{\circ}$ 5.452, de $1^{\circ}$ de maio de 1943. Brasília, DF.

1943.Disponívelem: <http://www.planalto.gov.br/ccivil_03/decreto-

lei/del5452.htm>Acessoem: 05 abr. 2020. hecho de realizar ocasionalmente su trabajo como asalariado em su domicilio, en vez de realizar lo em su lugar de trabajo habitual;

(c) La palabra empleador significa una persona física o jurídica que, de modo directo o por conducto de um intermediario, esté o no prevista esta figura em La legislación nacional, da trabajo a domicilio por cuenta de su empresa.

Em que pese a Organização Internacional do Trabalho não estabeleça uma legislação específica sobre o teletrabalho, ela permite no âmbito internacional o trabalho realizado na casa do empregado, ou qualquer local diverso a localidade da empregadora, sem que haja a perda do direito potestativo do empregador.

O conceito do trabalho a domicílio descrito pela Organização Mundial do Trabalho, assemelha aos requisitos transcritos por Jouberto de Quadros Pessoa Cavalcante (2019, p.112) ao conceituar o teletrabalho: ${ }^{10}$

Assim, os elementos característicos do teletrabalho são: (a) atividade realizada a distância, ou seja, fora dos limites de onde seus resultados são almejados; (b) as ordens são dadas por quem não tem condições de controlá-las fisicamente. O controle é ocasionado pelos resultados das tarefas executadas; (c) as tarefas são executadas por intermédio de computadores ou de outros equipamentos de informática e telecomunicações.

Desta forma, além do trabalho ser realizado pelos empregados através do uso da tecnologia, o direito do empregado ao controle do trabalho prestado, o qual não é omisso nessas situações, é realizado por intermédio dos meios tecnológicos de comunicação e, através de uma análise de produtividade.

Importante mencionar, que o trabalho realizado nessa modalidade não é distinguido do trabalho realizado dentro do estabelecimento do empregador. Neste sentido é o artigo $6^{\circ}$ da Lei 12.551/2011, a qual altera a CLT:

Art. $6^{\circ}$ Não se distingue entre o trabalho realizado no estabelecimento do empregador, o executado no domicílio do empregado e o realizado a distância, desde que estejam caracterizados os pressupostos da relação de emprego.

Parágrafo único. Os meios telemáticos e informatizados de comando, controle e supervisão se equiparam, para fins de subordinação jurídica, aos meios pessoais e diretos de comando, controle e supervisão do trabalho alheio. (NR)

Desta forma, tem-se que, apesar do trabalho poder ser realizado dentro da moradia do empregado, as garantias e deveres estabelecidos em lei permanecem inalterados, devendo os descansos dos empregados serem respeitados,

9 GENEBRA.Convenção $\mathbf{n}^{\circ} \mathbf{1 7 7}$ da OrganizaçãoInternacional do Trabalho de 1996: Convençãosobre o trabalho a domicílio. Disponívelem: $<$ https://www.ilo.org/dyn/normlex/es/f?p=NORMLEXPUB:12100:0::NO:: P12100_INSTRUMENT_ID:312322>Acessoem: 13 abr. 2020.

${ }^{10}$ CAVALCANTE, Jouberto de Quadros Pessoa; JORGE NETO, Francisco Ferreira. A tecnológica, o teletrabalho e a reforma trabalhista. Disponível em:

$<$ http://www.mflip.com.br/pub/escolajudicial/?numero $=75 \&$ edicao $=11020$ \#page/112> Acesso em: 10 de fev. de 2020. 
com rigorosa distinção entre o horário de expediente com o horário de desconexão, assegurando o direito do trabalhador e não ter invadida sua privacidade e intimidade fora do horário estabelecido.

Assim, entende-se que a única distinção entre o trabalho prestado na modalidade de teletrabalho e o trabalho dentro do ambiente empresarial é a presença física do empregado, cuja rotina, assiduidade e produtividade devem ser inalterados. Neste sentido é o conceito de Manuel Martín Pino Estrada: ${ }^{11}$

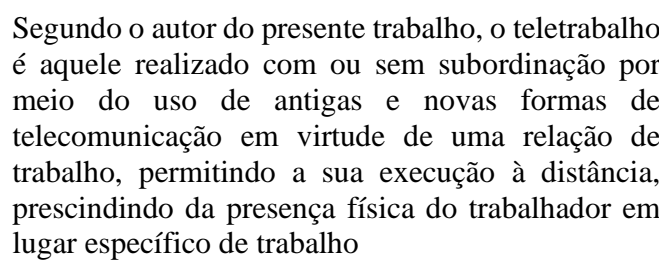

Outra questão a ser analisada se refere ao controle de jornada praticado pelo empregador em face do empregado que presta seus serviços de forma domiciliar, diante da dificuldade de fiscalização da jornada praticada. Por não haver um controle visual da rotina do trabalho e do cumprimento de horários, há uma confusão por parte das empresas na utilização dos meios tecnológicos para exercer os seus poderes diretivo, regulamentador, fiscalizatório e disciplinar. Poderes esses, os quais agora devem ser praticados com o auxílio dos meios tecnológicos e controle de produção.

Maurício Godinho Delgado (2009, p. 592) discorre perfeitamente sobre os poderes inerentes ao empregador, assim vejamos: ${ }^{12}$

Poder diretivo (ou poder organizativo ou, ainda, poder de comando) seria o conjunto de prerrogativas tendencialmente concentradas no empregador dirigidas à organização da estrutura e espaço empresariais internos, inclusive no processo de trabalho adotado no estabelecimento e na empresa, com a especificação e orientação cotidianas no que tange à prestação de serviços;

[...] Poder regulamentar seria o conjunto de prerrogativas tendencialmente concentradas no empregador dirigidas à fixação de regras gerais a serem observadas no Âmbito do estabelecimento e da empresa.

[...] Poder fiscalizatório (ou poder e controle) seria o conjunto de prerrogativas dirigidas a propiciar o acompanhamento contínuo da prestação de trabalho e a própria vigilância efetivada ao longo do espaço empresarial interno.

[...] Poder disciplinar é o conjunto de prerrogativas concentradas no empregador dirigidas a propiciar a imposição de sanções aos empregados em face do descumprimento por esses de suas obrigações contratuais.

Os poderes acima descritos, podem e devem ser exercidos na modalidade de teletrabalho, entretanto, assim como o trabalho, esses poderes serão realizados através dos meios tecnológicos.

11 ESTRADA, Manuel Martín Pino. Teletrabalho: conceitos e a suaclassificaçãoem face aosavançostecnológicos. p. 11. Disponívelem: <http://www.ltr.com.br/loja/folheie/5598.pdf>Acessoem: 13 abr. 2020.
Ocorre que, ao exercer esses poderes deve-se tomar cuidado em relação ao uso das formas de comunicação existentes na atualidade, a fim de respeitar os direitos e garantias mínimas do trabalhador, não utilizando os meios tecnológicos através de um poder excessivo, observando o direito de desconexão do empregado.

Neste sentido, deve ser observado um consenso entre a possibilidade do uso da tecnologia como meio de conexão de trabalho e ferramenta para o exercício dos poderes do empregador e, o direito de desconexão do empregado quando fora da jornada de trabalho para a qual foi contratado.

\section{CONCLUSÃO}

Os avanços tecnológicos são de grande valia para a evolução social, inclusive no ambiente de trabalho, de forma a desenvolver uma qualidade de trabalho mais efetiva, combatendo à morosidade e permitindo uma maior eficácia na produção desenvolvida pelas empresas.

Atualmente, a comunicação entre os seres humanos é de fácil e rápido acesso, entretanto, com essa inovação e melhoria há uma possível violação das garantias mínimas do empregado que labora através de teletrabalho onde encontrase conectado com a empresa através dos meios eletrônicos.

Ocorre que, os meios eletrônicos possibilitam o acesso do empregador ao empregado fora do seu horário de trabalho, de forma que, ainda que o mesmo não seja obrigado a prestar serviços neste horário tem seu direito ao descanso violado pelo recebimento de mensagens e ligações.

A desconexão quando fora de seu horário de trabalho, deve ser observada, não sendo viável o uso de meios tecnológicos para resolução de problemas e discussões sobre o trabalho fora do expediente, ainda que o empregado preste serviços na modalidade de teletrabalho.

\section{REFERÊNCIAS BIBLIOGRÁFICAS}

\section{BRASIL. Constituição da República Federativa do Brasil} de 1988. Brasília, DF. 1988. Disponível em: <http://www.planalto.gov.br/ccivil_03/constituicao/constitui cao.htm> Acesso em: 04 abr. 2020.

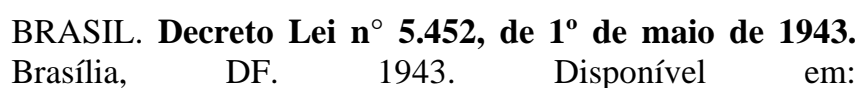
<http://www.planalto.gov.br/ccivil_03/decretolei/del5452.htm> Acesso em: 05 abr. 2020.

BRASIL. Lei 13.467, de 13 de julho de 2017. Altera a Consolidação das Leis do Trabalho. Disponível em: <http://www.planalto.gov.br/ccivil_03/_ato2015-

2018/2017/lei/L13467.htm> Acesso em: 11 de fev. de 2020.

BRASIL. Tribunal Regional do Trabalho $9^{\mathrm{a}}$ Região $\left(2^{\mathrm{a}}\right.$ Turma). Recurso Ordinário 04149-2006-663-09-00-4. Relator:Paulo Ricardo Pozzolo, 26 de outubro de 2007. Lex: jurisprudência do Tribunal Regional do Trabalho, Curitiba, PR, 2007. Disponível em:

12 DELGADO. MaurícioGodinho. Curso de direito do trabalho. 8. ed. São Paulo: LTr, 2009. p. 592-596. 
<https://www.trt9.jus.br/basesjuridicas/jurisprudencia.xhtml

> Acesso em: 13 abr. 2020.

BRASIL. Tribunal Regional do Trabalho $9^{\mathrm{a}}$ Região (4 Turma). Recurso Ordinário 05990-2007-013-09-00-4. Relator: Luiz Celso Napp, 03 de março de 2009. Lex: jurisprudência do Tribunal Regional do Trabalho, Curitiba, PR, 2009. Disponível em: <https://www.trt9.jus.br/basesjuridicas/jurisprudencia.xhtml $>$ Acesso em: 13 abr. 2020.

CAVALCANTE, Jouberto de Quadros Pessoa; JORGE NETO, Francisco Ferreira. A tecnológica, o teletrabalho e a reforma trabalhista. Disponível em: <http://www.mflip.com.br/pub/escolajudicial/?numero=75\& edicao=11020\#page/112> Acesso em: 10 de fev. de 2020 .

DELGADO. Maurício Godinho. Curso de direito do trabalho. 8. ed. São Paulo: LTr, 2009. p. 592-596.

ESTRADA, Manuel Martín Pino. Teletrabalho: conceitos e a sua classificação em face aos avanços tecnológicos. p. 11. Disponível em: <http://www.ltr.com.br/loja/folheie/5598.pdf> Acesso em: 13 abr. 2020.

GENEBRA.Convenção $\mathbf{n}^{\circ} 177$ da Organização Internacional do Trabalho de 1996: Convenção sobre o trabalho a domicílio. Disponível em: <https://www.ilo.org/dyn/normlex/es/f?p=NORMLEXPUB: 12100:0::NO::P12100_INSTRUMENT_ID:312322> Acesso em: 13 abr. 2020.

MELO, Sandro Nahmias. Teletrabalho, controle de jornada e direito à desconexão. Disponível em: <http://www.mflip.com.br/pub/escolajudicial/?numero=75\& edicao=11020\#page/80 > Acesso em: $11 \mathrm{de} \mathrm{fev.} \mathrm{De} 2020$.

\section{COPYRIGHT}

Direitos autorais: Os autores são os únicos responsáveis pelo material incluído no artigo. 


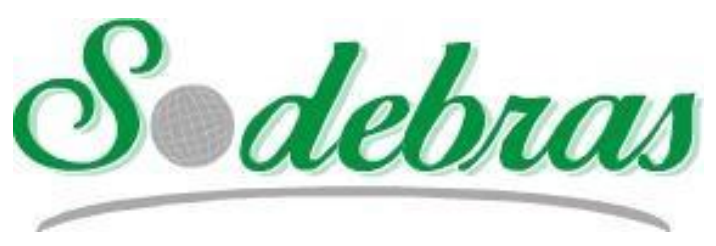

\author{
Volume 16 - No 174 - Junho / 2020 \\ XLII International Sodebras Congress \\ 28 a 30 de maio de 2020 - Web Conference.
}

\title{
A MANIFESTAÇÃO DE VONTADE CONTRATUAL NOS APLICATIVOS, FRENTE AO CÓDIGO DE DEFESA DO CONSUMIDOR THE EXPRESSION OF CONTRACTUAL WILL IN APPLICATIONS AND CONSUMER DEFENSE CODE
}

\author{
LUANA ESTECHE NUNES KOROCOSKI'; THIAGO ANDRE FONSECA SANTOS²; LUIZ EDUARDO \\ DOS SANTOS PEREIRA GOMES ${ }^{3}$, AMANDA FERREIRA PRIMO \\ 1 -UNIVERSIDADE ESTADUAL DO CENTRO-OESTE; 2 - FACULDADE ESTACIO DE SÁ DE \\ SERGIPE; 3 - CENTRO UNVERSITARIO DO LESTE MINEIRO; 4- ESCOLA ASSOC. DOS \\ MAGISTRADOS DO PR \\ luanaesteche@yahoo.com.br;thiagofonseca349@gmail.com; eduardo.ilheus@bol.com.br; \\ amandafprimo@hotmail.com
}

\begin{abstract}
Resumo - Os contratos, quando da sua assinatura, são observados princípios básicos como da bilateralidade contratual, a equidade, manifestação da vontade plena, boa-fé objetiva, função social do contrato. Ocorre que, quando da análise dos contratos de adesão, em geral, pode-se perceber uma exacerbação dos direitos do proponente fornecedor, ao passo que limita a manifestação volitiva do consumidor. $O$ consumidor aceita os termos dos aplicativos sem sequer ler o contrato, que, diga-se, é extremamente extenso, com linguagem não acessível e prevê permissões de uso que sequer são explicadas. $O$ contrato por adesão de aplicativos ("li e concordo") fere de morte princípios básicos das relações contratuais gerais e específicas do direito do consumo, única $e$ exclusivamente por negligenciar a lealdade contratual em detrimento da vontade unilateral do fornecedor.

Palavras-chave: Contrato de Adesão. Ausência de manifestação de vontade. Hipossuficiência presumida. Código de Defesa do Consumidor.
\end{abstract}

Abstract - When signing contracts, basic principles such as contractual bilaterality, equity, manifestation of full will, objective good faith, social function of the contract are observed. It happens that, when analyzing the adhesion contracts, in general, one can perceive an exacerbation of the rights of the supplier tenderer, while limiting the voluntary manifestation of the consumer. The consumer accepts the terms of the applications without even reading the contract, which, it is said, is extremely long, with nonaccessible language and provides usage permissions that are not even explained. The application subscription contract ("I read and agree") violently violates basic principles of general and specific contractual relations in consumer law, solely and exclusively by neglecting contractual loyalty to the detriment of the supplier's unilateral will.

Keywords: Adhesion Contract. Absence of manifestation of will. Presumed hyposufficiency. Consumer Protection Code.

\section{INTRODUÇÃO}

Com o mundo globalizado, caracterizado pela era digital, as vontades são satisfeitas como um toque de mágica, bastando estar em posse de um smartphone e acesso à internet. Neste toar, a "era dos app's" transformou as relações de consumo, trazendo facilidade e agilidade nas etapas contratuais de compra e venda, por meio da assinatura de contratos eletrônicos de adesão e aceitação de políticas de privacidade.

Tal dinâmica faz com que Consumidores, ávidos por consumir, acabem "assinando/aceitando" termos impostos pelos aplicativos, sem ao menos ter conhecimento de seu conteúdo. Segundo pesquisa do ano de 2016, restou constatado que cerca de $40 \%$ dos brasileiros praticam essa conduta. ${ }^{1}$

Uma atenção às etapas pré-contratuais a margem da manifestação de vontade e efeito jurídico produzido pelos contratos de adesão dos App's deve ser realizada frente aos princípios do Código de Defesa do Consumidor, Lei $\mathrm{n}^{\circ}$ 8.078/1990

\section{METODOLOGIA}

No artigo utilizou-se o método hipotético-dedutivo, levantadas conjecturas com base em hipóteses. Analisou-se a manifestação de vontade, realizada pelos usuários de aplicativos frente a princípio do Código de Defesa do Consumidor e seus efeitos no âmbito obrigacional.

De forma complementar, realizou-se pesquisa bibliográfica quanto ao "estado da arte", com busca de artigos científicos e doutrina do tema.

\section{RESULTADOS}

Em detida análise sobre a conceitualização doutrinária dos contratos em geral, tem-se, segundo Gagliano (2017, pág.64), que este é caracterizado por:

negócio jurídico bilateral, por meio do qual as partes, visando a atingir determinados interesses

\footnotetext{
${ }^{1}$ TECNOLOGIA-IG. Usuário pode expor sua privacidade e as informações salvas no dispositivo quando não lê o contrato de licença. 2016. Disponível em: <https://tecnologia.ig.com.br/2016-03-29/40-dos-usuarios-brasileiros-
} 
patrimoniais, convergem as suas vontades, criando um dever jurídico principal (de dar, fazer ou não fazer), e, bem assim, deveres jurídicos anexos, decorrentes da boa-fé objetiva e do superior princípio da função social ${ }^{2}$

Para que não pairem dúvidas conceituais cita-se o Saudoso Jurista Sílvio Salvo Venosa (2017, pág. 22), onde trás a ideia de que há a necessidade da proteção da função social dos contratos, a probidade e boa-fé como limitação contratual. Além de asseverar que não somente a vontade do credor deve ser analisada. Dessa forma, há a possibilidade de mitigação das obrigações dispostas em contrato.

Não podemos, dessa forma, considerá-lo como um instrumento de opressão, mas sim de realização. Lamentavelmente, não é raro um dos contraentes pretender utilizá-lo como açoite, visando a subjugar a parte economicamente mais fraca, em franco desrespeito à sua função social. (GAGLIANO, 2017, pág.64)

Retirando destes conceitos e críticas citadas alhures, pode-se perceber que o contrato é um elemento formalizador de um negócio jurídico entre duas partes. Partes que devem ser iguais, ou pelo menos paritárias, pautando-se na boa-fé, equidade e obedecendo a função social deste pacto.

Neste toar, são os seguintes elementos: sujeitos (ativo e passivo), objeto e o vínculo jurídico que traduz o adimplemento de uma obrigação (dar, fazer ou não fazer). Há o termo obrigação que é "relação jurídica pessoal por meio do qual uma parte (devedora) fica obrigada a cumprir, espontânea ou coativamente uma prestação patrimonial em proveito de outrem" (GAGLIANO E PAMPLONA, 2003, p.17)

O conceito obrigacional, ao passo que encontra-se incluso nos determinativos contratuais, amplia os caracteres deste, demonstrando uma possibilidade do credor (sujeito ativo) agir de maneira coercitiva, e até jurídico-contenciosa, para atingir a prestação plena daquela obrigação contratual. Pré-existindo, quando da assinatura do contrato, as características das obrigações pessoais, apresentadas por Gagliano e Pamplona, quais sejam: coercitividade, pessoalidade, transitoriedade, relatividade e patrimonialidade.

Somente para esclarecer de maneira principiológica e conceitual todos os elementos do contrato e das obrigações tem-se que: a função social do contrato é o princípio que

ora acolhido expressamente no Código Civil (arts. 421 e $1.228, \S 1 .^{\circ}$ ) constitui, em termos gerais, a expressão da socialidade no Direito Privado, projetando em seus corpora normativos e nas distintas disciplinas jurídicas a diretriz constitucional da solidariedade social $\left(\mathrm{CF}\right.$, art. $3 .^{\circ}$, III, in fine) (MARTINS-COSTA, 2005, p. 41)

Há um valor social em todos os contratos que deve ser protegido e perseguido, relacionando-se pessoas livres, informadas, confiáveis e transparentes. Já a boa-fé objetiva, é a atuação com

[...] sinceridade, seriedade, veracidade, lealdade e transparência, sem objetivos mal disfarçados de esperteza, lucro fácil e imposição de prejuízo ao outro. (ALMEIDA, 2003, p. 46).

E a equidade absoluta prevê

[...] que nenhuma das partes tenha significativamente mais direitos e vantagens que a outra (justiça substancial). Isso quer dizer que não é suficiente a igualdade formal pressuposta no momento antecedente à conclusão do contrato (justiça formal), para que a justiça contratual seja alcançada (SILVA, 2003, p. 74).

No presente caso foram analisadas as relações abrangidas pelo Direito do Consumidor, que são caracterizadas pelo fornecedor de um serviço ou bem frente ao consumidor, que segundo a lei sobrevive com uma situação de vulnerabilidade presumida como restará demonstrado.

Art. $2^{\circ}$ Consumidor é toda pessoa física ou jurídica que adquire ou utiliza produto ou serviço como destinatário final.

Parágrafo único. Equipara-se a consumidor a coletividade de pessoas, ainda que indetermináveis, que haja intervindo nas relações de consumo.

Art. $3^{\circ}$ Fornecedor é toda pessoa física ou jurídica, pública ou privada, nacional ou estrangeira, bem como os entes despersonalizados, que desenvolvem atividade de produção, montagem, criação, construção, transformação, importação, exportação, distribuição ou comercialização de produtos ou prestação de serviços.

$\S 1^{\circ}$ Produto é qualquer bem, móvel ou imóvel, material ou imaterial.

$\S 2^{\circ}$ Serviço é qualquer atividade fornecida no mercado de consumo, mediante remuneração, inclusive as de natureza bancária, financeira, de crédito e securitária, salvo as decorrentes das relações de caráter trabalhista.

Subsiste uma relação jurídica e contratual, onde, ativamente, há um fornecedor de bens e serviço que conhece apuradamente todos os meios de produção, produto e um aparato legal, jurídico, econômico intimidador quando comparado com o consumidor, que necessita daquele bem ou produto. Tanto para sobrevivência como para lazer.

Nos contratos dos aplicativos o fornecedor do serviço tem como público alvo o consumidor, veloz e feroz para ter aquela ferramenta de conforto e desfrute. Deixando de ler o contrato, assinando e permitindo as autorizações automáticamente, nos termos da pesquisa já apresentada.

O contrato apresentado é bastante extenso, em letras minúsculas e em vocabulário não acessível. Nota-se que, a assinatura não se dá de forma consciente e bilateral.

Para Bruno Miragem,

Há na sociedade atual o desequilíbrio entre os dois agentes econômicos, consumidor e fornecedor, nas relações jurídicas que estabelecem entre si. O reconhecimento desta situação pelo direito é que fundamenta a existência de regras especiais, uma lei ratione personae de proteção do sujeito mais fraco da relação de consumo (MIRAGEM, 2016, p. 18).

2 Gagliano (2017, pág.64)

Volume 16 - No 174 - Junho/2020. 
O próprio sujeito é presumidamente vulnerável, pelo simples fato de ser consumidor. A vulnerabilidade doutrinariamente é vislumbrada nas seguintes esferas:

Na vulnerabilidade técnica, o comprador não possui conhecimentos específicos sobre o objeto que está adquirindo e, portanto, é mais facilmente enganado quanto às características do bem ou quanto à sua utilidade, o mesmo ocorrendo em matéria de serviços. A vulnerabilidade técnica, no sistema do CDC, é presumida para o consumidor não profissional, mas também pode atingir excepcionalmente o profissional, destinatário final fático do bem, como vimos no exemplo da jurisprudência francesa. (MARQUES, 2002, p. 324)

Vulnerabilidade científica é pautada na "falta de conhecimentos, pelo consumidor, dos direitos e deveres inerentes, à relação de consumo que estabelece, assim como a ausência de compreensão sobre as consequências jurídicas dos contratos que celebra." (MIRAGEM,2016, p.63)

Faticamente, o consumidor, na grande maioria das vezes, é pobre intelectual e financeiramente, frente ao fornecedor. (MIRAGEM, 2016,p. 63)

A hipossuficiência informacional, apesar da globalização e do consumidor de aplicativos de celular estarem num mundo digital forte, ela está vislumbrada na manipulação do fornecedor de toda publicidade, apresentando apenas o que lhe convém. $\mathrm{O}$ leva a crer que o consumidor tem o conhecimento detido do produto, o que de fato não se observa. (MIRAGEM, 2016, p.64)

A norma consumerista é perfeitamente aplicada nesta espécie de contrato, que é chamado hodiernamente, de contrato por adesão ou de adesão. Haja vista a manipulação ou não possibilidade de realização da bilateralidade na contratação.

Por ser perfeitamente aplicável, é de extrema relevância apresentar os princípios que irão reger a relação contratual, com o objetivo de orquestrar tal discrepância e embasar a ausência de manifestação volitiva de maneira objetiva.

Art. $6^{\circ}$, do CDC. São direitos básicos do consumidor [...]

II - a educação e divulgação sobre o consumo adequado dos produtos e serviços, asseguradas a liberdade de escolha e a igualdade nas contratações; III - a informação adequada e clara sobre os diferentes produtos e serviços, com especificação correta de quantidade, características, composição, qualidade, tributos incidentes e preço, bem como sobre os riscos que apresentem;

IV - a proteção contra a publicidade enganosa e abusiva, métodos comerciais coercitivos ou desleais, bem como contra práticas e cláusulas abusivas ou impostas no fornecimento de produtos e serviços;

V - a modificação das cláusulas contratuais que estabeleçam prestações desproporcionais ou sua revisão em razão de fatos supervenientes que as tornem excessivamente onerosas;

VI - a efetiva prevenção e reparação de danos patrimoniais e morais, individuais, coletivos e difusos;

Art. $7^{\circ}$ Os direitos previstos neste código não excluem outros decorrentes de tratados ou convenções internacionais de que o Brasil seja signatário, da legislação interna ordinária, de regulamentos expedidos pelas autoridades administrativas competentes, bem como dos que derivem dos princípios gerais do direito, analogia, costumes e equidade (...).

Nos contratos assinados para utilização dos aplicativos, por óbvio não está permitida a utilização deste sem que sejam aceitas todas as permissões e acessos ao aparelho e, consequentemente, sua vida privada. Ferindo de morte princípios e direitos do consumidor traduzidos no art. $6^{\circ}$, II, III, IV, V, do Código de Defesa do Consumidor.

A título elucidativo, os incisos citados são violados nos seguintes pontos. Primeiro, não há liberdade de escolha, haja vista que o consumidor necessita daquele aplicativo, ou porque é o único no mercado ou é o que abrange suas necessidades primárias. A ausência da igualdade de contratação é vislumbrada pelo simples fato de que o aplicativo possui diversas ferramentas de acesso à vida privada do consumidor (celular), porém este sequer sabe qual empresa criou ou gerencia o software. Ausente completamente a igualdade na contratação, o que trucida a boa-fé objetiva e bilateralidade contratual.

O segundo é com relação à informação adequada, que também é mitigada. Quando da aceitação ou determinação de acesso ao aparelho (localização, contatos, mensagens de texto) nenhum aplicativo informa o motivo daquela necessidade de confirmação. O que demonstra total má-fé e inobservância dos princípios básicos da relação consumerista.

O inciso IV, é completamente trucidado no momento em que terminantemente ausente a publicidade leal e clara imposição de meios coercitivos, pois, como dito anteriormente, o consumidor não terá acesso ao aplicativo irrestritamente caso não aceite as permissões e assine o contrato, diga-se de passagem escrito, extenso, unilateral, com letras minúsculas e abusivo.

Todo o texto do código é protetivo e afasta totalmente o comportamento abusivo dos fornecedores

Art. 39, do CDC. É vedado ao fornecedor de produtos ou serviços, dentre outras práticas abusivas:

IV - prevalecer-se da fraqueza ou ignorância do consumidor, tendo em vista sua idade, saúde, conhecimento ou condição social, para impingir-lhe seus produtos ou serviços;

$\mathrm{V}$ - exigir do consumidor vantagem manifestamente excessiva;

Os princípios de proteção ao consumidor visam, principalmente, a manutenção da paz social e a segurança jurídica.

Por óbvio há a hipossuficiência do consumidor que é presumida, nos termos dos estudos e protegida via Código de Defesa do Consumidor. Civilmente, tal hipossuficiência é capaz de reduzir, ou até anular, a manifestação da vontade do adquirente (consumidor), posto que sem a expressão da vontade não há sequer indício contratual.

Segundo a Lei Civil, trazida pelo Código Civil, Lei $n^{\circ} 10.406 / 2002$, os negócios jurídicos, possuem os seguintes elementos de validez:

Art. 104. A validade do negócio jurídico requer: I - agente capaz;

II - objeto lícito, possível, determinado ou determinável; 
III - forma prescrita ou não defesa em lei.

Em que pese não haja a previsão da vontade, os artigos subsequentes debruçam-se a analisar e prever diversas possibilidade de afastar a manifestação volitiva, demonstrar vícios. Inclusive, citando que a manifestação não necessita ser explanada de maneira preestabelecida, somente quando prescrita em lei. ${ }^{3}$ Percorrendo o texto do Código Civilista Brasileiro, denotamos a importância e os efeitos da expressão inequívoca da vontade, restando transparente a vontade como um quarto elemento de validade do negócio jurídico e ou relações contratuais. ${ }^{4}$

Esse entendimento é coadunado pela doutrina de Gagliano (2017, pág. 73) "o que é imprescindível, para se entender existente um negócio jurídico, é justamente que tenha ocorrido uma declaração de vontade, faticamente aferível, e que decorra de um processo mental de cognição".

Sustentando a doutrina supra, se encontra Nader (2018, p. 49), quando leciona:

quando se indica a declaração de vontade como um dos elementos do contrato, a referência se faz ao consenso das partes. A formação do contrato não se opera com vontades paralelas ou coincidentes; é indispensável que sejam declaradas, isto é, que haja uma oferta e a correspondente aceitação.

Segundo

A legislação civil sobre contratos pressupõe a existência de partes livres e iguais que transigem sobre os respectivos interesses, com pleno domínio da vontade. [...] A este cenário corresponde a normas civis e empresariais. A realidade das relações de consumo, no entanto, é bem diferente. $\mathrm{O}$ consumidor não contrata se quiser e como quiser, mas se vê muitas vezes obrigado a contratar bens e serviços essenciais, de um ou poucos fornecedores e sem a menor possibilidade de discutir os termos da negociação.(COELHO, 2010, p.100)

O contrato nasce do seio social em virtude de uma necessidade econômica, tendo como principal objetivo traduzir a vontade das partes contratantes, porém, como dito, na espécie de contrato trazida neste trabalho não há manifestação plena da vontade, nem sequer obediência dos preceitos trazidos no Código de Defesa do Consumidor.

Portanto, em que pese a experimentação da vontade das partes nos contratos originários, o que os "fazia lei entre as partes" (pacta sunt servanda), atualmente, há uma nova sistemática nas relações.

Hodiernamente, os contratos de consumo são feitos em grande escala, sendo que suas cláusulas foram criadas e organizadas para dar maior eficiência e velocidade nas contratações. Deixando à baila a livre manifestação da

3 Art. 107. A validade da declaração de vontade não dependerá de forma especial, senão quando a lei expressamente a exigir.

Art. 110. A manifestação de vontade subsiste ainda que o seu autor haja feito a reserva mental de não querer o que manifestou, salvo se dela o destinatário tinha conhecimento.

Art. 111. O silêncio importa anuência, quando as circunstâncias ou os usos o autorizarem, e não for necessária a declaração de vontade expressa.

Art. 112. Nas declarações de vontade se atenderá mais à intenção nelas consubstanciada do que ao sentido literal da linguagem.

4 Art. 141. A transmissão errônea da vontade por meios interpostos é anulável nos mesmos casos em que o é a declaração direta.

Volume 16 - No 174 - Junho/2020. vontade e conhecimento asseverado das obrigações e cláusulas impostas no ato da contratação.

Para os doutrinadores modernos essa modalidade de contrato é chamada de contrato por adesão ou de adesão, sendo conceitualizado como sendo

aqueles em que o proponente não se dispõe a negociar quaisquer cláusulas do contrato, restando ao oblato a simples aceitação ou recusa da oferta Esses contratos cumprem a importante função de homogeneizar a estrutura de venda ou prestação de serviços de uma determinada firma, permitindo a redução dos custos de negociação e de customização. Embora essencial para a redução de custos de produção e oferta de bens, os contratos de adesão vem sendo criticados como um instrumento de imposição de uma parte mais forte economicamente em relação a mais fraca. (SALEME;FONTOURA;2009,P.81)

Sem que haja qualquer manifestação volitiva plena e desimpedida "[...] a manifestação de vontade de uma das partes é reduzida a mera anuência a uma proposta da outra; uma das partes adere às cláusulas já estabelecidas pela outra." (ESCOBAR, 2006 p.125)

Para o Código de Defesa do Consumidor:

Art. 54. Contrato de adesão é aquele cujas cláusulas tenham sido aprovadas pela autoridade competente ou estabelecidas unilateralmente pelo fornecedor de produtos ou serviços, sem que o consumidor possa discutir ou modificar substancialmente seu conteúdo.

$\S 1^{\circ}$ A inserção de cláusula no formulário não desfigura a natureza de adesão do contrato.

$\S 2^{\circ}$ Nos contratos de adesão admite-se cláusula resolutória, desde que a alternativa, cabendo a escolha ao consumidor, ressalvando-se o disposto no $\S 2^{\circ}$ do artigo anterior.

$\S 3$ ㅇ Os contratos de adesão escritos serão redigidos em termos claros e com caracteres ostensivos e legíveis, cujo tamanho da fonte não será inferior ao corpo doze, de modo a facilitar sua compreensão pelo consumidor. $\quad$ (Redação dada pela $\mathrm{n}^{\circ}$ 11.785 , de 2008)

$\S 4^{\circ}$ As cláusulas que implicarem limitação de direito do consumidor deverão ser redigidas com destaque, permitindo sua imediata e fácil compreensão.

Este é o cenário das relações contratuais e obrigacionais que se vive no mundo digital. Os contratos e liberações de acesso são por demais voláteis. Realizando a subsunção do fato (assinatura de contratos por aplicativos) à norma (Código de Defesa do Consumidor e Código Civil) temos as seguintes características: Contrato de adesão, onde cláusulas abusivas impostas e permissões infundadas são

Art. 151. A coação, para viciar a declaração da vontade, há de ser tal que incuta ao paciente fundado temor de dano iminente e considerável à sua pessoa, à sua família, ou aos seus bens.

Art. 215. A escritura pública, lavrada em notas de tabelião, é documento dotado de fé pública, fazendo prova plena.

$\S 1^{\circ}$ Salvo quando exigidos por lei outros requisitos, a escritura pública deve conter:

IV - manifestação clara da vontade das partes e dos intervenientes; 
aceitas mediante aceitação de termos ("li e concordo"), sem a devida publicidade, informação e lealdade. Além de que realizado por sujeito hipossuficiente que deve ser maximamente protegida frente ao fornecedor.

Sem dúvidas esta é a caracterização do contrato levando-se em consideração os sujeitos, o objeto, o vínculo firmado. Tais elementos acrescidos da conjuntura tecnológica atual torna-se impossível vislumbrar a vontade como ponto nodal e viabilizador da manutenção contratual, nos termos do pacta sunt servanda.

\section{CONCLUSÃO}

Atualmente, a satisfação da vontade no mercado de consumo passou a se dar de forma dinâmica e urgente, com o surgimento e proliferação de aplicativos com esse fim. O fornecedor dos serviços estão elaborando contratuais desiguais e impositivos para viabilizar essa necessidade do consumo, visualizada no mundo moderno. Essa dinâmica ofende os direitos dos consumidores, os quais renunciam direitos básicos em troca da agilidade no fornecimento de produtos e serviços.

Os contratos de aplicativos são a nova era tecnológica e merecem atenção no seio social e jurídico, tanto pela permissibilidade de acesso e manipulação da vida privada, violando princípios constitucionais e supraconstitucionais.

$\mathrm{O}$ abuso dos direitos dos consumidores torna-se explícito com a falta de privacidade, lealdade, boa-fé e segurança de dados cadastrais fornecidos, cláusulas abusivas e falta de informação sobre o produto contratado. Dessa forma, os Consumidores devem ser protegidos ante a ausência de manifestação volitiva contratual, vulnerabilidade e hipossuficiência, tendo o direito de revisar cláusulas abusivas, ressalvado a indenização em caso de dano.

\section{REFERÊNCIAS BIBLIOGRÁFICAS}

ALMEIDA, João Batista de. Manual de direito do consumidor. São Paulo: Saraiva, 2003.

BRASIL. Lei ${ }^{\circ}$. 8.078, de 11 de setembro de 1990. Código de Defesa do Consumidor. Dispõe sobre a proteção do consumidor e dá outras providências. Disponível em: http://www.planalto.gov.br/ccivil_03/Leis/L8078.htm, acesso em 02 de fevereiro de 2020.

BRASIL. Lei n. 10.406, 10 de janeiro de 2002. Institui o Código Civil. Diário Oficial da União, Brasília, DF, 11 jan. 2002. Disponível

em: http://www.planalto.gov.br/ccivil_03/leis/2002/110406.htm.

Acesso em: 25 março 2020.

COELHO, Fábio Ulhoa. Manual de direito de comercial: direito de empresa. v.1 22 ed. São Paulo: Saraiva, 2010.

ESCOBAR, Lauro R. Direito civil. 3 ed. São Paulo: Barros, Fischer e Associados, Exord, 2006. 240 p.

GAGLIANO, Pablo Stolze. PAMPLONA, Rodolfo Filho. Novo curso de direito civil. São Paulo: Saraiva, 2017.

MARQUES, Cláudia Lima. Contratos no Código de Defesa do Consumidor: o novo regime das relações contratuais. 4. ed. São Paulo: Editora Revista dos Tribunais, 2002.

MARTINS-COSTA, Judith. Reflexões sobre o princípio da função social dos contratos. Revista Direito GV, V. 1 N. 1 | P. 041 - 066 | MAIO 2005 : 041.
MIRAGEM, Bruno. Curso de Direito do Consumidor / Bruno Miragem. - 6. ed. rev., atual. e ampl. São Paulo: Editora Revista dos Tribunais, 2016.

SALEME, Edson Ricardo; FONTOURA, José augusto. Direto internacional público e privado: estudos direcionados: perguntas e respostas. 2 ed São Paulo: Saraiva, 2009. 168 p.

SILVA, Jorge Alberto Quadros de Carvalho. Código de Defesa do Consumidor Anotado e legislação complementar. 3.ed. São Paulo: Saraiva, 2003.

TECNOLOGIA-IG. Usuário pode expor sua privacidade e as informações salvas no dispositivo quando não lê o contrato de licença. 2016. Disponível em: <https://tecnologia.ig.com.br/2016-03-29/40-dos-usuariosbrasileiros-nao-leem-termos-de-uso-ao-instalaraplicativos.html>. Acesso em: 09 fev. 2020.

VENOSA, Sílvio de Salvo. Direito civil: contratos / Sílvio de Salvo Venosa. - 17. ed. - São Paulo: Atlas, 2017. (Coleção Direito Civil; 3)

\section{COPYRIGHT}

Direitos autorais: Os autores são os únicos responsáveis pelo material incluído no artigo. 


\author{
Volume $16-\mathrm{N}^{\mathrm{o}} 174$ - Junho / 2020 \\ XLII International Sodebras Congress \\ 28 a 30 de maio de 2020 - Web Conference.
}

\title{
VALIDADE DO RECONHECIMENTO POR FOTOGRAFIA COMO MEIO DE PROVA NO PROCESSO PENAL
}

\section{VALIDITY OF RECOGNITION BY PHOTOGRAPH AS A MEANS OF PROOF IN CRIMINAL PROCEEDINGS}

\author{
LUANA ESTECHE NUNES KOROCOSKI'; THIAGO ANDRE FONSECA SANTOS²; LUIZ EDUARDO \\ DOS SANTOS PEREIRA GOMES ${ }^{3}$, AMANDA FERREIRA PRIMO
1 -UNIVERSIDADE ESTADUAL DO CENTRO-OESTE; 2 - FACULDADE ESTACIO DE SÁ DE SERGIPE; 3 - CENTRO UNVERSITARIO DO LESTE MINEIRO; 4- ESCOLA ASSOC. DOS \\ MAGISTRADOS DO PR
}
luanaesteche@yahoo.com.br;thiagofonseca349@gmail.com; eduardo.ilheus@bol.com.br; amandafprimo@hotmail.com

\begin{abstract}
Resumo - $O$ presente artigo visa analisar os meios de reconhecimento de pessoas e trás um enfoque no reconhecimento através de fotografias. Após a análise de diversos casos, inclusive abordando que a maioria dos países aceitam o reconhecimento de pessoas como prova válida, inclusive os Tribunais Brasileiros que vão além e aceitam como válido o reconhecimento feito através de fotografias; chegou-se a conclusão que os métodos de reconhecimento são falhos e por diversas vezes levam a condenação de pessoas inocentes. Ressalte que o mínimo a ser feito é respeitar e tornar obrigatória as normas procedimentais do art. 226 do CPP e ainda atualizá-lo seguindo os dados colhidos através da psicologia experimental e por derradeiro deve ser considerado inadmissivel o reconhecimentos feito através de fotografias, haja vista seu elevado grau de sugestibilidade e frágil confiabilidade.

Palavras-chave: Prova. Reconhecimento Pessoal. Reconhecimento por Fotografia.
\end{abstract}

Abstract - This article aims to analyze the means of recognizing people and brings a focus on recognition through photographs. After the analysis of several cases, including addressing that most countries accept the recognition of people as valid evidence, including the Brazilian Courts that go beyond and accept as valid the recognition made through photographs; it has been concluded that the methods of recognition are flawed and often lead to the conviction of innocent people. Point out that the minimum to be done is to respect and make mandatory the procedural norms of art. 226 of the CPP and still update it following the data collected through experimental psychology and by last must be considered inadmissible the recognitions made through photographs, given its high degree of suggestibility and fragile Reliability.

Keywords: Proof. Personal Recognition. Recognition by Photography

\section{INTRODUÇÃO}

O reconhecimento pessoal é um dos meios de provas mais utilizados no sistema penal brasileiro. Ele se encontra tipificado no Código de Processo Penal, art. 226, o qual estabelece os procedimentos para sua realização.

Como desdobramento dos meios de prova previstos, tem se verificado o aumento da utilização do reconhecimento de pessoas por meio de fotografias, o que tem sido plenamente admitido pela jurisprudência.
Em contra ponto, tem crescido absurdamente o número de condenações de pessoas inocentes, as quais amargam longos anos de prisão por crimes que não cometeram. No Brasil inexiste pesquisa oficial que demonstre quais são os números de erros judiciários cometidos mediante a condenação de inocentes, mascarando a ineficácia do sistema penal.

Essa situação traz uma inquietude quanto a utilização dos meios de reconhecimento fotográfico como prova, existindo sérias dúvidas quanto a sua confiabilidade, na medida que tem sido um dos fatores determinantes nas condenações realizadas.

\section{METODOLOGIA}

No presente artigo fora utilizado o método hipotéticodedutivo ao passo que foram levantadas conjecturas com base em hipóteses. Passou-se a uma análise da norma procedimental consistente no reconhecimento de pessoas como meio de prova esculpido no artigo 226 do Código de Processo Penal Brasileiro.

Realizou-se de forma complementar, uma pesquisa bibliográfica com o intuito de analisar a validade do reconhecimento pessoal feito pela vítima, mediante busca de artigos científicos e doutrinas a respeito do tema.

\section{RESULTADOS}

Após análise da metodologia utilizada para realização do reconhecimento de criminosos através de fotografias, encontra-se alguns fatores que podem influenciar no resultado inequívoco da prova, como é o caso de questões emocionais da vítima, bem como presença de elementos externos que prejudicam o resultado almejado ocasionando a condenação de inocentes.

A prova é o elemento capaz de formar o convencimento do julgador em um processo judicial. Quanto à realização técnica, como meio de demonstração dos fatos, mister que seja realizada nos exatos termos do art. 226 do CPP sob pena de não ser validado o reconhecimento informal, visto que o mesmo carece de amparo legal.

A prova técnica é de tal importância no ordenamento jurídico brasileiro que se torna indispensável, porquanto 
somente nos moldes do artigo 226 do Código de Processo Penal poderemos chegar próximo à conclusão da verdade dos fatos.

Art. 226. Quando houver necessidade de fazer-se o reconhecimento de pessoa, proceder-se-á pela seguinte forma:

I - a pessoa que tiver de fazer o reconhecimento será convidada a descrever a pessoa que deva ser reconhecida;

Il - a pessoa, cujo reconhecimento se pretender, será colocada, se possível, ao lado de outras que com ela tiverem qualquer semelhança, convidandose quem tiver de fazer o reconhecimento a apontála;

III - se houver razão para recear que a pessoa chamada para o reconhecimento, por efeito de intimidação ou outra influência, não diga a verdade em face da pessoa que deve ser reconhecida, a autoridade providenciará para que esta não veja aquela;

IV - do ato de reconhecimento lavrar-se-á auto pormenorizado, subscrito pela autoridade, pela pessoa chamada para proceder ao reconhecimento e por duas testemunhas presenciais.

De acordo com Lopes Jr. (2014), o processo penal possui como fundamento a instrumentalidade processual, a qual possui juntamente a incumbência de proteção dos direitos e garantias individuais. Uma conotação de caráter instrumental diretamente relacionado ao Direito Penal e à pena, mas, principalmente, um instrumento com o fim de garantir a máxima eficácia das garantias constitucionais.

A importância da instrumentalidade das formas no processo penal se justifica na medida que certamente ao final do procedimento alguém será julgado culpado ou inocente de um crime, muitas vezes com disposição da própria liberdade, devendo-se haver a máxima de cautela diante da possibilidade de erro judiciário por intermédio da condenação de um inocente.

Condenar um inocente não é a função do processo penal, o qual possui com fim precípuo defender e resguardar as garantias e direitos individuais fundamentais de quem é réu, já que o aparato acusatório do Estado é enorme e o acusado nesta relação se torna a parte mais fraca da balança.

Umas das principais variantes que prejudica a idoneidade da prova de reconhecimento é o estado psicológico da vítima, a qual se encontra abalada e com "sede" de justiça, podendo que por ocasião do reconhecimento acabe apontando para uma pessoa inocente.

Por diversas vezes as vítimas têm a construção de falsas memórias que são distorções acerca das lembranças de uma determinada pessoa. Elas podem levar a uma completa inovação em relação ao fato original ou podem se apresentar nos detalhes. As falsas memórias se criam de forma natural pelas vítimas ou podem ser criadas por induções através de sugestões externas, podendo ser desencadeada até mesmo através da realização de uma mera pergunta.

O cérebro humano não é uma câmera fotográfica, nem uma máquina de filmar, alguns campos são preenchidos automaticamente e assim somos capazes de criar as já mencionadas falsas memórias e podemos nos lembrar de coisas que jamais existiram.

Mas mesmos diante dessas variantes, o reconhecimento pessoal tem sido um dos meios de provas mais utilizados no sistema penal brasileiro, em especial o reconhecimento de suspeitos através de fotografias. Ocorre que alguns fatores podem influenciar no resultado inequívoco da prova, como é o caso de questões emocionais da vítima, bem como presença de elementos externos que prejudicam o resultado almejado ocasionando a condenação de inocentes.

O Professor Ávila (2013) alerta que

O reconhecimento poderia ter peso importante no processo, desde que fossem seguidas algumas regras simples, decorrentes de anos de pesquisa da psicologia experimental: 1) instruções prévias à vítima/testemunha que irá reconhecer, dizendo que o suspeito pode ou não estar entre as pessoas a serem mostradas; 2) de 4 a 6 pessoas devem ser alinhadas para o reconhecimento, sendo que jamais deve ser feito o reconhecimento com apenas uma pessoa ou foto, em função de sua intolerável carga de sugestionabilidade; 3) as pessoas a serem alinhadas devem ser parecidas entre si; 4) quem organiza a linha de reconhecimento não deve saber quem é o suspeito para não influenciar quem está a reconhecer; e 5) gravação em vídeo de todo o procedimento

E essa preocupação não se dá à toa, posto que são diversos os casos em que pessoas inocentes foram condenadas com base em reconhecimentos falhos, apesar de no Brasil ainda não existirem dados sistematizados.

Apesar de não se tratar de dados científico, recente experiência realizada pelo programa de jornalismo Fantástico - Rede Globo, resultou em reportagem demonstrando a possibilidade de falhas que o "reconhecimento de suspeitos" à luz da norma processual penal pátria pode resultar. Aproximadamente $76 \%$ dos estudantes do Curso de Direito submetidos à simulação, apontaram erroneamente o autor do crime apesar de apontarem para um possível culpado. Da experiência verificou-se que alguns dos estudantes chegaram a expressar a criação de falsas memórias, onde um deles até mesmo chegou a apontar vestimentas do autor do crime completamente dissociadas da que o ator se utilizava por ocasião da experiência.

Mesmo a parcela dos estudantes que seguiram o protocolo recomendado, afirmaram que não se sentiram confiantes para apontarem o autor do crime, isso correspondeu a $63 \%$ desses estudantes. Por sua vez, outros $26 \%$ apontaram o autor e disseram ter certeza da autoria durante o reconhecimento, todavia erraram na identificação.

Infelizmente não foram encontrados dados sistematizados que apontem os países com menores taxas de falhas em condenações e as metodologias de reconhecimento aplicadas a eles. Não se sabe ao certo porque referidos dados não foram colhidos, todavia isso gera um temor social, porquanto o erro do judiciário pode ser comum a todos.

A evidência é de que mediante tensão a vítima não consegue captar todas as características do autor do crime, sem falar ainda que pode vir a ser traída por sua mente aterrorizada. Essa possibilidade é evidenciada por Lopes (2011) onde afirma que as falsas recordações são resultado de recordações verdadeiras combinadas com questões sugestiva de terceiros, dessa forma 
Durante o processo, os indivíduos podem esquecer a fonte da informação. Este é um exemplo clássico de confusão sobre a origem da informação na qual o conteúdo e a proveniência da informação estão dissociados.

A situação se agrava em crimes que possuem mais de uma vítima ou testemunha, posto que por diversas vezes ao efetuarem o reconhecimento, as pessoas que devem fazer o reconhecimento ficam juntas e se comunicam sobre os fatos. Portanto o reconhecimento fica contaminado, dado que uma pessoa influencia nas lembranças da outra, o que proporciona a criação de falsas memórias, além do que a mídia por diversas vezes influencia e consequentemente induz o reconhecimento, haja visto que suas reportagens passam a visão que o jornalista tem sobre o fato.

É verdade que o art.228 do CPP preceitua que: "Se várias forem as pessoas chamadas a efetuar $\mathrm{o}$ reconhecimento de pessoa ou de objeto, cada uma fará a prova em separado, evitando-se qualquer comunicação entre elas". Entretanto na prática o desrespeito a tal procedimento vem sendo considerado mera irregularidade formal não apta a geral a nulidade do procedimento.

Vale mencionar trecho do julgado do Egrégio Tribunal de Justiça do Estado de Minas que assim preceitua: "A regra dos artigos 226, inciso II, e 228, ambos do Código de Processo Penal, não é absoluta, uma vez que ainda que a identificação não tenha ocorrido de acordo com o rito previsto, tem sido aceita pela jurisprudência dos tribunais superiores, desde que corroborada com os demais elementos de convicção" (Apelação criminal $n^{\circ} 0708874$ 72.2010.8.13.0024).

De maneira muito semelhante à legislação brasileira, nossa terra irmã Argentina tipifica os meios de reconhecimento de pessoas nos artigos 270 e 275 do seu Código Processual Penal. Em suma o reconhecimento deve ser feito nos mesmos moldes do brasileiro, com uma pequena, porém significativa diferença o CPP Argentino aceita e tipifica o reconhecimento por fotografia, estando expresso no artigo 274 do CPP Argentino.

\section{Reconhecimento de foto \\ Art. 274. - Quando for necessário identificar ou reconhecer uma pessoa que não estava presente e não poderia estar, e de quem foram tiradas fotografias, estas serão apresentadas a eles, com outras pessoas semelhantes de pessoas diferentes, a quem $\mathrm{o}$ reconhecimento deve ser feito. No restante, as disposições anteriores serão observadas. \\ (tradução livre)}

Referido reconhecimento deve ser evitado, senão descartado dos meios legais, dado que o reconhecimento feito através de fotografia é muito temerário, diante do induzimento consciente ou não a um reconhecimento equivocado, além do seu alto grau de sugestibilidade que poderá ocasionar condenações de pessoas inocentes.

Mesmo se tratando de um método temerário, diante do induzimento consciente ou não a um reconhecimento equivocado, o Tribunal de Justiça do Estado de Minas Gerais também vem reconhecendo como válido a produção de prova feito por meio de fotografias (Apelação criminal $\mathrm{n}^{\circ}$ 0013368-78.2019.8.13.0194).

O Superior Tribunal de Justiça, por sua vez, firmou entendimento no sentido de que o fato do reconhecimento por fotografias não estar expresso no art. 226 do CPP não enseja nulidade do ato, posto ser tratar de mera recomendação e não uma exigência, validando a aplicabilidade do método probatório. (RHC 67.675/SP, Rel. Ministro Felix Fischer; DJe: 28/03/2016).

Constata-se que o artigo 226 do CPP encontra-se ultrapassado e não segue os protocolos recomendados internacionalmente, portanto ainda que siga rigorosamente todos os seus dispositivos, as chances de um reconhecimento equivocado são altíssimas. Isso se dá em virtude de que reconhecer uma pessoa estranha que somente foi vista uma vez por segundos ou minutos e mediante estado mental abalado é tarefa árdua.

Quando se trata de crime com iminente perigo a vida, a situação psicológica da vítima se agrava, desviando o foco do agressor para o perigo real contra a vida demonstrado pelo emprego de arma de fogo.

Mesmo não sendo apto a ensejar nulidade, o reconhecimento por fotografia deve ser usado com cautela e não deve ser prova exclusiva da condenação criminal, sob pena de ensejar em condenações errôneas e injustas, devendo a prova técnica expressar de forma mais assertiva possível a verdade real, sob pena de submeter um inocente a condenações injustas.

\section{CONCLUSÃO}

Em que pese os esforços dos órgãos competentes, os métodos utilizados para o reconhecimento pessoal são altamente falhos, posto que não são capazes de apresentar certeza de sua eficácia e por consequência acabam por levar a condenação de diversos inocentes. Percebe-se que nenhum dos dois meios de reconhecimento menciona/aceita o reconhecimento por fotografia, dado que isso aumentaria exponencialmente as chances de um reconhecimento equivocado, haja visto seu elevado grau de sugestibilidade.

Por certo se no mínimo fossem respeitadas as normas procedimentais esculpidas no artigo 226 do CPP até que se atualizem os métodos de reconhecimento de pessoas segundo protocolos recomendados internacionalmente e fossem seguidas algumas regras simples, decorrentes de anos de pesquisa da psicologia experimental, com certeza diminuiria significativamente o número de erros do judiciário.

Posto isso conclui-se que a norma procedimental do art. 226 e seguintes do CPP deve ser considerada obrigatória para validade de um reconhecimento. Ademais referido artigo merece uma reforma a fim de melhorar sua eficácia, além do que o reconhecimento por fotografias deve ser considerado inadmissível diante da sua frágil confiabilidade.

\section{REFERÊNCIAS BIBLIOGRÁFICAS}

\section{ARGENTINA. Código Processual Penal da Argentina.} Disponível em: http://servicios.infoleg.gob.ar/infolegInternet/anexos/04999/383/texact.htm. Acessado dia 06 de maio de 2020

ÁVILA, Gustavo Noronha de. Falsas Memórias e Sistema Penal: A Prova Testemunhal em Xeque. Rio de Janeiro; Ed. Lumen Juris, 2013. 
BRASIL. Código Penal Brasileiro. Disponível em http://www.planalto.gov.br/ccivil_03/decreto-

lei/del2848compilado.htm. Acesso dia 06 de maio de 2020.

BRASIL. Código de Processo Penal Brasileiro. Disponível em http://www.planalto.gov.br/ccivil_03/decretolei/del3689compilado.htm. Acesso dia 06 de maio de 2020.

LOPES Jr.; Aury. Direito Processual Penal.11 ed São Paulo; Saraiva, 2014.

LOPES, Mariângela Tomê. Tese Doutorado: O reconhecimento como meio de prova. Universidade de São Paulo. São Paulo - Janeiro 2011. P.43.

Reportagem programa jornalístico Fantástico - Rede Globo. Disponível em: https://www.youtube.com/watch?v=5iaSaMnRZYc\&feature =youtu.be/ Acesso dia 02 de Março de 2020.

\section{COPYRIGHT}

Direitos autorais: Os autores são os únicos responsáveis pelo material incluído no artigo. 


\author{
Volume $16-\mathrm{N}^{\mathrm{o}} 174$ - Junho / 2020 \\ XLII International Sodebras Congress \\ 28 a 30 de maio de 2020 - Web Conference.
}

\title{
INOVAÇÃO ABERTA NA GESTÃO PÚBLICA: O PAPEL DAS UNIVERSIDADES PÚBLICAS PARA UMA MELHOR EFICIÊNCIA DO ESTADO
}

\section{OPEN INNOVATION IN PUBLIC MANAGEMENT: THE ROLE OF PUBLIC UNIVERSITIES FOR BETTER EFFICIENCY IN THE STATE}

\author{
DAIANE TIEME KAWAHARA PAIVA ${ }^{1}$; RONIE GALEANO ${ }^{1}$ \\ 1 - PROGRAMA DE MESTRADO PROFISSIONAL EM ADMINISTRAÇÃO PÚBLICA EM REDE - \\ PROFIAP - UNIVERSIDADE TECNOLÓGICA FEDERAL DO PARANÁ - UTFPR
}

daiane.kawahara@gmail.com; roniegaleanoutfpr@gmail.com

\begin{abstract}
Resumo - Este artigo tem por objetivo demonstrar a capacidade das universidades públicas em firmar parcerias com o setor público e privado para desenvolver pesquisas, utilizando como pilar a inovação aberta. Este estudo justifica-se pela necessidade do Estado em obter uma melhor eficiência na prestação de serviços aos cidadãos e a inovação aberta é uma oportunidade para que as universidades públicas possam devolver à sociedade o que receberam por meio dos impostos. Algumas das vantagens da participação das universidades públicas neste processo compreendem: o corpo docente qualificado, a estrutura laboratorial, a contribuição dos alunos nos projetos e o baixo custo às organizações públicas. O Estado precisa fazer o seu papel e criar políticas públicas que facilitem essas parcerias, resultando em ganho de produtividade e sobretudo, na revitalização do atendimento ao seu público, o cidadão.

Palavras-chave: Gestão Pública. Inovação. Inovação Aberta.
\end{abstract}

\begin{abstract}
This article aims to demonstrate the capacity of public universities to enter into partnerships with the public and private sector to develop research, using open innovation as a pillar. This study is justified by the need for the State to obtain better efficiency in the provision of services to citizens and open innovation is an opportunity for public universities to return to society what they received through taxes. Some of the advantages of the participation of public universities in this process include: the qualified faculty, the laboratory structure, the contribution of students to projects and the low cost to public organizations. The State needs to play its role and create public policies that facilitate these partnerships, resulting in gains in productivity and, above all, in the revitalization of service to its public, the citizen.
\end{abstract}

Keywords: Public Management. Innovation. Open Innovation.

\section{INTRODUÇÃO}

A inovação constitui o pilar para o progresso social, técnico e econômico dos países, sejam eles desenvolvidos ou não, o conhecimento e tecnologia ocasionados por ela estão intrinsicamente correlacionados à criatividade, otimização da performance de profissionais e organizações, prosperidade produtiva, ganhos em competitividade e avanço de uma nação (VIEGAS e ARANTES, 2019).

Para O'Sullivan (2008), a inovação é o processo de formular alterações referentes a métodos ou sistemas já estabelecidos, através da introdução de algo novo. Pode ser radical ou incremental, aplicada a produtos, processos e serviços de qualquer instituição. Com esta afirmação pressupõe-se que as organizações públicas estejam inseridas neste contexto.

No seminário Open Innovation Seminar, realizado no dia 16 de junho de 2008 em São Paulo, Henry Chesbrough relatou que a inovação demanda parcerias e redes de cooperação entre organizações, na busca por compartilhar recursos e conhecimento, mencionando que as universidades, devido à superior capacitação que estas conservam, possuem uma função mais significativa na inovação aberta, se comparada àquela advinda dos programas tradicionais de inovação (CHESBROUGH, 2008 apud SENSATO, 2008). Para ele, a pesquisa básica oriunda de universidades e instituições de ciência e tecnologia, que deve ser financiada pelo setor público, representa uma das principais fontes de estímulo à inovação, contanto que o governo conceda autonomia financeira a tais entidades (CHESBROUGH, 2008 apud SENSATO, 2008).

Este artigo tem o objetivo de ratificar a competência das universidades públicas em fomentar a inovação aberta no Brasil. Para tanto, serão abordados os temas Gestão Pública, Inovação Aberta e Potencial Contributivo das Universidades para a Inovação Aberta.

\section{METODOLOGIA}

A pesquisa caracteriza-se como exploratória e descritiva, nesse sentido, busca entender o fenômeno da inovação aberta e seu emprego na gestão pública, por intermédio das expertises e estruturas das universidades públicas do país, com revisão de literatura e verificação de dados. Na opinião de Collins e Hussey (2005) a pesquisa exploratória permite um maior aprofundamento do tema pesquisado, quando o mesmo ainda é pouco conhecido ou pouco explorado. Em contrapartida, a pesquisa descritiva tem como objetivo apresentar certo fenômeno, situação, população, ou mesmo, experiência. Para Marconi e Lakatos (2010) a revisão da literatura tem posição elementar em um trabalho acadêmico, onde o investigador pode situar a pesquisa dentro da grande área em administração. Ao passo que o uso de dados secundários consiste na busca de informações já coletadas, tabuladas e divulgadas em 
algumas fontes como: dados internos da empresa, publicações, entidades e governo. (ROESCH, 1999).

\section{GESTÃO PÚBLICA}

A expressão Gestão Pública pode ser definida como o rol de atividades executadas pela administração estatal, através de órgãos e servidores designados a implementar as ações cruciais à gestão da coisa pública, mediante a aplicação de conhecimentos teóricos de administração e ciências gerenciais no setor público, simbolizando o estilo organizacional de governo, isto é, a distribuição e o exercício da autoridade política (AMATO, 1971; SILVA, 2013; FERREIRA, 2014).

As circunstâncias brasileiras no decorrer do século XX motivaram transformações na forma de administrar os bens públicos ao longo do tempo, adaptando-se às necessidades de inovação da sociedade, que está cada vez mais conectada às mídias sociais e, por isso, obtém rapidamente informações sobre tudo o que acontece ao seu redor. $\mathrm{Na}$ análise da conjuntura brasileira pertinente à Gestão Pública, duas abordagens se destacam, a burocrática e a gerencial, fundamentando o modo de dirigir o setor público no Brasil.

O paradigma tradicional burocrático, sintetizado pelo sociólogo alemão Max Weber, foi amplamente disseminado nas administrações públicas de diversos países do mundo entre os séculos XIX e XX. As diretrizes desse movimento, conhecidas por abranger processos lentos, valorização da hierarquia de autoridade, racionalidade e padronização, predominaram o gerenciamento público brasileiro desde 1936 até o fim da década de 1970, quando a teoria burocrática se tornou alvo de duras críticas, em razão de suas supostas ineficiências, justificando as reformas administrativas pelo mundo, inspiradas nos padrões gerenciais da New Public Management (NPM), a Nova Gestão Pública (NGP) (MEDEIROS, 2006; SECCHI, 2009; FURTADO, FORTUNATO e TEIXEIRA, 2011; CAVALCANTE, 2017).

A NGP voltada ao setor público é marcada pela transferência de conceitos gerenciais imaginados, a priori, para o setor privado, tencionando reduzir o tamanho do Estado, gerar eficiência e estatuir meios de responsabilizar os agentes (PIERANTI, RODRIGUES e PECI, 2007).

No Brasil, a corrente da NGP ganhou força com o fim do regime militar em 1985, após a promulgação da Constituição Federal de 1988, responsável pela democratização do Estado, descentralização administrativa e por prever a prática do controle social dos atos administrativos pela população (ABRUCIO, 2007; ROCHA, 2008; SARDO ET AL., 2017).

Todavia, apenas em 1995 consumou-se a Reforma do Aparelho do Estado, idealizada em face dessa lógica de controles, um de seus elementos fundamentais (BRESSER PEREIRA, 1998).

Em harmonia com o avanço da democracia participativa que vinha crescendo, a reforma de 1995 pretendia oportunizar a governança do Estado, manifesta pela intervenção financeira e administrativa estatal sobre a economia, sempre que o mercado não tem condições de se autorregular, embasando-se na administração pública gerencial, cujo foco no cidadão-cliente corresponde a sua máxima, na intenção de tornar a gestão mais rápida, descentralizada e integrada às novas tecnologias, mais direcionada aos resultados e menos aos procedimentos (BRESSER PEREIRA, 1996, 1998).
Assim, instaurou-se o Estado gerencial, refutando parcialmente a burocratização de Max Weber, e dando lugar a uma administração mais proativa e comprometida com a eficiência (PINHO, 2001).

Para Cavalcante (2017), após a concretização da Reforma do Aparelho do Estado de 1995, inaugurou-se no Brasil a era pós NGP. Sendo, contudo, mais um movimento de continuidade e incremento das teorias existentes (burocracia e NGP), do que propriamente uma descontinuidade dos paradigmas anteriores, conhecido como Estado Neoweberiano, que preconiza aperfeiçoar o papel de liderança estatal e ampliar a confiança da população na administração pública.

Porém, apesar da manutenção de certas metodologias, percebeu-se na era pós-NGP a formação de um novo protagonismo do Estado, no qual ele é o personagem central de políticas públicas, mas não o único encarregado por desenvolver soluções para problemas da sociedade, ofertar serviços e lidar com questões complexas ligadas à globalização, tecnologia, meio ambiente, entre outras (CAVALCANTE, 2017).

Quer dizer, a partir daí registra-se maior estímulo para que a sociedade, setor privado, enfim, os diversos interessados, participem dos processos decisórios que lhe afetem, aprimorando o relacionamento entre governo e outros atores, conforme proclama a governança pública, em simetria com seus demais princípios, a saber, efetividade, transparência, accountability, equidade, conformidade legal e integridade/ética (OSBORNE, 2010; OLIVEIRA e PISA, 2015).

Ainda que seja um desafio conquistar avanços nesses quesitos, há mecanismos que beneficiam a participação popular, fortalecem a democracia e governança, promovendo especialmente a accountability, vocábulo que segundo Pinheiro (2016), expressa não apenas o controle da sociedade e responsabilização de agentes, mas também a comunicação e socialização da experiência administrativa.

Dentre eles evidencia-se a aprovação da Lei Complementar $n^{\mathbf{0}}$ 101/2000, a Lei de Responsabilidade Fiscal (LRF), que determinou o planejamento e transparência das contas públicas, fixando limites e normas para a gestão de receitas, despesas e endividamento, além de estipular a responsabilização em caso de descumprimento. Enquanto a criação da Controladoria Geral da União (CGU) em 2001, levando em conta suas funções de controle, correição, prevenção e ouvidoria, traduz-se em um instrumento de transparência, ao disponibilizar pela internet informações sobre os valores de repasses de recursos federais (PINHO e SACRAMENTO, 2009).

Outra forma de corroborar as tentativas do Estado em dinamizar o diálogo com a sociedade, em atenção à governança pública, verifica-se na estratégia adotada pelo Governo Federal no período de 2003 a 2006, apoiando a realização de conferências nacionais e criando novos conselhos de direitos e políticas públicas (ROCHA, 2008).

Em torno da participação social nas conferências nacionais, assistiu-se, nesse período, a uma situação inédita, pois nunca os segmentos organizados da sociedade haviam demonstrado tanto dinamismo nas mais diferentes áreas de políticas públicas. Entre 2003 e 2006 foram realizadas 43 conferências - 38 nacionais e cinco internacionais -, que mobilizaram mais de dois milhões de pessoas da sociedade civil e do poder público, nas esferas municipal, estadual e nacional. 
É importante notar que, do conjunto de conferências realizadas no período 2003-2006, 15 conferências foram realizadas pela primeira vez [...] (ROCHA, 2008, p.146).

Em adição, a promulgação da Lei n ${ }^{\circ}$ 12.527/2011, a Lei de Acesso à Informação, configura-se em um importante mecanismo de transparência dos atos públicos, ao disciplinar os procedimentos que devem ser observados pelos entes federativos, visando assegurar o acesso a informações públicas a qualquer cidadão interessado (FREITAS e DACORSO, 2014).

Os esforços para concepção desses dispositivos representam a concretização de parte do controle social e descentralização prescritos pela Constituição Federal de 1988, auxiliando a governança, muito embora limitem, em sua maioria, a participação dos cidadãos à fase final de projetos e serviços, ou seja, avaliação de resultados (FREITAS e DACORSO, 2014).

Para modificar esse quadro, surgiu em 2011 a Open Government Partnership (OGP), uma iniciativa fundada pelo consórcio firmado entre oito países (África do Sul, Brasil, Estados Unidos, Filipinas, Indonésia, México, Noruega e Reino Unido) para difusão e incentivo global de práticas governamentais associadas aos princípios da transparência, prestação de contas e responsabilização (accountability), acesso à informação, participação cidadã nos atos públicos e incentivo à tecnologia e inovação, mediante a assinatura - em 20 de setembro daquele ano - da Declaração de Governo Aberto, quando os fundadores apresentaram seus Planos de Ação (BRASIL, 2020).

No site Governo Aberto (BRASIL, 2020) aponta-se que a OGP consiste em um meio, tendo em vista os compromissos assumidos pelos países integrantes, para se avançar na consolidação das democracias, diminuição da corrupção e no estímulo a inovações que intensifiquem a governança.

Contemplando a imposição pela modernização constante da gestão pública brasileira, somada à complexidade em lidar com velhos dilemas inerentes à dinâmica organizacional, como atores e interesses distintos (SILVA e REBELO, 2003; CORRÊA, 2017), é primordial o rompimento com os modelos tradicionais de administrar e gerir recursos e órgãos públicos, garantindo seu desenvolvimento e sustentabilidade (GUIMARÃES, 2000; SILVA e REBELO, 2003). Cabe incorporar outros métodos e técnicas de gerenciamento mais contemporâneos, para possibilitar o alcance dos resultados esperados na oferta de serviços e formulação de políticas públicas, com a finalidade última de atender aos anseios da sociedade. Entre eles, está o conceito de Inovação Aberta, que será debatido a seguir.

\section{INOVAÇÃO ABERTA}

Os conceitos, bem como as práticas relativas à inovação, vêm sendo discutidas e agregadas às estratégias de negócios das organizações. Rogers e Shoemaker (1971); Porter (1990); e Voss (1994), compreendem por inovação a concepção de quaisquer novas tecnologias e novos processos. Şener e Saridoğan (2011) afirmam que a mudança tecnológica e a inovação são os fatores basilares para o crescimento econômico. Para eles, os países precisam arquitetar políticas que favoreçam a edificação destes dois fatores e suscitem o aumento da competitividade global de forma sustentável. Por outro lado, os países devem fortalecer o aperfeiçoamento científico para afiançar e criar novas tecnologias. O nível de competitividade mundial somente será atingido quando a transformação da economia for baseada no conhecimento.

Tanto, que na década de 1970 a inovação desenrolouse por meio de políticas orientadas à tecnologia mais eficiente, havendo o aumento de pesquisas em ciência e desenvolvimento, e de investimentos nas áreas de educação, capital humano qualificado, tecnologias de informação e comunicação e políticas governamentais (ŞENER e SARIDOĞAN, 2011).

Já a inovação aberta é vista como uma maneira de auxiliar as organizações na consecução de vantagem competitiva sustentável, em um mercado global altamente competitivo, forçando as empresas a reavaliar suas posições de liderança, refletindo-se nos resultados de desempenho de suas estratégias negociais. (Chesbrough e Appleyard, 2007).

Ao considerar a natureza antagonista existente entre empresas privadas, entende-se claramente que o desempenho da inovação aberta nessas instituições é essencial. Quanto ao seu exercício na Gestão Pública, identificam-se algumas dificuldades, levando em conta que a burocracia dificulta ações do tipo, com vistas a renovar a gestão nas organizações públicas.

Chesbrough (2003); Chesbrough e Bogers (2014), declaram que a inovação aberta ocorre quando vários atores internos e externos participam de forma colaborativa no processo de inovação, dedicando-se a diferentes tipos de parcerias, aquisição de ideias e recursos do ambiente externo.

No Brasil, a inovação aberta ainda é pouco aproveitada nas organizações públicas, mas já é perceptível o aumento de trabalhos em relação ao tema. Isso fica evidente ao constatar que as organizações privadas estão à frente, utilizando a teoria como parte de sua estratégia. (CHESBROUGH, 2003).

Diante desse quadro, o Estado tem uma elevada importância na evolução da inovação aberta na gestão pública, fato incontestável ao se apreciar a pesquisa de Chiaroni, Chiesa e Frattini (2009). Segundo os autores, a efetividade da inovação aberta carece de um exame mais aprofundado para que seja aplicada no setor público, convertendo-se em uma base sólida de gestão. Para Jordão (2012), além da importância do Estado neste processo, há igualmente a necessidade de se modificar sua relação com a sociedade.

"As condições institucionais de um país e as suas políticas públicas podem atuar no sentido de potencializar ou de desincentivar as atividades de inovação" (VIEGAS e ARANTES, 2019, p.28).

Lamboglia et al. (2017) entabularam uma análise sobre a inovação aberta no setor público em países emergentes e detectaram que nações como as pertencentes ao BRICS (Brasil, Rússia, Índia, China e África do Sul), por exemplo, precisam engendrar novos processos para atuar com maior eficiência, necessitando, portanto, de uma aproximação a agentes externos, pois tais países manifestam limitações tecnológicas. $\mathrm{Na}$ visão dos autores, os governos somente serão capazes de implantar projetos de inovação aberta pública, ao estreitarem suas relações de colaboração com a sociedade, empresas privadas, universidades e agências públicas. 


\section{POTENCIAL CONTRIBUTIVO DAS UNIVERSIDADES PARA A INOVAÇÃO ABERTA}

A Lei $n^{\circ} 10.973$, que aprova o Plano Nacional de Educação (PNE), promulgada em 2 de dezembro de 2004, alterada pela Lei $\mathrm{n}^{\circ} 13.243$, de 11 de janeiro de 2016, o Novo Marco Legal de Ciência, Tecnologia e Inovação, elenca medidas de fomento à inovação e à pesquisa científica e tecnológica no ambiente produtivo, tendo como uma de suas premissas impulsionar atividades de inovação em instituições científicas e tecnológicas, com o propósito de expandir a capacidade e autonomia tecnológica brasileira, propiciando o desenvolvimento nacional e regional (BRASIL, 2004, 2016).

Vale ressaltar que as universidades públicas usufruem de um vasto quadro de professores bem instruídos, assim como de laboratórios para a produção de pesquisas variadas. Talvez nem todas detenham uma estrutura ideal, mas ao menos guardam conhecimento técnico e científico capazes de viabilizar a formação de parcerias com o setor público e privado na elaboração de pesquisas.

Conforme o Instituto Nacional de Estudos e Pesquisas Educacionais Anísio Teixeira (INEP), existiam no Brasil em 2018, com base no Censo daquele ano, 299 Instituições de Educação Superior (IES) públicas, 128 (42,8\%) estaduais; $110(36,8 \%)$, federais e $61(20,4 \%)$, municipais (BRASIL, 2019).

A Meta 13 da Lei $n^{\circ} 13.005$ de 2014, que impõe ampliar a proporção de docentes mestres e doutores da educação superior para $75 \%$ e $35 \%$, nessa ordem, foi atingida. Dos 384.474 professores da categoria, mais de $80 \%$ possuíam mestrado e/ou doutorado, $43 \%$, doutorado (BRASIL, 2014; CAPES, 2020).

Diante deste cenário, a rede pública de ensino superior tem experimentado um crescimento da atuação de mestres e doutores na casa de $64,3 \%$ e $25,5 \%$, respectivamente, exibindo em 2018 um quadro de cerca de 173.782 docentes formados em diversas áreas. (BRASIL, 2019).

Destaca-se ademais, que o grau de instrução típica dos professores da rede pública corresponde ao doutorado. Dados do Censo de 2018 apontam que 64,3\% deles portam o título de doutor (BRASIL, 2019), estimulando a abertura de programas desse nível e, consequentemente, a condução de pesquisas científicas e tecnológicas de qualidade.

Consoante às averiguações acima, torna-se indiscutível que as universidades públicas mantêm perícia e um corpo docente capacitado para empreender pesquisas nos mais diversificados campos do conhecimento, apoiando a otimização da eficiência na administração pública.

Apesar disso, Faedo et al. (2019) comprovam que a presença de universidades brasileiras nos rankings internacionais de universidades inovadoras é humilde e ínfima, quando comparada às instituições internacionais. Apenas a Universidade de São Paulo (USP), Unicamp e a Universidade Federal do Rio de Janeiro (UFRJ) figuram nessas classificações. As mesmas estavam, em 2017, entre as dez universidades brasileiras mais inovadoras, de acordo com o Ranking Universitário Folha (RUF), do Jornal Folha de São Paulo (FAEDO ET AL., 2019).

As universidades precisam aprimorar algumas características consideradas indispensáveis à expansão da capacidade inovadora, como ajustar a missão de acordo com as questões problemáticas de sua região; absorver a inovação na cultura organizacional; investir em seu capital humano; destinar recursos financeiros à inovação e estruturar adequadamente o Núcleo de Inovação Tecnológica (NIT), previsto pela Lei n ${ }^{\circ} 10.973 / 2004$ como gestor da política institucional de inovação (BRASIL, 2004; KURESKI e ROLIM, 2009; FAEDO ET AL., 2019).

\section{CONCLUSÃO}

Tendo em mente o escopo da pesquisa "demonstrar a capacidade das universidades públicas em firmar parcerias com o setor público e privado para desenvolver pesquisas, utilizando como pilar a inovação aberta", apreende-se que o mesmo foi alcançado, devido à construção teórica efetuada por meio da pesquisa exploratória e descritiva. A investigação corrobora que de fato o Brasil preserva universidades públicas com estruturas intelectuais razoáveis ao amparo na materialização de pesquisas e projetos tecnológicos que possibilitem atualizar a gestão pública do país. São 299 instituições públicas de ensino superior e diversos campi espalhados por todo o território nacional.

Entretanto, seus muros precisam ser urgentemente abertos para as comunidades nas quais estão inseridas, para que juntos, sociedade, universidades, organizações públicas e privadas, possam conceber pesquisas focadas na eficiência do Estado e na evolução econômica e social do país, para modernizar o atendimento ao cidadão, carente de processos ágeis e resultados menos burocráticos que facilitem a sua vida, concorrendo inclusive para a diminuição das desigualdades, em observância à Lei de Inovação, $\mathrm{n}^{\circ}$ $10.973 / 2004$.

Mostra-se mais acessível uma instituição levar suas demandas à universidade pública, que conta com um corpo docente altamente qualificado e laboratórios prontos à execução de pesquisas que gerem como resultado final a inovação, a contratar empresas que cobram altos valores pelos serviços prestados.

Destarte, o Estado precisa rever suas políticas de associação entre o público e o privado, visando promover o envolvimento coletivo em benefício de toda a sociedade, indo ao encontro dos preceitos da Open Government Partnership (OGP), iniciativa com a qual o Brasil se comprometeu.

Em síntese, as universidades públicas podem contribuir muito para o desenvolvimento social e econômico do país, mas fica clara a necessidade de implementar políticas públicas que as incentivem a inovar junto com o setor produtivo, Estado e sociedade, no desenvolvimento de ações que permitam melhorar a qualidade de vida dos cidadãos.

Dessa maneira, recomenda-se para pesquisas futuras que estudos sobre as dificuldades em incorporar a inovação aberta em universidades, com o intuito de alavancar o progresso do país e aperfeiçoar a gestão pública, sejam elaborados, para que a identificação dos obstáculos favoreça sua transposição.

\section{REFERÊNCIAS BIBLIOGRÁFICAS}

ABRUCIO, Fernando. Luiz. Trajetória recente da gestão pública brasileira: um balanço crítico e a renovação da agenda de Reformas. Revista de Administração Pública, Edição Especial Comemorativa, p. 67-86, Rio de Janeiro, 2007.

AMATO, Pedro Muñoz. Introdução à teoria geral de administração pública. In__. Caderno de Administração Pública. 2 ed. Rio de Janeiro: Fundação Getúlio Vargas, 1971. 
BRASIL. Lei $\mathbf{n}^{\mathbf{0}}$ 10.973. Promulgada em 2 de dezembro de 2004. Disponível em http://www.planalto.gov.br/ccivil_03/_ato20042006/2004/lei/110.973.htm>. Acesso em: 06 maio 2020.

Lei $n^{\circ}$ 13.005. Promulgada em 25 de junho de 2014. Disponível em < http://www.planalto.gov.br/ccivil_03/_ato2011-

2014/2014/lei/113005.htm\#anexo>. Acesso em: 06 maio 2020.

Lei $n^{0}$ 13.243. Promulgada em 11 de janeiro de 2016. Disponível em http://www.planalto.gov.br/ccivil_03/_ato2015-

2018/2016/Lei/L13243.htm>. Acesso em: 06 maio 2020.

MEC. Instituto Nacional de Estudos e Pesquisas Educacionais (Inep). Censo da educação superior 2018: notas estatísticas. [Online]. Brasília: Inep, 2019. Disponível em:<http://download.inep.gov.br/educacao_superior/censo_ superior/documentos/2019/censo_da_educacao_superior_20 18-notas_estatisticas.pdf >. Acesso em: 27 abr. 2020.

Governo Aberto. A OGP: o que é a iniciativa. Disponível em: < http://governoaberto.cgu.gov.br/a-ogp/oque-e-a-iniciativa>. Acesso em: 02 de abr. 2020.

BRESSER PEREIRA, Luiz Carlos. Da administração pública burocrática à gerencial. Revista do Servidor Público, Brasília, v. 47, n. 1, p. 1-28, jan/abr., 1996.

A reforma do Estado dos anos 90: lógica e mecanismos de controle. Lua Nova, São Paulo, n. 45, p. 4995, 1998 .

CAPES. Inep registra aumento de mestres e doutores no ensino superior. Disponível em: <https://www.capes.gov.br/36-noticias/10125-inep-registraaumento-de-mestres-e-doutores-no-ensino-superior>.

Acesso em: 27 abr. 2020

CAVALCANTE, Pedro. Gestão pública contemporânea: do movimento gerencialista ao pós-npm. Brasília: IPEA, 2017.

CHESBROUGH, H. W. Open innovation: the new imperative for creating and profiting from technology. Harvard Business Press, Boston, 2003.

CHESBROUGH, H.W., APPLEYARD, M. M. Open innovation and strategy, Management Review, California, v. 50, n.1, p. 57-76, 2007.

CHESBROUGH, H. W. and BOGERS, M. Explicating open innovation: clarifying an emerging paradigm for understanding Innovation. In Chesbrough et al. (eds.), 2014.

CHIARONI, Davide; CHIESA, Vittorio; FRATTINI, Frederico. The open innovation journey: howfirms dynamically implement the emerging innovation management paradigm. Amsterdam: Technovation, 2009.

COLlinS, J.; HUSSEY, R. Pesquisa em Administração. Porto Alegre: Bookman, 2005.

CORRÊA, Victor Trottmann. O campo do conhecimento em administração pública no Brasil: uma análise histórica a partir do seu contexto e caráter multifacetado. 2017. $192 \mathrm{f}$. Tese (Doutorado em Administração de Organizações) Universidade de São Paulo, São Paulo, 2017.
FAEDO, Juliane Yukie Yamamoto; et al. Fatores facilitadores de inovação em universidades: contribuições de casos brasileiros. International Journal of Knowledge Engineering and Management (IJKEM), Universidade Federal de Santa Catarina, Florianópolis, v.8, n. 20, p. 5075, mar.-jun. 2019.

FREITAS, Rony Klay Viana de; DACORSO, Antonio Luiz Rocha. Inovação aberta na gestão pública: análise do plano de ação brasileiro para a open government partnership. Revista de Administração Pública, Rio de Janeiro, v. 48, n. 4, p. 869-888, ago. 2014.

FERREIRA, Marco Aurélio M. Gestão pública, Departamento de Ciências da Administração - UFSC Florianópolis, 2014.

FURTADO, Maria Alice Pinheiro; FORTUNATO, Graziela; TEIXEIRA Aridelmo. A percepção dos gestores da área pública sob a política de gerenciamento de projetos.

Revista Eletrônica Sistemas \& Gestão, v. 6, n. 2, 2011, p. 167-183, DOI: 10.7177/sg.2011.v6. n2.a6.

GUIMARÃES, Tomas de Aquino. A nova administração pública e a abordagem da competência. Revista de Administração Pública, Rio de Janeiro, v. 34, n.3, p. 125 140, maio/jun. 2000.

JORDÃO, Claudia. A cidadania na reforma do Estado: redefinição de conceitos e consequências práticas. Encontro Nacional de Administração Pública e Governança, 5., 2012, Salvador. Anais [...]. Salvador, 2012.

KURESKI, Ricardo; ROLIM, Cassio. Impacto econômico de curto prazo das universidades federais na economia brasileira. Revista Paranaense de Desenvolvimento, $n$. 117, p. 29-51, 2009.

LAMBOGLIA, Galo Andrés Suasnavas; RODRIGUES Marques, Humberto Rodrigues; ROSA, Priscila Luiz; BERMEJO, Paulo Henrique de Souza. Inovação aberta no setor público de países com economias emergentes: uma revisão de literatura. Revista de Administração da Unimep, vol. 15, núm. 4, set-dez, 2017, pp. 46 -62.

MARCONI, M. A.; LAKATOS, E. M. Fundamentos de Metodologia Científica. $7^{\mathrm{a}}$ ed. rev., São Paulo: Atlas, 2010.

MEDEIROS, Paulo Henrique Ramos. Do modelo racionallegal ao paradigma pós-burocrático: reflexões sobre a burocracia estatal. Organizações e Sociedade, Salvador, v. 13, n. 37, p. 143-160, jun. 2006.

OLIVEIRA, Antonio Gonçalves de; PISA, Beatriz Jackiu. IGovP: índice de avaliação da governança pública instrumento de planejamento do Estado e de controle social pelo cidadão. Revista de Administração Pública, Rio de Janeiro, v. 49, n. 5, p. 1263-1290, Oct. 2015.

OSBORNE, S. (Ed.) The new public governance? emerging perspectives on the theory and practice of public governance, London and New York. UK: Routledge/Taylor and Francis, 2010.

O'SUllivan, David; DOOLEY, Lawrence. Applying innovation. Sage Publications, 2008.

PIERANTI, Octavio Penna; RODRIGUES, Silvia; PECI, Alketa. Governança e new public management: 
convergências e contradições no contexto brasileiro. In XXXI Encontro da ANPAD. Rio de Janeiro, 2007.

PINHEIRO, Douglas Antônio Rocha. A legitimidade do controle social da gestão pública: uma resposta a Herbert Wechsler. Revista de Administração Pública, Rio de Janeiro, v. 50, n. 5, p. 867-883, Oct. 2016.

PINHO, Antônio. Evolução do Estado moderno. In: MACHADO, Geraldo. Gestão pública: desafios e perspectivas. Salvador: Fundação Luiz Eduardo Magalhães, 2001.

PINHO, José Antonio Gomes de; SACRAMENTO, Ana Rita Silva. Accountability: já podemos traduzi-la para o português? Revista de Administração Pública, Rio de Janeiro, v. 43, n. 6, p. 1343-1368, Dec. 2009.

PORTER, Michael E. The Competitive Advantage of Nations. Harvard Business Review, v. 68, n. 2, p. 73-93, 1990.

ROCHA, Enid. A Constituição cidadã e a institucionalização dos espaços de participação social: avanços e desafios. In: VAZ, Flavio Tonelli; MUSSE, Juliano Sander; SANTOS, Rodolfo Fonseca (Coords.). 20 anos da constituição cidadã: avaliação e desafios da seguridade social. Brasília, ANFIP, 2008, p. 131-148.

ROESCH, S. M. A. Projetos de estágio e de pesquisa em administração. São Paulo: Atlas, 1999.

ROGERS, Everett M.; SHOEMAKER, F. Floyd. Communication of innovations; a cross-cultural approach. 1971.

SARDO, Bianca C. et al. A importância do escritório de gerenciamento de projetos (PMO) na administração pública. In Anais.: VI SINGEP, São Paulo, 2017.

SECCHI, Leonardo. Modelos organizacionais e reformas da administração pública. Revista de Administração Pública, Rio de Janeiro, v. 43, n. 2, p. 347-369, abr. 2009.

ŞENER, Sefer; SARIDOĞAN, Ercan. The effects of science-technology-innovation on competitiveness and economic growth. Procedia-Social and Behavioral Sciences, v. 24, p. 815-828, 2011.

SENSATO, Vanessa. O papel da universidade no modelo de inovação aberta. Jornal da Unicamp - Universidade Estadual de Campinas, jun. 2008. Disponível em: < https://www.unicamp.br/unicamp/unicamp_hoje/jornalPDF/ ju400pag02.pdf>. Acesso em: 29 abr. 2020.

SILVA, Adival do Carmo. Evolução da administração pública no Brasil e tendências de novos modelos organizacionais, 2013. Disponível em < http://www.ice.edu.br/TNX/storage/webdisco/2013/12/13/o utros/27b4d512efbac7d37520bc37aa78cac1.pdf>. Acesso em: 31 mar. 2020.

SILVA, Anielson Barbosa; REBELO, Luiza M. Bessa. A emergência do pensamento complexo nas organizações. Revista de Administração Pública, Rio de Janeiro, v. 37, n.4, p. 777-796, 2003.

VIEGAS, Thales de Oliveira Costa; ARANTES, Lídia Silveira. Sondagem de inovação: evidência brasileira. Revista Sodebras [on line], v. 14, n. 168, dez. 2019, p. 2129, ISSN 1809-3957. Disponível em: <
http://www.sodebras.com.br/edicoes/N168.pdf>. Acesso em: 30 abr. 2020.

VOSS, Christopher A. Significant issues for the future of product innovation. Journal of Product Innovation Management, v. 11, n. 5, p. 460-463, 1994.

\section{COPYRIGHT}

Direitos autorais: Os autores são os únicos responsáveis pelo material incluído no artigo. 


\section{Área: Ciências Agrárias e Biológicas}

\begin{tabular}{|c|c|}
\hline $5-3$ & $\begin{array}{l}\text { SISTEMAS DE IRRIGAÇÃO AUTOMATIZADO: REVISÃO } \\
\text { AUTOMATED IRRIGATION SYSTEMS: REVIEW } \\
\text { Jampierre V. Rocha }\end{array}$ \\
\hline $5-7$ & $\begin{array}{l}\text { SECAGEM DE AMOSTRAS DE BANANA: EFEITO DA GEOMETRIA DA } \\
\text { AMOSTRA E DA TEMPERATURA DE SECAGEM } \\
\text { DRYING OF BANANAS SAMPLES - EFFECT OF SAMPLE GEOMETRY AND } \\
\text { DRYING TEMPERATURE } \\
\text { Kelly Hofsetz; Carolina Baraldi E Silva }\end{array}$ \\
\hline
\end{tabular}




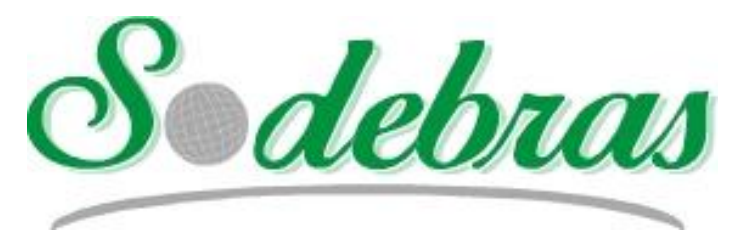

\author{
Volume 16 - $\mathrm{N}^{\mathrm{o}} 174$ - Junho / 2020 \\ XLII International Sodebras Congress \\ 28 a 30 de maio de 2020 - Web Conference.
}

\title{
SISTEMAS DE IRRIGAÇÃO AUTOMATIZADO: REVISÃO AUTOMATED IRRIGATION SYSTEMS: REVIEW
}

\author{
JAMPIERRE V. ROCHA ${ }^{1}$ \\ 1 - LENOVO \\ r.jampierre@gmail.com
}

\begin{abstract}
Resumo - A automatização de processos é uma realidade comum e tendencia para o futuro, com isso, não seria diferente pensar na automação dos sistemas de irrigações para aumentar sua eficiência de produção e gerenciar os recursos hídricos com a aplicação da irrigação de precisão. O objetivo desse estudo foi avaliar os trabalhos desenvolvidos a redor do mundo sobre o tema referente. $O$ presente trabalho foi realizado por meio de um instrumento base chamado Periódico Capes, através das bases de pesquisas Scopus, Scielo e IEEE. Dos 39 artigos, 19(49\%) deles focaram exclusivamente em automatizar a irrigação, deixando para o sistema decidir quando e quanto irrigar. Por meio desta pesquisa de revisão, pode-se concluir que os trabalhos procuram apresentar soluções de baixo custo e facilidade de uso afim de que seja acessível e de agrado a todos os agricultores através da comodidade e redução de mão de obra.
\end{abstract}

Palavras-chave: Irrigação. Automação. Recurso hídrico. Irrigação de precisão.

\begin{abstract}
The automation of processes is a common reality and a trend for the future, so it would not be different to think of the automation of irrigation systems in order to increase their production efficiency and to manage in an economic way the water resources with the application of irrigation accuracy. The objective of this study was to evaluate the works that are being developed around the world on the referent theme. The present work was carried out by means of a basic instrument called Periódico Capes, through the research bases Scopus, Scielo and IEEE. Of the 39 articles, 19(49\\%) of them focused exclusively on automating irrigation, leaving the system to decide when and how much to irrigate. Through this review research, it can be concluded that the works seek to present solutions of low cost and ease of use in order that it is accessible and pleasing to all farmers through the convenience and reduction of labor.
\end{abstract}

Keywords: Irrigation. Automation. Water resource. Precision irrigation.

\section{INTRODUÇÃO}

A agricultura é a atividade socioeconômica que mais utiliza água em todo o mundo, chegando a consumir $70 \%$, em média, de toda a água doce presente no planeta. No Brasil, esse valor pode atingir $72 \%$, e em alguns países subdesenvolvidos chega a ultrapassar os $80 \%$. Além de ser a atividade que mais consome água, é também a que mais desperdiçada: segundo dados do Fundo das Nações Unidas para Agricultura e Alimentação (FAO), quase metade de toda a água empregada no campo é desperdiçada e, caso o meio rural diminuísse o consumo em $10 \%$, o volume seria suficiente para abastecer a população mundial duas vezes, (PENA, 2017).
Para adequar o consumo de água em ambientes protegidos, e consequentemente, tornar a irrigação mais eficiente, tem-se desenvolvido novas técnicas que permitem determinar o momento correto de se irrigar e a quantidade de água a ser aplicada, necessária para o adequado desenvolvimento da planta (JÚNIOR, GERSÁSIO, ARMINDO, 2013).

A automação dos sistemas de irrigação é de extrema importância por gerenciar de forma eficiente os recursos hídricos, reduzir custos referentes à utilização de insumos, corroborando para que a atividade agrícola se torne sustentável do ponto de vista ambiental, social e econômico.

Por fim o objetivo dessa pesquisa é ver oque esta sendo feito ao redor do mundo em relação ao gerenciamento dos recursos hídricos voltado para a agricultura utilizando irrigação de precisão de forma automatizada.

\section{METODOLOGIA}

O presente trabalho foi realizado por meio de um instrumento base chamado Periódico Capes, através das bases de pesquisas Scopus, Scielo e IEEE. Para a base de dados Scielo foi filtrado a busca nos periódicos da revista Irriga e Angriabi utilizando a palavra chave "automation" no qual inicialmente foram encontrados 21 documentos dos quais 4 foram utilizados para o trabalho. Na base Scopus foi utilizada as seguintes palavras chaves: "precision irrigation" e "automation", e encontrados 85 documentos do qual 32 foram utilizados para o trabalho por terem maior relevância com o tema abordado. Na base de dados IEEE (Instituto de Engenheiros Eletricistas e Eletrônicos) utilizou-se "precision irrigation" como palavra chave, retornando 205 artigos de conferencias do qual 3 foram selecionados por serem de maior relevância com o tema (Figura 1). A seleção final foi feita detalhadamente, montado uma planilha no software Numbers avaliando os títulos de todas as literaturas, bem como os seus resumos(Abstract), materiais e métodos. A planilha foi composta dos seguintes informações: título, objetivo, conclusão, local e ambiente de teste, valor do projeto, plantio testado, tipo de irrigação, data de publicação, função principal do projeto, tipos de comodidade oferecidas para o usuário, sua empregabilidade, nível de automação e tipo de tecnologia empregada para cumprir o objetivo da pesquisa.

As bases foram acessadas para pesquisa no dia 24 de maio de 2018. 
Figura 1 - Número de artigos selecionados das bases Scopus, SciELO e IEEE

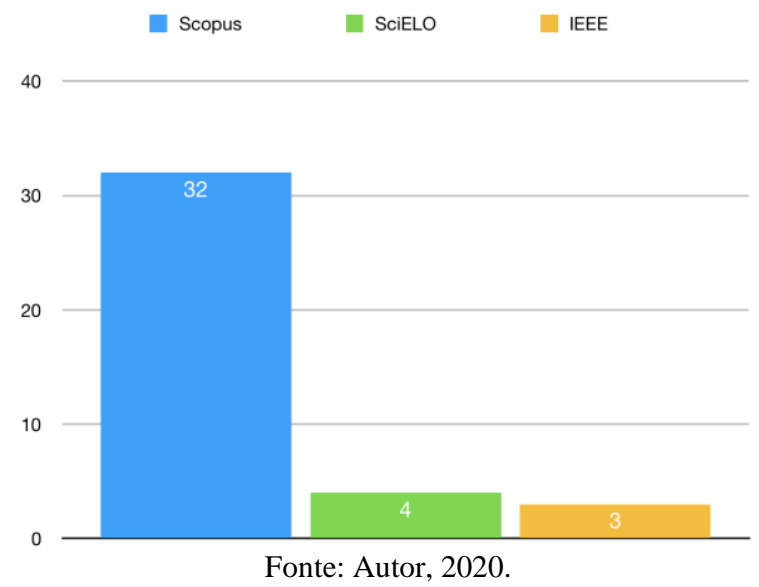

Para fins de ilustração, melhor compreensão e organização, foi criado uma tabela de classificação que define os sistemas de irrigação como: Manual, Manual com acompanhamento, Gerenciamento para tomada de decisão, Automação/Gerenciamento, Automatizado com configuração e Automatizado auto-configurável. O detalhamento de como foi classificado cada trabalho encontra-se na coluna "descrição" da Tabela 1.

Tabela 1 - Classificação dos sistemas de irrigação.

\begin{tabular}{|c|c|c|}
\hline $\begin{array}{c}\text { Nível de } \\
\text { Automação }\end{array}$ & Classificação & Descrição \\
\hline Manual & $\star$ & $\begin{array}{l}\text { Irrigação } \\
\text { convencional }\end{array}$ \\
\hline $\begin{array}{l}\text { Manual c/ } \\
\text { acompanhamento }\end{array}$ & $\star \star$ & $\begin{array}{l}\text { Utilização de } \\
\text { métricas para } \\
\text { estimar a } \\
\text { quantidade de água } \\
\text { a ser aplicada }\end{array}$ \\
\hline $\begin{array}{l}\text { Gerenciamento } \\
\text { p/ tomada de } \\
\text { decisão }\end{array}$ & $\star \star \star$ & $\begin{array}{l}\text { Composição de } \\
\text { sensores para } \\
\text { informar ao usuário } \\
\text { a situação da } \\
\text { plantação para o } \\
\text { mesmo intervir em } \\
\text { quando irrigar }\end{array}$ \\
\hline $\begin{array}{l}\text { Automação/ } \\
\text { Gerenciamento }\end{array}$ & $\star \star \star \star \star$ & $\begin{array}{l}\text { Composição de } \\
\text { sensores para } \\
\text { informar ao usuário } \\
\text { a situação da } \\
\text { plantação e irriga } \\
\text { quando o usuário } \\
\text { não intervir ou não } \\
\text { tomar nenhuma } \\
\text { decisão (sis. Irriga } \\
\text { p/ evitar condições } \\
\text { extremas) }\end{array}$ \\
\hline $\begin{array}{l}\text { Automação c/ } \\
\text { configuração }\end{array}$ & 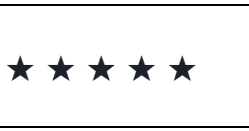 & $\begin{array}{l}\text { Sistema toma a } \\
\text { decisão de quando } \\
\text { e quanto irrigar }\end{array}$ \\
\hline $\begin{array}{l}\text { Automatizado } \\
\text { auto- } \\
\text { configurável }\end{array}$ & 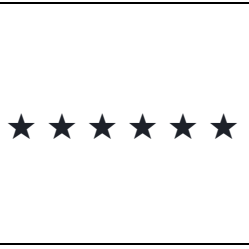 & $\begin{array}{l}\text { Sistema identifica e } \\
\text { ajusta de acordo } \\
\text { com o tipo de } \\
\text { cultura e fase } \\
\text { fenológica da } \\
\text { planta }\end{array}$ \\
\hline
\end{tabular}

\section{RESULTADOS}

Os 39 artigos significativos encontrados para pesquisa de irrigação de precisão e automatizada foram distribuídos na gráfico geográfico conforme mostra a Figura 2 e 3 , e distribuídos na linha temporal conforme demonstrado na Tabela 2.

Figura 2 - Mapa mundial com seus respectivos países com publicações

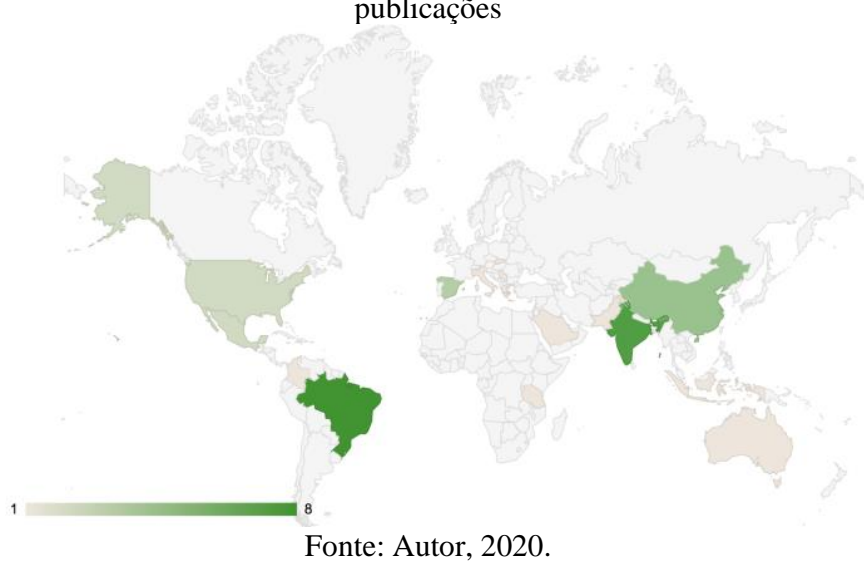

Figura 3 - Mapa do Brasil com seus respectivos estados com publicações

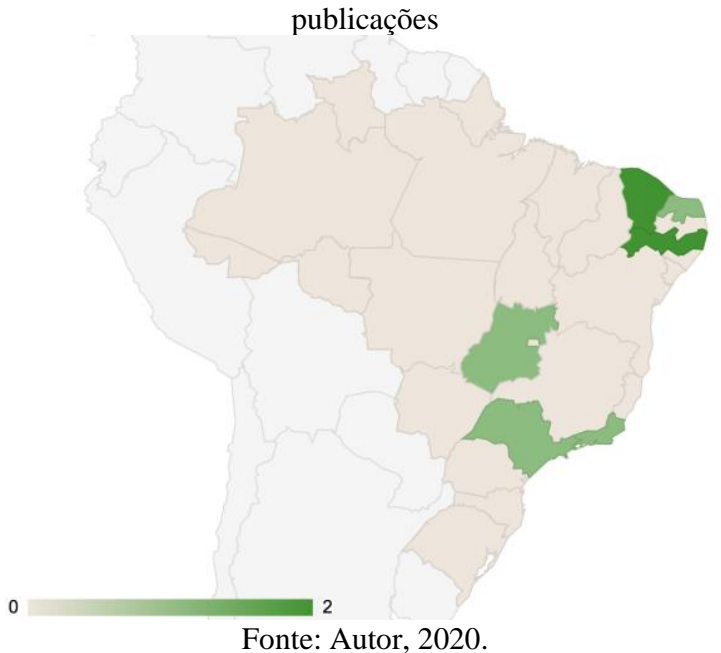

Tabela 1 - Ano de publicação dos artigos.

\begin{tabular}{cc} 
Ano da Publicação & Quantidade de Publicaçoes \\
\hline 2007 & 1 \\
2010 & 1 \\
2012 & 3 \\
2014 & 3 \\
2015 & 3 \\
2016 & 4 \\
2017 & 21 \\
2018 & 2 \\
\hline
\end{tabular}

De acordo com a Figura 2, é possível observar que no continente Asiático é onde se tem um maior número de estudos sobre o assunto, mais especificamente na Índia. Olhando para o Brasil (Figura 3) o nordeste é onde se tem o maior número de publicações sobre o tema.

Dos trabalhos selecionados, as ferramentas empregadas pelos autores estão expressas no Figura 4. É possível observarmos que dentro os artigos escolhidos 33\%(13) utilizou o Arduino, 8\%(3) trabalhou diretamente com PIC, $3 \%$ (1) com Raspberry PI, 28\%(11) não especificou e $28 \%(11)$ outros. 
Figura 4 - Microcontroladora utilizadas pelos autores

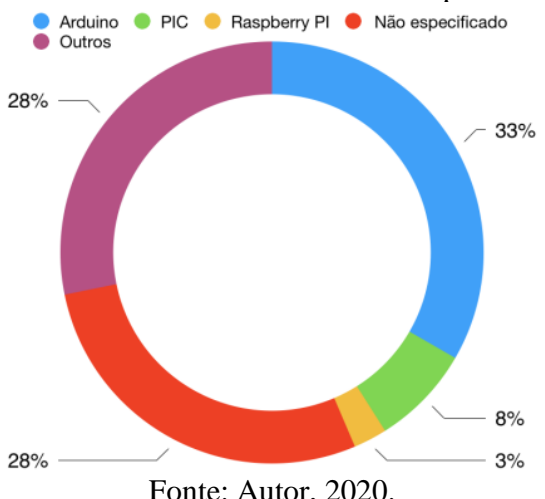

Fonte: Autor, 2020.

Por meio do Figura 5, podemos perceber que a preocupação dos autores não estavam simplesmente em automatizar o processo de irrigação, e sim, também em como informar o usuário final a forma de acesso ao sistema desenvolvido. Dos artigos selecionados, 62\%(24) fornece ao usuário informações que os autores consideram pertinentes de forma local, podendo ser por um display de LCD, SMS, bluetooth ou a uma página web acessível apenas localmente. $38 \%(15)$ dos trabalhos passam essas informações de forma online, podendo ser um aplicativo exclusivo para o sistema ou por uma pagina Web.

Figura 5 - Foma de acesso ao sistema desenvolvido - Local - Remoto

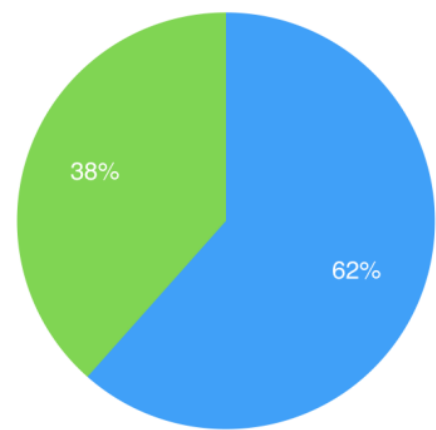

Fonte: Autor, 2020.

Conforme as revisões realizadas nos 39 artigos, apresentado na Figura 6, 49\%(19) dos sistemas foram desenvolvidos exclusivamente para tomar as decisões de quando e quanto irrigar, já, 36\%(14) gerencia apenas as informações para o usuário no qual o mesmo quem toma a decisão do que fazer com esses dados, ou seja, se irriga ou não. 15\%(6) aplica ambos os conceitos, gerencia a irrigação, porem dando espaço para que o usuário intervenha caso julgue necessário. Um dos caso foi o trabalho realizado por Savic e Radonjic (2017), onde o autor desenvolveu um sistema que irriga por tempo determinado sempre que as condições das regras estipuladas forem verdadeiras, mas da a opção de remotamente enviar uma mensagem de texto(SMS) para o sistema para irrigar.
Figura 6 - Finalidade dos trabalhos desenvolvidos

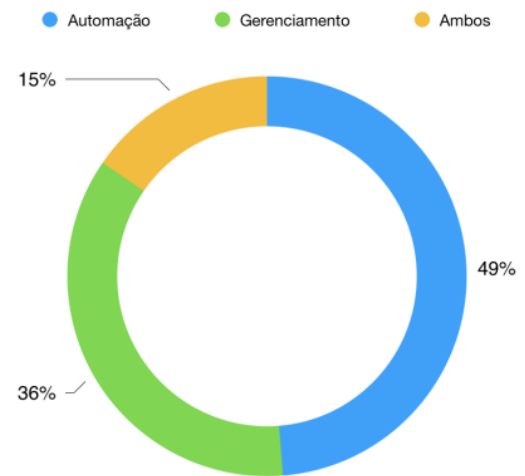

Fonte: Autor, 2020

Outro ponto observado foi o custo reduzido dos projetos, como foi citado por $14(36 \%)$ autores e outros $2(5 \%)$ tiveram uma redução de custo comparado com os métodos disponíveis no mercado como mencionado pelo autor Bezerra et al. (2017):

"The controller with one single extension has a $45 \%$ lower cost and, with six extensions, this cost becomes $37 \%$ higher if compared to the controller with four extensions (BEZERRA et al., p.401, 2017a)."

Das pesquisas feitas, foi relatado no Figura 7 que $84 \%$ (36) dos trabalhos foram implantados no meio rural e $16 \%$ (6) para centros urbanos. No segundo caso, exclusivamente para irrigação de gramados, com foco em comodidade e economia, como relatam Koprda et al. (2017) e Blado et al. (2017).

Figura 7 - Localidade das aplicações estudadas

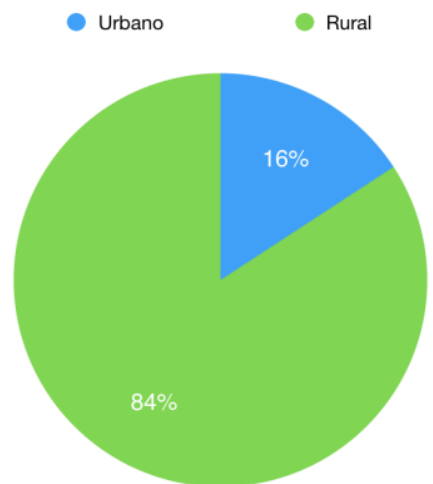

Fonte: Autor, 2020.

A Figura 8 apresenta que, dos locais utilizados para plantio, 26\%(10) dos autores fizeram em estufas, 49\%(19) em campo aberto e 26\%(10) não especificou. 
Figura 8 - Plantio protegido ou em local aberto

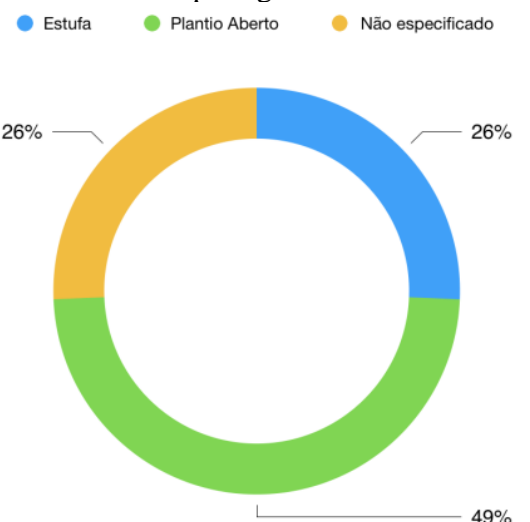

Fonte: Autor, 2020.

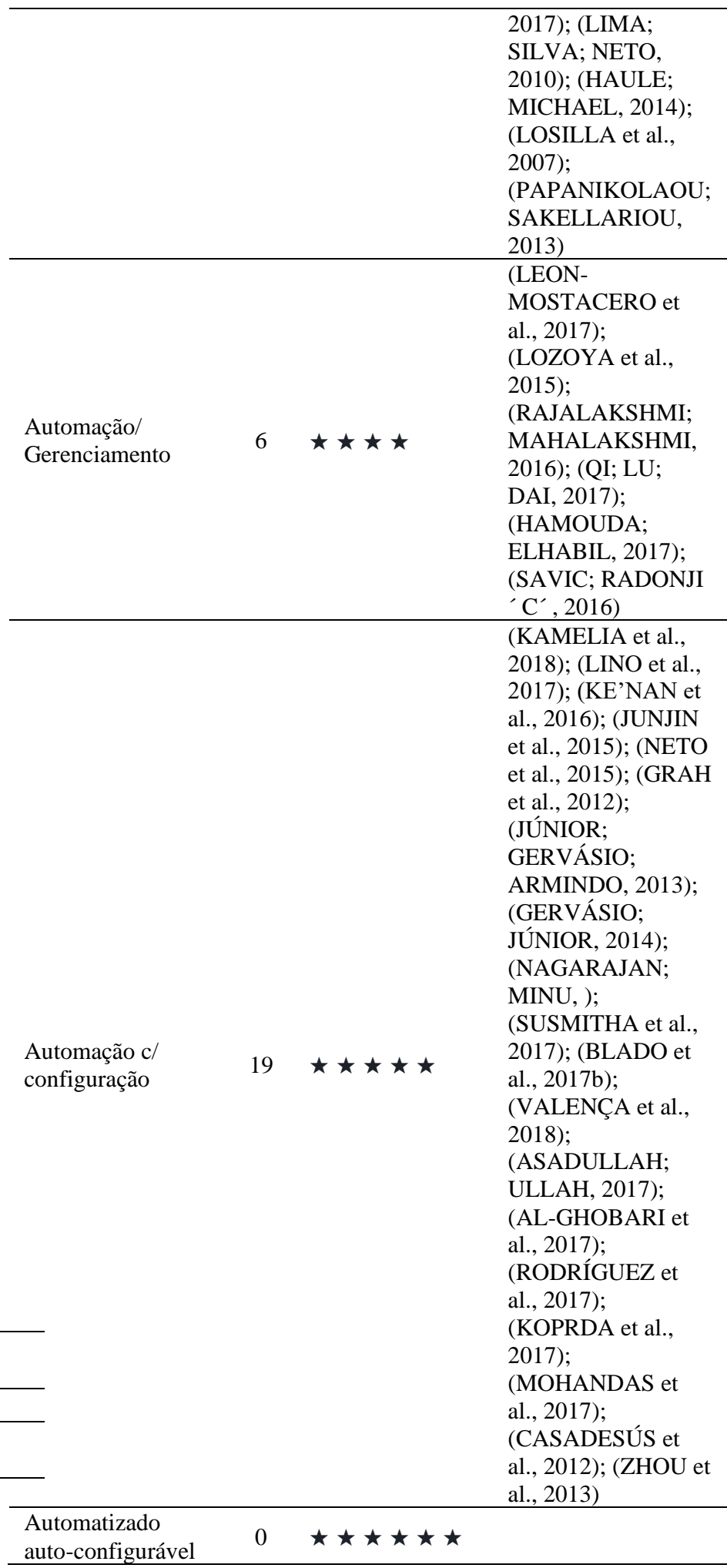

2016);

(ARVINDAN;

KEERTHIKA,

2016);

(OLSZEWSKI et al.,

ESQUIVA et al. sistema de irrigação, e sim, economizar aguá 2017); (SIROHI et potencialmente energia. Alguns trabalhos como o do Isik et al., 2016); al. (2017) utilizou placas solares, o que atualmente no (MASSERONI et mundo está se tornando uma grande tendencia em varias al., 2017); (LATHA;setores, por conta da necessidade de busca por fontes de SURIYA;

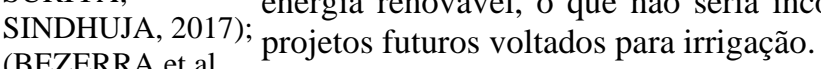

2017); (MONTOYA

et al., 2017); (I SIK

et al., 2017);

(GONZÁLEZ-

\section{CONCLUSÃO}

Por meio desta pesquisa de revisão, pode-se concluir Gerenciamento $\mathrm{p} /$
tomada de decisão 14 
Dos 7 artigos feito por autores brasileiros, apenas Lima, Silva e Neto (2010) exploram a tecnologia IoT para ter acesso remoto por meio da construção de um software. Os demais não exploraram nenhum recurso online ou mobile para trazer maior comodidade para o usuário, ao contrario do resto das pesquisas feita fora do pais que utilizou ao menos um dos recursos quando não ambas.

\section{REFERÊNCIAS BIBLIOGRÁFICAS}

AL-GHOBARI, Hussein M. et al. Automated irrigation systems for wheat and tomato crops in arid regions. Water SA, v. 43, n. 2, p. 354-364, 2017.

ANDRES LEON-MOSTACERO, Jose et al. Development of a precision irrigation system on central pivot team. TECNOLOGIA Y CIENCIAS DEL AGUA, v. 8, n. 4, p. 101-116, 2017.

ARVINDAN, A. N.; KEERTHIKA, D. Experimental investigation of remote control via Android smart phone of arduino-based automated irrigation system using moisture sensor. In: 2016 3rd International Conference on Electrical Energy Systems (ICEES). IEEE, 2016. p. 168175 .

ASADULLAH, Muhammad; ULLAH, Khalil. Smart home automation system using Bluetooth technology. In: 2017 International Conference on Innovations in Electrical Engineering and Computational Technologies (ICIEECT). IEEE, 2017. p. 1-6.

BEZERRA, Ricardo de $\mathrm{S}$. et al. LOW-COST AUTOMATION OF FERTIGATION WITH PROGRAMMABLE LOGIC CONTROLLER AND GASFILLED SENSORS. Engenharia Agrícola, v. 37, n. 2, p. 394-402, 2017.

BLADO, Leonard et al. Smart Automated Water Sprinkler (SAWS): Residential irrigation by boundary mapping and variable water pressure control. In: 2017 Systems and Information Engineering Design Symposium (SIEDS). IEEE, 2017. p. 174-179.

CASADESÚS, Jaume et al. A general algorithm for automated scheduling of drip irrigation in tree crops. Computers and Electronics in Agriculture, v. 83, p. 11-20, 2012.

DE FÁTIMA GRAH, Vanessa et al. Solução alternativa para bombeamento de água e automação da irrigação sem o uso de energia elétrica. Irriga, v. 1, n. 01, p. 309-323, 2012.

DE LIMA, Gracon HEL; E SILVA, Lenardo C.; NETO, Pedro FR. WSN as a Tool for Supporting Agriculture in the Precision Irrigation. In: 2010 Sixth International Conference on Networking and Services. IEEE, 2010. p. 137-142.

DE MELO JÚNIOR, Júlio César Ferreira; GERVÁSIO, Eliezer Santurbano; ARMINDO, Robson André. Sistema de automação para o manejo da subirrigação em ambiente protegido. Irriga, v. 18, n. 2, p. 337-350, 2013.

GERVÁSIO, Eliezer Santurbano; JÚNIOR, Júlio César Ferreira Melo. Utilização da técnica de lisimetria de pesagem na automação de um sistema de irrigação localizada para uso no manejo da irrigação de cultivos em recipientes. Irriga, v. 19, n. 4, p. 626-640, 2014.
GONZÁLEZ-ESQUIVA, J. M. et al. Development of a visual monitoring system for water balance estimation of horticultural crops using low cost cameras. Computers and Electronics in Agriculture, v. 141, p. 15-26, 2017.

HAMOUDA, Yousef EM; ELHABIL, Basel HY. Precision agriculture for greenhouses using a wireless sensor network. In: 2017 Palestinian International Conference on Information and Communication Technology (PICICT). IEEE, 2017. p. 78-83.

HAULE, Joseph; MICHAEL, Kisangiri. Deployment of wireless sensor networks (WSN) in automated irrigation management and scheduling systems: a review. In: Proceedings of the 2nd Pan African International Conference on Science, Computing and Telecommunications (PACT 2014). IEEE, 2014. p. 86-91.

IŞIK, Mehmet Fatih et al. Precision irrigation system (PIS) using sensor network technology integrated with IOS/Android application. Applied Sciences, v. 7, n. 9, p. 891, 2017.

JUNJIN, Ruan et al. Design and performance experiment of spherical mixing precision fertigation system. Transactions of the Chinese Society of Agricultural Engineering, p. S2, 2015.

KAMELIA, L. et al. Implementation of Automation System for Humidity Monitoring and Irrigation System. In: IOP Conference Series: Materials Science and Engineering. IOP Publishing, 2018. p. 012092.

KE'NAN, Liu et al. Autonomous navigation of solar energy canal feed sprinkler irrigation machine. Transactions of the Chinese Society for Agricultural Machinery, v. 47, n. 9, p. 141-146, 2016.

KOPRDA, Š et al. A Low Cost Irrigation System with Raspberry Pi-Own Design and Statistical Evaluation of Efficiency. AGRIS on-line Papers in Economics and Informatics, v. 9, n. 665-2017-1580, p. 79-90, 2017.

LINO, DAVID RIBEIRO et al. IRRIGAÇÃO AUTOMATIZADA COM PLATAFORMA DE DESENVOLVIMENTO ARDUINO NA HORTA DIDÁTICA DA UNIVERSIDADE FEDERAL DO CEARÁ. IRRIGA, v. 1, n. 1, p. 85-93, 2017.

LOSILLA, Fernando et al. A WSAN Solution for Irrigation Control from a Model Driven Perspective. In: IFIP Conference on Wireless Sensor and Actor Networks. Springer, Boston, MA, 2007. p. 35-46.

LOZOYA, Camilo et al. A scalable design approach for a precision irrigation data acquisition system. In: 2015 ASABE Annual International Meeting. American Society of Agricultural and Biological Engineers, 2015. p. 1.

MASSERONI, Daniele et al. Towards a smart automated surface irrigation management in rice-growing areas in Italy. 2017.

MOHANDAS, Prabu et al. An automated irrigation system based on a low-cost microcontroller for tomato production in South India. In: Computational Intelligence in Wireless Sensor Networks. Springer, Cham, 2017. p. 49-71.

MONTOYA, A. P. et al. Automatic aeroponic irrigation system based on Arduino's platform. In: Journal of 
Physics: Conference Series. IOP Publishing, 2017. p. 012003 .

NAGARAJAN, G.; MINU, R. I. Wireless soil monitoring sensor for sprinkler irrigation automation system. Wireless Personal Communications, v. 98, n. 2, p. 1835-1851, 2018.

OLSZEWSKI, Faith et al. Automated cycled sprinkler irrigation for spring frost protection of cranberries. Agricultural Water Management, v. 189, p. 19-26, 2017.

PAPANIKOLAOU, C.; SAKELLARIOUMAKRANTONAKI, M. The effect of an intelligent surface drip irrigation method on sorghum biomass, energy and water savings. Irrigation science, v. 31, n. 4, p. 807-814, 2013.

PENA, R. F. A. Economia de água na agricultura. 2017. Disponível em: <https://mundoeducacao.bol.uol.com.br/geografia/economia -agua-na-agricultura.htm>. Acesso em 26/03/2020.

QI, Di; LU, Guoping; DAI, Xinglei. Design of Urban Greening Intelligent Monitoring System Based on Internet of Things Technology. In: 2017 9th International Conference on Intelligent Human-Machine Systems and Cybernetics (IHMSC). IEEE, 2017. p. 317-321.

RAJALAKSHMI, P.; MAHALAKSHMI, S. Devi. IOT based crop-field monitoring and irrigation automation. In: 2016 10th International Conference on Intelligent Systems and Control (ISCO). IEEE, 2016. p. 1-6.

ROCHA NETO, ODÍLIO C. et al. Application of artificial neural networks as an alternative to volumetric water balance in drip irrigation management in watermelon crop. Engenharia Agrícola, v. 35, n. 2, p. 266-279, 2015.

RODRIGUEZ, Daniel et al. Automatic irrigation control system for soilless culture based on feedback from drainage hydrograph. Applied Engineering in Agriculture, v. 33, n. 4, p. 531-542, 2017.

SAVIĆ, Trifun; RADONJIĆ, Milutin. Proposal of solution for automated irrigation system. In: 2016 24th Telecommunications Forum (TELFOR). IEEE, 2016. p. $1-4$.

SAVIĆ, Trifun; RADONJIĆ, Milutin. Proposal of solution for automated irrigation system. In: 2016 24th Telecommunications Forum (TELFOR). IEEE, 2016. p. $1-4$.

SIROHI, Kshitij et al. Automated irrigation and fire alert system based on hargreaves equation using weather forecast and ZigBee protocol. In: 2016 2nd International Conference on Communication Control and Intelligent Systems (CCIS). IEEE, 2016. p. 13-17.

SMITH, R. J. et al. Evaluating the performance of automated bay irrigation. Irrigation science, v. 34, n. 3, p. 175-185, 2016.

SUSMITHA, A. et al. Automated Irrigation System using Weather Prediction for Efficient Usage of Water Resources. In: IOP Conference Series: Materials Science and Engineering. IOP Publishing, 2017. p. 012232.
VALENÇA, David da Cunha et al. Automatically controlled deficit irrigation of lettuce in "organic potponics". Scientia Agricola, v. 75, n. 1, p. 52-59, 2018.

WAHYUNI, Dwi; LATHIFA, Rifqi Fuadatul; SUSILO, Vendi Eko. Safety of Bioinsecticide Ekstract Sugar Apple Seed's Granule (Annona squamosa L.) on Histology of White Rat (Rattus norvegicus B.).

ZHOU, Bing et al. Greenhouse irrigation control system design based on zigbee and fuzzy PID technology. In: PIAGENG 2013: Intelligent Information, Control, and Communication Technology for Agricultural Engineering. International Society for Optics and Photonics, 2013. p. 87621B.

\section{COPYRIGHT}

Direitos autorais: $\mathrm{O}(\mathrm{s})$ autor(es) é(são) o(s) único(s) responsável(is) pelo material incluído no artigo. 


\author{
Volume $16-\mathrm{N}^{\mathrm{o}} 174$ - Junho / 2020 \\ XLII International Sodebras Congress \\ 28 a 30 de maio de 2020 - Web Conference.
}

\title{
SECAGEM DE AMOSTRAS DE BANANA: EFEITO DA GEOMETRIA DA AMOSTRA E DA TEMPERATURA DE SECAGEM
}

\section{DRYING OF BANANAS SAMPLES - EFFECT OF SAMPLE GEOMETRY AND DRYING TEMPERATURE}

\author{
KELLY HOFSETZ1; CAROLINA BARALDI E SILVA ${ }^{1}$ \\ 1 - SCHOOL OF APPLIED SCIENCES (FCA), STATE UNIVERSITY OF CAMPINAS - UNICAMP, \\ LIMEIRA/SP, BRAZIL
}

kellyhof@unicamp.br; khofsetz@gmail.com; carolina.baraldi@gmail.com

\begin{abstract}
Resumo - Este trabalho estudou o efeito da geometria (1/2 rodela; $1 / 4$ de rodela; rodela) e da temperatura de secagem (50 ${ }^{\circ} \mathrm{C}-60{ }^{\circ} \mathrm{C}-70{ }^{\circ} \mathrm{C}$ ) no tempo de secagem e no encolhimento de amostras de bananas desidratadas. $A$ análise estatística do planejamento fatorial foi significativa para o tempo de secagem indicando que menores geometrias (1/2 rodela até $1 / 4$ de rodela) e maiores temperaturas de secagem $\left(60^{\circ} \mathrm{C}\right.$ até $\left.70^{\circ} \mathrm{C}\right)$ resultaram em menores tempos de secagem; por outro lado, não foi conclusiva para o encolhimento. Assim sendo, a condição de menor tempo de secagem, apontado pelo planejamento fatorial, versus o maior índice de encolhimento, $60{ }^{\circ} \mathrm{C}$ e $1 / 4$ rodela, foi realizada avaliando em detalhes a estrutura e o encolhimento em diferentes tempos de amostragem. Os resultados mostraram que o encolhimento final foi de $43,95 \%$ e que as mudanças de volume foram relacionadas com as mudanças estruturais observadas. Palavras-chave: Secagem. Estrutura. Planejamento Fatorial.
\end{abstract}

\begin{abstract}
This work highlights the effect of sample geometry $\left(1 / 2\right.$ of disc; $1 / 4$ of disc; disc) and drying temperature $\left(50{ }^{\circ} \mathrm{C}-60\right.$ ${ }^{\circ} \mathrm{C}-70{ }^{\circ} \mathrm{C}$ ) on drying time and shrinkage of air-dried bananas samples. The statistical analysis of factorial design was significant for drying time and reported that low sample geometries (1/2 to 1/4 of disc) and high drying temperatures (60 ${ }^{\circ} \mathrm{C}$ to $70{ }^{\circ} \mathrm{C}$ ) resulted in lower drying time; on the other hand, it was not conclusive for shrinkage. Therefore, the lower drying time, pointed out by the factorial design, and highest shrinkage level $\left(60^{\circ} \mathrm{C}\right.$ and $1 / 4$ disc), was then analyzed in detail in terms of shrinkage and structure at different sampling times. The results showed that shrinkage reached a value of $43.94 \%$ at the end of the process, and changes in volume were related to structural changes observed.
\end{abstract}

Keywords: Drying. Structure. Experimental Design.

\section{INTRODUCTION}

Banana is a fruit largely cultivated in tropical and subtropical regions of the world. According to latest available data released by Food and Agriculture Organization of the United Nations (FAO), in 2018 banana production was around 100 million tonnes having India as its main producer (30.8 million tonnes), followed by China (11.2 million tonnes) and Indonesia (7.2 million tonnes). Brazil appears in fourth position with 6.7 million tonnes, practically the same production of the last four years and of which the export not exceed the amount of $2 \%$ of the national production (FAO, 2020).
Due to its fast ripening, banana normally passes to a fast deterioration after harvest, which makes to find economical alternatives to exceeding of the production even more important and challenging. Considering that, one alternative is the production of dried fruit, with intermediate moisture content (raisin), which presents a good flavor and an attractive texture, and can be consumed alone or as snacks, morning cereals and cereal.

According to Keey (1972), drying is a dehydration process and can be defined as the removal of moisture (water) by heat from a solid product. The dehydration process can be used to reduce losses in harvests, increase shelf life of a product, reduce the weight/volume, increase sensory attributes, preserve flavor and nutritional value, reduce microbial activity, and other advantages. However, the water removal can change physical, sensorial and nutritional properties of food, and may result in a product with no attractive texture, loss of flavor and color, and high shrinkage level. Additionally, the dehydration process can promote the growth and development of microorganisms if the water activity value is not reduced to a value that will inhibit significantly this enzyme activity (SAGAR and KUMAR, 2010; ZABALAGA, LA FUENTE and TADINI, 2016).

One of the most relevant characteristics of a dried food is its appearance. The volume of a moist material shrinks on drying and it is caused primarily by the self-contraction of the material as moisture is removed (KEEY, 1972). According to Mayor and Sereno (2004), heating and loss of water cause stresses in the cellular structure of the food leading to change in shape and decrease in dimension. For these reasons, the knowledge and prediction of the shrinkage behavior during a drying process, as well as the measurement of the structure by image processing/analysis, would help designing drying processes to reach higher quality products and have been the subject of scientific studies in the last years (RUSS, 2015; MONTEIRO, CARCIOFI and LAURINDO, 2016; JOARDDER and KARIM, 2019).

Considering all this, it is important to highlight that a drying process depends on ambient conditions temperature, relative humidity, and air velocity, and on material conditions - composition, moisture content, and geometry. For this reason, the main objective of the present 
work was to conduct a factorial experimental design to study the effect of sample geometry and drying temperature on shrinkage and drying time of air-dried banana samples. After that, the condition with highest shrinkage level at the end of the process, and lower drying time, pointed out by the factorial design, was analyzed in more detail in terms of shrinkage and structure observations, at different drying sampling times.

\section{METODOLOGY}

\section{1 - Material Preparation}

Banana - cultivar nanica (Musa acuminata Colla subgroup Cavendish) fruit were purchased in a local market and stored at ambient temperature until reaching a range of $20^{\circ}$ Brix to $25^{\circ}$ Brix. The fruit was peeled and both ends were removed and discarded. Afterwards, fruit was transversally cut into discs, one centimeter thick, using a handmade stainless-steel cutter.

\section{2 - Drying Equipment}

A forced convection oven (80 L, 400/3ND model, Nova Ética, Brazil), operating with hot air forced circulation at $0.1 \mathrm{~m} . \mathrm{s}^{-1}$, was used for the drying experiments. With accessible psychrometric ambient data, provided by the Meteorological Data Collection Centre from the School of Technology (FT, 2019), and having the air-drying temperature, it was possible to obtain all psychometric airdrying properties using the free GRAPSI program (version 6.1) (MELO, LOPES and CORRÊA, 2019).

\section{3 - Drying Experiments - Factorial Experimental Design}

A factorial experimental design $2^{2}$ with four factorial points and three center points was carried out to determine the effect of drying temperature and sample geometry on drying time and shrinkage of air-dried banana samples. For that, the levels of the factors - drying temperature $\left(50{ }^{\circ} \mathrm{C}, 60\right.$ ${ }^{\circ} \mathrm{C}$ and $\left.70^{\circ} \mathrm{C}\right)$ and sample geometry (1/2 of disc; $1 / 4$ of disc; disc $-1 \mathrm{~cm}$ thickness) were defined according to an experimental design (Table 1). The final drying time and shrinkage of samples, at the end of drying, were determined as response variables. The temperature and sample geometry conditions were chosen by literature searches and were adapted for our labor conditions (SILVA, RODRIGUES, SILVA et al., 2015; PORCIUNCULA, SEGURA and LAURINDO, 2016). The drying process of the factorial design was performed to final moisture content of around 40 $\%$ (wet basis).

The response surface methodology assumes that there is a predictive model that relates response variables and independent variables. Considering that, a response variable $(\hat{y})$ is influenced by independent variables $\mathrm{T}$ (drying temperature) and G (geometry), and can be estimated by a prediction model described by Equation (1):

$\hat{y}_{\text {pred }}=\mathrm{b} 0+\mathrm{b} 1 \mathrm{~T}+\mathrm{b} 2 \mathrm{G}+\mathrm{b} 12(\mathrm{TG})$

where $\hat{y}_{\text {pred }}$ is the response variable predicted by the statistic model (dying time and shrinkage), b0-b1-b2-b12 are the regression coefficient predicted by the statistic model, $\mathrm{T}$ and $\mathrm{G}$ are the coded independent variables (drying temperature and geometry, respectively - Table 1), TG is the interaction of independent variables (drying temperature and geometry, respectively) and the sub-index 12 represents the model coefficient in the interaction of $\mathrm{T}$ and $\mathrm{G}$ variables (RODRIGUES and IEMMA, 2005).

The Statistica software (version 5.0) was used to carry out the statistical model (Equation 1). The accuracy of the model was based on a significance level of $95 \%$, i.e., the p-value $\leq 0.05$, for each coefficient of regression obtained by the model (Equation 1). Soon after, an Analysis of Variance (ANOVA) was conducted to investigate the coefficient of determination $\left(\mathrm{R}^{2}\right)$ and the F-test. To complement the statistical analysis, it was determined the Relative Mean Error (Equation 2) of the predictive model for experimental data. According to Lomauro, Bakshi and Labuza (1985), the representative model of experimental data only is valid if the mean value of $\mathrm{RME}<10 \%$.

$\operatorname{RME}(\%)=\frac{100}{n} \sum_{i=}^{n} \frac{\left|m_{e, i}-m_{p, i}\right|}{m_{e, i}}$

where, $\mathrm{n}=$ number of experimental runs, $\mathrm{m}_{\mathrm{e}, \mathrm{i}}=$ experimental values of each response variable (drying time and shrinkage) and $\mathrm{mp}, \mathrm{i}=$ predicted values by the statistic model for each response variable (drying time and shrinkage).

\section{4 - Drying Experiments - Highest Shrinkage Level and Lower Drying Time}

The condition with highest shrinkage level at the end of the process, and lower drying time, pointed out by the factorial design results, was chosen to be repeated and analyzed in more detail. In this case, the drying process was performed to final moisture content of around $25 \%$ (wet basis), the approximate water content of commercial dehydrated fruits (raisins), and different drying sampling times were chosen for moisture content, structural and shrinkage determinations: 0 hour (fresh samples), 1 hour, 2 hours, 3 hours, 4 hours and 5 hours of drying.

\section{5 - Soluble solids content $\left({ }^{\circ}\right.$ Brix)}

Soluble solids content of fresh samples as ${ }^{\circ}$ Brix was determined with an Abbe refractometer (Carl Zeiss, Abbe model, Rochester, Germany) at $25^{\circ} \mathrm{C}$.

The readings were done in six times and the result is the average value of these six measures (Table 1).

This analysis was performed for fresh samples of all runs of the factorial design, and for fresh samples of the condition chosen by the results of the factorial design.

\section{6 - Moisture Content}

It was obtained by drying the samples to constant mass in a vacuum oven (Sulab, EST 920/300 model, Brazil) at 70 ${ }^{\circ} \mathrm{C}$, according to the AOAC standard procedure (AOAC, 1997). The weight loss was determined using an analytical digital balance (Radwag, AS220/C/2 model, $200 \mathrm{~g} \pm 0.2 \mathrm{mg}$ ).

The moisture content determination was made using three samples. Each experimental point shown as a result is the average value of these three samples.

The moisture content determination was carried out for all runs of the factorial design: for fresh samples and for the final dried samples; and for the condition chosen by the results of the factorial design: fresh samples and for samples collected at different drying sampling times (1 hour, 2 hours, 3 hours, 4 hours and 5 hours of drying).

\section{7 - Structural Determinations}

It was used a stereomicroscope (BEL Photonics, SZT 
model, WF10X Ocular) and images were calibrated using a $2 \mathrm{~mm}$ long stage micrometer with $0.01 \mathrm{~mm}$ intervals. Images were processed using the Paint Shop Pro 4.12 software.

Prior the bulk volume determination, pictures of the samples were made to structure changes analysis. In this case, five samples were removed from the dryer and one picture of each one was chosen to represent the variation in structure in this article.

This analysis was performed only for the condition chosen by the results of the factorial design: fresh samples and for samples collected at different drying sampling times ( 1 hour, 2 hours, 3 hours, 4 hours and 5 hours of drying).

\section{8 - Bulk volume}

The bulk volume $\left(\mathrm{V}_{\mathrm{b}}\right)$ was determined by measuring the buoyant forces of the samples when immersed in nhexane or water (LOZANO, ROTSTEIN and URBICAIN, 1980). For that, it was used a semi-analytical balance (Shimadzu, UX420H model, $420 \mathrm{~g}, \pm 0.001 \mathrm{~g}$ ), n-hexane density of $0.66{\mathrm{~g} . \mathrm{cm}^{-3}}^{-}$at $20{ }^{\circ} \mathrm{C}$ (Vetec, pureness $\geq 98.5 \%$, Brazil) and distilled water of $1.00 \mathrm{~g} . \mathrm{cm}^{-3}$ at $20^{\circ} \mathrm{C}$.

Volume changes of individual samples were expressed as the bulk shrinkage ratio $\left(\mathrm{S}_{\mathrm{b}}\right)$ of the sample bulk volume after a certain drying time $\left(\mathrm{V}_{\mathrm{b}}\right)$ as compared to its initial bulk volume $\left(\mathrm{V}_{\mathrm{b} 0}\right)$ (Equation 3 ).

$\mathrm{S}_{\mathrm{b}}=\mathrm{V}_{\mathrm{b}} / \mathrm{V}_{\mathrm{b} 0}$

The bulk volume measurements were made after structural measures using five samples removed from the dryer. Each experimental point shown as variation in shrinkage is the average value of these five samples.

This analysis was performed for all runs of the factorial design: for fresh samples and for dried samples; and for samples dried in the condition chosen by the results of the factorial design: fresh samples and for samples collected at different drying sampling times (1 hour, 2 hours, 3 hours, 4 hours and 5 hours of drying).

\section{9 - Drying Curves}

During the drying of all runs of the factorial design (Table 1), samples were weighed at intervals of 40 minutes of drying using an analytical digital balance (Radwag, AS220/C/2 model, $200 \mathrm{~g} \pm 0.2 \mathrm{mg}$ ) and the moisture ratio (MR) was determined using the following equation (Equation 4):

$M R=\frac{X-X_{e}}{X_{0}-X_{e}}$

where $\mathrm{X}, \mathrm{X}_{\mathrm{e}}$ and $\mathrm{X}_{0}$ are the moisture content at a time $\mathrm{t}$, the equilibrium moisture content and the initial moisture content, respectively.

For the condition chosen by the results of the factorial design, samples were collected and weighed at different sampling times ( 0 hour - fresh sample, 1 hour, 2 hours, 3 hours, 4 hours and 5 hours of drying).

\section{RESULTS AND DISCUSSION}

\section{1 - Factorial Experimental Design}

Banana samples were dried at conditions of factorial design (Table 1) to final moisture content of around $40 \%$ (wet basis) and results are presented in Table 1. The respective drying curves obtained are presented Figure 1. Each experimental moisture ratio (MR) pointed in the Figure represents the average value of three samples.

Table 1 - Drying of banana samples - experimental conditions and results of the $2^{2}$ factorial design with three center points

\begin{tabular}{c|c|c|c|c}
\hline Run* & $\begin{array}{c}\text { Drying } \\
\text { T ('C) }\end{array}$ & Geometry & $\begin{array}{c}\text { Drying } \\
\text { time } \\
(\mathbf{m i n})\end{array}$ & $\begin{array}{c}\text { Shrinkage } \\
(\boldsymbol{\%})\end{array}$ \\
\hline 1 & 50 & $1 / 4$ of disc & 300 & $43.43 \pm 4.73$ \\
2 & 70 & $1 / 4$ of disc & 160 & $51.58 \pm 5.45$ \\
3 & 50 & disc & 480 & $45.37 \pm 3.78$ \\
4 & 70 & disc & 240 & $50.67 \pm 5.89$ \\
5 & 60 & $1 / 2$ of disc & 300 & $42.94 \pm 1.45$ \\
6 & 60 & $1 / 2$ of disc & 300 & $43.02 \pm 1.79$ \\
7 & 60 & $1 / 2$ of disc & 360 & $52.32 \pm 5.12$ \\
\hline
\end{tabular}

${ }^{*}$ Range of ${ }^{\circ}$ Brix: between $20.40( \pm 0.65)$ and $23.50( \pm 0.44)$.

Figure 1 - Experimental moisture ratio (MR) versus time (in minutes) during the drying of banana samples

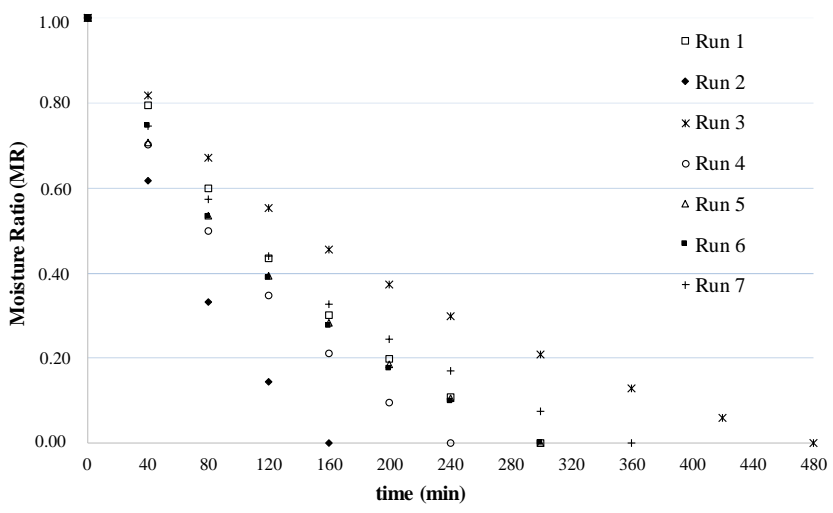

Source: Authors, 2020.

Figure 1 shows the typical behavior reported for the convective drying of fruits. In the early stages of drying the moisture decrease was a bit fast, and as from a certain time (above 120 minutes), the moisture content decreased more slowly up to the end of the drying process. The drying behavior showed that a period with a constant drying rate was not found, and the drying always occurred in the falling rate period. This same behavior was observed during the convective drying of cylindrical pieces of bananas with 21 mm of length at $40{ }^{\circ} \mathrm{C}, 50{ }^{\circ} \mathrm{C}, 60{ }^{\circ} \mathrm{C}$ and $70{ }^{\circ} \mathrm{C}$ and airvelocity of $1.5 \mathrm{~m} . \mathrm{s}^{-1}$ (SILVA, SILVA and GOMES, 2013), whole bananas dried at $70{ }^{\circ} \mathrm{C}$ and air-velocity of $0.55 \mathrm{~m} . \mathrm{s}^{-1}$ (SILVA, RODRIGUES, SILVA et al., 2015), and 5-mm thick bananas slices dried at $50{ }^{\circ} \mathrm{C}-60{ }^{\circ} \mathrm{C}$ and air-velocity of $1.0 \mathrm{~m} . \mathrm{s}^{-1}$ (LA FUENTE and TADINI, 2018). As noted by all the authors of these studies, there was nonexistence of a constant rate period in drying of these fruits, which may have been an effect of the transfer area of the sample (KATEKAWA and SILVA, 2007).

According to Figure 1, Run $2\left(70{ }^{\circ} \mathrm{C}-1 / 4\right.$ of disc) was faster to dry, whereas Run $3\left(50{ }^{\circ} \mathrm{C}-\right.$ disc $)$ took longer time. This suggests that the air-drying temperature and geometry of samples had a significant influence on the dehydration rates (drying time). By contrast, the same could not be said for shrinkage, where all experimental runs seem have shown similar final shrinkage values (Table 1).

Therefore, in order to evaluate the influence of drying temperature and sample geometry variables on the drying 
time and shrinkage, the results were statistically analyzed, and the effects of each variable were calculated. The regression coefficients predicted by the statistic model (Equation 1) are shown on Table 2.

Table 2 - Effects of temperature and geometry on the drying time and shrinkage of bananas samples

\begin{tabular}{c|c|c|c|c}
\hline \multirow{2}{*}{} & \multicolumn{2}{|c|}{ Drying Time } & \multicolumn{2}{c}{ Shrinkage } \\
\cline { 2 - 5 } & $\begin{array}{c}\text { Regression } \\
\text { Coefficients }\end{array}$ & $\begin{array}{c}\text { p- } \\
\text { value }\end{array}$ & $\begin{array}{c}\text { Regression } \\
\text { Coefficients }\end{array}$ & $\begin{array}{c}\text { p- } \\
\text { value }\end{array}$ \\
\hline Mean & 305.71 (b0) & $0.00^{*}$ & 48.47 & $0.00^{*}$ \\
T & $-95.00(\mathrm{~b} 1)$ & $0.01^{*}$ & 5.86 & 0.11 \\
\hline G & $65.00(\mathrm{~b} 2)$ & $0.03^{*}$ & -2.24 & 0.46 \\
\hline TG & $-25.00(\mathrm{~b} 12)$ & 0.23 & -79.12 & 0.32 \\
\hline
\end{tabular}

* p-value $\leq 0.05 ; \mathrm{T}=$ drying temperature; $\mathrm{G}=$ geometry; $\mathrm{TG}=$ interaction of independent variables (drying temperature and geometry, respectively) time

\subsection{1 - Effects of temperature and geometry on drying}

According to Table 2, almost all coefficients were statistically significant for drying time, except for TG interaction that showed few impacts in the range investigated. The parameters without statistical significance were removed from the model and added to the lack of adjustment. After that, the statistically significant variables at $95 \%$ level of confidence were tested for drying time using ANOVA and the results were: $\mathrm{R}^{2}=0.941 ; \mathrm{F}_{\mathrm{tab}(0.005,3,3)}$ $=9.28$ and $F_{\text {calculated }}=15.99$. The goodness of fit provided by $\mathrm{R}^{2}$ and since $\mathrm{F}_{\text {calculated }}>\mathrm{F}_{\text {tab }}$, it may be concluded that the regression was significant at 0.05 probability for drying time response. Therefore, the predicted model (Equation 1) obtained for drying time was as follows (Equation 5):

$\hat{\mathrm{y}}_{\text {pred }}=305.71-95 \mathrm{~T}+65 \mathrm{G}$

According to this Equation 5, temperature had a negative effect, while geometry had a positive effect on drying time in the range of variation of each variable selected for the present study.

The values predicted by the model ( $\left.\hat{y}_{\text {pred }}\right)$ (Equation 5 ) were compared with those of experimental data $\left(\hat{y}_{\exp }\right)$ and the Relative Mean Error (Equation 2) was calculated, as shown on Table 3. At last, the results of experimental and predicted values were validated by $\operatorname{RME}$ (mean value) = $8.23 \%(<10 \%)$ (LOMAURO, BAKSHI and LABUZA, 1985).

After the validation of the model by the statistical analysis, level curves were generated and used to analyze the influence of the temperature and geometry on drying time of banana samples (Figure 2).

According to Figure 2, low geometries (1/2 to $1 / 4$ of disc) and high drying temperatures $\left(60{ }^{\circ} \mathrm{C}\right.$ to $\left.70{ }^{\circ} \mathrm{C}\right)$ leaded to lower drying time, as noted previously. A similar conclusion was pointed by Pornpraipech, Khusakul, Singklin et al. (2017) in the drying of cassava chips: they observed that the drying time spent on removing the moisture content in rectangular cassava chips was less than that for the circular chips indicating that the former was a more effective oven drying process. The lower the mean size of the samples, the shorter the distance traveled from within to the surface of the samples, the more moisture is removed in a shorter time (OLOWOYEYE and EVBUOMWAN, 2014).

Table 3 - Drying time: data of predictive model

\begin{tabular}{c|c|c|c|c|c}
\hline Runs & $\mathbf{T}\left({ }^{\mathbf{0}} \mathbf{C}\right)$ & $\mathbf{G e o m e t r y}$ & $\begin{array}{c}\hat{\mathbf{y}} \mathbf{e x p} \\
{[\mathbf{d r y i n g}} \\
\mathbf{t i m e} \\
(\mathbf{m i n})]\end{array}$ & $\begin{array}{c}\hat{\mathbf{y}} \text { pred } \\
{[\mathbf{d r y i n g}} \\
\mathbf{t i m e} \\
(\mathbf{m i n})]\end{array}$ & $\begin{array}{c}\mathbf{R M E}^{*} \\
(\mathbf{\%})\end{array}$ \\
\hline 1 & 50 & $1 / 4$ of disc & 300 & 336 & 11.90 \\
2 & 70 & $1 / 4$ of disc & 160 & 146 & 8.93 \\
3 & 50 & disc & 480 & 466 & 2.98 \\
4 & 70 & disc & 240 & 276 & 14.88 \\
5 & 60 & $1 / 2$ of disc & 300 & 306 & 1.90 \\
6 & 60 & $1 / 2$ of disc & 300 & 306 & 1.90 \\
7 & 60 & $1 / 2$ of disc & 360 & 306 & 15.08 \\
\hline
\end{tabular}

${ }^{*}$ Mean RME value $=8.23 \%(<10 \%)($ LOMAURO, BAKSHI and LABUZA, 1985)

Figure 2 - Level curves - effect of drying temperature and sample geometry on drying time of air-dried banana samples

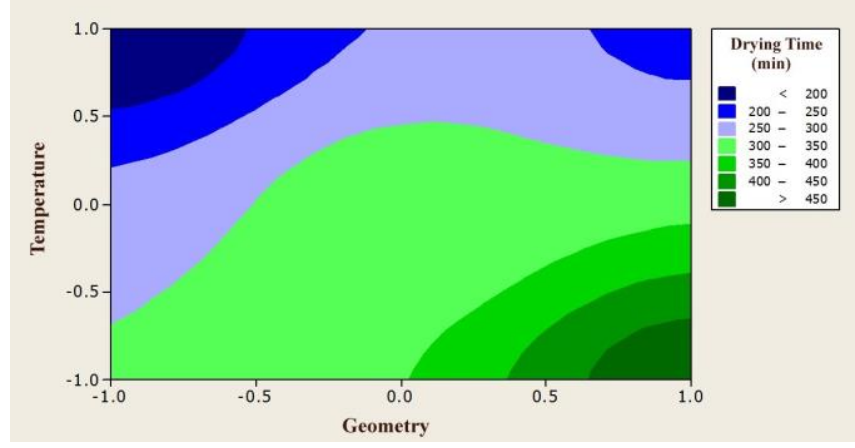

Source: Authors, 2020.

3.1.2 - Effects of temperature and geometry on shrinkage

For shrinkage, the predicted model was not statistically significant (Table 2; p-value $\leq 0.05$ ), within the levels used for each independent variable in experimental design. This statistical non-significance may be due to problems related to the heterogeneity of replicates submitted to bulk volume measures. And, in such conditions, a $95 \%$ confidence interval could be a high confidence value. Moreover, according to Table 1, all experimental runs reached similar final shrinkage results, which enhances the statistical analysis even further. It is also known that a drying process can promote the formation of a crust on the external surface of samples. This crust offers resistance to shrinkage in the latter stages of the process, thus yielding almost constant volume, which may have occurred with samples in this study.

3.2 - The condition chosen by the factorial design analysis Highest Shrinkage Level and Lower Drying Time

Considering statistical results of the factorial design for drying time, and considering the shrinkage observations, the condition range chosen to be studied in more detail was $1 / 4$ of disc at $60^{\circ} \mathrm{C}$.

Table 4 and Figure 3 show the shrinkage data during the drying of bananas at $1 / 4$ of disc at $60{ }^{\circ} \mathrm{C}$. Each experimental point represents the average value of five samples, as described in Section 2.8. And as previously stated, prior the shrinkage determination, pictures of the samples were made to structure changes analysis. Figure 4 shows the structure of these samples. 
Table 4 - Shrinkage and moisture content of banana samples (at 1/4 of disc and $60{ }^{\circ} \mathrm{C}$ ) collected in different sampling times

\begin{tabular}{c|c|c}
\hline $\begin{array}{c}\text { Drying sampling } \\
\text { times (min) }\end{array}$ & $\begin{array}{c}\text { Moisture content } \\
(\mathbf{w . b .})(\boldsymbol{\%})\end{array}$ & Shrinkage (\%) \\
\hline 0 (fresh samples) & $72.01 \pm 0.23$ & $100.00 \pm 1.56$ \\
60 & $61.24 \pm 0.80$ & $77.04 \pm 1.21$ \\
120 & $50.69 \pm 1.45$ & $56.35 \pm 2.22$ \\
180 & $44.31 \pm 1.68$ & $51.28 \pm 2.97$ \\
240 & $32.86 \pm 1.88$ & $50.26 \pm 1.52$ \\
300 & $22.99 \pm 0.69$ & $43.94 \pm 1.46$ \\
\hline
\end{tabular}

Figure 3 - Experimental shrinkage data of banana samples versus normalized moisture ratio (MR) (at $1 / 4$ of disc and $60{ }^{\circ} \mathrm{C}$ )

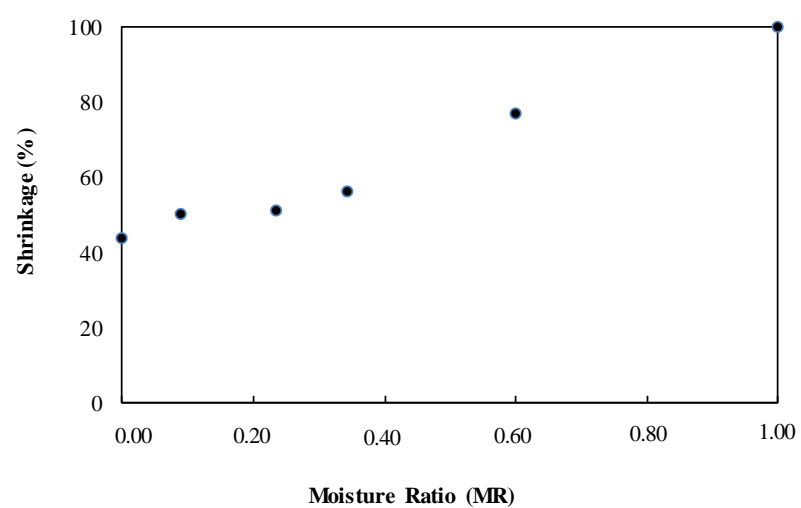

Source: Authors, 2020.

Figure 4 - Structural changes of banana samples at $1 / 4$ of disc and $60{ }^{\circ} \mathrm{C}$ at different sampling times: a) fresh banana sample; b) after 1 hour of drying; c) after 2 hours of drying; d) after 3 hours of drying; e) after 4 hours of drying; f) after 5 hours of drying.

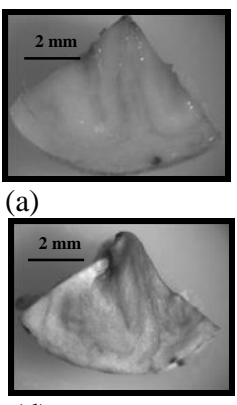

(d)

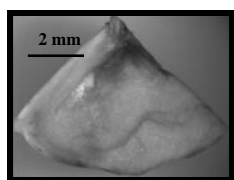

(b)

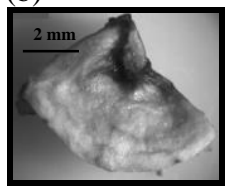

(e)

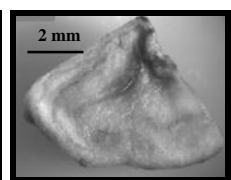

(c)

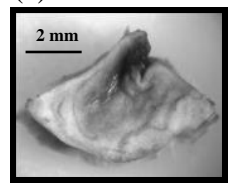

(f)
Source: Authors, 2020.

According to Figure 3 and Table 4, initially, there was a decrease in the volume, which was accompanied by the moisture decrease and tended to be linear (until 120 minutes of drying). At the last stages of the drying, this behavior was non-linear and shrinkage reached $43.94 \%$ of the initial volume at the end of the process. This shrinkage behavior was also reported in cylindrical slices of banana with $4 \mathrm{~mm}$ thick and $20 \mathrm{~mm}$ of diameter dried at $30{ }^{\circ} \mathrm{C}-40{ }^{\circ} \mathrm{C}-50{ }^{\circ} \mathrm{C}$ in a Dynamic Vapor Sorption (KATEKAWA and SILVA, 2007). Also, authors observed that the variation of the transfer area was not significantly influenced by drying temperature in the last stages of drying. According to Mayor and Sereno (2004), in the beginning of drying, the cellular tissues are elastic enough to shrink in the space left by the evaporate moisture and, as drying time progresses, a more rigid skeleton begins to be formed due to structural changes in cellular tissues, which leads to a linearity deviation. This deviation is a consequence of a continuous collapse of the solid matrix of the vegetable tissue because of the contracting stresses produced by the removal of the water. Lima, Tribuzi, Souza et al. (2016) observed that the moisture removal from the pineapple's samples air-dried at $1 / 8$ of disc $-5 \mathrm{~mm}$ thickness and $60{ }^{\circ} \mathrm{C}$ leaded to tensions on the cellular wall, which caused shrinkage.

The shrinkage changes (Table 4 and Figure 3) are according to structure changes observed during drying (Figure 4). Observing the structure pictures (Figure 4), shrinkage was anisotropic and was more accentuated in the middle area of samples probably due to the fibre-oriented structure of the banana fruit (Figure 4d-f). Due to this nonhomogeneous shrinkage, the shape of the samples changed considerably as drying proceeded. According to Qiu, Khalloufi, Martynenko et al. (2015), one reason for the nonhomogeneous shrinkage could be the tissue and air distribution within the food matrixes. Besides that, the water removal in the last stages of drying was not very accentuated probably due to an external crust formation, thus yielding almost constant volume up to the end of the drying process (Figure 4d-f). Joardder and Karim (2019) studied the drying of apple samples sliced into $1 \mathrm{~cm}$ thick and $4 \mathrm{~cm}$ diameter discs hot air dried at $50{ }^{\circ} \mathrm{C}-65{ }^{\circ} \mathrm{C}$ and $1 \mathrm{~m} . \mathrm{s}^{-1}$ and noted a slower rate of deformation of food sample at the later part of the drying due to case hardening, what probably happened to the samples in this study.

\section{CONCLUSION}

The statistical analysis of factorial design for dying time highlight that low sample geometries $(1 / 2$ to $1 / 4$ of disc) and low drying temperatures $\left(60{ }^{\circ} \mathrm{C}\right.$ to $\left.70{ }^{\circ} \mathrm{C}\right)$ lead to lower drying time, what had already been observed in drying curves behavior. By contrast, statistical analysis of factorial design was not conclusive for shrinkage. This may have occurred due to the samples' heterogeneity and the high confidence interval $(95 \%)$ used for this analysis. As drying process proceeds, a crust on the external surface of samples begins to be formed and offers resistance to shrinkage, leading to almost constant volume in the last stages of drying. This may have occurred with samples in this study, once the heterogeneity of samples may have influenced the statistical results.

After analyzing all results for drying time, and considering the shrinkage observations, the condition chosen by the factorial design analysis to be analyzed in detail was $1 / 4$ of disc and $60^{\circ} \mathrm{C}$. In this case, the volume of samples decreased considerably at the end of the process reaching $43.94 \%$ of the initial volume at the end of the process. A linear decrease in volume with the decrease in moisture ratio was observed in the first stages of drying, being non-linear in the last stages. These shrinkage changes were confirmed by the structural observations of the dehydrated banana samples, being anisotropic. It is believed that a rigid skeleton was formed due to structural changes in cellular tissues as moisture content decreased while drying process proceeded. It can be said that the air-drying process promoted a shrank aspect on the samples in accordance with structure results.

\section{REFERENCES}

AOAC. Official methods of analysis. In $\mathbf{1 6}^{\text {th }}$ Associations of Analytical Chemists, Washington, D.C., 1997. 
FAO. Food and Agricultural Organization of the United Nations. Agricultural Production Statistic Database (FAOSTAT). Rome, Italy. Available in: <http://www.fao.org/faostat/en/\#rankings/countries_by_com modity >. Accessed January 19, 2020.

FT. School of Technology. State University of Campinas (UNICAMP). Meteorological Data Collection Centre. Available

<https://www.ft.unicamp.br/en/dadosmeteorologicos>.

Accessed July 23, 2019.

JOARDDER, Mohammad U.H..; KARIM, Azharul. Development of a porosity prediction model based on shrinkage velocity and glass transition temperature. Drying Technology.

https://doi.org/10.1080/07373937.2018.1555540, 2019.

KATEKAWA, Marcel E.; SILVA, Maria Aparecida. Drying rates in shrinking medium: case study of banana. Brazilian Journal of Chemical Engineering, 24(04), 561-569. http://dx.doi.org/10.1590/S0104-66322007000400009, 2007.

KEEY, Roger Bryan. Drying: principles and practice. 1st.; Pergamon Press: New York, 1972.

LA FUENTE, Carla Ivonne; TADINI, Carmen Cecilia. Ultrasound pre-treatment prior to unripe banana air-drying: effect of the ultrasonic volumetric power on the kinetic parameters Journal of Food Science and Technology, 55(12), 5098-5105. https://doi.org/10.1007/s13197-0183450-1, 2018.

LIMA, Marla Mateus.; TRIBUZI, Giustino; SOUZA, José Antonio Ribeiro; SOUZA, Ivan Gonçalves; LAURINDO, João Borges; CARCIOFI, Bruno A.M. Vacuum impregnation and drying of calcium-fortified pineapple snacks. LWT - Food Science and Technology, 72, 501509. http://dx.doi.org/10.1016/j.lwt.2016.05.016, 2016.

LOMAURO, C.J.; BAKSHI, A.S.; LABUZA, Theodore P. Evaluation of food moisture sorption isotherm equations. Part I: fruit, vegetable and meat products. LWT - Food Science and Technology, 18, 111-117, 1985.

LOZANO, J.E.; ROTSTEIN, Enrique; URBICAIN, M.J. Total porosity and open-pore porosity in the drying of fruits. Journal of Food Science, 45, 1403-1407. doi: 10.1111/j.1365-2621.1980.tb06564.x, 1980.

MAYOR, Luis; SERENO, Alberto M. Modeling shrinkage during convective drying of food materials: a review. Journal of Food Engineering, 61, 373-386. https://doi.org/10.1016/S0260-8774(03)00144-4, 2004.

MELO, Evandro de Castro; LOPES, Daniela de Carvalho; CORRÊA, Paulo César. Grapsi - Programa computacional para o cálculo das propriedades psicométricas do ar. Avalilable in: <http://www.evandro.eng.br/grapsi.html>. Accessed November 13, 2019.

MONTEIRO, Ricardo Lemos; CARCIOFI, Bruno Augusto Mattar; LAURINDO, João Borges. A microwave multiflash drying process for producing crispy bananas. Journal of Food Engineering, 178: 1-11. http://dx.doi.org/10.1016/j.jfoodeng.2015.12.024, 2016.
OLOWOYEYE, O.I.; EVBUOMWAN, B.O. Comparative analysis of the effect of size reduction on the drying rate of cassava and plantain chips. International Journal of Geology, Agriculture and Environmental Sciences, 2, 20-27. ISSN: 2348-0254, 2014.

PORCIUNCULA, Bárbara D.A.; SEGURA, Luis A.; LAURINDO, João Borges. Processes for controlling the structure and texture of dehydrated banana. Drying Technology, 34(2), 167-176. http://dx.doi.org/10.1080/07373937.2015.10149, 2016.

PORNPRAIPECH, Pechaporn; KHUSAKUL, Morakot; SINGKLIN, Raksuda; SARABHORN, Prysathryd; AREEPRASERT, Chinnathan. . Effect of temperature and shape on drying performance of cassava chips. Agriculture and Natural Resources, 51, 402-409. https://doi.org/10.1016/j.anres.2017.12.004, 2017.

QIU, Jun; KHALLOUFI, Seddik; MARTYNENKO, Alex; VAN DALEN, Gerald; SCHUTYSEr, Maarten; ALMEIDA-RIVERA, Christian. Porosity, bulk density, and volume reduction during drying: review of measurement methods and coefficient determinations. Drying Technology, 33(14), 1681-1699. DOI: 10.1080/07373937.2015.1036289, 2015.

RODRIGUES, Maria Isabel; IEMMA, Antônio Francisco. Planejamento de experimentos e otimização de processos: Uma estratégia sequencial de planejamentos. 1st, Campinas: Editora Casa do Pão, 326p. 2005.

RUSS, John C. Image analysis of foods. In: JFS Special Issue: 75 Years of Advancing Food Science, and Preparing for the Next 75. Journal of Food Science. 80(9), E1974E1987. doi: 10.1111/1750-3841.12987, 2015.

SAGAR, V.R.; KUMAR, Suresh. Recent advances in drying and dehydration of fruits and vegetables: a review. Journal of Food Science and Technology, 47(1), 15-26. DOI: 10.1007/s13197-010-0010-8, 2010.

SILVA, Wilton Pereira; SILVA, Cleide M.D.P.S.; GOMES, Josivanda Palmeira. Drying description of cylindrical pieces of bananas in different temperatures using diffusion models. Journal of Food Engineering, 117, 417-424. http://dx.doi.org/10.1016/j.jfoodeng.2013.03.030, 2013

SILVA, Wilton Pereira; RODRIGUES, Andrea Fernandes; SILVA, Cleide M.D.P.S; CASTRO, Deise Souza; GOMES, Josivanda Palmeira. Comparison between continuous and intermittent drying of whole bananas using empirical and diffusion models to describe the processes. Journal of Food Engineering, 166, 230-236. http://dx.doi.org/10.1016/j.jfoodeng.2015.06.018, 2015.

ZABALAGA, Rosa F.; LA FUENTE, Carla Ivonne; TADINI, Carmen C. Experimental determination of thermophysical properties of unripe banana slices (Musa cavendishii) during convective drying. Journal of Food Engineering, 187, 62-69. http://dx.doi.org/10.1016/j.jfoodeng.2016.04.020, 2016.

\section{COPYRIGHT}

Authors are the sole responsible for the material described/included in the article. 


\section{Área: Ciências Exatas e Engenharias}

\begin{tabular}{|c|c|}
\hline $1-3$ & $\begin{array}{l}\text { PREVISÃO DE PRECIPITAÇÃO DE CHUVA USANDO SÉRIES TEMPORAIS E } \\
\text { NEURO-FUZZY } \\
\text { FORECAST OF RAIN PRECIPITATION USING TIME SERIES AND NEURO- } \\
\text { FUZZY } \\
\text { Jampierre V. Rocha; Marcelo Da C. Ferreira; Taís B. Ferreira }\end{array}$ \\
\hline $1-5$ & $\begin{array}{l}\text { AVALIAÇÃO DA INCERTEZA DE MEDIÇÃO NA CALIBRAÇÃO DE MEDIDOR DE } \\
\text { VAZÃO DE LíQUIDOS PELO MÉTODO GRAVIMÉTRICO } \\
\text { MEASUREMENT UNCERTAINTY IN THE CALIBRATION OF FLUID FLOW } \\
\text { METER BY THE GRAVIMETRIC METHOD } \\
\text { IdrisSa Deme }\end{array}$ \\
\hline 3-3 & $\begin{array}{l}\text { CARACTERIZAÇÃO DE FILME DE DIAMANTE CVD POLICRISTALINO } \\
\text { DEPOSITADO EM SILÍCIO COM DIFERENTES ORIENTAÇÕES CRISTALINAS } \\
\text { CHARACTERIZATION OF POLYCRYSTALLINE CVD DIAMOND FILM } \\
\text { DEPOSITED ON INTRINSIC SILICON WITH DIFFERENT CRYSTALLINE } \\
\text { ORIENTATIONS } \\
\text { Alexandre Marcello Cavalca De Almeida; Evaldo Chagas Gouvêa; Teófilo Miguel De } \\
\text { Souza }\end{array}$ \\
\hline $3-4$ & $\begin{array}{l}\text { PLANEJAMENTO ELÉTRICO CIMATEC PARK: ESTUDO DE FLUXO DE } \\
\text { POTÉNCIA, CURTO-CIRCUITO E PERDAS DA ATUAL REDE DE DISTRIBUIÇÃO } \\
\text { DE ENERGIA ELÉTRICA DO COMPLEXO. } \\
\text { ELECTRICAL PLANNING CIMATEC PARK: STUDY OF POWER FLOW, SHORT- } \\
\text { CIRCUIT AND LOSSES OF THE CURRENT NETWORK OF DISTRIBUTION OF } \\
\text { ELECTRIC ENERGY OF THE COMPLEX. } \\
\text { Lucas Do Espirito Santo Fernandes; Tales Silva De Santana; Ana Tereza Andrade } \\
\text { Borba; Luiz Fernando Taboada Gomes Amaral }\end{array}$ \\
\hline $3-5$ & $\begin{array}{l}\text { ANÁLISE ABRANGENTE DE SISTEMA HIDROSTÁTICO E DE TURBINA EÓLICA } \\
\text { COM BASE BIBLIOMÉTRICA, } 1983-2019 \\
\text { A COMPREHENSIVE ANALYSIS OF HYDROSTATIC SYSTEM AND WIND } \\
\text { TURBINE WITH BIBLIOMETRIC BASE, } 1983-2019 \\
\text { Thamyres Machado David; Luciano Lizardo De Souza Guimarães; Vanessa } \\
\text { Aparecidade De Sá Machado; Diego Menegusso Pires }\end{array}$ \\
\hline $3-5$ & $\begin{array}{l}\text { ANÁLISE DA INFLUÊNCIA DO COMPORTAMENTO DO VENTO NA EFICIÊNCIA } \\
\text { DE TURBINAS EÓLICAS DE EIXO VERTICAL UTILIZANDO CFD } \\
\text { ANALYSIS OF THE INFLUENCE OF WIND BEHAVIOR ON THE EFFICIENCY OF } \\
\text { VERTICAL AXIS WIND TURBINES USING CFD } \\
\text { Alex R. A. Rodrigues; Claudinei R. Calado; EnZO R. R. Dos Santos }\end{array}$ \\
\hline
\end{tabular}




\begin{tabular}{|c|c|}
\hline $3-5$ & $\begin{array}{l}\text { APLICAÇÃO DE FERRAMENTAS DA QUALIDADE NA ANÁLISE DE FALHAS } \\
\text { EM MANGUEIRAS HIDRÁULICAS APLICADAS A ROV } \\
\text { APPLICATION OF QUALITY TOOLS IN FAILURE ANALYSIS IN HYDRAULIC } \\
\text { HOSES APPLIED TO ROV } \\
\text { Vanessa Aparecida De Sá Machado; Luciano Lizardo De Souza Guimarães; Wallice } \\
\text { Medeiros De Souza; Eyko Medeiros Rios }\end{array}$ \\
\hline $3-5$ & $\begin{array}{l}\text { AUTOMATIZAÇÃO DE UMA BANCADA DE CALIBRAÇÃO DE MEDIDORES DE } \\
\text { VAZÃO DE LíUIDOS } \\
\text { AUTOMATION OF A LIQUID FLOW METER CALIBRATION SYSTEM } \\
\text { Idrissa Deme }\end{array}$ \\
\hline $3-5$ & $\begin{array}{l}\text { ESTUDO E DESENVOLVIMENTO DE UM MODELO MATEMÁTICO PARA UM } \\
\text { MONOTRILHO ELÉTRICO DE ALTA VELOCIDADE MOVIDO A ENERGIA } \\
\text { SUSTENTÁVEL, VISANDO A DIMINUIÇÃO DA EMISSÃO DE DIÓXIDO DE } \\
\text { CARBONO NO DESLOCAMENTO ENTRE AS CIDADES DE SÃO PAULO E RIO } \\
\text { DE JANEIRO } \\
\text { STUDY AND DEVELOPMENT OF A MATHEMATICAL MODEL FOR A ELECTRIC } \\
\text { HIGH SPEED MONORAIL POWERED BY RENEWABLE ENERGY, LOOKING TO } \\
\text { DECREASE THE DISPLACEMENT OF CARBON DIOXIDE IN THE } \\
\text { DISPLACEMENT BETWEEN THE CITIES OF SÃO PAULO AND RIO DE } \\
\text { JANEIRO } \\
\text { Carlos Augusto Marcondes Dos Santos; Teófilo Miguel De Souza }\end{array}$ \\
\hline
\end{tabular}




\author{
Volume $16-\mathrm{N}^{\mathrm{o}} 174$ - Junho / 2020 \\ XLII International Sodebras Congress \\ 28 a 30 de maio de 2020 - Web Conference.
}

\title{
PREVISÃO DE PRECIPITAÇÃO DE CHUVA USANDO SÉRIES TEMPORAIS E NEURO-FUZZY
}

\section{FORECAST OF RAIN PRECIPITATION USING TIME SERIES AND NEURO- FUZZY}

\author{
JAMPIERRE V. ROCHA ${ }^{1}$; MARCELO DA C. FERREIRA ${ }^{1}$; TAÍS B. FERREIRA ${ }^{1}$ \\ 1 - LENOVO
}

r.jampierre@gmail.com; marcelo.ferreira@fgv.edu.br; taisborgesferreira@gmail.com

\begin{abstract}
Resumo - A previsão do tempo é um fator essencial para planejar e decidir sobre vários tipos de negócios. Essas informações afetam decisões relacionadas à irrigação, plantio, transporte, produção de proteínas animais e outras. Nesse contexto, o presente trabalho propôs prever a precipitação do dia seguinte (amanhã) usando dados meteorológicos dos últimos sete dias. Algoritmos de redes neurais artificiais (RNA) e Fuzzy para séries temporais foram aplicadas à previsão de chuvas. Dos vários algoritmos avaliados, Levenberg-Marquardt $e$ Regularização Bayesiana apresentaram menor raiz do erro do quadrado médio (RMSE) entre os valores observados $e$ os previstos. Obtivemos com Neuro-Fuzzy, 42 dados de entrada, dez neurônios, o algoritmo de treinamento Regularização Bayesiana e o modelo $N$ com dados aleatórios, uma média geral de 95,37\% de precisão para precipitação pluviométrica no dia seguinte. Palavras-chave: Previsão de Chuva. Rede Neural. Fuzzy.
\end{abstract}

Abstract - Weather forecasting is an essential factor for planning and deciding on various types of business. Such information affects decisions related to irrigation, planting, transportation, animal protein production, and others. In this context, the present work proposed to predict the rainfall of the following day (tomorrow) using weather data from the last seven days. Artificial Neural Networks (ANN) and Fuzzy Time Series algorithms were evaluated and applied to rain prediction to fulfill this purpose. Of the various algorithms evaluated, LevenbergMarquardt and Bayesian Regularization presented a lower Root of Mean Square Error (RMSE) between observed and predicted values. We obtained with Neuro-Fuzzy, 42 input data, ten neurons, Bayesian Regularization training algorithm, and model $N$ with random data, an overall average of $95.37 \%$ accuracy for rainfall precipitation to the day after.

Keywords: Rain Forecast. Neural Network. Fuzzy.

\section{INTRODUÇÃO}

A previsão de chuva é um fator importante para vários setores, pois, tendo noção da possibilidade de chuva e da quantidade estimada da queda d'água, pode-se usufruir dessas informações para tomada de decisões e gerenciamento, como por exemplo, no manejo de irrigação no setor agrícola ou até mesmo no transporte de cargas em terrenos acidentados. Essa previsão é de difícil acerto por conta da sua ocorrência (NASUTI et al., 2013), onde, diferentemente de uma previsão de temperatura, que é observado uma mudança gradativa dos valores, com a precipitação de chuva é diferente, em um dia ensolarado em questão de algumas horas o tempo pode ter mudanças consideráveis e chover torrencialmente. Utilizando os instrumentos de uma estação meteorológica e observando os fenômenos descritos pela literatura (TREWARTH, 1943), com a queda da pressão atmosférica e o aumento da umidade do ar é possível classificar, com um elevado grau de acerto, entre um dia com chuva ou não, utilizando Redes Neurais Artificiais (RNA) ou Sistemas Fuzzy (HARTIGAN \& CALLOIS, 1993). Porém, com o interesse e a necessidade de saber a quantidade de precipitação de chuva, isso torna o sistema mais complexo como demostrado por Luk, Ball e Sharma (2001).

Neste contexto, o presente trabalho pretende avaliar dois modelos de regressão não linear. O primeiro com TDNN (Time Delay Neural Network ou Rede neural com atraso de tempo) aplicado para precipitação de chuva, usando os seguintes algoritmos: Levengerg-Marguardt, regularização bayesiana (Bayesian Regularization) com $\mathrm{N}$ (Nonlinear Input-Output ou Entrada-saída não linear) e NARX (Nonlinear Autoregressive with External Input ou Auto-regressão não linear com entrada externa). E o segundo com ANFIS (Adaptive Neuro-Fuzzy Inference System ou Sistema de Inferência Neuro-Fuzzy Adaptativo) de série temporal aplicado para precipitação de chuva, usando os algoritmos Grip Partitioning com PCA (Principal Component Analysis ou Análise de Componente Principal) e FCM (Fuzzy C-Mean).

Em ambos os modelos, foi utilizado, como entrada, intervalo de tempo de 7 dias para os dados da estação meteorológica para prever a precipitação de chuva no oitava dia. Além disso, foi utilizado o cálculo do RMSE (Root of Mean Square Error ou Raiz do Erro Quadrático Médio) para avaliar o desvio médio entre observado e predito dos modelos como feito por outros autores (BUENO et al., 2015; SOARES et al., 2017 e YASEEN et al., 2018).

\section{DADOS E AS TOPOLOGIAS DOS MODELOS}

As variáveis utilizadas foram a Temperatura, Umidade, Orvalho, Pressão, Direção do Vento, Velocidade do Vento, Rajada do Vento, Radiação e Precipitação. Os dados foram coletados da estação meteorológica automática localizada em Viçosa/MG, que coleta os dados de hora em hora, gerando 8736 dados para cada variável no período de 20/12/2016 a 18/12/2017, acumulando um total de 78.624 dados ao longo de 363 dias. Inicialmente, os dados das 
coletas foram ordenados por dia, em seguida, o montante de 24 dados por variável (ou um dia) foram convertidos em médias diárias, somente para a precipitação de chuva foi feito o somatório. Desta maneira chegou-se a uma matriz de 363x9 (dia x variável). Com os dados referentes a cada dia, foram selecionados as variáveis mais relevantes (sessão 3 ) e separado um intervalo (janela) de tempo de 7 dias anteriores, buscando como saída o nível de precipitação (em milímetros) do dia seguinte, como expresso na figura 1.

Figura 1 - Janela de tempo de 7 dias com predição do oitavo

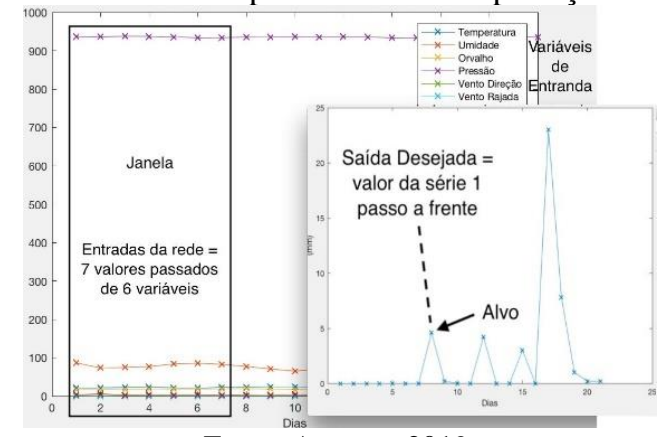

Fonte: Autores, 2019.

A estrutura base da topologia da rede neural deste projeto é dada pelas entradas dos valores das variáveis mais relevantes na camada de entrada (input layer, na Figura 2) e processados ao passar pela camada oculta (hidden layer), número igual de neurônios da camada de entrada, devolvendo um valor previsto na saída do neurônio na camada de saída (output layer).

Figura 2 - Uma rede neural com neurônios de entrada, camada

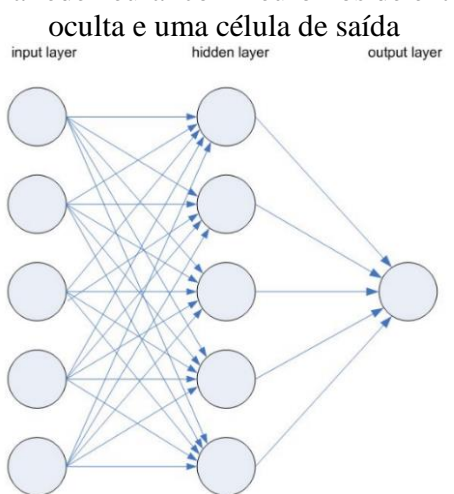

Fonte: Mediun, 2020.

A estrutura do sistema fuzzy, semelhantemente a estrutura base da rede neural, é composta pelas variáveis mais relevantes na entrada e uma saída referente a previsão da chuva, expresso na Figura 3 por $y^{K+1}$.
Figura 2 - Estrutura do modelo de predição Fuzzy

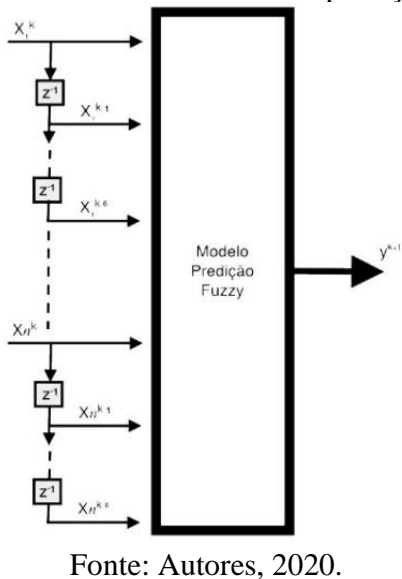

\section{TREINAMENTO DOS MODELOS}

Para treinar os modelos primeiramente foram analisadas as variáveis mais relevantes, que foram dadas através de uma análise de correlação da saída com a entrada, gerando uma matriz $\mathrm{n}$ por $\mathrm{n}$ de valores entre -1 e 1 , onde quanto mais próximo de 0 menor é sua relação com a saída, deste modo, observou-se que os próprios dados de precipitação não se correlacionam, tendo um valor médio de 0.3703. A velocidade do vento e radiação também mostraram baixa correlação, com valores 0.4494 e 0.765 respectivamente, Tabela 1. Tendo por fim restado 6 variáveis relevantes. Com isso, o sistema base foi composto por 42 entradas (6 variáveis vezes 7 dias, que é a janela de tempo) e uma saída.

Tabela 1 - Correlação dos dados com a precipitação de chuva.

\begin{tabular}{ccccc}
\hline Temperatura & Umidade & Orvalho & Pressão & $\begin{array}{c}\text { Dir. } \\
\text { Vento }\end{array}$ \\
\hline 0.9095 & 0.8054 & 0.907 & 0.9157 & 0.9238 \\
\hline Vel. Vento & $\begin{array}{c}\text { Raj. } \\
\text { Vento }\end{array}$ & Radiação & Precipitação \\
\hline 0.4494 & 0.9238 & 0.765 & 0.3703 \\
\hline
\end{tabular}

Após estruturado a base de dados, para o treinamento com RNA utilizou-se o NNT (Neural Networks Toolbox), do software Matlab R2018b, que por padrão separa os dados em $70 \%$ para treinamento, $15 \%$ para validação e $15 \%$ para teste. Alternando as variáveis de entrada em 42, 21 e 14, onde 42 entradas se referem as 6 variáveis mais relevantes no período de 7 dias, 21 entradas referentes aos dados de umidade, temperatura e pressão, dados descritos pela literatura necessarios para previsão de chuva, e 14 entradas referentes a direção e rajada de vento, dados com maiores valores de correlação com a saída.

Os teste foram realizados com o suporte do NNT com os dados ordenados e embaralhados, ambus em função do tempo, seguindo os padrão de $70 \%$ para treinamento, $15 \%$ para validação e $15 \%$ para teste e janela de tempo de 7 dias.

Utilizando fuzzy, o método de regressão não linear com ANFIS com grid partitioning e FCM com algoritmo de otimização híbrida, para fins de teste, as configurações padrões estabelecidas foram 200 épocas de treinamento e 15 clusters. Os dados foram separados em $85 \%$ para treinamento e $15 \%$ para teste, segundo o padrão do FLT (Fuzzy Logic Toolbox) do Matlab. Alternando as variáveis de entrada como no RNA e redimensionando o tamanho da matriz de dados com PCA, afim de avaliar os melhores resultados. 


\section{RESULTADOS}

Para o fuzzy, utilizando o algoritmo grid partitioning com 42, 21 e 14 entradas o tempo de processamento mostrou-se inviável por conta da complexidade numérica e o custo computacional. Afim de tornar o tempo de resposta viável, foi utilizado PCA na janela de tempo de 7 dias da temperatura, umidade e pressão, reduzindo as entradas para 5, mantendo-se $90.79 \%$ da integridade dos dados, o que apresentou no treinamento desvio médio entre observado e predito de RMSE $=1.981161$ e na previsão (dados de teste) $\mathrm{RMSE}=72.695$.

Com a dimensionalização para 6 entradas, com $93.21 \%$ da integridade dos dados, a uma melhora considerável no treinamento $(\mathrm{RMSE}=0.000069)$, porem, o desvio médio entre observado e predito superior na previsão (RMSE = 74.091), comparado ao teste anterior.

Com 7 entradas, $94.82 \%$ da integridade dos dados, houve melhoria tanto no treinamento $(\mathrm{RMSE}=0.000054)$, quanto na previsão (RMSE $=67.0852$ ).

A utilização de grid partitioning com PCA mostrou-se ineficiente em relação ao tempo de resposta com entradas acima de 7 , então foi utilizada a técnica de FCM por apresentar resultados mais rápidos. Com FCM e entradas de temperatura, umidade, orvalho, pressão, direção do vento e rajada do vento com janela de 7 dias, gerando um total de 42 entradas, obteve-se resultados de previsão RMSE = 37.6952, com 15 clusters e 200 épocas de treinamento. A Figura 4 apresenta o resultado descrito anteriormente, tendo como alvo (Target) os dados reais de precipitação de chuva diária em milímetros, coletados pela estação meteorológica de Viçosa e expresso na figura por uma linha preta, e como predito (Output) pelo algoritmo a linha vermelha, podendo ser observado que no período de treinamento $(85 \%$ dos dados iniciais e ordenados) o alvo alcançado pelo predito é preciso e no período de teste $(15 \%)$ houve desvios do alvo em relação ao alcançado.

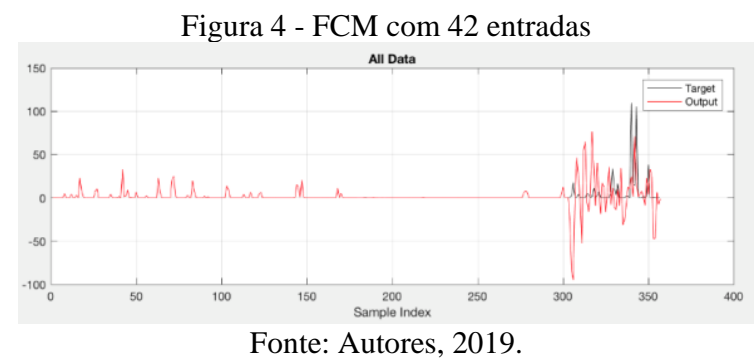

Diferente do encontrado na literatura, que aponta umidade e pressão como variáveis mais relevantes para previsão de chuva, na avaliação da correlação apontou que a direção do vento e rajada de vento tiveram maior relevância. Testando algumas variações dos dados de entrada foram encontrados os seguintes resultados: RMSE $=0.484744$ no treinamento para entradas de umidade e pressão, e 0.068830 para entradas de direção do vento e rajada de vento. O melhor resultado de previsão encontrado foi por meio de 14 entradas com as variáveis de direção do vento e rajada de vento $(\mathrm{RMSE}=25.6423)$ como pode ser observado na Figura 5 que ilustra como alvo (Target) a linha preta e alcançado (Output) a linha vermelha. Durante o treinamento o alcançado foi o alvo e durante os teste (previsão) houve desvios do alvo em relação ao alcançado. Diferentemente do esperado, para previsão, 14 entradas se mostraram melhor que 42 , pois, espera-se que quanto maior o volume de dados de entrada para treinamento melhor a capacidade de previsão. Este ocorrido foi devido a qualidade dos dados selecionados, pois, os dados de direção do vento e rajada de vento tiveram maior correlação com a precipitação de chuva.

Figura 5 - FCM com 14 entradas

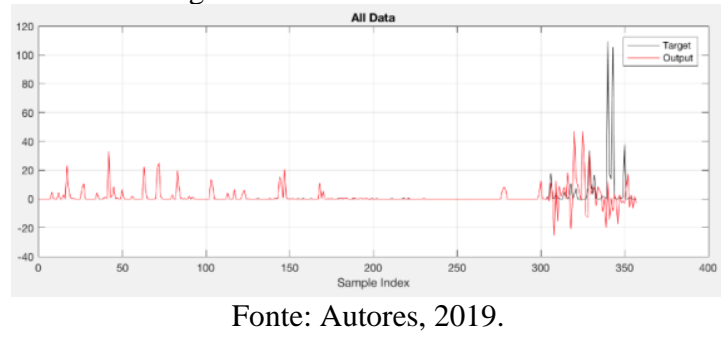

Testando com o algoritmo Levengerg-Marguardt com as 6 variáveis com janela de tempo de 7 dias, 10 neurônios e dados ordenados, os resultados mostraram desvio médio entre observado e predito no treinamento RMSE $=2.4435 \mathrm{e}$ previsão RMSE $=13.8311$. A Figura 6 ilustra o resultado descrito anteriormente, podendo ser mais facilmente compreendido pelo gráfico de erro onde quanto mais próximo de 0 mais próximo do alvo (Target) foi alcançado, onde os dados azuis expressão os dados de treinamento, verde para os dados de validação e vermelho para os dados de teste (Output).

Figura 6 - Dados de entrada: Temperatura, Umidade, Orvalho, Pressão, Vento direção, Vento rajada com janela de 7 dias

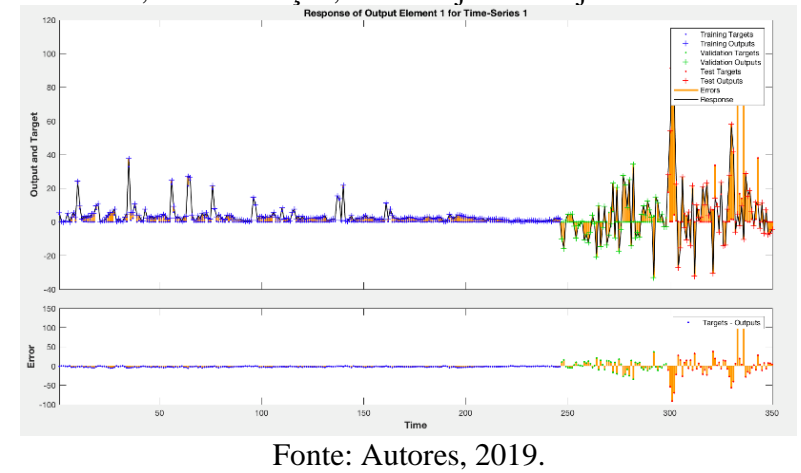

Utilizando as entradas mais correlacionadas com a saída e dados randômicos houve um melhora no resultado de previsão com o algoritmo Levengerg-Marguardt (RMSE = 10.1849), como pode ser observado no erro expresso na Figura 7, onde as saidas (Output) estão mais próximos de zero comparados ao resultado anterior.

Figura 7 - Dados de entrada: Vento direção, Vento rajada com janela de 7 dias

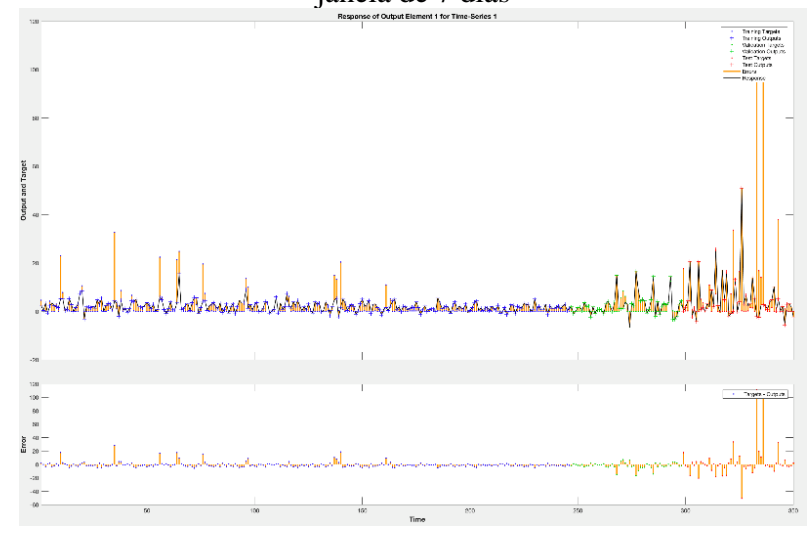

Fonte: Autores, 2019. 
Com o algoritmo Bayesian Regularization, 42 entradas, 10 neurônios, dados randômicos e 1000 épocas de treinamento, chegou-se ao resultado de RMSE $=3.6546$, obtendo uma taxa de $100 \%$ de acerto para os dados de treinamento como pode ser observado na Figura 8, onde, todos os alvos do treinamento tiveram erro zero.

Figura 8 - Dados de entrada: Temperatura, Umidade, Orvalho, Pressão, Vento direção, Vento rajada. 10 neurônios e dados randômicos

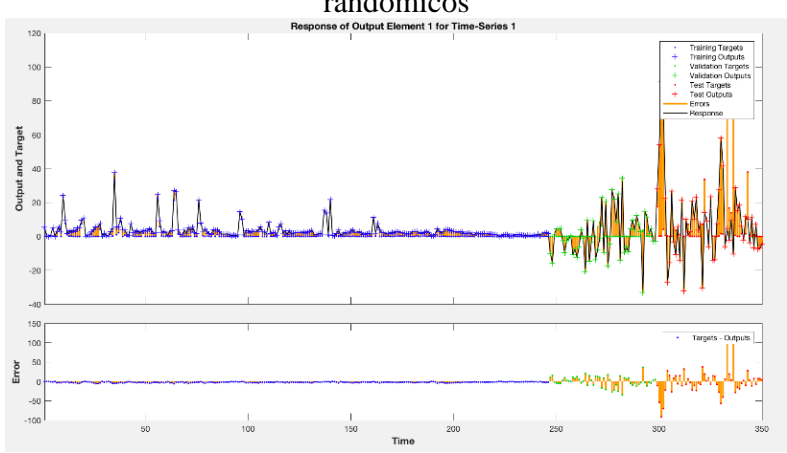

Fonte: Autores, 2019.

Para os dados de teste obteve-se $41.19 \%$ de acerto na previsão, chegando a uma media final de $95.37 \%$ de acertos da previsão de precipitação de chuva levando-se em consideração os $100 \%$ de acerto dos dados de treinamento e $41.19 \%$ dos dados de teste, figura 9.

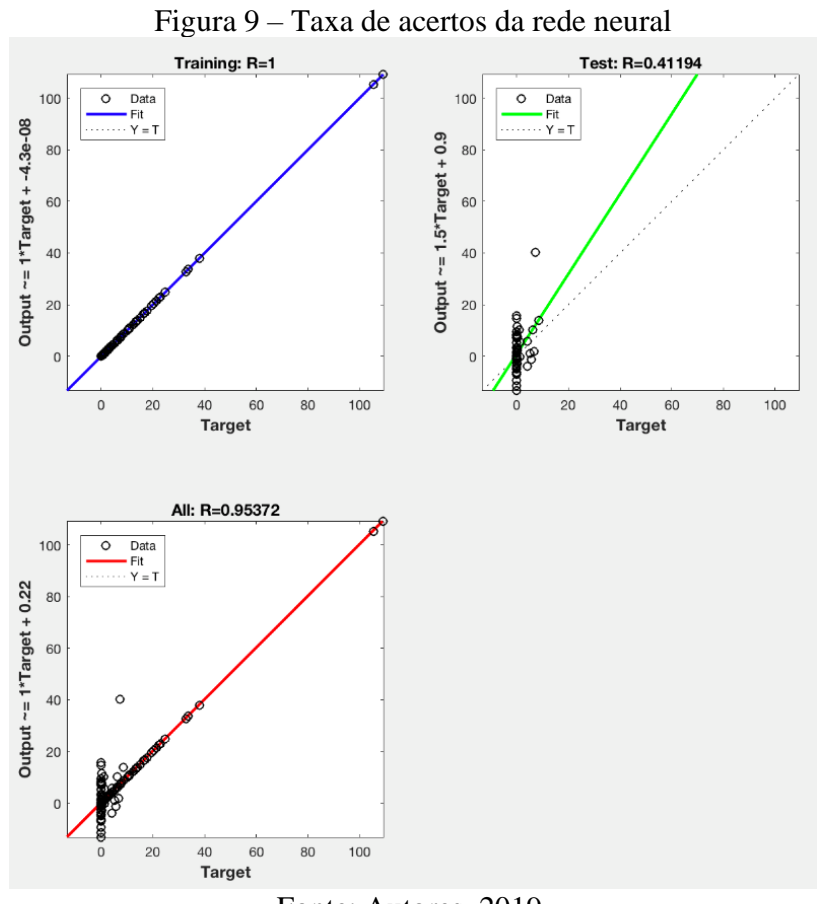

Fonte: Autores, 2019.

Alterando a topologia para o modelo NARX, que direciona a saida para entrada, e refazendo o ultimo teste, ouve uma piora no resultado (RMSE $=6.3501$ ), algo esperado por conta da saída ter baixa correlação com ela mesma.

\section{CONCLUSÃO}

Diante dos resultados encontrados, o melhor cenário obtido foi com Neuro-Fuzzy com 42 entradas, 10 neurônio, algoritmo de treinamento Bayesian Regularization e modelo
$\mathrm{N}$ com os dados randômicos e 1000 épocas de treinamento. Obtendo resultados com desvio médio entre observado e predito de RMSE $=3.6546$ com uma média geral de acerto de $95.37 \%$ dos dados, sendo que $41.19 \%$ é referente aos dados de teste.

De todas as variações realizadas com o número de entradas, algoritmos, número de neurônios e estrutura da topologia, a variação que mostrou melhoria significativa foi a utilização dos dados randômicos, em que todos os teste tiveram melhor resultado comparado com os dados ordenados. Utilizando FCM com o método de otimização híbrida, o tempo de processamento dos dados foram menores, diferente do grid partitioning que, por conta do elevado custo computacional, apresentou tempo de resposta inviável dependendo do número de entradas acima de 7 .

Há uma grande dificuldade e complexidade de se prever séries temporais de chuva, em razão dos longos períodos do ano onde não há nenhuma chuva. Com isso, durante os treinamentos o sistema tende a convergir para zero e em alguns momentos o sistema retorna valores negativos, o que não são valores reais possíveis e não é possível informar para o sistema a impossibilidade de se gerar esses valores como saída. O ideal é desenvolver um algoritmo específico que leva em consideração todas as peculiaridades inerentes da previsão de chuva.

\section{REFERÊNCIAS BIBLIOGRÁFICAS}

BUENO, Lourenco et al. Evolving ensemble of fuzzy models for multivariate time series prediction. In: 2015 IEEE International Conference on Fuzzy Systems (FUZZ-IEEE). IEEE, 2015. p. 1-6.

HARTIGAN, P. F.; GALLOIS, A. P. The use of satellite imagery for forecasting rain attenuation. In: 1993 Eighth International Conference on Antennas and Propagation. IET, 1993. p. 206-209.

LUK, Kin C.; BALL, James E.; SHARMA, Ashish. An application of artificial neural networks for rainfall forecasting. Mathematical and Computer modelling, v. 33, n. 6-7, p. 683-693, 2001.

MEDIUM. Example of na ANN. Disponível em: https://medium.com/analytics-vidhya/predicting-playerperformance-using-neural-networks-f6142784b681. Acesso em 23 mar 2020.

SOARES, Eduardo et al. Ensemble of evolving data clouds and fuzzy models for weather time series prediction. Applied Soft Computing, v. 64, p. 445-453, 2018.

TREWARTHA, Glenn Thomas. An introduction to weather and climate. 1943.

YASEEN, Zaher Mundher et al. Rainfall pattern forecasting using novel hybrid intelligent model based ANFISFFA. Water resources management, v. 32, n. 1, p. 105$122,2018$.

\section{COPYRIGHT}

Direitos autorais: $\mathrm{O}(\mathrm{s})$ autor(es) é(são) o(s) único(s) responsável(is) pelo material incluído no artigo. 


\author{
Volume 16 - $\mathrm{N}^{\mathrm{o}} 174$ - Junho / 2020 \\ XLII International Sodebras Congress \\ 28 a 30 de maio de 2020 - Web Conference.
}

\title{
AVALIAÇÃO DA INCERTEZA DE MEDIÇÃO NA CALIBRAÇÃO DE MEDIDOR DE VAZÃO DE LÍQUIDOS PELO MÉTODO GRAVIMÉTRICO
}

\author{
MEASUREMENT UNCERTAINTY IN THE CALIBRATION OF FLUID FLOW \\ METER BY THE GRAVIMETRIC METHOD \\ IDRISSA DEME \\ UNIVERSIDADE DO ESTADO DO RIO DE JANEIRO (UERJ) \\ idrissdeme@yahoo.fr
}

\begin{abstract}
Resumo - O principal objetivo deste trabalho é avaliação da incerteza de medição na calibração de um medidor de vazão de líquido usando o método gravimétrico que é um método de calibração primário. O sistema calibração usado é a bancada de calibração de medidores de vazão de líquidos da Divisão de Metrologia em Dinâmica de Fluidos (Dinam) do Instituto Nacional em Metrologia Qualidade e Tecnologia (Inmetro) e tipo de medidor de vazão usado é o medidor de vazão mássico tipo Coriolis. A avaliação da incerteza de medição é fundamental para a garantia da conformidade, da confiabilidade $e$ da rastreabilidade de todo sistema de medição. A vazão é uma das grandezas mais medidas nos processos industriais, juntamente com as grandezas temperatura e pressão. A medição de vazão de um fluido é um passo crítico em muitos processos. Em várias operações é necessário que o fluido correto seja disponibilizado em momento e quantidade bem definidos. Qualquer falha pode levar a danos graves, ou perdas enormes. A estimativa da incerteza de medição seguiu os passo do Guia Para a Expressão de Incerteza de Medição (ISO-GUM) e permitiu avaliar as diferentes fontes de incerteza do sistema e suas respectivas contribuições, e determinar a performance do sistema de calibração e as condições ideias de funcionamento do medidor. Palavras-chave: Incerteza de medição. Calibração. Medição de Vazão.
\end{abstract}

Abstract - The main objective of this work is to evaluate the measurement uncertainty in the calibration of a liquid flow meter using the gravimetric method, which is a primary calibration method. The calibration system used is the bench for calibrating liquid flow meters of the Division of Metrology in Fluid Dynamics (Dinam) of the National Institute for Metrology Quality and Technology (Inmetro) and the type of flow meter used is the mass flow meter Coriolis type. The estimation of measurement uncertainty is essential to ensure the conformity, reliability and traceability of the entire measurement system. Flow is one of the most measured quantities in industrial processes, together with the temperature and pressure quantities. Flow measurement of a fluid is a critical step in many processes. In several operations, it is necessary that the correct fluid is available at a well-defined time and quantity. Any failure can lead to serious damage, or huge losses. The estimation of measurement uncertainty followed the steps of the Guide to the Expression of Measurement Uncertainty (ISO-GUM) and allowed to evaluate the different sources of uncertainty of the system and their respective contributions, and to determine the performance of the calibration system and the ideal conditions of the meter operation.

Keywords: measurement uncertainty. Calibration. Liquid flow measurementr.

\section{INTRODUÇÃO}

A calibração de medidores de vazão de líquidos permite assegurar a confiabilidade desses instrumentos de medição, por meio da comparação do valor medido com um padrão rastreado ao Sistema Internacional de Unidades (SI) (Bergam,2011). Com base no resultado de uma calibração avalia-se o quanto um instrumento responde às exigências de exatidão e faixa de operação para ser utilizado no propósito pretendido. Os instrumentos calibrados permitem também ao fabricante ou o processador produzir mercadorias de qualidade, já que as medições são confiáveis e os limites de incertezas e erros são conhecidos (Soisson,2012).

Existem basicamente dois métodos primários de medição para a calibração de medidores de vazão de líquidos: o volumétrico e o gravimétrico (Ryhming,2004). A Divisão de Metrologia em Dinâmica de Fluidos (Dinam/Inmetro) do Instituto Nacional de Metrologia, Qualidade e Tecnologia (INMETRO), dentre a sua infraestrutura laboratorial dispõe de uma bancada para calibração de medidores de vazão de água usando o método gravimétrico de calibração que é o método primário mais confiável.

O presente trabalho apresenta um processo de avaliação da incerteza de medição de um medidor de vazão mássico tipo Coriolis pelo método gravimétrico usando os passos descritos pelo Guia para avaliação de incerteza de medição da ISO (ISO-GUM) (BIPM, 2012). O sistema usado para as medições é a bancada automatizada de calibração de medidores de vazão de líquidos do Instituto Nacional em Metrologia Qualidade e Tecnologia (Inmetro).

A metodologia adotada, os principais resultados obtidos e as conclusões são apresentados nas linhas a seguir.

\section{METODOLOGIA}

O método de calibração usado é método gravimétrico e o medidor calibrado é o medidor mássico de vazão de líquido. A avaliação da incerteza de medição segue os passo do guia para avaliação de incerteza de medição da ISO (ISO-GUM). As medições foram realizadas em cinco faixas de vazão indo do mais baixo ao máximo do medidor usado correspondendo às faixas de vazão de $20 \mathrm{~kg} / \mathrm{min}, 60 \mathrm{~kg} / \mathrm{min}$, $80 \mathrm{~kg} / \mathrm{min}, 100 \mathrm{~kg} / \mathrm{min}$ e $120 \mathrm{~kg} / \mathrm{min}$. Para cada faixa foram realizadas seis (6) medições dando um total de trinta (30) medições. O mensurando é o fator de calibração Fm, um 
número adimensional que representa a ração do da massa totalizada na balança da bancada gravimétrica e do da massa totalizado pelo medidor. O modelo matemático é o seguinte: - Forma geral da equação para determinação do mensurando (Fm)

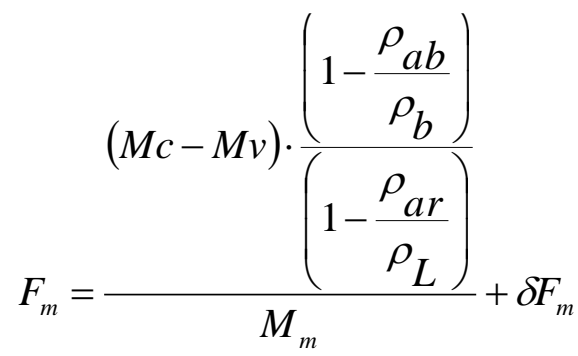

(II.1)

- Forma detalhada da equação para determinação do mensurando (Fm)

$$
F_{m}=\frac{\left(1-\frac{\rho_{A B}}{\rho_{B}}\right)}{\left(1-\frac{\left.\left(\frac{k_{1} \cdot P_{a}-k_{2} \cdot \varphi \cdot \exp \left(k_{3} \cdot T_{a}\right)}{k_{4}+T_{a}}\right)+\delta \rho_{a}\right)}{\left.a_{5} \cdot\left(1-\frac{\left(T_{L}+a_{1}\right)^{2} \cdot\left(T_{L}+a_{2}\right)}{a_{3} \cdot\left(T_{L}+a_{4}\right)}\right)+\delta \rho_{L}\right)}\right.} M_{i} F_{m}
$$

(II.2)

Onde:

$M c$ : Massa do recipiente cheio medido na balança $(\mathrm{kg})$.

$M v$ : Massa do recipiente vazio medido na balança $(\mathrm{kg})$.

$\rho_{A B}$ : Massa específica do ar no momento da calibração da balança $\left(\mathrm{kg} / \mathrm{dm}^{3}\right)$

$\rho_{B}$ : Massa específica dos pesos padrão que calibraram a balança $\left(\mathrm{kg} / \mathrm{dm}^{3}\right)$

$\mathrm{M}_{\mathrm{i}}$ : Massa indicada pelo medidor $(\mathrm{kg})$

$\rho_{L}$ : massa específica do líquido na temperatura $\mathrm{T}_{\mathrm{L}}\left({ }^{\circ} \mathrm{C}\right)$

$T_{L}$ : temperatura do líquido $\left({ }^{\circ} \mathrm{C}\right)$ e $\mathrm{T}=\mathrm{T}_{\mathrm{L}}+\delta \mathrm{T}_{\mathrm{L}} ; \delta \mathrm{T}_{\mathrm{L}}$ :

variação de $\mathrm{T}_{\mathrm{L}}$ durante uma série

$a_{1}=3,983035{ }^{\circ} \mathrm{C} ; a_{2}=301,797{ }^{\circ} \mathrm{C} ; a_{3}=522528,9{ }^{\circ} \mathrm{C} ; a_{4}$

$=69,34881^{\circ} \mathrm{C} ; a_{5}=999,97495 \mathrm{~kg} \cdot \mathrm{m}^{-3}$

$\delta \rho_{L}$ : erro devido a diferença entre o tipo de líquido da equação padrão e o líquido de trabalho

$\rho_{\text {ar: }}$ :massa específica do ar $(\mathrm{kg}) / \mathrm{m}^{3}$

$\mathrm{k}_{1}: 0,34848 ; \mathrm{k}_{2}: 0,009024 ; \mathrm{k}_{3}: 0,0612 ; \mathrm{k}_{4}: 273,15$

$P_{a}$ :pressão barométrica em $\mathrm{hPa}$

$\varphi$ : umidade relativa do ar em \%

$T_{a}$ : temperatura do ar em ${ }^{\circ} \mathrm{C}$

$\delta \rho_{\text {ar: }}$ ajuste de $\rho_{\mathrm{a}}$ na equação (4.4) para caçulo da massa específica do ar.

$\delta \mathrm{F}_{\mathrm{m}}$ : variação aleatória de $\mathrm{F}_{\mathrm{m}}$

\section{RESULTADOS}

Os principais resultados alcançados são apresentados abaixo. A tabela 1 apresenta as fontes de incerteza e a determinação da incerteza padrão associada a cada uma e a figura 1 mostra o diagrama de Ishikawa com os fatores de influência. A tabela 2 mostra a contribuição dos fatores de influência na incerteza. A tabela 3 mostra as incertezas relativas em função das faixas de vazão. A contribuição $u_{c}(i)$ de cada fonte foi avaliada fazendo o produto da incerteza padrão associada a ela com o coeficiente de sensibilidade correspondente.
Cada grau de liberdade foi calculado pela fórmula de Welch-Satterthwaite como recomendado pelo ISO-GUM.

\begin{tabular}{|c|c|c|}
\hline Grandeza & $\begin{array}{c}\text { Avaliação da fonte de } \\
\text { incerteza }\end{array}$ & $\begin{array}{c}\text { Estimativa } \\
\text { medidor mássico }\end{array}$ \\
\hline \multirow[b]{2}{*}{$\mathrm{M}_{\mathrm{c}}:(\mathrm{kg})$} & Certificado balança (tipo & $\mathrm{u}=\mathrm{U} / \mathrm{k}=0,002$ \\
\hline & $\begin{array}{l}\text { B): } \\
\text { Repetição (tipo A) (Grau } \\
\text { de liberdade } v=87 \text { ) }\end{array}$ & $s_{\overline{M_{c}}}=\sqrt{\frac{\sum_{1}^{n}\left(\overline{M_{C}}-M_{C_{i}}\right.}{n(n-1)}}$ \\
\hline \multirow{3}{*}{$\mathrm{M}_{\mathrm{v}}:(\mathrm{kg})$} & Certificado da balança & $\mathrm{u}=\mathrm{U} / \mathrm{k}=\mathrm{U}: 0,002$ \\
\hline & (tipo B) & $\sum_{1}^{n}\left(\overline{M_{v}}-M_{V i}\right.$ \\
\hline & $\begin{array}{l}\text { Repetiçao (tipo A) } \\
(\text { Grau de liberdade } v=87)\end{array}$ & $s_{\overline{M_{V}}}=\sqrt{ }$ \\
\hline \multirow[b]{2}{*}{$\mathrm{T}_{\mathrm{L}}:\left({ }^{\circ} \mathrm{C}\right)$} & Certificado do pt100 (tipo & $\mathrm{u}=\mathrm{U} / \mathrm{k}=0,005$ \\
\hline & $\begin{array}{l}\text { B) } \\
\text { Repetição (tipo A) (Grau } \\
\text { de liberdade } v=\infty \text { ) }\end{array}$ & $s_{\overline{T_{L}}}=\sqrt{\frac{\Sigma_{1}^{n}\left(\overline{T_{L}}-T_{L_{i}}\right.}{n(n-1)}}$ \\
\hline$\delta \mathrm{T}_{\mathrm{L}}$ & $\begin{array}{l}\text { Repetição (tipo A) } \\
(\text { Distribuição retangular v } \\
(\infty))\end{array}$ & $\left(\mathrm{T}_{\mathrm{Lmax}}-\mathrm{T}_{\mathrm{Lmin}}\right) / 2 . \quad \sqrt{ }$ \\
\hline \multirow[b]{2}{*}{$\mathrm{T}_{\mathrm{a}}:\left({ }^{\circ} \mathrm{C}\right)$} & Certificado da estação & $\mathrm{u}=\mathrm{U} / \mathrm{k}=0,15$ \\
\hline & 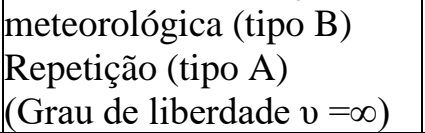 & $s_{T_{a}}=\sqrt{\frac{\sum_{1}^{n}\left(\overline{T_{a}}-T_{a_{i}}\right.}{n(n-1)}}$. \\
\hline \multirow[b]{2}{*}{$\mathrm{P}_{\mathrm{a}}:(\mathrm{kPa})$} & Certificado da estação & \multirow[b]{2}{*}{$s_{\overline{\mathrm{P}_{\mathrm{a}}}}=\sqrt{\frac{\sum_{\mathrm{i}}^{4}\left(\mathrm{P}_{\mathrm{a}}-\mathrm{P}_{\mathrm{a}_{\mathrm{i}}}\right.}{n(n-1)}}}$. \\
\hline & $\begin{array}{l}\text { meteorológico (tipo B) } \\
\text { Repetição (tipo A) } \\
\text { (Grau de liberdade } v=\infty \text { ) }\end{array}$ & \\
\hline$\varphi:(\%)$ & $\begin{array}{l}\text { Certificado da estação } \\
\text { meteorológica (tipo B) } \\
\text { Repetição (tipo A) } \\
(\text { Grau de liberdade v }=\infty \text { ) }\end{array}$ & $s_{\bar{\varphi}}=\sqrt{\frac{\sum_{1}^{n}\left(\bar{\phi}-\varphi_{i}\right.}{n(n-1)}, \ldots}$ \\
\hline $\begin{array}{c}\rho_{\mathrm{AB}}: \\
\left(\mathrm{kg} / \mathrm{m}^{3}\right)\end{array}$ & $\begin{array}{l}\text { Certificado (tipo B) } \\
(\text { Grau de liberdade } v=\infty)\end{array}$ & $\mathrm{u}=\mathrm{U} / \mathrm{k}=0,014$ \\
\hline $\begin{array}{c}\rho_{\mathrm{B}}: \\
\left(\mathrm{kg} / \mathrm{m}^{3}\right)\end{array}$ & $\begin{array}{l}\text { Certificado -pe: } \\
\text { (Grau de liberd }\end{array}$ & $\mathrm{u}=\mathrm{U} / \mathrm{k}=0,115$ \\
\hline $\begin{array}{c}\delta \rho_{\mathrm{L}}: \\
\left(\mathrm{kg} / \mathrm{m}^{3}\right)\end{array}$ & $\begin{array}{l}\text { Equação de Tanaka (tipo } \\
\text { B) (Grau de liberdade } v \\
=\infty \text { ) }\end{array}$ & $\mathrm{u}=\mathrm{U} / \mathrm{k}=0,012$ \\
\hline $\begin{array}{c}\delta \rho_{\mathrm{ar}:}(\mathrm{kg} / \\
\left.\mathrm{m}^{3}\right)\end{array}$ & $\begin{array}{l}\text { Equação para } \\
\text { determinação da massa } \\
\text { específica do ar (tipo B) } \\
(\text { Grau de liberdade } v=\infty) \\
\end{array}$ & $\mathrm{u}=\mathrm{U} / \mathrm{k}=1,15 \cdot 10^{-5}$ \\
\hline $\begin{array}{c}\mathrm{V}_{\mathrm{m}}:(\mathrm{L}) \\
\mathrm{Ou} \\
\mathrm{M}_{\mathrm{m}}:(\mathrm{kg})\end{array}$ & $\begin{array}{l}\text { Repetição (tipo A) (Grau } \\
\text { de liberdade n-1) }\end{array}$ & $s_{\overline{M_{m}}}=\sqrt{\frac{\sum_{1}^{n}\left(\overline{M_{m}}-M_{m_{i}}\right.}{n(n-1)}}$ \\
\hline$\delta F_{m}:$ & $\begin{array}{l}\text { Repetição de Fm (tipo A) } \\
\text { (Grau de liberdade n-1) }\end{array}$ & $s \overline{\delta_{\mathrm{m}}}=\sqrt{\frac{\sum_{1}^{n(}\left(\overline{\mathrm{F}_{\mathrm{m}}}-\mathrm{F}_{\mathrm{m}_{i}}\right.}{n(n-1)}}$ \\
\hline
\end{tabular}

Tabela 1: Fontes de incerteza e suas avaliações 
Figura1: diagrama de Ishikawa

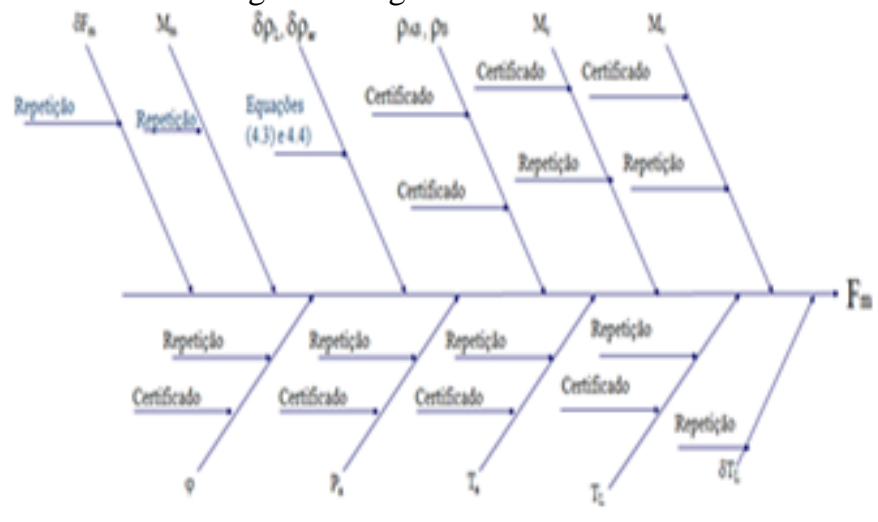

Tabela 2: Fatores de influência e suas contribuições na incerteza

\begin{tabular}{|c|c|c|c|c|c|}
\hline \multirow{3}{*}{$\begin{array}{c}\text { Variáveis } \\
\text { de entrada } \\
i\end{array}$} & \multicolumn{5}{|c|}{ Vazão (kg/min) } \\
\hline & 20 & 60 & 80 & 100 & 120 \\
\hline & \multicolumn{5}{|c|}{$100 \times c_{i} \times u_{i} / u$} \\
\hline$\delta \mathrm{Fm}$ & $74,00 \%$ & $43,73 \%$ & $35,64 \%$ & $34,72 \%$ & $32,42 \%$ \\
\hline $\mathbf{M}_{\mathbf{c}}$ & $8,70 \%$ & $15,50 \%$ & $17,20 \%$ & $15,25 \%$ & $16,66 \%$ \\
\hline $\mathbf{M}_{\mathbf{v}}$ & $8,70 \%$ & $15,50 \%$ & $17,20 \%$ & $15,25 \%$ & $16,66 \%$ \\
\hline $\mathbf{T}_{\mathbf{a}}$ & $3,55 \%$ & $13,04 \%$ & $15,65 \%$ & $19,36 \%$ & $18,66 \%$ \\
\hline$\delta \rho a r$ & $1,27 \%$ & $4,59 \%$ & $5,50 \%$ & $6,92 \%$ & $6,73 \%$ \\
\hline mini & $1,52 \%$ & $2,74 \%$ & $3,05 \%$ & $2,71 \%$ & $2,96 \%$ \\
\hline $\mathbf{m}_{\mathrm{fim}}$ & $1,52 \%$ & $2,74 \%$ & $3,05 \%$ & $2,71 \%$ & $2,96 \%$ \\
\hline$\rho_{a b}$ & $0,20 \%$ & $0,71 \%$ & $0,86 \%$ & $1,08 \%$ & $1,05 \%$ \\
\hline$\varphi$ & $0,14 \%$ & $0,54 \%$ & $0,64 \%$ & $0,76 \%$ & $0,72 \%$ \\
\hline $\mathbf{T}_{\mathbf{L m}}$ & $0,14 \%$ & $0,50 \%$ & $0,61 \%$ & $0,78 \%$ & $0,77 \%$ \\
\hline$\delta T_{L m}$ & $0,25 \%$ & $0,29 \%$ & $0,47 \%$ & $0,30 \%$ & $0,27 \%$ \\
\hline $\mathbf{P a}$ & $0,029 \%$ & $0,11 \%$ & $0,13 \%$ & $0,16 \%$ & $0,16 \%$ \\
\hline$\delta \rho_{\mathrm{L}}$ & $0,0015 \%$ & $0,0055 \%$ & $0,0066 \%$ & $0,0082 \%$ & $0,0080 \%$ \\
\hline$\rho \mathbf{b}$ & $0,00021 \%$ & $0,00078 \%$ & $0,00094 \%$ & $0,0012 \%$ & $0,0011 \%$ \\
\hline Total & $100,00 \%$ & $100,00 \%$ & $100,00 \%$ & $100,00 \%$ & $100,00 \%$ \\
\hline
\end{tabular}

Tabela 3: incertezas de medição em função da faixa de vazão

\begin{tabular}{|l|l|l|l|l|l|}
\hline Faixa de vazão (kg/min) & 20 & 60 & 80 & 100 & 120 \\
\hline $\begin{array}{l}\text { Incerteza do Fm do } \\
\text { sistema (\%) }\end{array}$ & $\mathbf{0 , 1 5}$ & $\mathbf{0 , 0 3 0}$ & $\mathbf{0 , 0 2 1}$ & $\mathbf{0 , 0 1 7}$ & $\mathbf{0 , 0 1 7}$ \\
\hline
\end{tabular}

A tabela 2 mostra que os principais fatores de influência na incerteza são relacionadas a repetitividade e a massa do líquido que atravessa o medidor e a massa totalizada. A temperatura ambiente se torna um fator importante nas faixas de vazão alta $(100 \mathrm{~kg} / \mathrm{min}$. e $120 \mathrm{~kg} / \mathrm{min}$.).

A tabela 3 mostra que a faixa de menor vazão é a que apresenta uma maior incerteza relativa devido a dificuldades de controles dos parâmetros nesta faixa pelo fato do escoamento ser menos desenvolvido. A incerteza atinge valores menores à medida que a vazão aumenta. Porém, nas faixas mais altas, a incerteza tem valores próximos entre si.
Como a repetitividade não varia consideravelmente nas vazões mais altas, observa-se uma tendência de estabilidade na vazão, o que é esperado pelo fato do escoamento estar completamente desenvolvido na tubulação e os efeitos de turbulência menores. Nessas faixas fatores que não depende do sistema de teste como a temperatura ambiente começam a ter uma contribuição importante na incerteza, mostrando assim a importância do controle dos efeitos ambientais para o funcionamento otimizado do medidor de vazão.

\section{CONCLUSÃO}

Este estudo possibilitou a apresentação de um método que possibilita a estimação das diferentes fontes de incerteza num sistema de medição dinâmico e suas contribuições na incerteza da medição. Possibilitou também destacar as condições de funcionamento ideal do medidor de vazão pela comparação dos valores de incerteza em diferentes faixas de vazão. Os resultados obtidos estão em conformidade e até melhores que outros sistemas de calibração parecidos.

\section{REFERÊNCIAS BIBLIOGRÁFICAS}

BERGMANN, G. Avaliação metrológico de sistemas de medição de vazão. Lajedo. 2011.

JOINT COMMITTEE FOR GUIDES IN METROLOGY (JCGM). International vocabulary of metrology - Basic and general concepts and associated terms (VIM).

Bureau International des Poids et Mesures (BIPM). Paris. 2012.

KNOPF,D. ;BARBE, J.; RICHTER, W.; MARSCHAL, A., Comparison of the gas mass flow calibration systems of the BNM LNE and the PTB, Metrologia N ${ }^{\circ} 38,2001$ p.197.

RAINER, E.; KARL HEINZ, B.; HANS-JOACHIM B. Design and realization of the high precision weighing systems as the gravimetric references in PTB's national water flow standard, Measurement. Science. Technology. $\mathrm{N}^{\mathrm{o}} 23,2012$.

RYHMING, I. L. Dynamique des fluides: um cours de base du deuxième cycle universitaire. Romande: Presse Polytechnique et Universitaire , 2004.

\section{AGRADECIMENTOS}

Agradecimentos ao:

Inmetro: Instituto Nacional De Metrologia Qualidade e Tecnologia

Pronametro: Programa Nacional de Apoio ao Desenvolvimento da Metrologia, Qualidade e Tecnologia.

\section{COPYRIGHT}

Direitos autorais: O autor é o único responsável pelo material incluído no artigo. 


\author{
Volume $16-\mathrm{N}^{\mathrm{o}} 174$ - Junho / 2020 \\ XLII International Sodebras Congress \\ 28 a 30 de maio de 2020 - Web Conference.
}

\title{
CARACTERIZAÇÃO DE FILME DE DIAMANTE CVD POLICRISTALINO DEPOSITADO EM SILÍCIO COM DIFERENTES ORIENTAÇÕES CRISTALINAS
}

\section{CHARACTERIZATION OF POLYCRYSTALLINE CVD DIAMOND FILM DEPOSITED ON INTRINSIC SILICON WITH DIFFERENT CRYSTALLINE ORIENTATIONS}

\author{
Alexandre Marcello Cavalca de Almeida ${ }^{1}$, Evaldo Chagas Gouvêa ${ }^{1}$, Teófilo Miguel de Souza ${ }^{1}$ \\ 1 - FACULDADE DE ENGENHARIA DE GUARATINGUETÁ, UNESP - UNIVERSIDADE ESTADUAL \\ PAULISTA, CAMPUS GUARATINGUETÁ
}

marcello.cavalca@gmail.com,evaldo.gouvea@unesp.br,teofilo_miguel@yahoo.com.br

\begin{abstract}
Resumo - O método de deposição química a partir da fase vapor (CVD) é empregado no presente estudo. Sendo o diamante CVD portador das mesmas propriedades do diamante natural, ele se torna um excelente substituto para aplicações práticas. Dessa forma estudos em relação a sua morfologia são necessários, estudando como a orientação do substrato pode influenciar na formação de grãos, assim fazendo análises das estruturas dos filmes em DRX e leitura das imagens obtidas pelo MEV a respeito de sua morfologia de grãos. Após obtenção dos dados, classificar a respeito de qual orientação teve um melhor desempenho em relação a formação de grãos.

Palavras-chave: Diamante artificial. Caracterização de filmes de diamante. Dispositivo eletrônico.
\end{abstract}

Abstract - The chemical vapor deposition method (CVD) is used
in the present study. Since CVD diamond has the same properties
as natural diamond, it becomes an excellent substitute for
practical applications. Thus, studies in relation to its morphology
are necessary, studying how the orientation of the substrate can
influence the formation of grains, thus making analyzes of the
structures of the films in XRD and reading the images obtained
by SEM regarding its grain morphology. After obtaining the
data, classify as to which orientation had the best performance in
relation to grain formation. Keywords: Artificial diamond. Characterization of diamond films. Electronic devices.

\section{INTRODUÇÃO}

Dentre os métodos atuais de produção de diamante sintético, destacam-se, o de alta pressão e alta temperatura (High Pressure High Temperature - HPHT) e o de deposição química a partir da fase vapor (Chemical Vapor Deposition - CVD), sendo este último o método a ser empregado no presente estudo (FREIRE, 2000).

$\mathrm{O}$ diamante CVD é um material que, embora seja produzido sinteticamente, apresenta as mesmas propriedades físicas e químicas do diamante natural. Devido às propriedades do filme de diamante CVD, são diversas as possibilidades de aplicação: em ferramentas de corte para metalurgia, brocas perfurantes, instrumentos odontológicos, dissipadores de calor, células de amostra para equipamentos analíticos, indústria óptica, rastilhos de instrumentos musicais de corda, recobrimento de ligas de nióbio e titânio, dispositivos eletrônicos, entre outras.

Portanto, a avaliação de fatores que influenciam na qualidade do diamante obtido sinteticamente torna-se extremamente importante.

Apresenta-se como objetivo a caracterização de filmes de diamante CVD dopado com diferentes orientações cristalinas de cada substrato, e categorizar quanto ao desempenho de qual orientação obteve um melhor desempenho no crescimento do filme (DOMONKOS, 2018).

\section{METODOLOGIA}

Foi aplicada a técnica de deposição por filamento de tungstênio quente à alta temperatura $\left(2000\right.$ a $\left.2500^{\circ} \mathrm{C}\right) . \mathrm{O}$ processo ocorreu dentro de uma câmara em baixa pressão (cerca de $50 \mathrm{mmHg}$ ) na qual é inserida uma mistura de gás metano diluído em hidrogênio (YAO, 2018). Podem ser adicionados outros gases na mistura, como por exemplo, nitrogênio para obter um filme de diamante CVD mais cristalino ou em diferentes proporções de dopantes. Neste método, a taxa de crescimento depende de vários parâmetros de reacionais, como:

- Temperatura do filamento;

- Pressão de gases no interior da câmara;

- Fluxo de gás utilizado;

- Distância entre o filamento e o substrato;

- Tempo de reação.

O reator instalado e que foi utilizado no projeto aqui proposto é um equipamento multifilamento de grande porte que pode trabalhar com uma área de até $150 \mathrm{~cm}^{2}$. Este sistema é composto do reator propriamente dito, que é a parte mecânica (câmara) e o sistema de controle, composto de bomba mecânica para vácuo, medidor de pressão, válvulas solenoide, medidores de vazão para gases e fonte estabilizada de corrente e tensão. Todos os parâmetros dos quais depende a taxa de crescimento do filme de diamanteCVD foram ajustados e otimizados em função das 
características exigidas pela aplicação do filme. Foi verificada a diferença entre a massa antes e após da deposição do filme utilizando-se uma balança semi-analítica com resolução de $1 \times 10^{-5} \mathrm{~g}$ (ACHARD, 2011).

Estudos exploratórios já realizados apresentam as condições gerais de obtenção de filmes nesse reator, como se segue:

- Não menos que duas horas de deposição do filme utilizando gás metano ( 0,1 a $5 \%$ em volume) e hidrogênio (balanço em volume) e como eventual dopante o fósforo, boro, arsênio, alumínio, gálio, outros com características similares $(0,1$ a $5 \%$ em volume) sob temperatura entre $600^{\circ} \mathrm{C}$ e $900^{\circ} \mathrm{C}$. A pressão deve ser da ordem de $50 \mathrm{mmHg}$.

- A taxa de dissociação de hidrogênio, cuja concentração influencia no crescimento do filme aumenta com o aumento da temperatura (WHEELER, 2018).

Os filmes de diamante-CVD foram caracterizados quanto à morfologia, textura e propriedades através de Microscopia Eletrônica de Varredura (MEV) operado no modo de baixo vácuo, para obter a propriedade de condutividade elétrica de cada filme e obtendo três imagens para cada filme, sendo estas imagens com ampliações de (2000X), (5000X) e (10000X). Análise de difração de raios $X$ foi realizada a fim de confirmar e entender tanto a estrutura cristalina como sua interação com o substrato (ZHAO, 2017).

Para o trabalho foram produzidas e testadas uma amostra do crescimento do filme para cada substrato de Silício. Utilizou-se três substratos, cada um apresentando uma orientação cristalina diferente, especificada pelo fabricante.

Tabela 1 - Orientações das amostras.

\begin{tabular}{cc}
\hline Amostras & Orientações \\
\hline 1 & $\begin{array}{c}\text { Orientado no } \\
\text { plano (100) } \\
\text { Orientado no } \\
\text { plano (111) } \\
2\end{array}$ \\
3 & Sem orientação
\end{tabular}

A execução do projeto foi realizada, utilizando as instalações e equipamentos do Laboratório de Pesquisa e Desenvolvimento de Filmes Finos e Novos Materiais, Laboratório de Eficiência Energética, Laboratório de Instrumentação e do Centro de Energias Renováveis. A Figura 1 apresenta o reator, o qual produziu os filmes.

Figura 1 - Reator para formação de filmes de diamante CVD

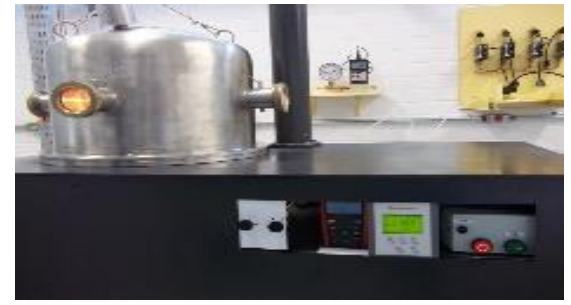

Fonte: Teófilo Miguel de Souza, 2019.

\section{RESULTADOS}

Com base em resultados preliminares, verificou-se que o filme de diamante dopado depositado em substrato de silício sofreu efeito do tempo de deposição e da orientação cristalina do silício

As análises do efeito das diferentes orientações de cada amostra para a formação, espessura e qualidade do filme obtido, forneceram informações úteis para estudos sobre a aplicação direta do diamante CVD em diversos tipos de dispositivos eletroeletrônicos.

Cada amostra obteve três imagens no modo de baixo vácuo, no qual é possível verificar a condutividade elétrica da amostra. Para todas as amostras, suas imagens seguem um aumento na ampliação de 2000X, 5000X e 10000X, respectivamente.

As três amostras também obtiveram difratogramas, os quais representam picos em determinados valores de $2 \theta$. Estes difratogramas podem mostrar a estrutura cristalina do filme. Caso tenham picos bem definidos eles representam um material cristalino, caso contrário será um material amorfo.

As Figuras 2 a 4 representam a morfologia de cada amostra, com um aumento na ampliação da esquerda para a direita. As imagens têm como principal função, apresentar os tamanhos de grãos formados em cada orientação, as imagens foram obtidas no modo baixo vácuo. Neste modo de operação, o contraste presente nas figuras mostra acúmulos de cargas e assim pouca condutividade elétrica.

\section{1 - Resultados da Morfologia dos grãos}

Figura 2 - Morfologia da Amostra 1, orientado no plano (100).
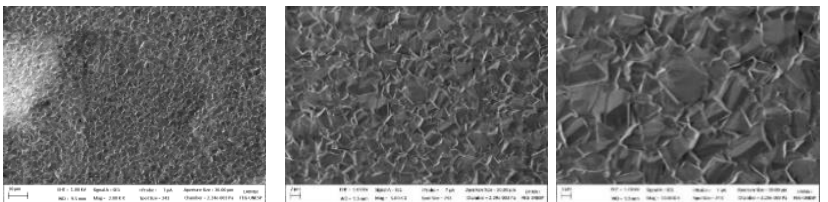

Fonte: Microscópio Eletrônico de Varredura/FEG, 2019.

Figura 3 - Morfologia da Amostra 2, orientado no plano (111).
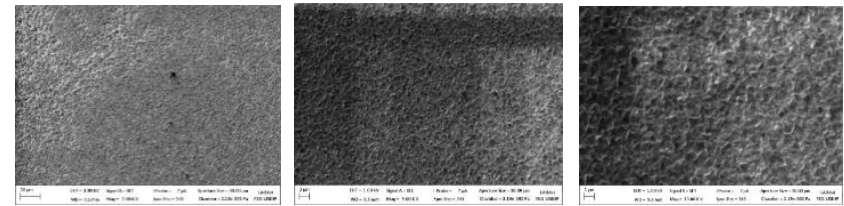

Fonte: Microscópio Eletrônico de Varredura/FEG, 2019.

Figura 4 - Morfologia da Amostra 3, sem orientação.
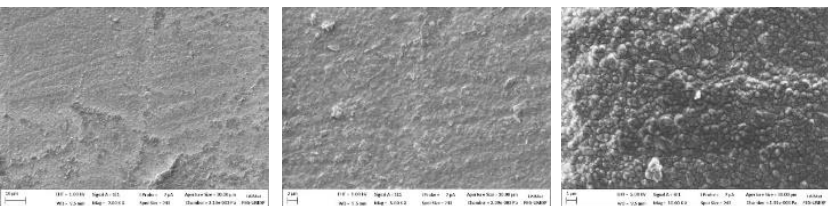

Fonte: Microscópio Eletrônico de Varredura/FEG, 2019

\section{2 - Resultados da Estrutura dos filmes.}

Sabe-se através da literatura e de outros trabalhos realizados que o difratograma do diamante CVD é semelhante à Figura 5: 
Figura 5 - Difratograma do diamante CVD.

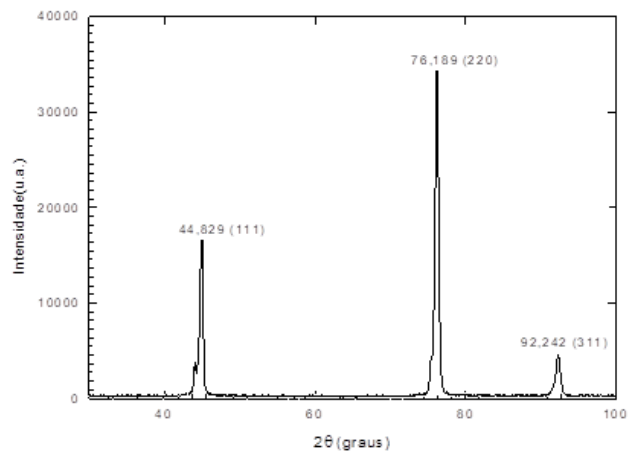

Fonte: Laboratório de Pesquisa e Desenvolvimento de Dispositivos com Diamante CVD, 2002.

As Figuras 6 a 8 apresentam os picos dos difratogramas dos filmes de diamante CVD do trabalho atual. plano (100)

Figura 6 - Difratograma da Amostra 1, orientado no

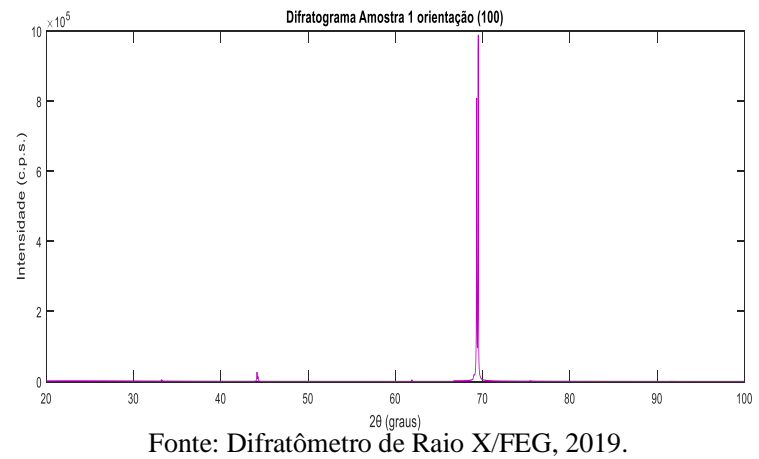

Figura 7 - Difratograma da Amostra 2, orientado no plano (111)

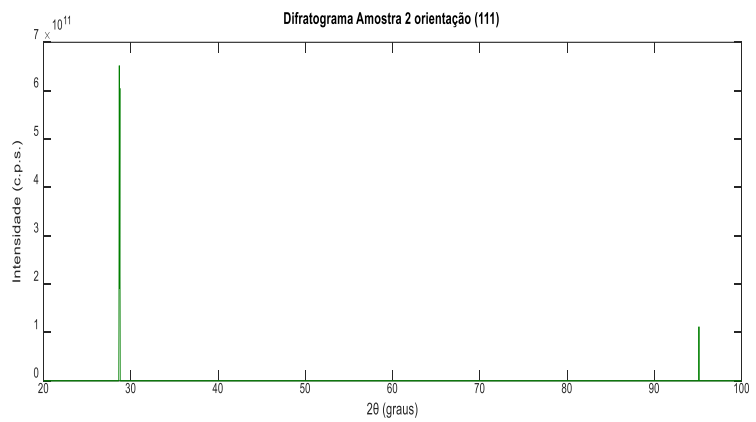

Fonte: Difratômetro de Raio X/FEG, 2019.

Figura 8 - Difratograma da Amostra 3, sem orientação

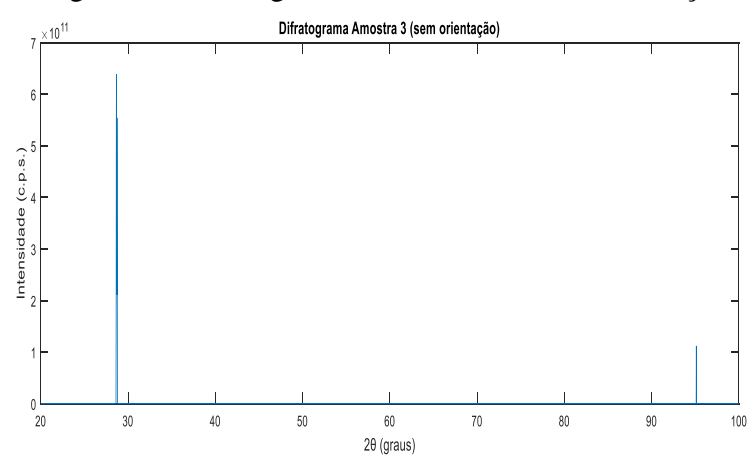

Fonte: Difratômetro de Raio X/FEG, 2019.
Assim, pode-se notar que os picos dos difratogramas das amostras não estão alinhados com os picos do difratograma real, podendo pressupor a presença de uma segunda fase ou de impurezas. Contudo todos os difratogramas são apresentados por picos bem definidos, dizendo que todas as amostras apresentam caráter cristalino.

\section{CONCLUSÃO}

Em primeira análise, pode-se notar que todas as amostras formaram fases cristalinas como mostra a Difração de Raio-X, contudo ao analisar as imagens do Microscópio Eletrônico de Varredura, percebe-se que em cada amostras formou-se grãos de tamanhos diferentes e com isso nota-se características diferentes.

A amostra com orientação (100) foi a que obteve maiores e mais definidos grãos, além de apresentar a melhor condutividade elétrica visto que os contrastes de branco e preto nas imagens, mostram acúmulos de cargas, assim piorando a condutividade elétrica do material. Porém na primeira amostra este contraste é notado apenas na ampliação de 2000X, e some com as demais ampliações.

Já na segunda amostra com orientação (111) obteve grãos relativamente menor do que a primeira amostra, e uma condutividade elétrica inferior, sendo que o contrastes de cores aparece nas ampliações de 5000X e 10000X.

Enquanto que na terceira amostra, sem orientação definida, foi a amostra com menor tamanho de grão, quase não sendo visíveis os grãos nas ampliações de 2000X e 5000X, sendo eles notados mais nitidamente na ampliação de 10000X, e nesta ampliação ainda percebe-se um alto contraste de cor, assim sendo, a terceira amostra além de obter o menor tamanho de grão ainda obteve a menor condutividade elétrica.

Em relação aos difratogramas, tanto o difratograma do diamante CVD da literatura, quanto os difratogramas das amostras, ambos foram obtidos através de um DRX, o qual emitia radiação de $\mathrm{C}_{\mathrm{u}}-\mathrm{K} \alpha$, $\log \mathrm{o}$ as diferenças de picos não podem ser devido a radiação ou ao equipamento, sendo assim a diferença podendo ser devido a segundas fases ou impurezas.

Pelos estudos feitos no presente trabalho, a amostra com orientação (100) apresentou o melhor desempenho, tanto pelos tamanhos de grãos, quanto pela condutividade elétrica. Já a segunda amostra com orientação (111) apresenta resultados medianos em ambos aspectos e a terceira amostra, sem orientação, foi a amostra com os piores resultados, tanto pelos tamanhos de grãos, quanto pela condutividade elétrica. Como visto no trabalho de Ullah (2018), a respeito da condutividade elétrica do filme de diamante CVD, com uma redução do gap de energia $(\sim 0,865 \mathrm{eV})$, ele afirma:

"Em resumo, nossos cálculos revelaram que a incorporação dos átomos de oxigênio na superfície do diamante $\left(\begin{array}{lll}1 & 0 & 0\end{array}\right)$ é parcialmente favorável (ULLAH, p.407, 2018, tradução nossa)."

Visto que no trabalho mencionado, o substrato do filme também era de silício, com a mesma orientação utilizada no presente trabalho. Pode-se pressupor que a amostra orientada no plano (100) obteve melhor desempenho devido ao oxigênio no processo de fabricação do filme. Uma vez 
que o difratogramas apresenta um deslocamento, causado por a presença de uma impureza, sendo a impureza o oxigênio, justificando o melhor desempenho da amostra orientada (100) com as demais amostras.

\section{REFERÊNCIAS BIBLIOGRÁFICAS}

Achard, J.; Silva, F. Diamond and Related Materials. Brazilian Journal of Physics, Vol.20,pp.145-152,Julho 2011.

FREIRE, Jr.; FERNANDO, Lázaro; CAMARGO, JR.; Et al. Diamond and Related Materials. Brazilian Journal of Physics, Vol.30(3), pp.469-469, Janeiro 2000.

DOMONKOS, Mária; Varga, Marián; Demo, Pavel; Et al. Diamond nucleation and growth on horizontally and vertically aligned $\mathrm{Si}$ substrates at low pressure in a linear antenna microwave plasma system. Diamond \&amp; Related Materials, Vol. 82, pp.41-49,Fevereiro 2018.

ULLAH, M., MANZOOR, R.A., AHMED, E. (2018) Electrical Conductivity of CVD Diamond Thin Films. In: Jackson M., Ahmed W. (eds) Micro and Nanomanufacturing Volume II. Springer, Cham

WHEELER, Dw; WOOD, Rjk. High velocity erosion of CVD diamond coatings by diamond particles. Diamond \&amp; Related Materials, Vol. 84, pp. 32-32, Abril 2018.

YAO, Kaili; DAI, Bing; ZHAO, Jiwen; Et al. Diamond films and particles growth in hydrogen microwave plasma with graphite solid precursor: Optical emission spectroscopy study. Diamond \&amp; Related Materials, Vol. 82, pp. 33-40, Fevereiro 2018.

ZHAO, Zhifeng; LIU, Yongsheng; FENG, Wei; Et al. Improvement on the thermal conductivity of Diamond/CVD-SiC composites using large diamond particles. Diamond \&amp; Related Materials, Vol. 74, pp. 1-1, Abril 2017.

\section{AGRADECIMENTOS}

Agradecimento para a CAPES/CNPQ pela bolsa de iniciação científica e para o meu orientador Teófilo Miguel de Souza por deixar eu ter a honra de trabalhar com ele.

\section{COPYRIGHT}

Direitos autorais: Os autores (Alexandre Marcello Cavalca de Almeida, Evaldo Chagas Gouvêa e Teófilo Miguel de Souza) são os únicos responsáveis pelo material incluído no artigo. 


\author{
Volume $16-\mathrm{N}^{\mathrm{o}} 174$ - Junho / 2020 \\ XLII International Sodebras Congress \\ 28 a 30 de maio de 2020 - Web Conference.
}

\title{
PLANEJAMENTO ELÉTRICO CIMATEC PARK: ESTUDO DE FLUXO DE POTÊNCIA, CURTO-CIRCUITO E PERDAS DA ATUAL REDE DE DISTRIBUIÇÃO DE ENERGIA ELÉTRICA DO COMPLEXO.
}

\section{ELECTRICAL PLANNING CIMATEC PARK: STUDY OF POWER FLOW, SHORT-CIRCUIT AND LOSSES OF THE CURRENT NETWORK OF DISTRIBUTION OF ELECTRIC ENERGY OF THE COMPLEX.}

\author{
LUCAS DO ESPIRITO SANTO FERNANDES ${ }^{1}$; TALES SILVA DE SANTANA ${ }^{1}$; ANA TEREZA \\ ANDRADE BORBA ${ }^{1}$; LUIZ FERNANDO TABOADA GOMES AMARAL ${ }^{1}$ \\ 1 - SENAI CIMATEC;
}

lucas.fernandes@fbter.org.br; tales.santana@fbter.org.br; ana.borba@fieb.org.br; luiz.amaral@fieb.org.br

\begin{abstract}
Resumo - Este trabalho é resultado de parte do projeto do planejamento do sistema elétrico do CIMATEC Park, executado pelo Centro de Competência de Sistemas Elétricos de Potência (SEP) do SENAI CIMATEC, que tem por objetivo realizar estudos de Planejamento da expansão do sistema elétrico em um horizonte de dez anos. Apresentam-se a metodologia $e$ os resultados dos estudos de fluxo no que tange a análise de níveis de tensão, carregamento e perdas, e dos estudos de curto-circuito da rede de distribuição de energia elétrica do CIMATEC Park. Para simulações usou-se o programa SINAPGrid voltado para a distribuição, e os níveis de tensão nas barras avaliados conforme os limites estabelecidos pela ANEEL.

Palavras-chave: Planejamento do sistema elétrico. Fluxo de potência. CIMATEC Park.
\end{abstract}

\begin{abstract}
This work is a result of part of the planning project of the CIMATEC Park electrical system. Carried out by the Competence Center for Electric Power Systems (EPS) at SENAI CIMATEC, this article aims to present a series of studies for planning the expansion of the electrical system at CIMATEC Park for the next ten years. This work also presents the methodology and results of the power flow studies regarding the analysis of voltage levels, loading and losses, and the short-circuit studies of the electricity distribution system of CIMATEC Park. The SINAPGrid program was used for simulation of the distribution grid, and the voltage levels in the bars were evaluated according to the limits established by ANEEL.
\end{abstract}

Keywords: Electrical system planning. Power flow. CIMATEC Park.

\section{INTRODUÇÃO}

O planejamento, o design e a operação de sistemas de energia industriais e comerciais requerem estudos de engenharia para avaliar o desempenho, a confiabilidade, a segurança e a economia do sistema existente e proposto. Os estudos, adequadamente concebidos e realizados, são uma maneira econômica de evitar surpresas e otimizar a seleção de equipamentos. $\mathrm{Na}$ fase de projeto, os estudos identificam e evitam possíveis deficiências no sistema antes de entrar em operação. Nos sistemas existentes, os estudos ajudam a localizar a causa da falha e operação incorreta do equipamento e a determinar medidas corretivas para melhorar o desempenho do sistema (IEEE, 1997).

Os estudos de fluxo de potência, ou fluxo de carga, determinam a tensão, corrente, potência ativa e reativa e o fator de potência em um sistema de potência. Os estudos de fluxo de carga são uma excelente ferramenta para o planejamento do sistema. Vários procedimentos operacionais podem ser analisados, incluindo condições de contingência, como a perda de um gerador, uma linha de transmissão, um transformador ou uma carga. Esses estudos alertarão o usuário sobre condições que podem causar sobrecarga no equipamento ou baixos níveis de tensão. Os estudos de fluxo de potência podem ser usados para determinar o valor e a localização ideais dos capacitores para melhoria do fator de potência. Além disso, são muito úteis na determinação de tensões do sistema sob diversas condições de cargas ou suprimento repentinamente aplicadas ou desconectadas.

Estudos de curto-circuito são feitos para determinar a magnitude das correntes prospectivas que fluem pelo sistema de energia em vários intervalos de tempo após a ocorrência de uma falha. A magnitude das correntes de curto após uma falha varia com o tempo até atingirem uma condição de estado estacionário. Esse comportamento é devido às características e dinâmicas do sistema. Durante esse período, o sistema de proteção é chamado para detectar, interromper e isolar essas falhas. $\mathrm{O}$ dever imposto a este equipamento depende da magnitude da corrente, que depende do tempo desde o início da falha. Isso é feito para vários tipos de falhas (trifásica, fase-fase, fase dupla-terra e fase-terra) em diferentes locais do sistema. As informações são usadas para selecionar classificações de fusíveis, disjuntores e comutadores, além de definir relés de proteção

O CIMATEC Park é um moderno complexo tecnológico e industrial pensado para atender às demandas diversas da indústria nacional, nas áreas de pesquisa, inovação, testes, desenvolvimento ou fabricação, cuja primeira etapa já foi inaugurada em 2019. Na Figura 1 pode ser vista uma foto da estrutura do complexo do CIMATEC Park. 
Figura 1 - Complexo CIMATEC Park atual estrutura.

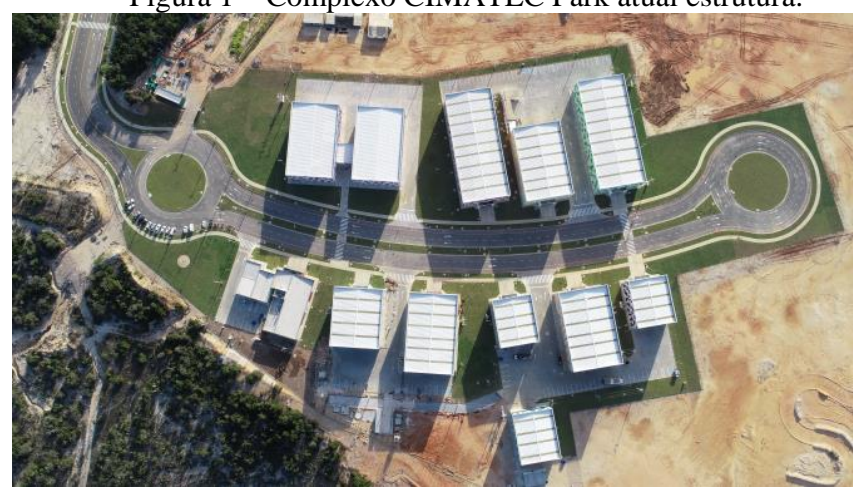

Fonte: Autores, 2020.

\section{METODOLOGIA}

Neste artigo foi analisada a rede atual que supre 10 galpões industriais e um prédio administrativo, abastecidos por uma rede trifásica radial em média tensão $(13,8 \mathrm{kV})$ com cabo de alumínio nu com alma de aço 4/0 CAA, sendo um total de 43 barras, 1 swing e 14 barras de carga. O sistema é alimentado por uma rede de média tensão da concessionária Coelba. Logo após a conexão há o sistema de medição constituído por TC e TP; há ainda um disjuntor à vácuo com valores nominais de 17,5 kV, $350 \mathrm{MVA}, 630 \mathrm{~A}$. A cada galpão é destinado um transformador com as seguintes configurações: Os galpões de 3 a 9 e o sistema de metrologia são abastecidos por transformadores trifásicos de valores nominais $225 \mathrm{kVA}, 13,8 / 11,4 \mathrm{kV}-380 / 220 \mathrm{~V}$, o galpão 1 é abastecido por um transformador trifásico de valores nominais $300 \mathrm{kVA}, 13,8 / 11,4 \mathrm{kV}-380 / 220 \mathrm{~V}$ e o galpão 2 é abastecido por dois transformadores trifásicos de valor nominal igual ao que abastece o galpão 1 . A rede ainda é composta por um transformador trifásico com valor nominal de $112,5 \mathrm{KVA}, 13,8 / 11,4 \mathrm{kV}-380 / 220 \mathrm{~V}$, que abastece o prédio administrativo do complexo, dois transformadores trifásicos, um de $30 \mathrm{KVA}$ e outro de 15 KVA, com valores de 13,8/11,4 kV - 380/220V para iluminação externa e um transformador trifásico de $45 \mathrm{kVA}$, 13,8/11,4 kV - 380/220V para iluminação da guarita. O diagrama unifilar da atual rede está ilustrado na Figura 2.

Figura 2 - Diagrama unifilar rede atual CIMATEC Park.

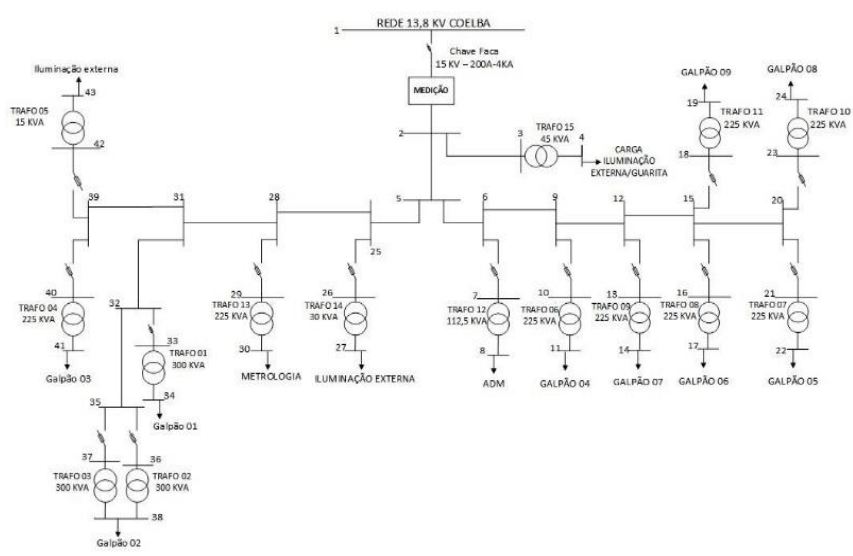

Fonte: Autores, 2020.

Fez-se evoluir a carga do Complexo dentro de um horizonte de dez anos. Possivelmente a rede deverá se expandir cobrindo outras áreas do CIMATEC Park. Foram considerados três cenários de carregamento dos transformadores da rede, o primeiro cenário de carga leve, o segundo de uma carga média e um terceiro cenário de carga pesada. $\mathrm{O}$ cenário de carga leve considera os transformadores com 3 patamares de carga ao longo do dia, com um máximo de $10 \%$ da potência nominal, exceção dos transformadores de iluminação que tiveram $4,8 \mathrm{MWh}$ de consume mensal cada durante 12 horas seguidas, este cenário é uma representação do atual momento da rede. Para o cenário de carga média, foi considerando um carregamento de $80 \%$ das potências nominais dos transformadores das cargas, mantendo os valores prefixados para os transformadores de iluminação externa. Usou-se a curva típica de demanda industrial fornecida pelo programa computacional SINAPGrid, que apresenta um pico de demanda no horário de 10:00 às 11:00 horas. Para o último cenário, carga pesada, assumiu-se $100 \%$ do carregamento dos transformadores da rede, não sendo alterados os valores de carregamentos dos transformadores de iluminação e sendo considerada a curva típica de demanda fornecida pelo programa.

Os cenários foram simulados para duas condições da tensão da concessionária, considerando o primeiro caso em que a tensão fornecida é de 1,0 pu e um segundo caso a tensão da concessionaria chegando ao limite inferior contratado de $0,93 \mathrm{pu}$. No estudo foi considerado um modelo de carga de corrente constante, um método mais conservador seria a utilização das barras de carga como potência constante, pois apresentaria menores valores de tensão.

Para o estudo de Perdas, foi utilizado o módulo especial do SinapGrid o qual considera em suas configurações de simulação os dados de acordo com o módulo 7 do PRODIST (ANEEL, 2018b).

O estudo também abrangeu um caso de contingência, onde no Galpão 02, abastecido por dois transformadores, é retirado um dos transformadores de $300 \mathrm{kVA}$ ficando toda carga alimentada por um único transformador. Esta contingência foi simulada para os casos de carga média e pesada.

As tensões nas barras são estudadas em por-unidade $(\mathrm{pu})$, tendo como valores base para cálculo uma tensão de $13,8 \mathrm{kV}$ no ponto de entrega da concessionária e potência de 100 MVA. Além destas, estudou-se também o fator de potência de cada cenário. Os limites operativos que devem ser respeitados nos barramentos de tensão são estabelecidos pela ANEEL (2018a) e divididos em: adequados, precários e críticos, de acordo com o nível de tensão em regime permanente

Destaca-se que está em andamento uma prospecção de como se dará a expansão do Complexo de modo a melhor estimar a carga ao final do horizonte de dez anos.

\section{RESULTADOS}

\section{1 - Tensão de 1,0 pu pela Concessionária}

Foram iniciadas as simulações para o primeiro caso em que a tensão no ponto de entrega da concessionária é de 1,0 pu.

\subsection{1 - Simulação Carga Leve}

Na Figura 3 está ilustrado o gráfico da demanda para a simulação da carga leve do sistema. Nota-se o seu formato em patamares, justificando as considerações do perfil de carga para tal cenário. São apresentadas as demandas de potência aparente, ativa e reativa do sistema. O total de 
energia mensal consumida para o cenário simulado foi de 81,2 MWh/mês.

As tensões nos barramentos ficaram dentro dos limites classificados como adequados com base nos valores fixados pela ANEEL (2018a), o menor valor encontrado para tensão nos barramentos foi de 0,997 pu. A Tabela 1 apresenta os valores de potência para o horário de pico às 10:00 horas, bem como o valor do fator de potência (FP) visto do ponto de conexão com a concessionária e o percentual de perda técnica de energia da rede.

Figura 3 - Demanda de potência para Carga Leve.

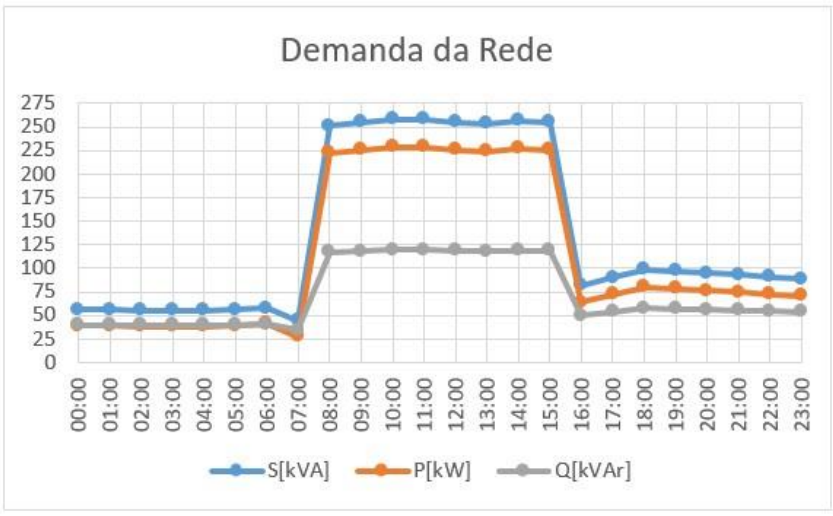

Fonte: Autores, 2020.

Tabela 1 - Potências, fator de potência e perda no ponto de conexão com a concessionária para carga leve.

\begin{tabular}{ccccc}
\hline $\begin{array}{c}\text { S requerida } \\
(\mathbf{k V A})\end{array}$ & $\begin{array}{c}\text { P ativa } \\
(\mathbf{k W})\end{array}$ & $\begin{array}{c}\text { Q reativa } \\
(\mathbf{k V A r})\end{array}$ & FP & $\begin{array}{c}\text { Perdas } \\
(\boldsymbol{\%})\end{array}$ \\
\hline 264,8 & 234,1 & 123,7 & 0,88 & 8,02 \\
\hline
\end{tabular}

\subsection{2 - Simulação Carga Média}

Para essa configuração o consumo total da rede foi de 900,1 MWh mensal, e a demanda por hora em um dia podem ser observados na Figura 4.

Figura 4 - Demanda de potência para Carga Média.

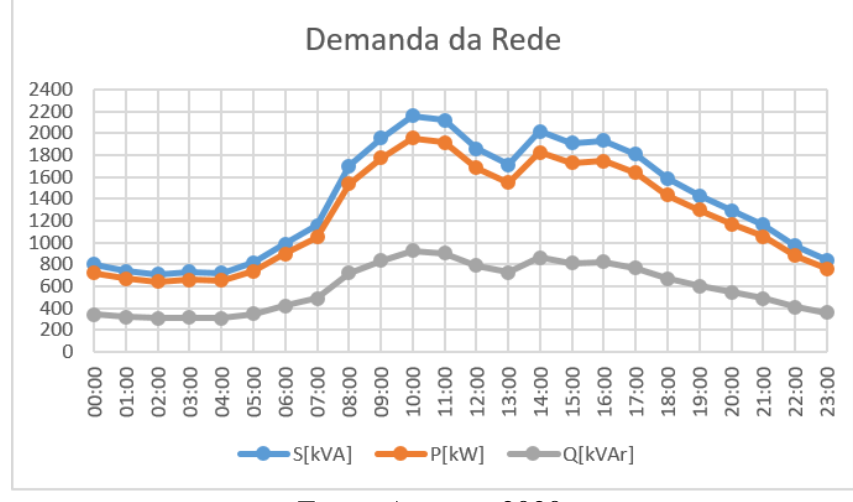

Fonte: Autores, 2020.

Na Tabela 2 são apresentados os valores das potências requeridas pelo sistema bem como o fator de potência e as perdas técnicas para a simulação da carga média. As tensões nos barramentos continuaram dentro dos limites classificados como adequados segundo ANEEL (2018a), o menor valor encontrado para tensão nos barramentos foi de $0,975 \mathrm{pu}$.
Tabela 2 - Potências, fator de potência e perda no ponto de conexão com a concessionária para carga média.

\begin{tabular}{ccccc}
\hline $\begin{array}{c}\text { S requerida } \\
(\mathbf{k V A})\end{array}$ & $\begin{array}{c}\text { P ativa } \\
(\mathbf{k W})\end{array}$ & $\begin{array}{c}\text { Q reativa } \\
(\mathbf{k V A r})\end{array}$ & FP & $\begin{array}{c}\text { Perdas } \\
(\boldsymbol{\%})\end{array}$ \\
\hline 2.162 & 1.955 & 923,6 & 0,90 & 1,49 \\
\hline
\end{tabular}

\subsection{3 - Simulação Carga Pesada}

Para a configuração da Carga Pesada o consumo de energia chega a valores de 1,1 GWh mensal, as demandas de potência e a curva de carga característica podem ser vistas através do gráfico da Figura 5.

Figura 5 - Demanda de potência para Carga Pesada.

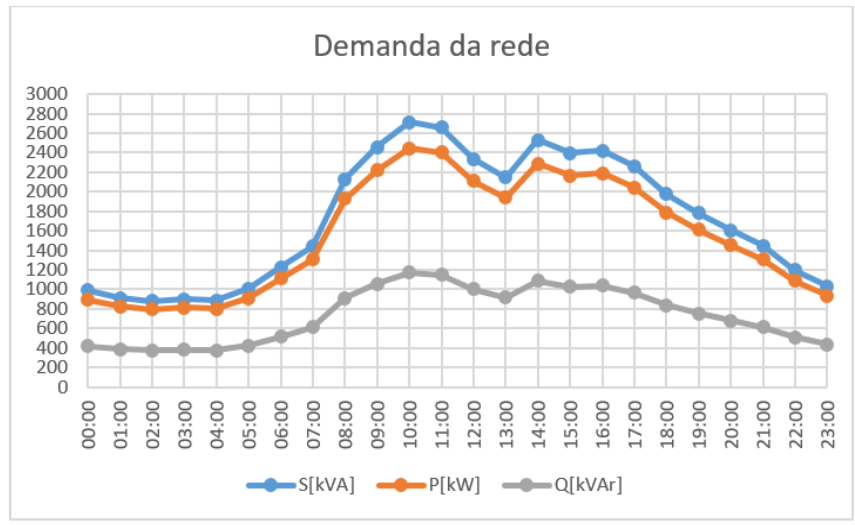

Fonte: Autores, 2020.

Na Tabela 3 estão descritos os valores das potências requeridas, fator de potência e o percentual das perdas do sistema para o caso em questão. O menor valor da tensão nos barramentos encontrado foi de $0,969 \mathrm{pu}$, dentro do limite considerado adequado.

Tabela 3 - Potências, fator de potência e perda no ponto de conexão com a concessionária para carga leve.

\begin{tabular}{ccccc}
$\begin{array}{c}\text { S requerida } \\
(\mathbf{k V A})\end{array}$ & $\begin{array}{c}\text { P ativa } \\
(\mathbf{k W})\end{array}$ & $\begin{array}{c}\text { Q reativa } \\
(\mathbf{k V A r})\end{array}$ & FP & $\begin{array}{c}\text { Perdas } \\
(\boldsymbol{\%})\end{array}$ \\
\hline 2.711 & 2.445 & 1.172 & 0,90 & 1,54 \\
\hline
\end{tabular}

3.1.4-Contingência a 1,0 pu.

No estudo da contingência, foi considerada a perda de um dos transformadores de $300 \mathrm{kVA}$ (Trafo 02) que abastece o Galpão 02, ficando somente um transformador para o abastecimento da potência total do galpão. Considerando ainda uma tensão entregue pela concessionária de 1,0 pu. As tensões nos barramentos se mantiveram dentro dos limites fixados como adequadas, destacando um menor nível de tensão no secundário do transformador sobrecarregado do Galpão 02 (Trafo 03), que para o caso da carga média se manteve nos limites adequados, já no caso da carga pesada a tensão ficou abaixo do limite adequado, chegando a um valor precário segundo os valores da ANEEL (2018a). Os resultados estão especificados na Tabela 4.

Tabela 4 - Nível de tensão no secundário do Trafo 03 para contingência com tensão de 1,0 pu.

\begin{tabular}{ccc}
\hline Carga & Média & Pesada \\
\hline $\begin{array}{c}\text { Tensão no secundário } \\
\text { do Trafo 03 }(\mathrm{pu})\end{array}$ & 0,942 & 0,917 \\
\hline
\end{tabular}




\section{2 - Tensão de 0,93 pu pela Concessionária.}

Caso a tensão da concessionária chegue ao limite inferior contratado de $0,93 \mathrm{pu}$, as tensões em várias barras de carga nas situações de carga média e pesada já atingem mínimos de $0,9 \mathrm{pu}$, chegando a valores precários. Na Tabela 5 estão apresentados os valores das tensões mínimas encontradas nos barramentos, a potência aparente requerida, o fator de potência e as perdas, para os casos de carga média e pesada. Nota-se uma queda na potência requerida, isso se deve ao modelo de carga de corrente constante que foi utilizada nas simulações deste trabalho.

Tabela 5 - Níveis de tensão, potência, perdas e fator de potência com tensão de 0,93 pu.

\begin{tabular}{ccc}
\multicolumn{3}{c}{ potência com tensão de 0,93 pu. } \\
\hline Carga & Média & Pesada \\
\hline Menores Tensões (pu) & 0,906 & 0,90 \\
S requerida (kVA) & 2.029 & 2.538 \\
Perdas (\%) & 1,50 & 1,57 \\
Fator de Potência (FP) & 0,90 & 0,90 \\
\hline
\end{tabular}

\subsection{1 - Contingência a 0,93 pu.}

Para a mesma situação de contingência anterior em que é retirado um dos transformadores que abastece o Galpão 02, agora considerando que a tensão fornecida pela concessionária é de 0,93 pu, os valores das menores tensões para os casos de carga média e pesada, foram encontrados no secundário do Trafo 03.

Tabela 6 - Nível de tensão no secundário do Trafo 03 para contingência com tensão de 0,93 pu.

\begin{tabular}{ccc}
\hline Carga & Média & Pesada \\
\hline $\begin{array}{c}\text { Tensão no secundário } \\
\text { do Trafo 03 }(\mathrm{pu})\end{array}$ & 0,87 & 0,84 \\
\hline
\end{tabular}

\section{3 - Curto-Circuito.}

No estudo de curto, foram simulados os curtos trifásicos, monofásicos, bifásico e bifásicos-terra, nas barras de carga e no ponto de entrega da concessionária. Para iniciar a simulação foram necessários alguns dados de entrada para caracterizar a rede instalada no local, como por exemplo: tipos de estruturas e cabos da rede de média tensão, parâmetros dos transformadores, característica das chaves fusíveis, valores de impedância de sequência positiva e de sequência zero vistas pela concessionaria no ponto de entrega em que a rede do CIMATEC Park está conectada. Os valores das impedâncias de sequência positiva $\left(Z_{1}\right)$ e zero $\left(Z_{0}\right)$, informados pela concessionária Coelba no ponto de entrega são: $Z_{1}=1,4855+j 2,6609$ e $Z_{0}=2,5380+$ j13,3093. Já o valor das impedâncias de alguns trafos são: $300 \mathrm{kVA}, \mathrm{Z}_{\mathrm{T}}=0,00939+\mathrm{j} 0,04421 ; 225 \mathrm{kVA}, \mathrm{Z}_{\mathrm{T}}=0,01049$ $+\mathrm{j} 0,04376 ; 15 \mathrm{kVA}, \mathrm{Z}_{\mathrm{T}}=0,01990+\mathrm{j} 0,02905$. Com isso, os resultados das simulações estão expressos na Tabela 7 e Tabela 8.

O SinapGrid permite que sejam feitos até 4 tipos de curto-circuito: curto-circuito trifásico, bifásico, bifásicoterra e monofásico, além de determinar a corrente assimétrica do curto trifásico. Esse estudo possibilita verificar se os fusíveis existentes no sistema estão de acordo com a corrente de curto e se a corrente máxima de cada disjuntor vai suportar um curto-circuito operando de forma correta.
Tabela 7 - Níveis de curto trifásico e bifásico nos barramentos.

\begin{tabular}{ccc}
\hline Barra & $\begin{array}{c}\text { Curto-circuito } \\
\text { trifásico (abc) } \\
(\mathbf{k A})\end{array}$ & $\begin{array}{c}\text { Curto-circuito } \\
\text { bifásico (bc) } \\
(\mathbf{k A})\end{array}$ \\
\hline 1 & $\mathbf{I a = I b = I c}$ & $\mathbf{I b}=-\mathbf{I c}$ \\
\hline 4 & 1,10 & 0,95 \\
8 & 1,85 & 1,60 \\
11 & 4,12 & 3,57 \\
14 & 6,36 & 5,51 \\
17 & 6,35 & 5,50 \\
22 & 6,35 & 5,50 \\
19 & 6,34 & 5,49 \\
24 & 6,35 & 5,50 \\
27 & 6,34 & 5,49 \\
30 & 1,26 & 1,09 \\
34 & 6,36 & 5,51 \\
38 & 8,03 & 6,96 \\
41 & 13,32 & 11,54 \\
43 & 6,34 & 5,49 \\
\hline & 0,64 & 0,55 \\
\hline
\end{tabular}

Tabela 8 - Níveis de curto bifásico-terra e monofásico nos barramentos.

\begin{tabular}{cccc}
\hline Barra & $\begin{array}{c}\text { Curto-circuito } \\
\text { bifásico terra (bct) } \\
\text { (kA) }\end{array}$ & $\begin{array}{c}\text { Curcuito-circuito } \\
\text { monofásico (at) } \\
\text { (kA) }\end{array}$ \\
\hline & Ib & Ic & Ia \\
\hline 1 & 0,92 & 1,01 & 0,52 \\
4 & 1,86 & 1,87 & 1,88 \\
8 & 4,18 & 4,23 & 4,27 \\
11 & 6,57 & 6,50 & 6,68 \\
14 & 6,46 & 6,64 & 6,71 \\
17 & 6,46 & 6,64 & 6,71 \\
22 & 6,45 & 6,63 & 6,71 \\
19 & 6,46 & 6,64 & 6,71 \\
24 & 6,45 & 6,63 & 6,71 \\
27 & 1,26 & 1,27 & 1,27 \\
30 & 6,47 & 6,65 & 6,72 \\
34 & 8,22 & 8,52 & 8,62 \\
38 & 13,98 & 14,81 & 15,04 \\
41 & 6,46 & 6,63 & 6,71 \\
43 & 0,64 & 0,64 & 0,64 \\
\hline & & &
\end{tabular}

Os valores da corrente assimétrica para o curto trifásico nas barras de carga e do ponto de entrega da concessionaria, estão ilustrados pela Tabela 9. 
Tabela 9 - Níveis de corrente assimétrica para o curto trifásico nas barras.

\begin{tabular}{cc}
\hline Barra & $\begin{array}{c}\text { Corrente } \\
\text { assimétrica trifásica } \\
(\mathbf{k A})\end{array}$ \\
\hline 1 & 1,16 \\
4 & 2,06 \\
8 & 4,66 \\
11 & 7,47 \\
14 & 7,46 \\
17 & 7,46 \\
22 & 7,42 \\
19 & 7,46 \\
24 & 7,42 \\
27 & 1,39 \\
30 & 7,47 \\
34 & 9,44 \\
38 & 15,22 \\
41 & 7,42 \\
43 & 0,66 \\
\hline
\end{tabular}

\section{CONCLUSÃO}

Do estudo de fluxo de potência da rede atual do CIMATEC Park sendo feita uma análise dos cenários simulados, pôde ser observado que no cenário de carga leve há um alto valor de reativos no sistema, o que pode ser justificado pelos vários transformadores trabalharem quase a vazio, resultando no baixo valor encontrado para o fator de potência da rede, abaixo dos valores limites fixados pela ANEEL (2018a) que é de 0,92 e altos valores de perda da rede, encontrado para o caso um valor de 7,96\%. Através de estudos como este caso esta situação de carga venha a perdurar por vários meses será feito o estudo de compensação de reativos visando que os valores do fator de potência sejam corrigidos para limites aceitáveis., buscando chegar em valores de fator de potência aceitáveis conforme ANEEL.

A simulação do cenário de carga média mostrou carregamentos e níveis de tensão dentro de padrões adequados, e que quando for atingido esta situação de carga há a possibilidade do CIMATEC Park se tornar um consumidor livre, com base na portaria $\mathrm{n}^{\circ} 514$ do Diário Oficial que estabelece que consumidores com carga igual ou superior a $2000 \mathrm{~kW}$ poderão optar por serem consumidores livres.

Da simulação em carga pesada conclui-se que para níveis de tensão da concessionária próximos a $1,0 \mathrm{pu}$, os carregamentos e tensões nas barras estão adequados, entretanto quando a empresa fornecer tensões próximas ao mínimo permitido $(0,93)$ já atingiriam limites precários de tensão. Pode se observar também, o alto valor demandado de potência da rede, o que possibilitaria ao CIMATEC Park ser abastecido em alta tensão, num valor de $69 \mathrm{kV}$, pois segundo a resolução normativa $\mathrm{n}^{\circ} 414$ da ANEEL, consumidores com demanda superior a $2500 \mathrm{~kW}$ poderão optar por ser atendido em tensão primária de $69 \mathrm{kV}$.
Tanto no cenário de carga média quanto pesada os níveis de perdas estão aceitáveis.

Acrescenta-se que após a conclusão dos estudos de prospecção visando melhor estimar a carga ao final do horizonte de dez anos, deverão ser novamente analisados o fluxo de potência e os estudos de curto circuito. Também ainda pendente análise de partida de motores no horizonte futuro.

Conforme o estudo de curto, é possível concluir que o disjuntor de entrada que tem potência de 350 MVA e que está submetido a mesma corrente que passa na barra 1 está adequado, pois abriria até $14 \mathrm{kA}$. O valor dos curtos nas barras de carga decresce conforme a potência do transformador, ou seja, o menor valor de curto é na barra 43, pois o transformador que alimenta a barra 43 tem $15 \mathrm{kVA}$, e o que tem o maior valor de curto é a barra 38 , pois é alimentada por dois transformadores em paralelo, cada um com $300 \mathrm{kVA}$. Ao observar os valores de curto é possível concluir que podem ser usados disjuntores de 10 kA na rede de baixa tensão, exceto na barra 38 que precisará ser $20 \mathrm{kA}$.

\section{REFERÊNCIAS BIBLIOGRÁFICAS}

AGÊNCIA NACIONAL DE ENERGIA ELÉTRICA ANEEL. Módulo 8 - Qualidade da Energia Elétrica. 2018a.

AGÊNCIA NACIONAL DE ENERGIA ELÉTRICA ANEEL. Módulo 7 - Cálculo de Perdas na Distribuição. $2018 b$.

AGÊNCIA NACIONAL DE ENERGIA ELÉTRICA ANEEL. RESOLUÇÃO NORMATIVA N $N^{\circ} 414,0909$ 2020.

DIÁRIO OFICIAL DA UNIÃO, “PORTARIA No 514,” 27 $122018 . \quad$ [Online] Disponível: http://www.in.gov.br/materia/-/asset_publisher/Kujrw0T ZC2Mb/content/id/57219064/do1-2018-12-28-portaria-n514-de-27-de-dezembro-de-2018-57218754.

IEEE Std 399-1997, IEEE Recommended Practice for Industrial and Commercial Power Systems Analysis. reconhecido pelo American National Standards Institute (ANSI)em abril, 1998.

SINAPSIS - Platafoma. [Online] Disponível: SINAPGridhttp://www.sinapsisenergia.com.

\section{AGRADECIMENTOS}

Ao sistema FIEB SENAI CIMATEC pelo aporte financeiro e estrutural, fundamental para a realização do trabalho.

Ao Prof. Dr. Paulo Roberto Ferreira de Moura Bastos pela orientação e revisão do trabalho.

O presente trabalho foi realizado com apoio da coordenação do setor de Geração, Transmissão e Distribuição do SENAI CIMATEC.

\section{COPYRIGHT}

Direitos autorais: $\mathrm{O}(\mathrm{s})$ autor(es) é(são) o(s) único(s) responsável(is) pelo material incluído no artigo. 


\author{
Volume $16-\mathrm{N}^{\mathrm{o}} 174$ - Junho / 2020 \\ XLII International Sodebras Congress \\ 28 a 30 de maio de 2020 - Web Conference.
}

\title{
ANÁLISE ABRANGENTE DE SISTEMA HIDROSTÁTICO E DE TURBINA EÓLICA COM BASE BIBLIOMÉTRICA, 1983 - 2019
}

\section{A COMPREHENSIVE ANALYSIS OF HYDROSTATIC SYSTEM AND WIND TURBINE WITH BIBLIOMETRIC BASE, 1983 - 2019}

\author{
THAMYRES MACHADO DAVID ${ }^{1}$; LUCIANO LIZARDO DE SOUZA GUIMARÃES ${ }^{1}$; VANESSA \\ APARECIDADE DE SÁ MACHADO ${ }^{2}$; DIEGO MENEGUSSO PIRES ${ }^{3}$ \\ 1 - UNIVERSIDADE ESTADUAL PAULISTA; 2 - CENTRO FEDERAL DE EDUCAÇÃO \\ TECNOLÓGICA CELSO SUCKOW DA FONSECA; 3 - UNIVERSIDADE FEDERAL DE SANTA \\ MARIA
}

thamyres.machado@unesp.br; luciano.lizardo@unesp.br; vasmachadovr@yahoo.com.br;
diego.msso@gmail.com

\begin{abstract}
Resumo - Foi aplicado um estudo bibliométrico para analisar as publicações científicas na área de sistemas hidrostáticos $e$ turbinas eólicas, utilizando o banco de dados Scopus entre os anos de 1983 e 2019. Foram analisados aspectos como o histórico da publicação e a frequência de ocorrência das palavras-chave e evolução dos tópicos de pesquisa. Os resultados mostram que a diversidade do grau de conhecimento é baixa e que ainda há um espaço significativo para o desenvolvimento de pesquisas sobre transmissão hidrostática aplicada em turbinas eólicas, dado o pequeno número de estudos que abordaram o segmento em tendências futuras de pesquisa. Os dados obtidos por meio da análise da evolução dos temas da pesquisa, explorados com o software Scimat, estão diretamente relacionados a coocorrência das palavras-chave e da análise das lacunas de pesquisa obtidas.
\end{abstract}

Palavras-chave: Turbina Eólica. Sistema Hidrostático. Bibliometria.

\begin{abstract}
A bibliometric study was applied to analyze the scientific publications in the area of hydrostatic system and wind turbine using the Scopus database between the years of 1983 and to 2019. Aspects, such as the history in the publication, were analyzed as well as the keyword occurrence frequency and evolution of research topics. The results show that the knowledge degree diversity is low and that there's still a significant space for the development of research regarding hydrostatic transmission applied in to wind turbines given the small number of studies that addressed the segment in future research trends. The data obtained through the analysis of the evolution of the research themes, using the Scimat softwate, is directly related to the keywords co-occurrence and the analysis of the research gaps. Keywords: Wind turbine. Hydrostatic System. Bibliometry.
\end{abstract}

\section{INTRODUÇÃO}

Nos tempos atuais é percebido uma demanda por consumo de energia cada vez maior. Em vista das barreiras para a produção sem comprometer o meio ambiente, as fontes de energia renovável estão cada vez mais em destaque nas pesquisas. A energia eólica, que tem sua geração através dos ventos, oferece uma opção que contribui para o desenvolvimento sustentável e a segurança energética em um momento em que a diminuição das reservas globais de combustíveis fósseis ameaça a sustentabilidade a longo prazo (JOSELIN HERBERT et al., 2007).

O desenvolvimento eficiente de projetos de geração de energia renovável é um sistema complexo que é influenciado ou dificultado por vários fatores. O foco da pesquisa futura em relação à fonte eólica deve ser direcionado ao desenvolvimento de novas metodologias e/ou modalidades para revelar técnicas de preferências para a avaliação da fonte considerando as dimensões econômica, tecnológica e ambiental (NAZIR et al., 2019).

As tecnologias de energia eólica estão sendo desenvolvidas para reduzir os custos da eletricidade gerada e para aumentar o desempenho tecnológico. Portanto, entender os caminhos do desenvolvimento tecnológico é relevante para o desenvolvimento de pesquisas (MADVAR, et al., 2019). Em vista disso, tem-se aplicado a transmissão hidrostática que tem como vantagens a eliminação do conversor de energia bem como da caixa redutora. A fonte eólica tem como característica o uso de caixa redutora, ou caixa multiplicadora devido a aplicação na fonte eólica, que faz a multiplicação da velocidade para condizer com a faixa de trabalho do gerador, e é um dos principais fatores que causam o aumento do tempo de inatividade nas modernas turbinas eólicas. Isso aumenta o custo de manutenção da turbina e, portanto, o custo de energia da turbina. Uma transmissão hidrostática não apenas melhora a confiabilidade da turbina através de sua transmissão "suave", mas também elimina o uso dos componentes como conversor de energia e da caixa redutora por meio da sua função de transmissão variável contínua (WANG et al., 2019).

O presente artigo busca apresentar uma análise bibliométrica das publicações sobre sistema hidrostático e turbina eólica no período de 1983 a 2019. Diante de tal perspectiva e com base nas lacunas científicas, foi estabelecido a seguinte questão de pesquisa que norteou o desenvolvimento deste artigo: como a bibliometria em relação a sistema hidrostático e turbina eólica pode fornecer uma perspectiva global do tema, correlacionando as interações existentes entre análise de coocorrência de 
palavras-chave, tendências de pesquisas futuras e a da análise da evolução dos temas de pesquisa?

Neste sentido, este artigo apresenta uma avaliação abrangente do campo de sistema hidrostático e turbina eólica. Esta análise, começando com uma pesquisa de, aproximadamente, 138 artigos publicados e filtrando esse grupo para trabalhos e pesquisadores que exercem grande influência. Uma análise de rede abrangente como a análise de coocorrência de palavras chave e o estudo de evolução dos temas de pesquisa é realizada e assim as principais tendências são identificadas. Os resultados gerados com as análises bibliométricas permitem identificar os atuais interesses de pesquisa e orientações potenciais para futuras pesquisas.

\section{METODOLOGIA}

O primeiro passo do estudo bibliométrico foi a busca no banco de dados Scopus para obter um conjunto de dados para todos os trabalhos publicados relacionados ao tema de pesquisa. $\mathrm{O}$ intervalo da análise foi entre os anos de 2011 a 2019. Para identificar quais artigos são exclusivamente relacionados a sistema hidrostático limitado a aplicação em turbina eólicas, foram analisados os títulos e resumos de todos os artigos. Aquelas que não estavam no escopo desta pesquisa foram eliminadas após a checagem do texto do próprio artigo. As palavras chaves utilizadas para a coleta de dados incluem "hydrostatic system", "wind turbine" $\mathrm{e}$ "hydrostatic". Foram utilizadas duas combinações destas palavras-chave com os operadores booleanos para combinar os termos de pesquisa da seguinte forma: (i) "hydrostatic system" and "wind turbine"; (ii) "hydrostatic" and "wind turbine"

Para lançar luz sobre as tendências e contribuições do tema pesquisado, análises bibliométricas e qualitativas são conduzidas nesta pesquisa. Para a análise da c-ocorrência de palavras-chave, utilizou-se o software VoSviewer (MARTINHO, 2018) e para a realização do mapeamento científico sob uma estrutura longitudinal, foi utilizado o software SciMAT.

\section{RESULTADOS}

\section{1 - Publicações por ano}

Os dados obtidos na base de dados Scopus, como apresentado na Figura 1, mostra o número de publicações sobre o tema em um período de trinta e seis anos. Uma tendência identificada foi o número baixo de artigos obtidos, foram retornados somente 138 artigos para a análise. Mesmo tendo um número baixo de artigos obtidos, percebese uma tendência de crescimento de publicações ao longo dos anos.
Figura 1 - Publicações por ano.

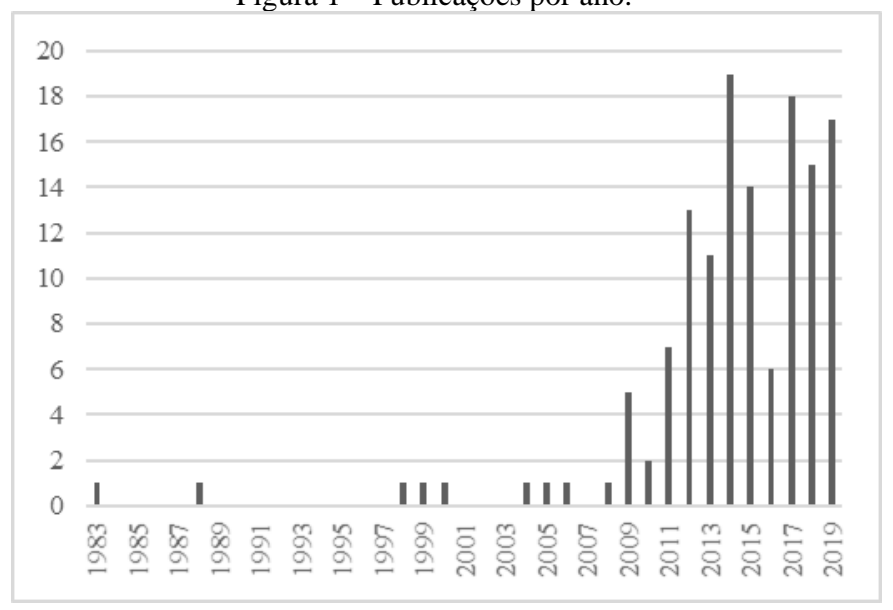

Fonte: Scopus, 2020.

Entre os anos de 1983 e 2008 percebe-se um número extremamente baixo de publicações, somente nove estudos foram abordados. A partir de 2009 é percebido um crescimento no tema e que se segue até 2019. A alta de publicações neste período pode ser justificada pela relevância atribuída nos Parques Eólicos Offshore, que diferentemente do tradicionalismo em ser instalados em terra, a modalidade apresenta parques eólicos localizados ao longo da costa marinha.

\section{2 - Análise de coocorrência de palavras-chave}

Com base na análise de palavras-chave, obteve-se alguns conhecimentos básicos sobre a distribuição de palavras-chave na área de sistema hidrostático e turbina eólica, o que estabelece uma base sólida de análise de frequência de coocorrência. Para este estudo foi produzido uma rede de coocorrências de título e resumo (Figura 2) baseada em artigos sobre o tema usando dados da base Scopus e o software VOSviewer (VAN ECK; WALTMAN 2010). 
Figura 2 - Palavras-chave - a) 1983 a 2010 b) 2011 e 2012 c) 2013 e 2014 d) 2015 a 2019 e) 1983 a 2019.
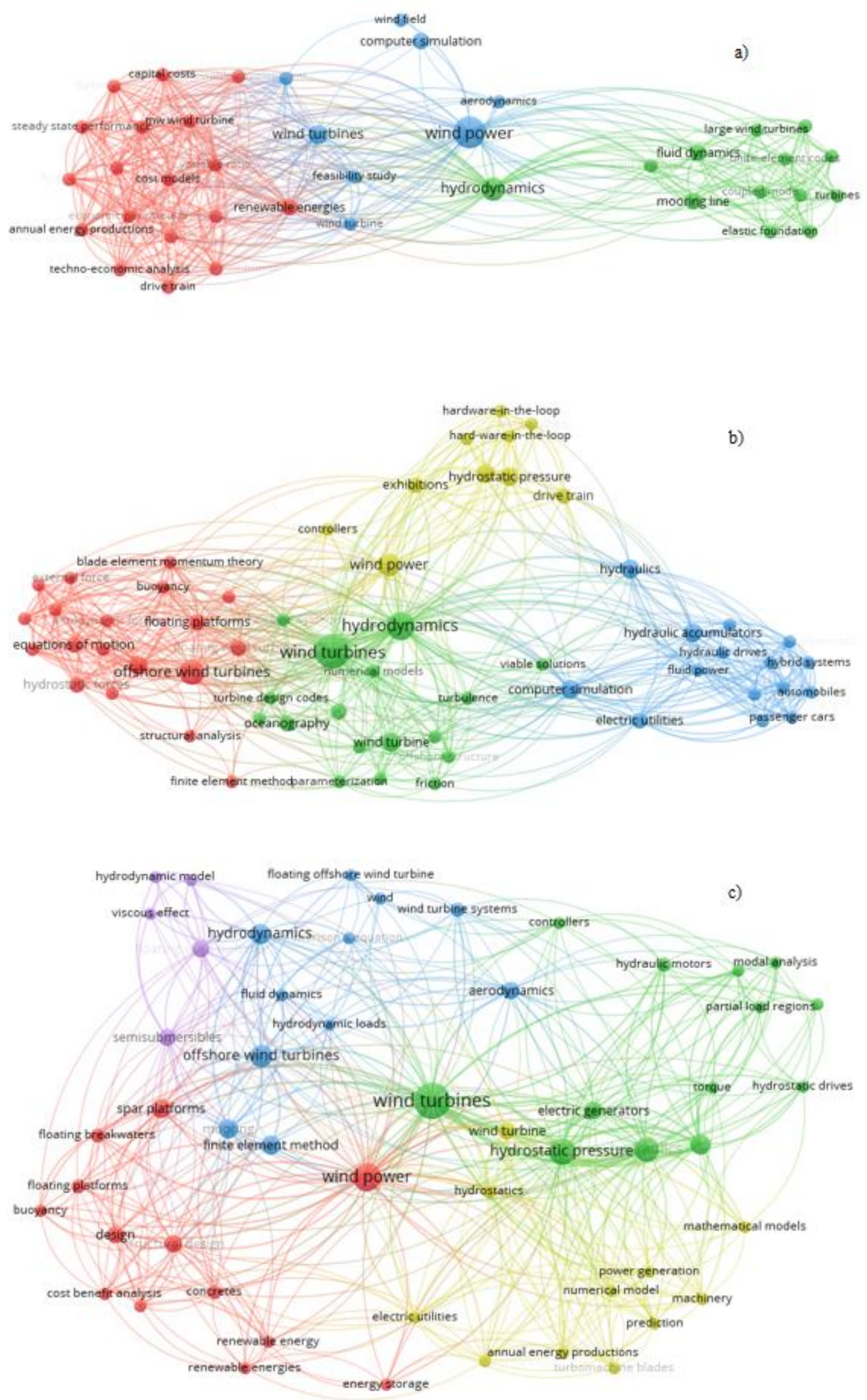

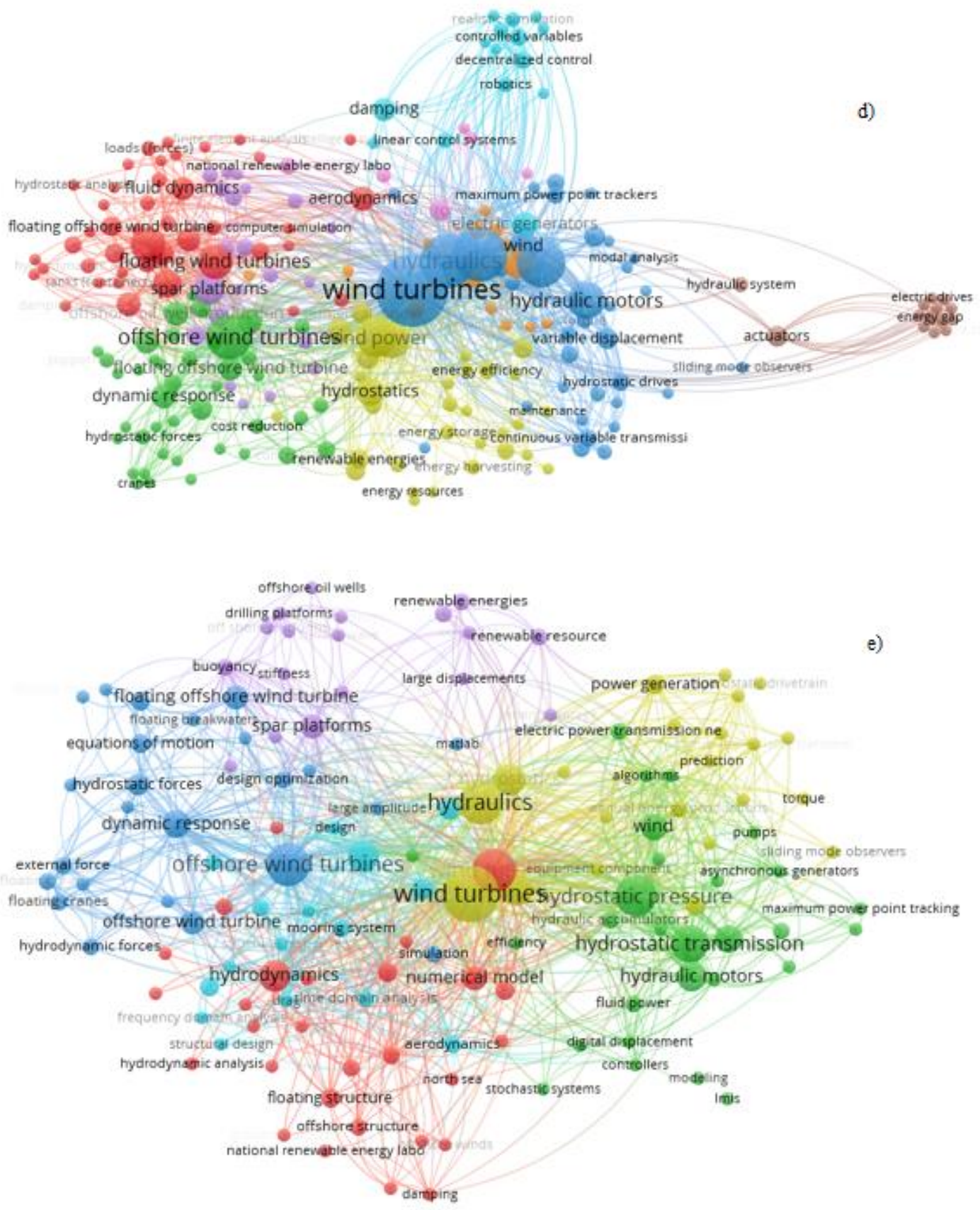

Fonte: Autores, 2019.

Neste estudo, para gerar o mapa de coocorrência, foram utilizadas as seguintes configurações no VOSviewer: ucontagem binária, uma palavra-chave teve que ocorrer pelo menos duas vezes e; o número de clusters foi determinado com base em motivos de interpretabilidade. Dos títulos e resumos destes 138 artigos analisados no presente trabalho, foram extraídas 136 palavras-chave que ocorreram duas ou mais vezes. O primeiro passo foi a análise dos clusters gerados por períodos (1983 a 2010; 2011 e 2012; 2013 e 2014; 2015 a 2019 e 1983 a 2019). Os períodos foram determinados pela média da quantidade de documentos obtidos na base de dados Scopus.

Pelas análises dos resultados, no primeiro período os clusters abordam viabilidade, tecnologia e a aplicabilidade da tecnologia; nos períodos de 2011 a 2014 a abordagem se dá em eficiência; entre 2015 e 2019. Além da eficiência é abordado, também, o controle e o mapa gerado de forma global incluindo todos os períodos têm como abordagem principal a eficiência e a aplicabilidade de componentes.

Pela análise da rede pode-se observar que a rede de coocorrência de palavras-chave mostrou parcialmente os principais aspectos abordados sobre o tema além de fornecer uma visão aproximada para futuras pesquisas, como o desenvolvimento das turbinas em alto mar (offshore).

\section{3 - Tendências futuras de pesquisa}

Para avaliar futuras tendências de pesquisa, os artigos publicados em 2018 e 2019 foram analisados com relação às lacunas da literatura científica que eles propuseram. Então, optou-se por limitar esta análise aos artigos de 2018 e 2019 , pois as propostas de pesquisas futuras provavelmente não serão resolvidas até o momento. Dos 19 artigos sobre o tema que foram publicados no período limitado, 5 não estavam acessíveis e 10 não incluíam propostas para pesquisas futuras, restando assim, 4 artigos para análise. Portanto, 
apenas os 4 artigos remanescentes foram mapeados e analisados. Para melhor compreensão das tendências futuras, foi proposto um breve resumo acerca de cada artigo:

(1) Exploração de energia e a piscicultura em águas profundas com estabilidade hidrostática

Zheng and Lei (2018) abordaram como tema o uso de turbinas eólicas flutuantes, devido ao custo considerado inferior em comparação as turbinas fixadas no fundo do mar. Os autores apresentaram uma estrutura inovadora que integra uma turbina eólica offshore flutuante com uma gaiola de piscicultura em aço. Desta maneira, sendo a parte superior do sistema, uma turbina eólica de vários megawatts e a parte inferior do sistema é uma gaiola de aço que atua como base flutuante da turbina eólica para o uso da pesca. O projeto combina a exploração de energia e a piscicultura em águas profundas com estabilidade hidrostática. Como tendências futuras de pesquisa, os autores enfatizam a investigação de amortecimento viscoso não linear de redes de liga de cobre e a identificação dos coeficientes de arrasto das forças das ondas em redes de liga de cobre usando testes em modelos em bacias oceânicas e fluidos computacionais de simulações de dinâmicas. Além disso, como os movimentos do projeto são de baixas frequências, é necessário um estudo aprofundado do efeito de ondas aleatórias de segunda ordem e cargas de ondas com diferentes frequências.

(2) Projeto e simulação de bomba de pistão radial para transmissão de turbina eólica de alta potência

Tao et. al. (2019) apresentaram um projeto de bomba de pistão radial para sistemas de transmissão de turbinas eólicas em larga escala com a combinação de modelagem paramétrica. Este projeto generativo sendo baseado em algoritmos e modelo acoplado mecânico-hidráulico desenvolvido para avaliação de desempenho baseada em simulação do projeto da bomba.

Para os autores, a falta de componentes hidráulicos disponíveis restringe o desenvolvimento de turbinas eólicas offshore em grande escala. Para projetar uma bomba de pistão radial de baixa velocidade e alta potência, adequada para turbinas eólicas com alta potência, é fundamental entender seus princípios de trabalho, requisitos funcionais e restrições de projeto, bem como índices de desempenho e métodos de avaliação.

Os resultados sugeriram que a bomba proposta possui eficiência um pouco menor em relação a com transmissão hidrostática devido a mais pistões e maior perda de vazamento. Porém, apresenta uma estrutura mais compacta, maior densidade de potência e potencialmente melhor controlabilidade e confiabilidade, que são preferidas para aplicação de turbinas eólicas. Como tendência futura de pesquisa, é comentado do esquema de controle de carga variável, que não foi abordado no estudo, sendo essencial para um projeto a implementação de esquemas de controle aprimorados.

(3) Resposta hidrodinâmica de uma plataforma semisubmersível para suportar uma turbina eólica

Shokouhian et. al. (2019) realizaram uma investigação numérica sobre a resposta de uma plataforma semisubmersível por meio de análises hidrostáticas e hidrodinâmicas. Nestas análises, várias linhas de ancoragem são examinadas com especial atenção aos polímeros e materiais sintéticos para determinar qual é a mais adequada para esta plataforma.

Os resultados revelam que o uso das linhas de amarração sintéticas oferece melhor desempenho para a plataforma em comparação com outros materiais investigados no artigo.

Como forma de estender o estudo proposto, os autores comentam que são necessárias mais pesquisas para determinar a melhoria dos movimentos da plataforma flutuante na produção geral de geração eólica da turbina e o efeito de diferentes sistemas de ancoragem na estabilização da plataforma.

(4) Otimização de sistemas dinâmicos de cabos para turbinas eólicas offshore flutuantes

Rentschler et al. (2019) comentam em relação a tecnologia eólica flutuante (offshore) sobre seu enorme potencial mas que ainda não atingiu a maturidade comercial. Os autores constataram que há muitos problemas a serem tratados e que existe uma grande lacuna de conhecimento em relação ao comportamento dinâmico dos cabos entre matrizes em movimento livre, que ligam as turbinas flutuantes. Neste sentido desenvolveram uma ferramenta de projeto para investigar e otimizar o comportamento dinâmico destes cabos (incluindo análise de fadiga) bem como também a abordagem de condições climáticas extremas, componentes auxiliares de cabos e detalhes econômicos apresentando uma abordagem de design baseada em um algoritmo genético. O ponto de partida para a análise dinâmica foram configurações de cabos da otimização hidrostática.

Com base nesta melhoria hidrostática, uma regra geral de projeto para cabos de ondas suaves pode ser deduzida na faixa de profundidade de 70 a $200 \mathrm{~m}$, sendo classificada uma recomendação de design generalizada única na literatura.

Como tendência de pesquisa futura do artigo, os autores comentam que os próximos estudos devem envolver modelagem climática mais realista, especialmente com relação à mudança de direção das ondas e do vento como também a influência das correntes.

\section{4 - Evolução dos temas de pesquisa}

Para a análise da evolução dos temas de pesquisa, foi utilizado o software Scimat. Com o software foi possível validar os resultados obtidos com a análise das lacunas da pesquisa e da coocorrência de palavras-chave. Esse software é uma ferramenta desenvolvida para realizar análises de mapeamento científico sob uma estrutura longitudinal por meio de um diagrama estratégico de representação. 
Figura 3 - Diagrama estratégico dos períodos 1983 a 2010 (a), 2011 e 2012 (b), 2013 e 2014 (c) e 2015 a 2019 (d).
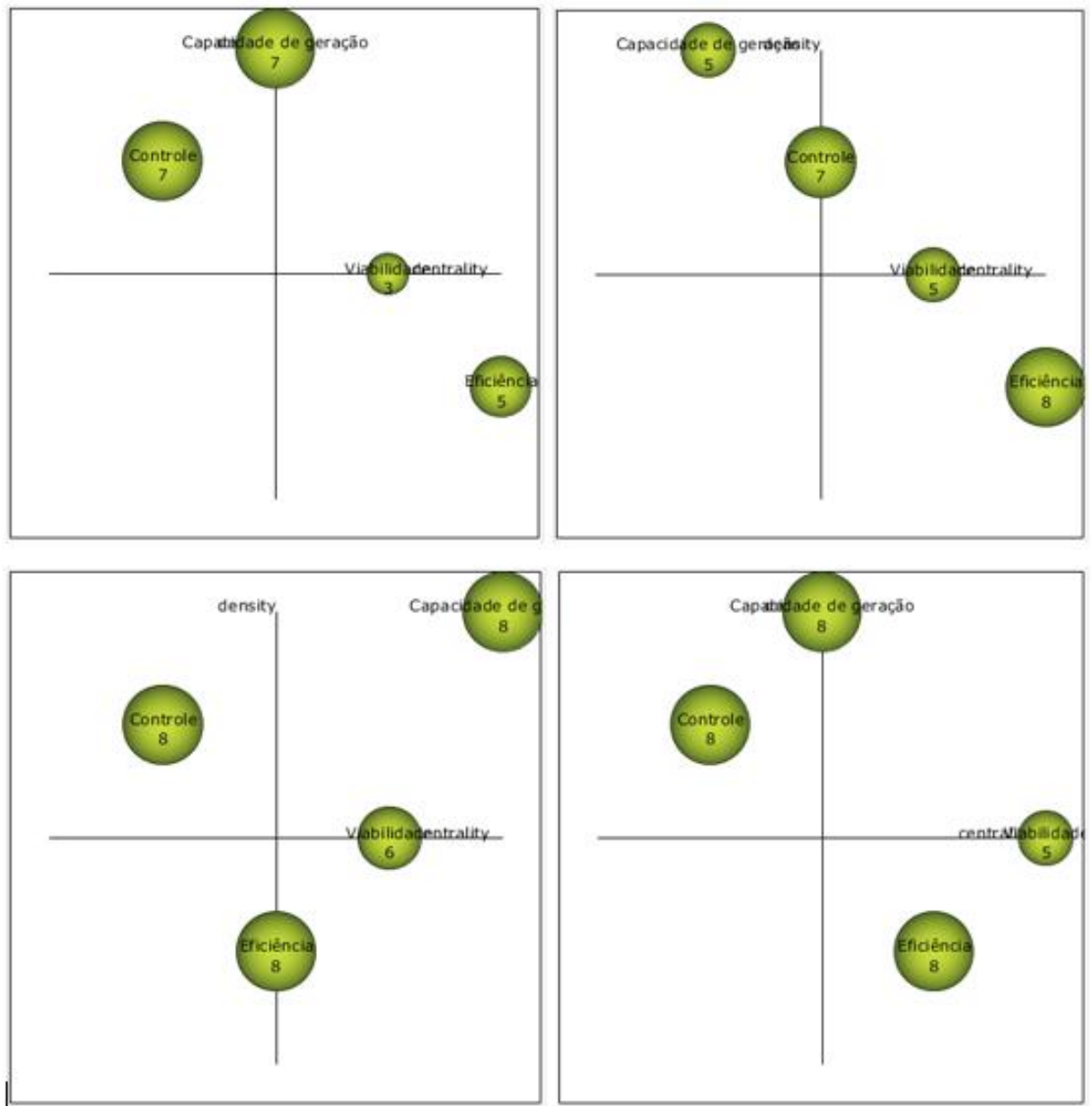

Fonte: Autores, 2019.

A primeira parte caracteriza-se pelo carregamento do arquivo obtido pela base de dados Scopus em formato RIS (tag padronizado para permitir que programas de citação troquem dados). Em seguida, de acordo com o tema global abordado no artigo, foram definidos quatro fatores para serem analisados nos quatro quadrantes do diagrama estratégico, são eles: "eficiência"; "capacidade de geração"; "controle" e "viabilidade". O terceiro passo, após a definição dos fatores abordados, caracteriza-se pela distribuição das palavras-chaves (total de 1213) para cada fator correspondente.

Como resultado, e de acordo com os diagramas estratégicos, obtiveram-se observações acerca de cada fator, que foram:

"Eficiência": O fator se encontra em todos os períodos como um tema transversal (quarto quadrante) para o desenvolvimento de pesquisa, somente no período de 2013 a 2014 tende a tornar-se um tema obsoleto (terceiro quadrante), tendo como hipótese o fator de "capacidade de geração" que estava sendo mais desenvolvido no mesmo período. Como forma de ilustrar de acordo com o Diagrama, o fator "eficiência" encontra-se no eixo y (entre os terceiro e quarto quadrante) no mesmo momento que o fator "capacidade de geração" está sendo mais abordado como motor.

"Capacidade de geração": o fator encontra-se no período de 1983 a 2010 como um tema consolidado (segundo quadrante) e motor (primeiro quadrante), em 2011 e 2012 como um tema consolidado. Por fim, em 2013 e 2014, volta a ser um tema motor, em vista da hipótese de que no período sendo um tema motor, foi abordada uma potência nos sistemas mais alta comprometendo a eficiência, tendo então a necessidade de desenvolvimento de pesquisa novamente.

"Controle": o fator encontra-se em todos os períodos como um tema consolidado (segundo quadrante), somente no período de 2011 a 2012 tende a se tornar um tema motor (primeiro quadrante), ou seja, na maioria dos estudos da área o termo é presente.

"Viabilidade": o fator encontra-se em todos os períodos como um tema motor (primeiro quadrante) e transversal (quarto quadrante), tendo como inferência a relevância da sua inclusão em pesquisa, em que se torna um tema transversal com outros assuntos.

\section{CONCLUSÃO}

O presente artigo buscou apresentar algumas possibilidades de pesquisa da base de dados sobre sistema hidrostático e turbina eólica por meio de técnicas bibliométricas, que podem ser obtidas com o intuito de descrever, conhecer ou explicar fenômenos. Pode-se verificar que a maior concentração de interesse se insere no contexto de eficiência, como também aplicação.

O campo de pesquisa que foi investigado está crescendo e se consolidando como um tema relevante, porém foram encontrados somente 138 documentos na filtragem. Infere-se que ainda existe um espaço significativo para o desenvolvimento de pesquisa em relação à transmissão hidrostática aplicadas em turbinas eólicas, 
desencadeado pelo pequeno número de trabalhos que abordam o segmento nas tendências de pesquisas futuras.

Nas palavras-chave, os resultados mostram que o grau de diversidade de conhecimento é baixo, conforme elucidado pelo número de palavras-chave correlacionadas. Para análise, foi produzido uma rede de coocorrências de título e resumo e pode-se observar os principais aspectos abordados na área, como a viabilidade, tecnologia, aplicabilidade da tecnologia e de componentes, eficiência, controle e desenvolvimento das turbinas.

Os dados obtidos com a análise da evolução dos temas de pesquisa, explorado com o softwate Scimat, tem relação direta com os análise das lacunas da pesquisa e da coocorrência de palavras-chave, validando os resultados.

A findar a pesquisa, o presente artigo buscou explorar os principais assuntos sobre sistema hidrostático e turbina eólica a serem abordados como tendência futuras a fim de auxiliar desenvolvimento de pesquisas inéditas.

\section{REFERÊNCIAS BIBLIOGRÁFICAS}

JOSELIN HERBERT, G.M., INIYAN, S., SREEVALSAN, E., RAJAPANDIAN, S. A review of wind energy technologies. Renewable and Sustainable Energy Reviews. v. 6, p. 1117-1145. 2007.

MADVAR, Mohammad Dehghani; AHMADI, Farzin; SHIRMOHAMMADI, Reza; ASLANI, Alireza. Forecasting of wind energy technology domains based on the technology life cycle approach. Energy Reports. v. 5, p. 1236-1248. 2019.

MARTINHO, Vitor João Pereira Domingues. Interrelationships between renewable energy and agricultural economics: An overview. Energy Strategy Reviews, v. 22, p. 396 - 409. 2018.

Nazir, Muhammad Shahzad; MAHDI, Ali Jafer; BILAL, Muhammad; SOHAIL, Hafiz M.; ALI, Nisar; IQBAL, Hafiz M.N. Environmental impact and pollution-related challenges of renewable wind energy paradigm - A review. Science of The Total Environment. v. 683, p. 436-444. 2019.

Pritchard, A. Statistical bibliography an interim bibliography, New Western Polytechnic school of Librarianship. London. 1969.

RENTSCHLER, M.U.T., ADAM, F., CHAINHO, P. Design optimization of dynamic inter-array cable systems for floating offshore wind turbines. Renewable and Sustainable Energy Reviews. v. 111, p. 622- 635. 2019.

SHOKOUHIAN, M., HEAD, M., SEO, J., SCHAFFER, W., ADAMS, G. Hydrodynamic response of a semi-submersible platform to support a wind turbine. Journal of Marine Engineering \& Technology. 2019.

TAO, J., WANG, H., LIAO, H., YU, S. Mechanical design and numerical simulation of digital-displacement radial piston pump for multi-megawatt wind turbine drivetrain. Renewable Energy. v. 143, p. 995-1009. 2019.

VAN ECK, Nees Jan, WALTMAN, L. Software survey: VOSviewer, a computer program for bibliometric mapping. Scientometrics v. 84, p. 523-538. 2010.
WANG, F., CHEN, J. XU, B., STELSON, K.A. Improving the reliability and energy production of large wind turbine with a digital hydrostatic drivetrain. Applied Energy. v. 251. 2019.

ZHENG, X.Y., LEI, Y. Stochastic Response Analysis for a Floating Offshore Wind Turbine Integrated with a Steel Fish Farming Cage. Applied Sciences. v. 8. 2018.

\section{COPYRIGHT}

Direitos autorais: Os autores são os únicos responsáveis pelo material incluído no artigo. 


\author{
Volume $16-\mathrm{N}^{\mathrm{o}} 174$ - Junho / 2020 \\ XLII International Sodebras Congress \\ 28 a 30 de maio de 2020 - Web Conference.
}

\title{
ANÁLISE DA INFLUÊNCIA DO COMPORTAMENTO DO VENTO NA EFICIÊNCIA DE TURBINAS EÓLICAS DE EIXO VERTICAL UTILIZANDO CFD
}

\author{
ANALYSIS OF THE INFLUENCE OF WIND BEHAVIOR ON THE \\ EFFICIENCY OF VERTICAL AXIS WIND TURBINES USING CFD
}

\author{
ALEX R. A. RODRIGUES ${ }^{1}$; CLAUDINEI R. CALADO²; ENZO R. R. DOS SANTOS \\ 1 - CEFET-MG; 2 - CEFET-MG; 3 - CEFET-MG \\ alexrodriguesbaja@gmail.com ; crcalado@cefetmg.br ; enzorafaello@gmail.com
}

\begin{abstract}
Resumo - Neste trabalho estuda-se o comportamento dinâmico do escoamento de ar em torres de aerogeradores. A simulação fluído dinâmica foi aplicada pelo método de elementos finitos no software SolidWorks ${ }^{\circledR}$ com intuito de verificar a diferença de pressão e velocidade do ar, deste modo avaliar seus efeitos na eficiência da potência que pode ser extraída As análises levam em conta três variações de geometria aplicadas ao mesmo escoamento tridimensional com velocidade de ar atmosférico de $5 \mathrm{~m} / \mathrm{s}$, uniformemente aplicada, axialmente à turbina. Os resultados obtidos apresentam os campos de pressão e velocidade no instante da análise entre as geometrias.

Palavras Chaves: Turbina eólica; velocidade; pressão; eficiência; CFD.
\end{abstract}

\begin{abstract}
In this work, the dynamic behavior of air flow in wind turbine towers is studied. The dynamic fluid simulation was applied by the finite element method in the SolidWorks ${ }^{\circledR}$ software in order to verify the difference in air pressure and speed, thus evaluating its effects on the efficiency of the power that can be extracted. The analyzes take into account three variations of geometry applied to the same flow with an atmospheric air velocity of $5 \mathrm{~m} / \mathrm{s}$, uniformly applied, axially to the turbine. The results obtained show the pressure and velocity fields at the time of analysis between the geometries.
\end{abstract}

Keywords: Wind turbine; velocity; pressure; efficiency; CFD.

\section{INTRODUÇÃO}

A indústria de energia elétrica busca a diversificação das fontes energética, bem como a redução de tarifas, geração de energia limpa com melhor eficiência para a sociedade. Com base nesta perspectiva, o setor elétrico brasileiro busca o seu crescimento na capacidade de geração eólica no país. De acordo com a Global Wind Energy Council (GWEC), organização especializada em energia eólica, em 2018, o país aumentou $2 \mathrm{GW}$ de capacidade eólica à sua matriz energética, posicionando na $9^{\mathrm{a}}$ posição no ranking mundial e o líder na América Latina.

Em 2015, o Brasil assinou um termo de compromisso internacional na COP 21, 21 ${ }^{a}$ Conferência das Partes das Nações Unidas para reduzir emissões de gases de efeito estufa para o desenvolvimento sustentável, de aumentar para $33 \%$, considerando a matriz total, o uso de fontes renováveis até o ano de 2030. E com pelo menos $23 \%$ de aumento do fornecimento energético de fontes renováveis até o mesmo ano (MINISTÉRIO DO MEIO AMBIENTE, 2016).
A liderança brasileira na produção deste tipo de energia renovável é confirmada também pelos órgãos brasileiros. Como Agência Nacional de Energia Elétrica (Aneel), que em 2016, constatou uma expansão de 2.491MW, e a Câmara de Comercialização de Energia Elétrica (CCEE), indicam que de janeiro a agosto de 2019, a geração de energia pela força dos ventos foi de 5.501,52 MW médios ante 4.794,91 MW médios no mesmo período de 2018, o que representam um crescimento de $14,7 \%$. Com isso, apenas em 2018, foram evitadas emissões de 20,58 milhões de toneladas de CO2 na atmosfera (CCEE, 2019).

O estado de Minas, hoje com 1,56 MW de produção de energia eólica, está em $14^{\circ}$ entre os estados brasileiros, mas tem grande potencial de crescimento, segundo a Aneel. No âmbito Estadual o potencial eólico tem mesma ordem de grandeza que a capacidade atualmente instalada de recursos hidráulicos.

A partir da primeira crise energética, em 1970, houve uma crescente nos estudos de aerogeradores e energia eólica. Estes estudos apresentam análise de viabilidade de implantação, o estudo de potencial eólico da região e a modelagem e simulação de escoamento dos ventos em diferentes tipos de rotores e pás. Segundo Isam (2008), há vários modelos para análise dinâmica em turbinas Darrieus. Os modelos mais estudados e melhores validados podem ser classificados em três categorias: Modelo de Vórtice; Modelo de Cascada; e Modelo de momento do elemento de pá.

$\mathrm{O}$ terceiro modelo, utilizado neste artigo, pode ser considerado o de melhor precisão, segundo Islam (2008). Se trata de um modelo baseado no cálculo da velocidade do fluxo que passa pela turbina pela equalização da força aerodinâmica na pá no sentido do fluxo com a taxa de mudança do momento do ar, que é igual a diferença da velocidade multiplicada pela vazão mássica do ar. A força também é igual a diferença média da pressão no rotor.

Este modelo pode ser complementado com o submodelo de, Tubo de Corrente Múltiplo Duplo (TCMD). De acordo com Batista (2013) a teoria do TCMD a área é dividida em dois discos atuadores essenciais, um representando o lado montante e o outro o lado vazante. $\mathrm{O}$ ar ao percorrer as pás no lado montante influencia o escoamento de vento no lado vazante. $O$ cálculo de desempenho é feito separadamente para cada metade do rotor. É considerado a variação da velocidade induzida como uma função do ângulo de azimute. Esta teoria 
apresenta melhores correlações entre resultados calculados e experimentais, especialmente para forças aerodinâmicas locais nas pás.

\section{METODOLOGIA}

Para se analisar a eficiência, quanto a conversão de energia cinética em mecânica, das turbinas proposta, foi realizado uma simulação CFD considerando a modelagem matemática, as condições de contorno e computacionais adequadas com intuito de gerar resultados coerentes e mais confiáveis.

\subsection{Modelo Matemático}

Nesta seção será apresentado a proposta matemática empregada na descrição do modelo do escoamento de fluido, viscoso e incompressível. Para descrever a turbulência do escoamento do ar, foi utilizado as equações de conservação de RANS - Reynolds Average Navier-Stokes. Segundo Lauder \& Shima (1989), este modelo é o mais indicado para aplicações aerodinâmicas, por apresentar maior grau de modelagem e também requer menor recurso computacional.

\section{2 - Modelo de turbulência de Reynolds -RSM (Reynolds Strees model)}

Segundo Alho e Ilha (2006), o modelo para o complemento das equações RANS para o regime turbulento podem ser obtidas através das equações de Navier-Stokes e equações de médias de Reynolds, equação 1.

$$
\frac{\partial \overline{u_{i}^{\prime} u_{j}^{\prime}}}{\partial t}+\overline{u_{\ell}} \frac{\partial \overline{u_{i}^{\prime} u_{j}^{\prime}}}{\partial x_{\ell}}=D_{i j}+P_{i j}+\Phi_{i j}-\varepsilon_{i j}
$$

Onde Dij é o termo de transporte difusivo, Pij é o termo de produção de tensão, $\Phi \mathrm{ij}$ o termo de pressão e cij o termo de dissipação viscosa.

\section{3 - Modelo físico}

O modelo físico das pás em análise são derivadas do modelo de eixo vertical de Darrieus. A torre 1 é composta por um eixo de $1,80 \mathrm{~m}$ de altura de aço 1035 . O rotor possui diâmetro de 1,30 m. e três pás de perfil NACA de $0,70 \mathrm{~m}$ de comprimento com aparadores de vento arredondados nas hastes de fixação, todos em PETG, um copolímero, muito utilizado para impressão $3 \mathrm{D}$, formadoao combinar $\mathrm{o}$ PET(Polietileno tereftalato) com glicol. Conforme figura 1:
Figura 1 - Torre 1 de modelo Darrieus.

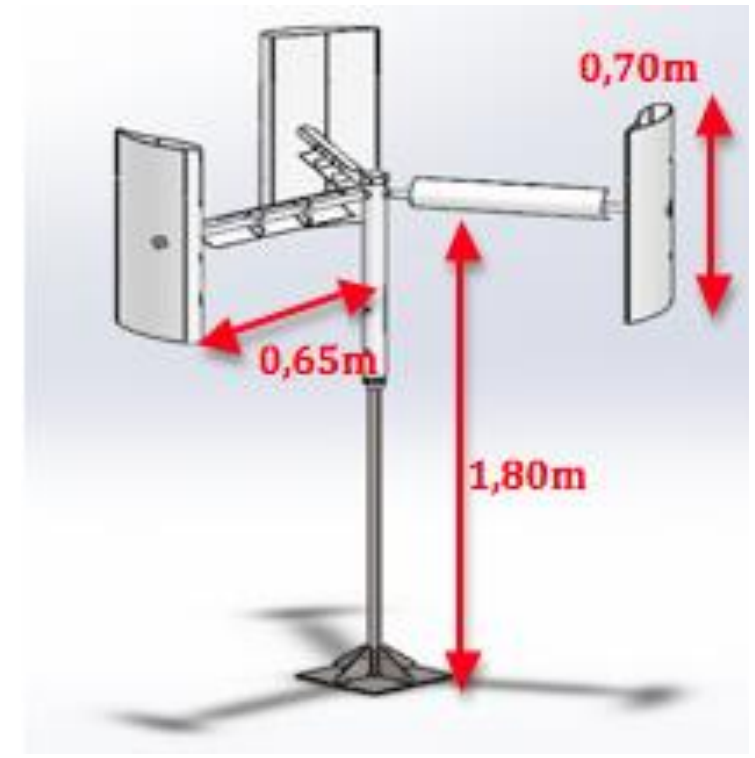

Fonte: Autor.

A Torre 2 possui mesma medida de altura do eixo e diâmetro de rotor, porém com pás de 2,00 m de comprimento e 2,00 m de diâmetro, além de duas pás côncavas no centro do eixo, defasadas $180^{\circ}$, estas pás irão auxiliar no torque de partida. Além disso, os aparadores de vento fixados na haste de fixação das asas tem formato mais aerodinâmico e sem enclausuramento como o rotor Savonius para reduzir a força de arrasto contrária ao movimento de rotação positivo, esse menor arrasto melhora a eficiência durante o movimento, conforme mostrado na figura 2.

Figura 2 - Torre 2 com pás no centro do eixo e asas com maior comprimento.

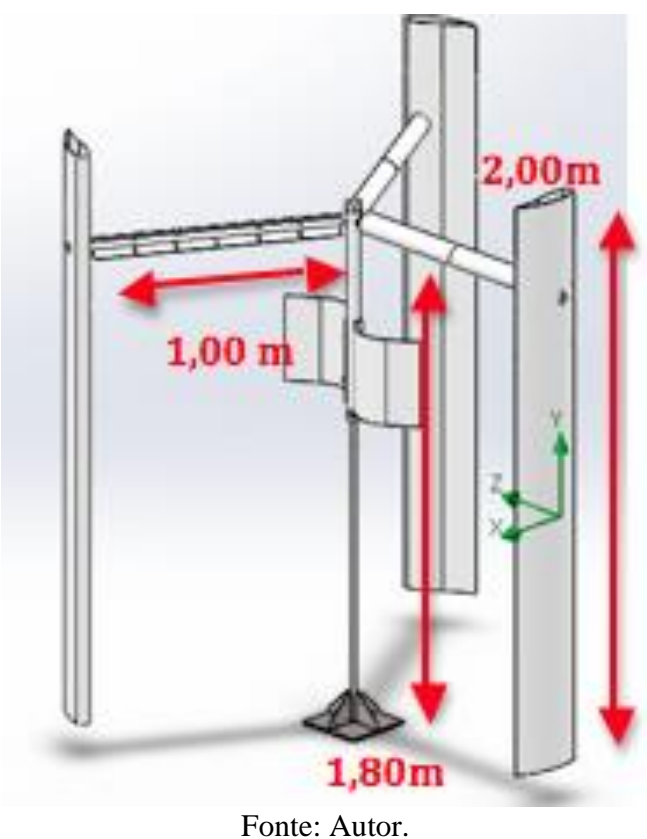

A Torre 3 difere da Torre 2 pelo formato otimizado aerodinamicamente das hastes de sustentação das asas e pela presença de discos fixado nas pás de auxílio ao torque de partida centrais que possui configuração Savonius. As mudanças no design da torre 3 são mostradas na figura 3 . 
Figura 3 - Torre 3, modelo similar ao Darrieus-Savonius

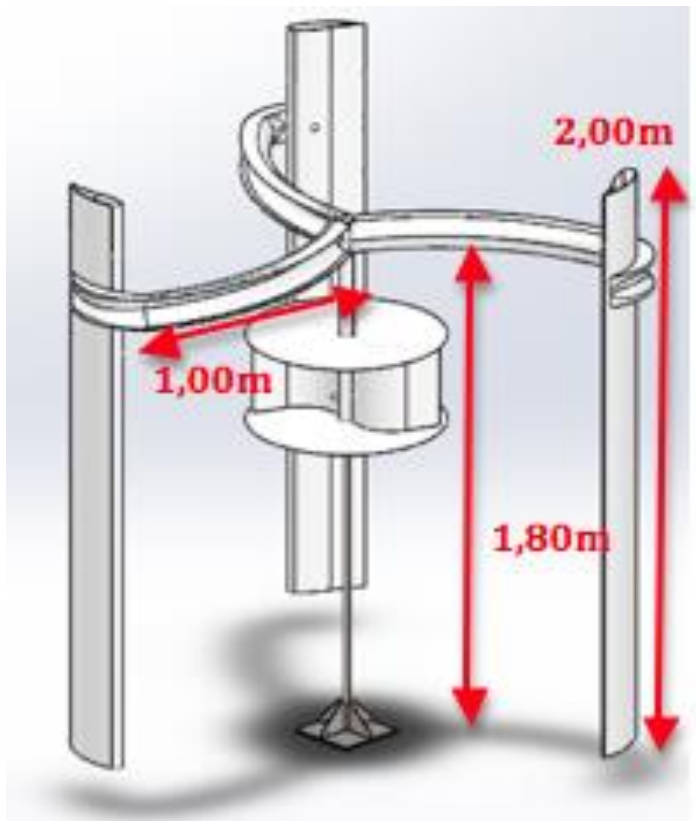

Fonte: Autor.

\subsection{Condições ambiente}

Nas simulações realizadas para cada modelo, foi considerado um vento com velocidade média de $5,0 \mathrm{~m} / \mathrm{s}$, umidade $62 \%$ e temperatura de $22^{\circ} \mathrm{C}$ conforme média apontada pelo atlas eólico para a região de Belo Horizonte MG (CEMIG, 2010). Foi considerado para análise a direção aplicada aos rotores de $60^{\circ}$ em relação ao eixo de sustentação da pá para se analisar a velocidade e pressão nos principais pontos do rotor, conforme figura 4.

Figura 4 - Ângulo de $60^{\circ}$ em relação ao eixo de sustentação da pá.

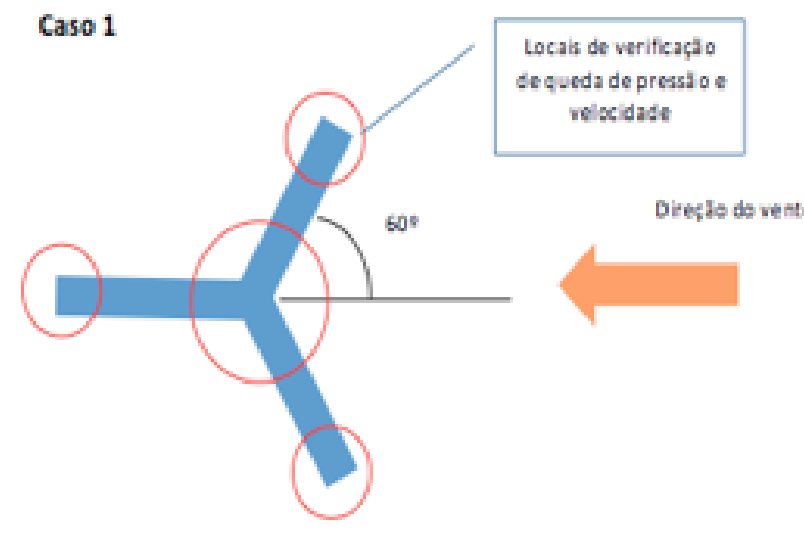

Fonte: Autor.

\section{5 - Condições de contorno}

Com o intuito de parametrização dos resultados encontrados, os dados de entrada e considerações no software foram os mesmos para os três (3) tipos de torres e são:

1 - É considerado o escoamento uniforme isotérmico e incompressível do ar atmosférico a $5 \mathrm{~m} / \mathrm{s}$.

2 - A entrada é na face geradora de escoamento e a saída é considerado como condição de abertura. Já os contornos superficiais, laterais e base foi definido escoamento com deslizamento livre e viscosidade infinita.

3 - As peças que formar o gerador são consideradas sólidas e impermeáveis de parede lisa, com condição de não deslizamento.

4 - Análise realizada no software SolidWorks pelo método RANS para equações de conservação de massa e quantidade de movimento e o método RSM para a resolução de turbulência.

\section{6 - Malha computacional}

Para garantir que os resultados obtidos com as malhas geradas forneçam informações confiáveis, foi utilizado a malha de formato tetraédrico com 9512 elementos, pois segundo Biswas e Strawn (1998) ela reproduz de forma mais precisa corpos mais complexos. E para a malha de refino foi utilizada em formato piramidal para se obter elementos com tamanho mais próximos.

\section{7 - Visualização de resultados}

Para melhor visualização dos resultados foram considerados 2 cortes paralelos em cada turbina. Assim podese melhor visualizar e analisar o efeito do eixo de sustentação da asa e também dos rotores centrais, a figura 5 mostras estes cortes.

Figura 5 - Cortes na Turbina 3.

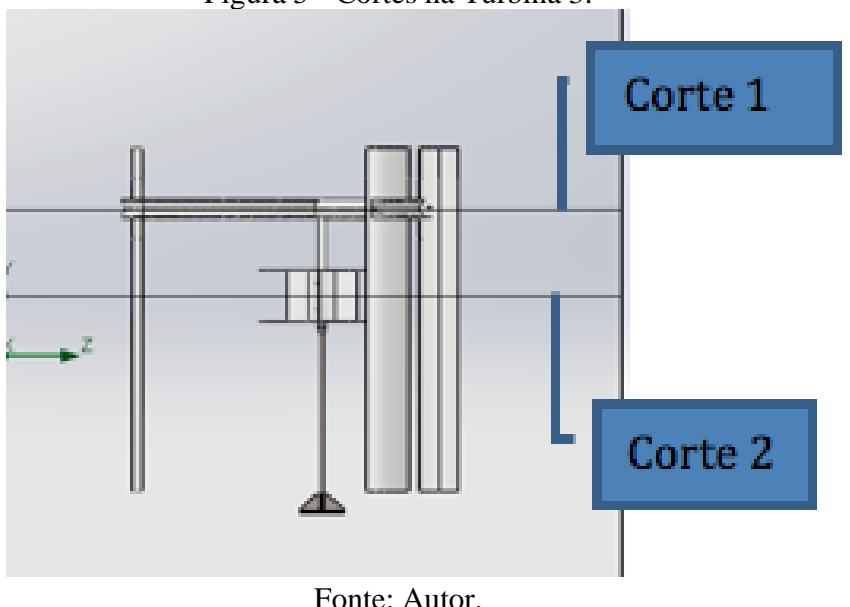

\section{RESULTADOS}

Os resultados estão dispostos com os cortes 1 e 2, para os valores de pressão e velocidade.

\section{1- Turbina 1}

Para o angulo de $60^{\circ}$ em relação ao eixo, é observado grande queda de pressão nas áreas de impacto do ar devido a turbulência. Que evidencia melhor propulsão no formato côncavo do eixo, conforme figura 6 : 
Figura 6 - Efeito da pressão para o angulo de $60^{\circ}$ em relação ao eixo de sustentação da pá. (a) Considerando o corte 1 e (b) corte 2.

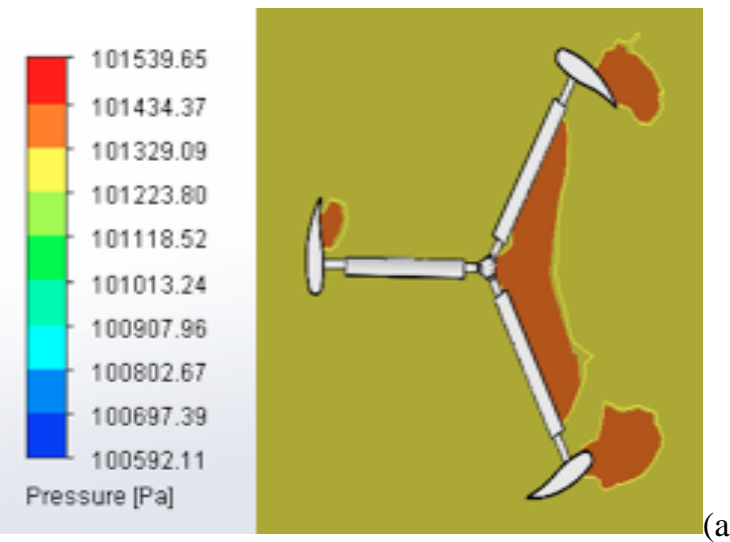

(a)

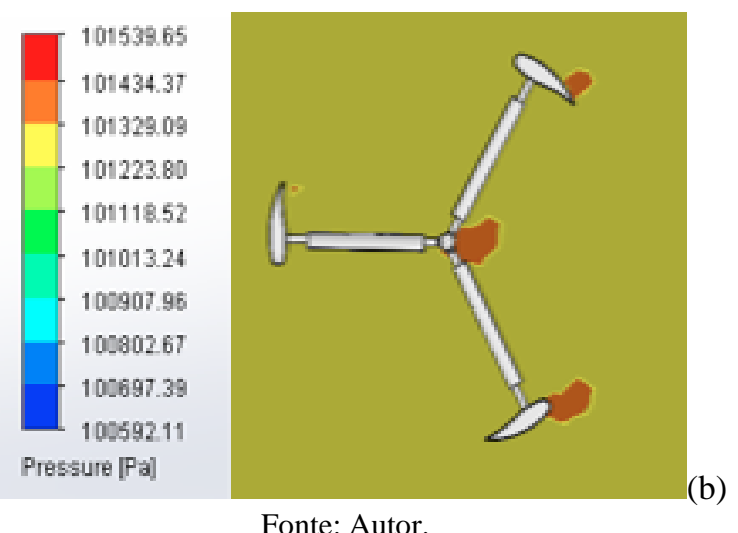

Para velocidade é evidenciado a perda de velocidade no corte 1 devido ao efeito parede nos eixos de sustentação e nas pás quando há uma queda na parte anterior devido ao formato de asa da pá, conforme mostra a figura 7.

Figura 7 - Efeito da velocidade para o angulo de $60^{\circ} \mathrm{em}$ relação ao eixo de sustentação da pá. (a) Considerando o corte 1 e (b) para o segundo corte de visualização.

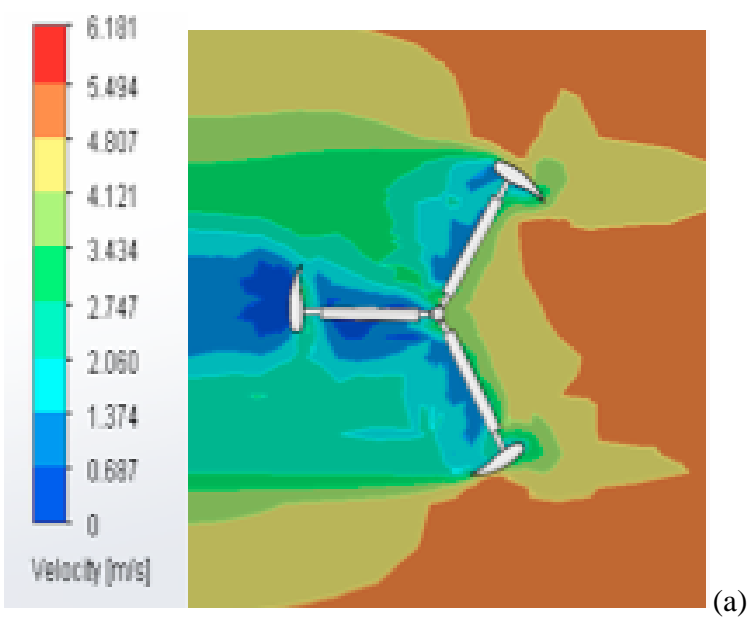

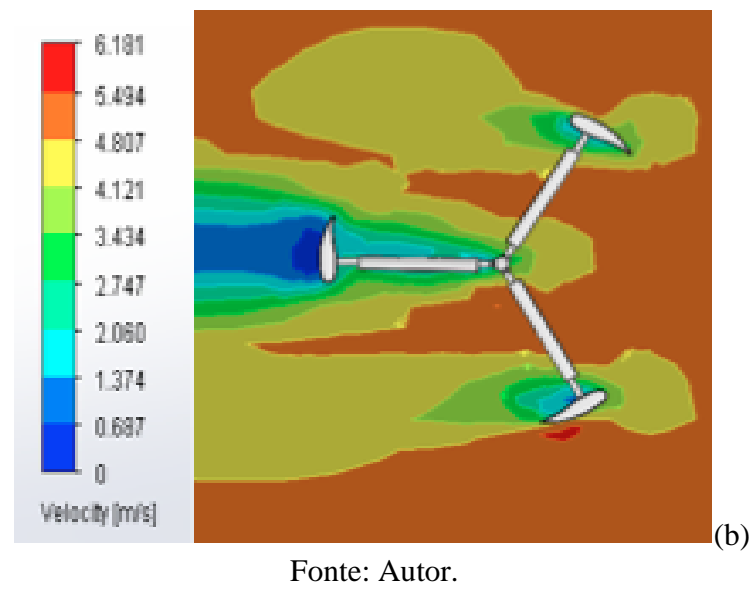

\section{2 - Turbina 2}

Para o angulo de $60^{\circ}$ em relação ao eixo, também é observado grande queda de pressão atrás das superfícies da turbina devido ao vácuo formado, principalmente após as pás centrais que auxiliam no torque de partida, conforme mostra a figura 8 .

Figura 8 - Efeito da pressão para o angulo de $60^{\circ}$ em relação ao eixo de sustentação da pá. (a) Considerando o corte 1 e (b) para o segundo corte de visualização.
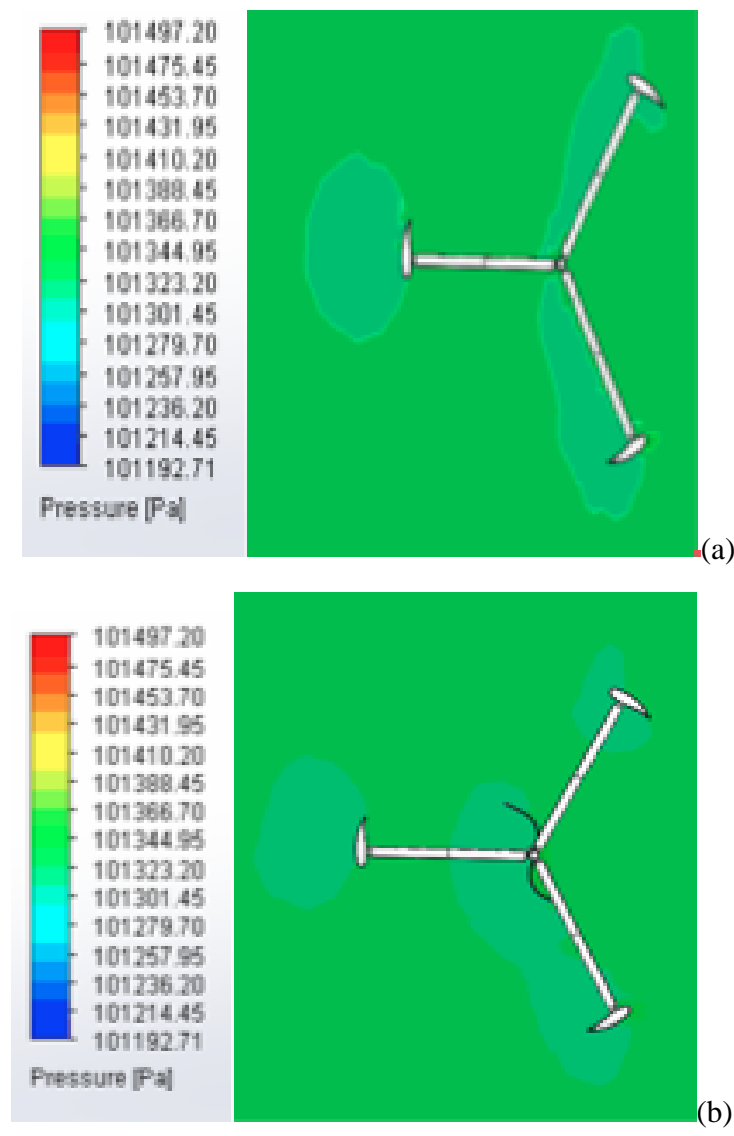

Fonte: Autor.

A figura 9 mostra a perda de velocidade no lado anterior das pás em ângulo, e na pá no centro do eixo que auxiliam o movimento. 
Figura 9 - Efeito da velocidade para o angulo de $60^{\circ}$ em relação ao eixo de sustentação da pá. (a) Considerando o corte 1 e (b) para o segundo corte de visualização.

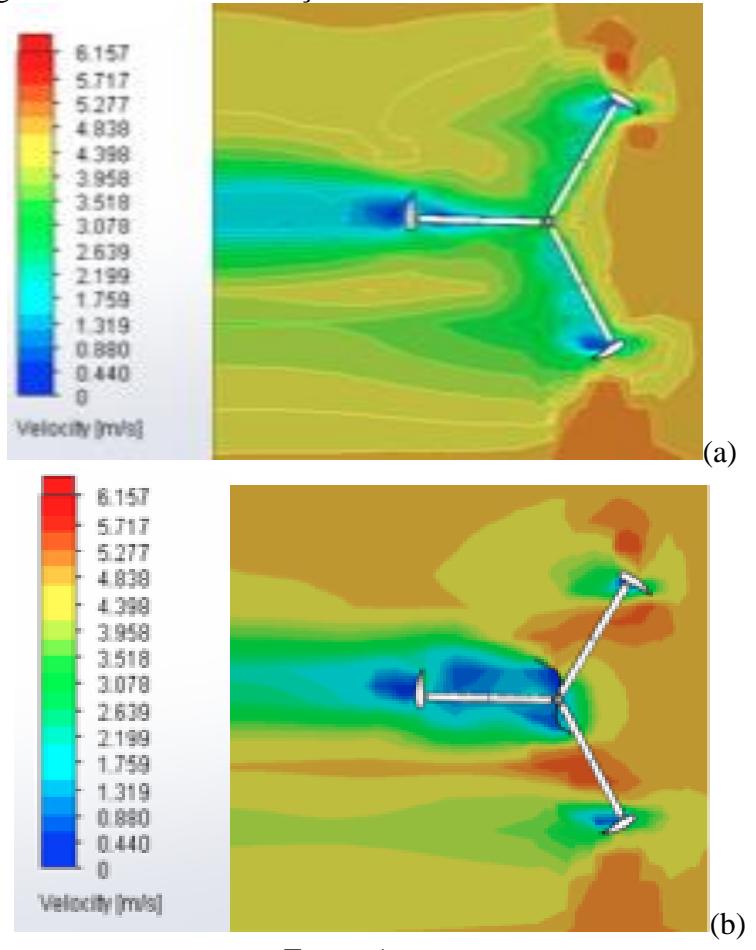

Fonte: Autor.

\section{3 - Turbina 3}

Para o ângulo de $60^{\circ}$ em relação ao eixo, é observado grande queda de pressão após o rotor Savonius, figura 10:

Figura 10 - Efeito da pressão para o angulo de $60^{\circ}$ em relação ao eixo de sustentação da pá.(a) Considerando o corte 1 e (b) para o segundo corte de visualização.

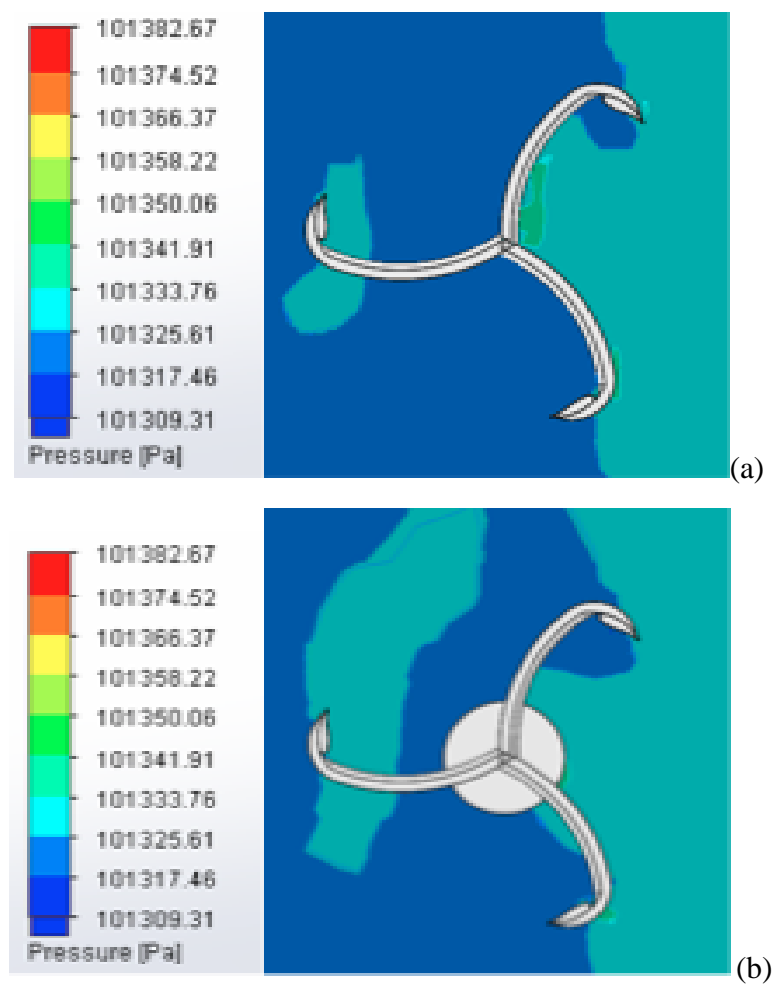

Fonte: Autor.

Para a simulação de velocidade é mostrado na figura 11 uma grande queda distribuída após o rotor Savonius, justificando a boa eficiência para conversão de energia. E também melhor distribuição da velocidade devido ao perfil curvo dos eixos de sustentação.

Figura 11 - Efeito da velocidade para o angulo de $60^{\circ}$ em relação ao eixo de sustentação da pá.(a) Considerando o corte 1 e (b) para o segundo corte de visualização.
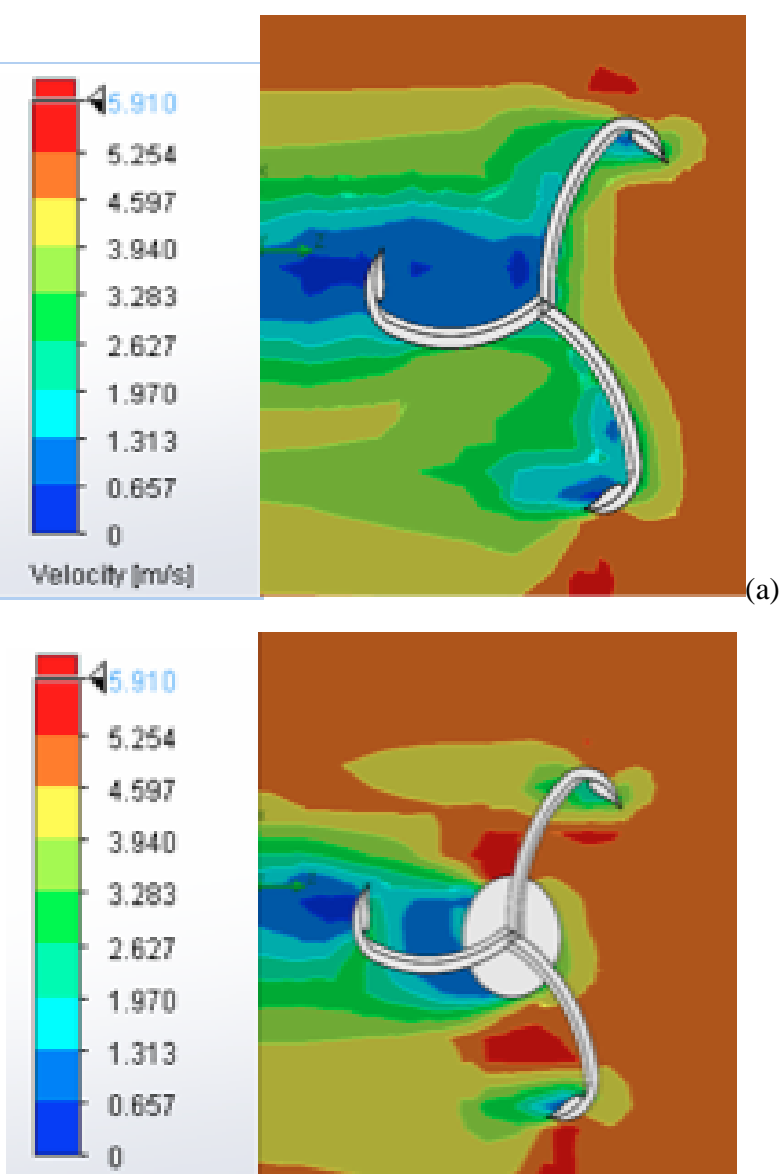

Velocity ims:

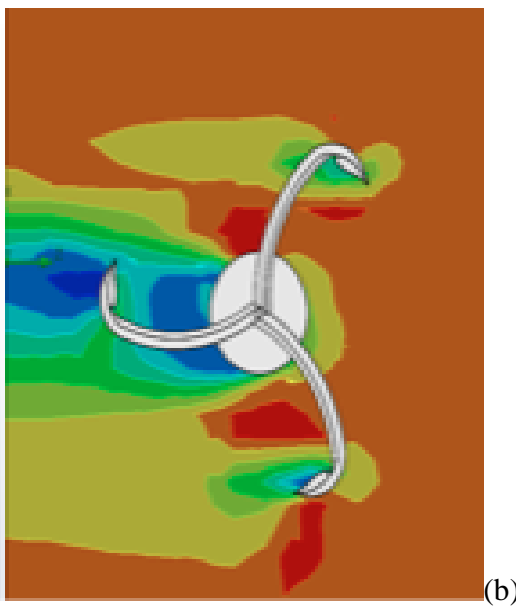

Fonte: Autor.

\section{4 - Eficiência das turbinas}

Com o resultado das simulações das turbinas quanto ao comportamento da pressão e velocidade do vento e analisar o coeficiente de potência de cada turbina, que é a razão entre a potência gerada pela turbina $P_{o t}$ e a potência disponível no ar em movimento $P_{A r}$. De acordo com a equação 2 .

$$
C_{P o t}=\frac{P o t}{P_{A r}}
$$

A potência da turbina é dada multiplicando o torque $T$ da turbina pela sua velocidade angular $\omega$ pela equação 3 .

$$
\text { Pot }=T * \omega
$$

E a potência do ar pela energia cinética do ar conforme equação 4.

$$
P_{A r}=\frac{1}{2} * \rho * V_{\infty}^{3} * A
$$

Onde $\rho$ é a densidade do ar, $V$ a velocidade do vento e $A$ a área que a turbina cobre. 
Para cada turbina estimou-se o rendimento aerodinâmico pelo cálculo do coeficiente de potência, obtendo-se os valores de eficiência, para a turbina 1 de $23 \%$, da turbina 2 de $25 \%$ e para a turbina $3 \operatorname{com} 27 \%$.

\section{CONCLUSÃO}

A análise de escoamento unidirecional sobre as turbinas eólicas geram diversas informações que permitem analisar e otimizar o rendimento de conversão de energia. No presente estudo verifica-se que, considerando os resultados das três configurações de turbinas eólicas, a maior eficiência de conversão de energia cinética em mecânica, é da turbina 3, pois apresenta campos de pressão e velocidades melhor distribuídos e gerando maior torque no início do giro devido ao rotor Savonius e eficiência de $27 \%$.

\section{REFERÊNCIAS BIBLIOGRÁFICAS}

ALHO, A.; ILHA, A. Turbulência, simulação numérica de escoamentos complexos. V Escola de Primavera em Transição e Turbulência-5a EPTT, ABCM, Rio de Janeiro, 2006.

AGÊNCIA NACIONAL DE ENERGIA ELÉTRICA. http://www.aneel.gov.br, 2015. Evolução da energia eólica no Brasil. Disponível em:< http://www.aneel.gov.br/aneelessencial//asset_publisher/c4M6OIoMkLad/content/evoluca o-da-energia-eolica-no-brasil?inheritRedirect=false>

Acessado em: 10 de março de 2020.

BATISTA, N. A. M. D. C. Novo aerogerador de eixo vertical integrado numa rede inteligente em contexto urbano. Universidade de Évora. [S.1.], p. 222. Novembro de 2013

BISWAS, R.;STRAWN, R. C. Tetrahedral and hexahedral mesh adaptation for CFD problems. Applied Numerical Mathematics, v. 26, p. 135-151. Janeiro de 1998. Disponível em:

<https://www.sciencedirect.com/science/article/abs/pii/S016 8927497000925>. Acesso em: 09/03/2020.

CÂMARA DE COMERCIALIZAÇÃO DE ENERGIA EÓLICA. https://www.ccee.org.br, 2019. Geração de energia por usinas eólicas aumenta 14,7\%. Disponível em:<https://www.ccee.org.br/portal/faces/pages_publico/not icias-

opiniao/noticias/noticialeitura?contentid=CCEE_651407\&_ afrLoop=240977083842291\&_adf.ctrl-

state $=1$ dgujnmuar_40\#!\%40\%40\%3Fcontentid\%3DCCEE_ 651407\%26_afrLoop\%3D240977083842291\%26_adf.ctrlstate\%3D1dgujnmuar_44>. Acesso em: 12 de março de 2020 .

CEMIG. http://www.cemig.com.br/, 2010. Atlas Eólico Minas Gerais. Disponível em: < http://www.cemig.com.br/pt-

br/A_Cemig_e_o_Futuro/inovacao/Alternativas_Energeticas /Documents/atlas\%20eolico\%20MG.pdf> Acesso em: $12 \mathrm{de}$ março de 2020.

GWEC. Global wind report: Annual market up date 2019. Disponível em: <http://www.gwec.net/>. Acesso em: $10 \mathrm{de}$ março 2020.

ISLAM, M.; TING, D. S.-K.; FARTAJ, A. Aerodynamic models for Darrieus-type straight- bladed vertical axis wind turbines. Renewable and Sustainable Energy Reviews, 20 Outubro 2008.

LAUNDER, B. E. ; SHIMA, N. Second-Moment Closure for the Near-Wall Sublayer: Development and Application. AIAA Journal, 27(10):1319-1325,

1989.

Disponível

em:

<https://arc.aiaa.org/doi/abs/10.2514/3.10267>. Acesso em: 02 de abril de 2020.

\section{MINISTÉRIO DE MINAS E ENERGIA.}

https://www.mma.gov.br/. Acordo de Paris. Disponível em https://www.mma.gov.br/clima/convencao-das-nacoesunidas/acordo-de-paris>. Acessado em: 09 de março de 2020.

\section{COPYRIGHT}

Direitos autorais: $\mathrm{O}(\mathrm{s})$ autor(es) é(são) o(s) único(s) responsável(is) pelo material incluído no artigo. 


\author{
Volume $16-\mathrm{N}^{\mathrm{o}} 174$ - Junho / 2020 \\ XLII International Sodebras Congress \\ 28 a 30 de maio de 2020 - Web Conference.
}

\title{
APLICAÇÃO DE FERRAMENTAS DA QUALIDADE NA ANÁLISE DE FALHAS EM MANGUEIRAS HIDRÁULICAS APLICADAS A ROV \\ APPLICATION OF QUALITY TOOLS IN FAILURE ANALYSIS IN HYDRAULIC HOSES APPLIED TO ROV
}

\author{
VANESSA APARECIDA DE SÁ MACHADO'ㄹ LUCIANO LIZARDO DE SOUZA GUIMARÃES ${ }^{2}$; \\ WALLICE MEDEIROS DE SOUZA ${ }^{1}$; EYKO MEDEIROS RIOS ${ }^{1}$ \\ 1 - CENTRO FEDERAL DE EDUCAÇÃO TECNOLÓGICA CELSO SUCKOW DA FONSECA; 2 - \\ UNIVERSIDADE ESTADUAL PAULISTA
}

\begin{abstract}
vasmachadovr@yahoo.com.br; luciano.lizardo@unesp.br; wallicemedeiros@hotmail.com;
watashiwaeyko@gmail.com
\end{abstract}

\begin{abstract}
Resumo - Num sistema hidráulico, entre diversos componentes, as mangueiras hidráulicas se destacam pela sua relevância em vista da segurança, confiabilidade e vida útil de todo o sistema. As mangueiras protegem o sistema de vibrações ou impactos $e$ são usadas para transferir energia em todos os segmentos da indústria. Em relação a vazamentos que podem ocorrer por meio das mangueiras, tem-se uma grande preocupação com vazamentos de óleos em alto mar. Nesse sentido, o presente artigo tem como objetivos mitigar as falhas em mangueiras hidráulicas e analisá-las em veículos ROV por meio de duas ferramentas da qualidade: o ciclo PDCA (planejar-fazer-checar-agir) e diagrama de causa e efeito.

Palavras-chave: Mangueira Hidráulica. Veículo Remotamente Operado. Diagrama de causa e efeito. PDCA.
\end{abstract}

\begin{abstract}
In a hydraulic system, among several components, hydraulic hoses stand out for their relevance in view of the safety, reliability and service life of the entire system. The hoses protect the system from vibrations or impacts and are used to transfer energy in all segments of the industry. In relation to leaks that can occur through the hoses, there is a great concern about oil leaks in the high seas. In this sense, the present article aims to mitigate the failures in hydraulic hoses and analyze them in ROV vehicles through two quality tools: the PDCA cycle (plan-do-check-act) and cause and effect diagram.
\end{abstract}

Keywords: Hydraulic hose. Remotely Operated Vehicle. Cause and Effect Diagram. PDCA.

\section{INTRODUÇÃO}

Num sistema hidráulico, entre diversos componentes, as mangueiras hidráulicas se destacam pela sua relevância em vista da segurança, confiabilidade e vida útil de todo o sistema. A partir disso, estudos para testes nas mangueiras a fim de analisar o impulso de alta pressão e de alta temperatura que atendam a requisitos experimentais vêm sendo publicados desde 1976, porém a análise dos dados experimentais é escassa (LV E XING, 2020).

As mangueiras protegem o sistema de vibrações ou impactos e são usadas para transferir energia em todos os segmentos da indústria como componentes, automóveis e aviões. Esta proteção desempenhada pode resultar em falhas, vazamentos, arrancamento das juntas, fratura do cabo e ruptura da mangueira que para ser evitado é preciso suportar uma ampla faixa de temperaturas e pressões. Um aspecto primordial para garantir a qualidade diz respeito a metalurgia e ao revestimento do acoplamento, que são altamente negligenciados (LEE et al., 2010; DEANS, 2011).

Em relação a vazamentos que podem ocorrer por meio das mangueiras, tem-se uma grande preocupação com vazamentos de óleos em alto mar. À medida que o uso da perfuração e as profundidades em alto mar se expandem, é relevante o desenvolvimento de abordagens a fim de evitar como também medir com rapidez e precisão as taxas de vazamentos de petróleo (SHAFFER et al., 2015).

A causa de defeitos nas mangueiras bem como as consequências da falha é um dos assuntos mais estudados no segmento (FEDORKO, et al., 2015). Sendo assim, o presente artigo se concentra em vazamentos ocasionados por falhas em mangueiras hidráulicas utilizados por Veículo Remotamente Operado (ROV). Os ROV's têm como função auxiliar na exploração de petróleo, nas atividades de prospecção petrolífera em profundidades que o ser humano não suporta realizar em alto mar e outras diversas intervenções. Os ROVs são veículos operados debaixo d'água e controlados por uma superfície, são conectados a uma plataforma por um cabo que fornece energia e controle de comunicação. Os ROV's são utilizados em várias fases de operação e são classificados em: veículos somente de observação, observação e transporte de pequenas cargas, intervenção e tratores submarinos de cabos de linha (FERREIRA, 2008).

Nesse sentido, o presente artigo tem como objetivos mitigar as falhas em mangueiras hidráulicas e analisá-las em veículos ROV por meio de duas ferramentas da qualidade: o ciclo PDCA (planejar-fazer-checar-agir) e diagrama de causa e efeito. Classifica-se como um estudo de caso amparado por pesquisa bibliográfica, observações em campo e pesquisa documental em procedimentos técnicos.

\section{METODOLOGIA}

A pesquisa pode ser denominada quantitativa e qualitativa, quanto à natureza das variáveis e descritiva quanto aos seus objetivos (GIL, 2008, p. 175). O presente 
artigo caracteriza-se como estudo de caso, essa metodologia permite a sua utilização em muitos cenários fenomológicos, pode assim contribuir para os fenômenos individuais, organizacionais, sociais, políticos e de grupo, além de outros fenômenos relacionados (YIN, 2005, p. 32).

O levantamento do material bibliográfico foi realizado para aprofundar o conhecimento do fenômeno estudado para sustentar as argumentações que são necessárias para a escrita do presente trabalho. O levantamento bibliográfico foi realizado em artigos científicos, normas técnicas e pesquisa documental. No que diz respeito aos dois assuntos do artigo ("Rovs" e "Mangueiras Hidráulicas"), foram encontrados somente dois artigos que os abordava como tema principal (SCOPUS, 2020, p. 1). Como exibido na revisão de literatura, o primeiro artigo foi publicado em 1986 e o segundo em 2016, com isso é constatado sua relevância para a sociedade científica desde a década de 1980 , porém foram publicados pouquíssimos estudos no segmento.

\section{RESULTADOS}

\section{$3.1-R O V s$}

Para auxiliar na exploração de petróleo, nas atividades de prospecção petrolífera em profundidades que o ser humano não suporta realizar e outras diversas intervenções é utilizado um equipamento chamado Veículo Remotamente Operado (ROV) (FERREIRA, 2008). Os ROVs são veículos operados debaixo d'água e controlados por uma superfície. Todos os tipos de ROVs são conectados a uma plataforma por um cabo que fornece energia e controle de comunicação. Em 1975, o primeiro veículo comercial foi construído para a indústria de petróleo offshore. Desde deste período, mais de $90 \%$ dos ROVs produzidos foram desenvolvidos para este segmento, que incluem suporte à perfuração de petróleo, inspeção e reparo de cabos (SHEPHERD, 2001).

Os ROVs são utilizados em várias fases de operação e são classificados em: veículos somente de observação (Figura 1a), observação e transporte de pequenas cargas (Figura 1b), intervenção (Figura 1c) e tratores submarinos de cabos de linha (FERREIRA, 2008).

Figura 1 - a) ROV de observação; b) ROV de observação e transporte; c) ROV de intervenção
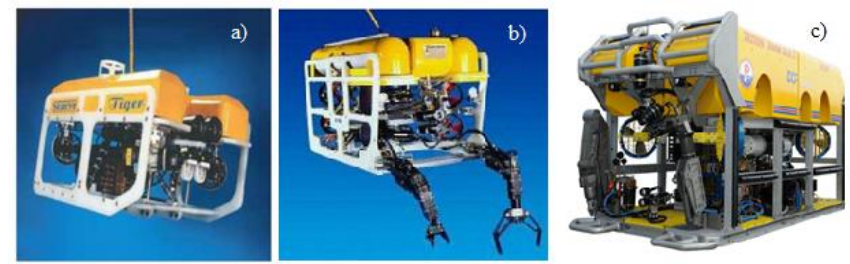

Fonte: Ferreira, 2008.

Os braços manipuladores são responsáveis pelas trocas e operações de válvulas, colocação ou remoção de cordas e correntes, limpeza e observação das estruturas, acionamento e recuperação dos equipamentos sendo de grande importância para as operações no fundo do mar. As principais atividades dos ROVs são: observação, survey de linhas, inspeção de estruturas, procura de vazamentos, inspeção do poço, posicionamento de unidades, manipulação de ganchos e manilhas (FERREIRA, 2008).

Num sistema de ROV é abordado vários fatores, incluindo custo, tamanho, recursos/plataforma de implantação e requisitos operacionais. Em relação aos requisitos operacionais, o ambiente ideal para a operação do equipamento é água limpa, mar calmo e sem corrente (movimento horizontal da água). Para concluir uma tarefa subaquática com êxito, é necessário garantir que os fatores que afetam o resultado da operação sejam cronometrados de maneira a mitigar seus efeitos, é relevante planejar a operação para o início durante os períodos onde a corrente é mínima, pois a hidrodinâmica da água que flui sobre uma estrutura subaquática pode ter consequências dramáticas no sucesso da operação. Além disso, um entendimento da dinâmica do fluxo de água sobre rios e lagos também é relevante. Em geral, quanto mais profunda a água no ambiente oceânico, menor a corrente (CHRIST; WERNLI, 2014).

Para fins de classificação dos procedimentos, os sistemas são divididos em categorias menores para facilitar a atribuição de procedimentos. Os sistemas mais potentes permitem maior deslocamento de distância por meio das correntes maiores. Nos sistemas de ROV na categoria de classe de observação existem três categorias gerais com base em seus respectivos tamanhos, capacidades, peso e potência de propulsão direta disponíveis. As atribuições são: Pequeno (peso submerso menor que $5 \mathrm{~kg}$ com saída do propulsor dianteiro menor que $5 \mathrm{~kg}$ ); Médio (peso submerso entre 5 e $32 \mathrm{~kg}$ com saída do propulsor dianteiro 5 e $9 \mathrm{~kg}$ ) e Grande (peso submersível acima de $32 \mathrm{~kg}$ e/ou com saída do propulsor para frente maior que $9 \mathrm{~kg}$ (CHRIST; WERNLI, 2014).

\section{2 - Mangueiras hidráulicas}

A mangueira hidráulica consiste em tubulações que funcionam para transportar fluido entre o reservatório, a bomba, a válvula hidráulica e o cilindro hidráulico no sistema de energia de fluidos e geralmente consiste em pelo menos três partes: um tubo interno que transporta o fluido, uma camada de reforço e uma camada externa de proteção. Salienta-se que o tubo interno deve ter flexibilidade e precisa ser compatível com o tipo de fluido que transportará. Estes tubos comumente usados incluem borracha sintética, termoplásticos, bem como também de Teflon. A camada de reforço consiste em uma ou mais bainhas de fio trançado, fio enrolado em espiral ou fio têxtil. A camada externa geralmente é resistente a intempéries, óleo ou abrasão, dependendo do tipo de ambiente para o qual a mangueira foi projetada. Na Figura 2 é mostrado um exemplo de mangueira que deve ser usada com fluidos hidráulicos à base de petróleo e água (UMANI et al., 2019; HYDRAULICS \& PNEUMATICS, 2012).

Figura 2 - Exemplo de mangueira usada com fluidos hidráulicos à base de petróleo e água

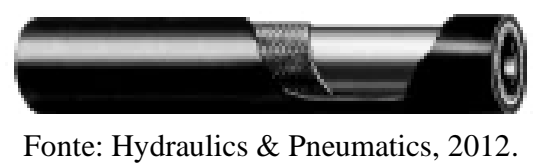

É comentado sete etapas recomendadas pelo projetista do sistema hidráulico durante o processo de seleção de mangueiras e acoplamentos, que são: tamanho (tamanho adequado, medir os diâmetros interno e externo), temperatura (classificação de temperatura máxima de trabalho), aplicação (atender aos requisitos de raio de curvatura), materiais (consultar tabela para verificar se o composto do tubo é compatível com o fluido usado), 
recursos de pressão (a pressão de trabalho da mangueira deve ser maior ou igual à pressão máxima do sistema), extremidades da mangueira (interface mecânica do acoplamento deve ser compatível) e entrega (disponibilidade do produto) (HYDRAULICS \& PNEUMATICS, 2012).

\section{3 - Falhas em Mangueiras Hidráulicas}

As condições de operação, temperatura de trabalho, condições do ambiente de instalação e procedimentos de manutenção que definem a vida útil das mangueiras hidráulicas. É indicado por estudo realizado por fabricantes de fluidos as duas causas mais comuns de falhas em mangueiras hidráulicas: o mau uso e a canalização imprópria. É comentado que pode ser reduzido, ou até mesmo eliminado as falhas prematuras se a seleção e instalação do conjunto se tornar prioridade (DOF, 2019). Na Figura 3 é mostrado os principais tipos de falhas, causa das falhas e recomendações para evitá-las.

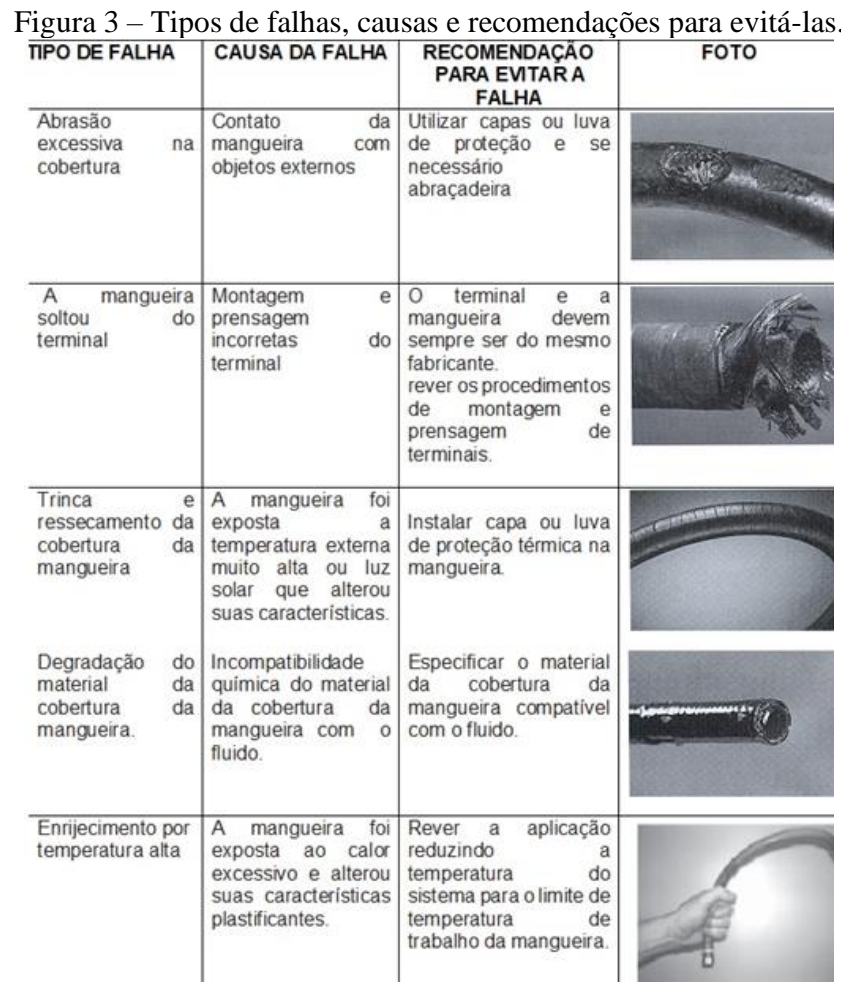

Fonte: Dof, 2019.

Como pode ser observado na Figura 3 , medidas de prevenção simples como a utilização de capas, revisão de procedimentos de montagem, especificar o material da cobertura correto para ser compatível com o fluido e a redução da temperatura do sistema podem mitigar de forma significativa as falhas nas mangueiras.

Estudos publicados apontam também para a análise de material alternativo, como o elastômero fluorado, para fabricação de mangueiras hidráulicas em camadas a fim de mitigar falhas (DRUMOND, PASQUALINO; COSTA, 2016; LEGALLAIS et al. 1993).

\section{4 - Aplicação}

Em relação ao ciclo PDCA, na fase planejar, foi criada uma meta de reduzir a falha em mangueiras hidráulicas dos ROVs. O segundo passo consiste em determinar as causas do problema a partir da montagem do diagrama de causaefeito ou "espinha de peixe". Na etapa definição de causa- efeito, o efeito é um problema e no presente estudo é a falha nas mangueiras hidráulicas.

$\mathrm{Na}$ geração de ideias, o Brainstorming, a equipe gera muitas ideias e discutem por meio de reuniões. No estudo de caso foi realizado uma série de reuniões com a equipe técnica para o Brainstorming. A etapa de identificação da principal categoria é baseada na lista de ideias, que não podem ultrapassar sete. No estudo de caso o diagrama de causa e efeito ficou com seis categorias, sendo: mão de obra, processo, equipamento, materiais, meio ambiente e método. Em seguida, é feita a avaliação das ideais que pode conter a explanação. Na etapa de projeção da folha para a coleta de dados registra-se em uma folha de coleta de dados as informações (MARIANI, 2005).

Depois de levantadas as possíveis causa por meio do Brainstorming, foi apresentado o Diagrama de Ishikawa com as possíveis causas identificadas do problema (Figura $3)$.

Na Figura 4 é possível observar que as causas baseiamse em falta de informação, falta de qualificação e treinamento em relação a mão de obra; especificação técnica realizada, fornecedor desconhece características de aplicação do material e falta de seguimento de procedimentos de normas em relação ao processo; falhas das mangueiras proporcionando paradas de equipamento, falhas com vazamentos de óleo e falhas ocasionando riscos de acidentes pessoais em relação a equipamento; especificação incorreta do material, material fora das especificações e armazenamento incorreto em relação a materiais; falta de espaço para armazenar material, material armazenado em condições inadequadas em relação ao meio ambiente e faltas de procedimento para especificação e aquisição de mangueiras hidráulicas e falta de procedimento para execução de manutenção em relação a método.

Figura 4 - Diagrama de causa e efeito.

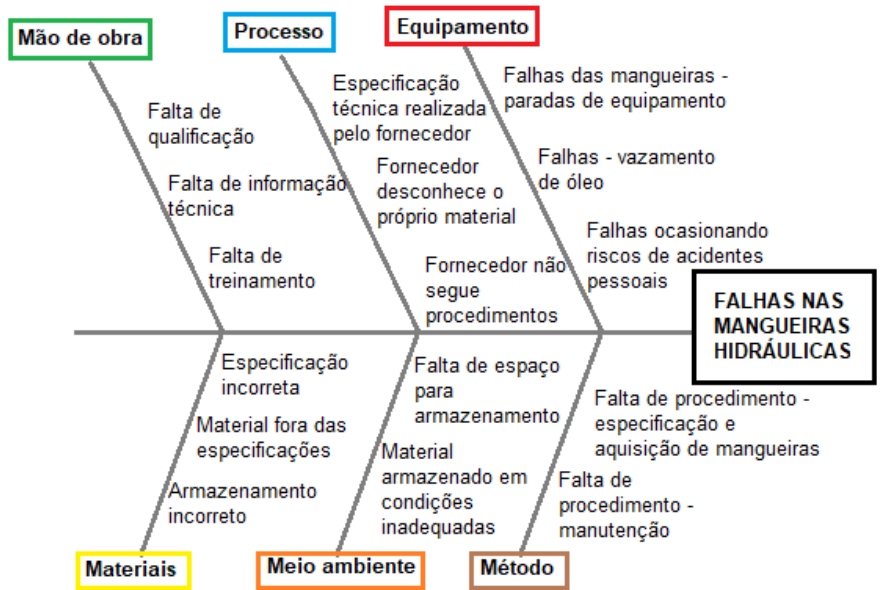

Fonte: Lins, 1993.

Diante das causas apontadas pelo diagrama elabora-se um plano de ação para atuar na solução do problema (Figura 5). Após a elaboração do plano de ação, é iniciada a segunda fase do ciclo, a fase "Fazer" consiste em cumprir as ações propostas no plano de ação. 


\begin{tabular}{|c|c|c|c|c|c|}
\hline PROBLEMA & OQUÉ? & QUEM? & COMO? & QUANDO? & STATUS \\
\hline \multirow[t]{4}{*}{$\begin{array}{l}\text { Falhas em } \\
\text { mangueiras } \\
\text { hidráulicas }\end{array}$} & $\begin{array}{l}\text { Falta de } \\
\text { procedime } \\
\text { nto técnico } \\
\text { para } \\
\text { especificaç } \\
\text { ão e } \\
\text { aquisição } \\
\text { de } \\
\text { mangueira } \\
\text { s }\end{array}$ & $\begin{array}{l}\text { Coordenador } \\
\text { técnico }\end{array}$ & $\begin{array}{l}\text { Criar } \\
\text { procediment } \\
0 \quad \text { técnico } \\
\text { para } \\
\text { aquisição e e } \\
\text { especificaçã } \\
0 \quad \text { de } \\
\text { mangueiras } \\
\text { hidráulicas } \\
\text { baseados } \\
\text { em normas } \\
\text { técnicas }\end{array}$ & set $/ 19$ & $\begin{array}{l}\text { Norma } \\
\text { técnica } \\
\text { adquirida e } \\
\text { equipe } \\
\text { criando a } \\
\text { especificaç } \\
\text { ão técnica }\end{array}$ \\
\hline & $\begin{array}{l}\text { Falta de } \\
\text { procedime } \\
\text { nto técnico } \\
\text { para } \\
\text { execução } \\
\text { da } \\
\text { manutençã } \\
\text { o de de } \\
\text { mangueira } \\
\mathrm{s} \\
\text { hidráulicas }\end{array}$ & $\begin{array}{l}\text { Coordenador } \\
\text { técnico }\end{array}$ & $\begin{array}{l}\text { Criar } \\
\text { procediment } \\
\text { o técnico } \\
\text { para } \\
\text { execução } \\
\text { da } \\
\text { manutenção } \\
\text { de } \\
\text { mangueiras } \\
\text { hidráulicas }\end{array}$ & out/19 & $\begin{array}{l}\text { Norma } \\
\text { técnica } \\
\text { adquirida e } \\
\text { equipe } \\
\text { elaborand } \\
\text { o } \\
\text { procedime } \\
\text { nto }\end{array}$ \\
\hline & $\begin{array}{l}\text { Armazena } \\
\text { mento } \\
\text { incorreto } \\
\text { das } \\
\text { mangueira } \\
\text { s } \\
\text { hidráulicas } \\
\text { na base e } \\
\text { no barco }\end{array}$ & $\begin{array}{l}\text { Coordenador } \\
\text { técnico }\end{array}$ & $\begin{array}{l}\text { A partir da } \\
\text { norma criar } \\
\text { procediment } \\
\text { os corretos } \\
\text { de } \\
\text { armazenam } \\
\text { ento das } \\
\text { mangueiras } \\
\text { hidráulicas } \\
\text { na base eno } \\
\text { barco }\end{array}$ & out/19 & $\begin{array}{l}\text { Norma } \\
\text { técnica } \\
\text { adquirida e } \\
\text { equipe } \\
\text { elaborand } \\
\text { o } \\
\text { procedime } \\
\text { nto }\end{array}$ \\
\hline & $\begin{array}{l}\text { Mangueira } \\
\text { s } \\
\text { hidráulicas } \\
\text { fora das } \\
\text { especificaç } \\
\text { őes } \\
\text { normalizad } \\
\text { as }\end{array}$ & $\begin{array}{l}\text { Gerente de } \\
\text { suprimentos }\end{array}$ & $\begin{array}{l}\text { Trocar de } \\
\text { fornecedor }\end{array}$ & dez/19 & $\begin{array}{l}\text { Em } \\
\text { licitação } \\
\text { para } \\
\text { escolha de } \\
\text { novo } \\
\text { fornecedor } \\
\text { de } \\
\text { mangueira } \\
\text { s } \\
\text { hidráulicas }\end{array}$ \\
\hline
\end{tabular}

Fonte: Autores, 2020.

Em consequência as fases especificas pelo ciclo PDCA, a terceira fase caracteriza-se pela checagem do plano de ação, verifica-se a eficácia das ações tomadas por meio da comparação de dados. Sendo o objetivo a mitigação de falhas em mangueiras hidráulicas, é verificado que o plano de ação diminui o índice em pelo menos $18 \%$. E por fim, a última fase do ciclo se caracteriza por agir, em que o plano de ação se torna o procedimento padrão da empresa, prevenindo contra o reaparecimento do problema.

\section{CONCLUSÃO}

Devido as grandes expansões das operações com ROVs e da importância de sua confiabilidade, os equipamentos precisam estar com a manutenção correta para que não ocorram falhas ou vazamentos de óleo no mar que ocasionem paradas de equipamento ou multas ambientais.

O presente artigo contribuiu para a mitigação de falhas em mangueiras hidráulicas e para analisar as falhas em veículos ROV por meio de duas ferramentas da qualidade: o ciclo PDCA (planejar-fazer-checar-agir) e diagrama de causa e efeito. Com a obtenção dos resultados foi possível inferir que os objetivos formulados foram atingidos com a elaboração do plano de ação e também se verifica a eficácia das ações tomadas por meio da comparação de dados. Sendo o primeiro objetivo a mitigação de falhas em mangueiras hidráulicas, é verificado que o plano de ação diminui o índice em pelo menos $18 \%$.

No diagrama de causa e efeito foi realizado análises de todo o processo desde a compra do material com seu fornecedor, seu armazenamento, sua aplicação e manutenção. Observou-se falhas em todos os pontos e essas foram passadas para o plano de ação.

E por fim, com o desenvolvimento do estudo de caso e da pesquisa bibliográfica, é constatado que a metodologia proposta é considerada confiável e fornece uma referência abrangente e útil para a mitigação de falhas em mangueiras hidráulicas.

\section{REFERÊNCIAS BIBLIOGRÁFICAS}

CAMERON, G. M. Using an ROV for Simultaneous Lay and Burial of Subsea Umbilicals. In: ROV '86: Remotely Operated Vehicles. Springer, 1986.

CARPINETTI, L. C. R.; MIGUEL, P. A. C.; GEROLAMO, M. C. Gestão da qualidade ISO 9001: 2008: princípios e requisitos. 5. ed. São Paulo: Atlas, 2011.

CARVAlHO, M. M.; PALADINI, E.P. (Org.) Gestão da Qualidade: Teoria e Casos. Rio de Janeiro: Editora Campus, 2012.

CHRIST, R. D.; WERNLI, R. L. Chapter 21 - Practical Applications, The ROV Manual, Butterworth-Heinemann. 2014.

DEANS, T. How materials impact hose-connector performance. Machinedesign, 2011.

DOF, S. Procedimento - Utilização/ Inspeção/ Análise de Falha de Mangueiras e Conexões Hidráulicas. 2019.

DRUMOND, G. P; PASQUALINO, I. P; COSTA, M. F. Study of an alternative material to manufacture layered hydraulic hoses. Polymer Testing, p. 29 - 39, 2016.

FEDORKO, G; MOLNAR, V; DOVICA, M; TOTH, T; FABIANOVA, J. Failure analysis of irreversible changes in the construction of the damaged rubber hoses. Engineering Failure Analysis, p. 31 - 43, 2015.

FERREIRA, Arlen Wanderson Landim. Veículo Remotamente Operado (ROV): A Importância da Aplicação de sua Tecnologia na Produção Petrolífera. 2008. Trabalho de Conclusão de Curso. Centro Federal de Educação Tecnológica de Campos, 2008.

FORNARI, C. C. M. J. Aplicação da Ferramenta da Qualidade (Diagrama de Ishikawa) e do PDCA no Desenvolvimento de Pesquisa para a reutilização dos Resíduos Sólidos de Coco Verde. INGEPRO - Inovação, Gestão e Produção, 2010.

GIL, A. C. Métodos e Técnicas de Pesquisa Social. 6.ed. São Paulo: Atlas, 2008.

HYDRAULICS \& PNEUMATICS. Engineering Essentials: Types of Hydraulic Hose. 2012. Disponível em: $<$ https://www.hydraulicspneumatics.com/technologies/hosetubing/article/21884159/engineering-essentials-types-ofhydraulic-hose>. Acesso em: 2 mar. 2020.

LEE, G; HYOUNG-EUI, K; YOU-HEE, C; JAE-HOON, K. A Study of Life Characteristic of Hydraulic Hose Assembly by Adopting Complex Accelerated Model with Acceleration Factors of Pressure and Temperature. Transactions of the Korean Society of Mechanical Engineers. p. 1697-1703, 2010. 
LEGALLAIS, L; STRATFOLD, M; HARDY, J. A new generation of umbilical hoses. In: Offshore Technology Conference. Offshore Technology Conference, 1993.

LINS, B. F. E. Ferramentas básicas da qualidade. Ci. Inf., Brasília, 1993.

LV, Y; XING, K. Life Expectancy and Its Reliability Analysis of Hydraulic Hose Based on Impulse Test. Springer Nature Singapore, p. 1540 -1546, 2020.

MARIANI, C. A. Método PDCA e ferramentas da qualidade no gerenciamento de processos industriais - um estudo de caso. RAI- Revista de Administração e Inovação, São Paulo, p. 110-126, 2005.

MIRANDA, M. A. Um Modelo de otimização inteira mista na programação de produção de mangueiras hidráulicas. 2015. 68 f. Trabalho de conclusão de curso (Bacharelado Engenharia Mecânica) - Universidade Estadual Paulista, Faculdade de Engenharia de Guaratinguetá, 2015.

SCOPUS. Base de dados Elsevier. Disponível em: <https://www.scopus.com/home.uri>. Acesso em: 2 de mar. 2020.

SHAFFER, F; SAVAŞ, O; LEE, K; DE VERA, G. Determining the discharge rate from a submerged oil leak jet using ROV video. Flow Measurement and Instrumentation. p. $34-46,2015$.

SHEPHERD, k. Remotely Operated Vehicles (ROVs), Encyclopedia of Ocean Sciences (Second Edition), Academic Press. p. 742-747, 2001.

SLOCUM, A; GUTIERREZ, L. An ROV Operated Undersea Hydraulic Hose Repair Coupling. Precision Engineering, 2015.

UMANI, K. C.; FAKAYODE, O. A.; ITUEN, E. U.U.; OKOKON, F. B. Development and testing of an automated contact plate unit for a cassava grater. Computers and Electronics in Agriculture, v. 157, p. 530-540, 2019.

YIN, R. Estudo de caso. Planejamento e Métodos. Porto Alegre: Bookman, 2005.

\section{COPYRIGHT}

Direitos autorais: Os autores são os únicos responsáveis pelo material incluído no artigo. 


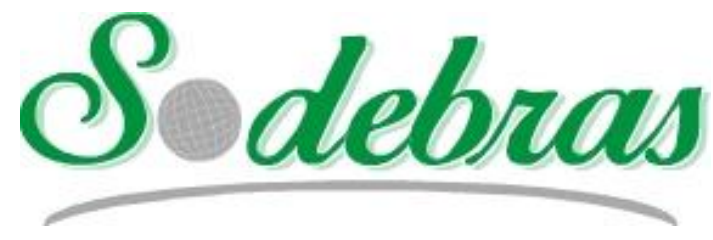

\author{
Volume 16 - No 174 - Junho / 2020 \\ XLII International Sodebras Congress \\ 28 a 30 de maio de 2020 - Web Conference.
}

\title{
AUTOMATIZAÇÃO DE UMA BANCADA DE CALIBRAÇÃO DE MEDIDORES DE VAZÃO DE LÍQUIDOS AUTOMATION OF A LIQUID FLOW METER CALIBRATION SYSTEM IDRISSA DEME \\ UNIVERSIDADE DO ESTADO DO RIO DE JANEIRO (UERJ) idrissdeme@yahoo.fr
}

\begin{abstract}
Resumo - O presente trabalho tem como objetivo principal a automatização do sistema calibração de medidores de vazão de líquidos da Divisão de Metrologia em Dinâmica de Fluidos (Dinam) do Instituto Nacional em Metrologia Qualidade $e$ Tecnologia (Inmetro), que é baseado no método gravimétrico e inicialmente era totalmente operado manualmente. Para isso foi preciso especificar e dimensionar os instrumentos de medição $e$ atuadores e integrar as diferentes partes do sistema usados nas medições $e$ desenvolver procedimentos de operação. A automatização e consistiu na aquisição de dados de forma automática de alguns instrumentos e no controle de outros usando o software LabVIEW (Laboratory Virtual Instrument Engineering Workbench). Um programa foi desenvolvido neste ambiente com uma interface de usuário que corresponde às diferentes fases do processo de calibração incluindo a transferência automática dos dados para planilha Excel. Foram realizadas calibrações testes com um medidor de deslocamento positivo a fim de avaliar o funcionamento do sistema
\end{abstract}

Palavras-chave: Automatização. Calibração. Medidor de vazão.

\begin{abstract}
This main objective of this work is to present the automation process of the calibration system of liquid flow meters of the Metrology Division in Fluid Dynamics (Dinam) of the National Institute for Metrology Quality and Technology (Inmetro), which is based on the gravimetric method and was initially fully manually operated. For that, it was necessary to specify and dimension the measuring instruments and actuators and integrate the different parts of the system used in the measurements and develop operating procedures. Automation consisted of automatically acquiring data from some instruments and controlling others using LabVIEW® software (Laboratory Virtual Instrument Engineering Workbench). A program was developed in this environment with a user interface that corresponds to the different phases of the calibration process including the automatic transfer of data to an Excel spreadsheet. Calibrations tests were performed with a positive displacement meter in order to evaluate the operation of the system.
\end{abstract}

Keywords: Automation. Calibration. Flow meter.

\section{INTRODUÇÃO}

A dinâmica dos fluidos é o campo da física que trata do movimento dos líquidos e gases e dos efeitos causados por este movimento ou a ele associados (Ryhming, 2004), e se encontra em variadas aplicações, tais como no campo da aeronáutica, da energia eólica e hidráulica, dos oleodutos e gasodutos, dos sistemas de ar-condicionado, dos serviços meteorológicos, farmacêuticos, dentre muitas outras. É centro de atenções desde a antiguidade, especialmente, a vazão de líquidos. A vazão de líquido é o objeto da presente pesquisa.

A vazão é definida como a quantidade de líquido que atravessa uma seção por unidade de tempo. Vale ressaltar que foi a partir do século $\mathrm{XX}$, que a necessidade de se medir a vazão dos fluidos, em geral adquiriu proporção e sofisticação realmente elevadas (DELMÉ,2003).

Ficou muito comum em procedimentos industriais a necessidade de medição e de controle da quantidade de líquidos e gases em decorrência do uso de processos contínuos. A vazão se tornou assim uma das grandezas mais medidas nos processos industriais, juntamente com as grandezas temperatura e pressão (Frenzel et al., 2011).

As aplicações são muitas, indo desde as mais simples, tal como a medição de vazão de água em estações de tratamento e residências, até medição em aplicações médicas, gases industriais e combustíveis (Cassiolato e Alves,2008). Suas múltiplas aplicações exigem que os valores medidos sejam confiáveis. Sendo assim, as normas nacionais e internacionais, como a serie ISO-5167 (Associação Brasileira de Normas Técnicas, 2003), baseadas em requisitos técnicos metrológicos cada vez mais específicos e exigentes foram estabelecidas para regular a qualidade da produção, como também para fins contábeis e fiscais, já que a questão tem tomado proporções importantes no comércio internacional (Delmé,2003).

A calibração de medidores de vazão de líquidos permite assegurar a confiabilidade desses instrumentos de medição, por meio da comparação do valor medido com um padrão rastreado ao Sistema Internacional de Unidades (SI) (Bergman, 2011). A calibração é uma etapa essencial em qualquer operação de medição e controle, pois um instrumento não calibrado é um dispositivo no qual não se pode confiar. Deste modo, o resultado de uma calibração é a garantia de que um instrumento responde às exigências de precisão e faixa de operação para ser utilizado no propósito pretendido. (Gerard, N, et al., 2017). Os instrumentos calibrados permitem também ao fabricante ou o processador produzir mercadorias de qualidade, já que as medições são confiáveis e os limites de incertezas e erros são conhecidos. (Soisson,2002).

Diante deste cenário a eficiência, agilidade, a redução do tempo e controle dos processos de calibração tornam-se fundamentais para o uso dos medidores de vazão. A preocupação pela questão da automatização dos sistemas de calibração dos medidores de vazão de líquidos é perceptível nos trabalhos de vários Institutos Nacionais de Metrologia. O Physikalisch Technische Bundesanstalt (PTB) no seu projeto de concepção e elaboração do sistema de pesagem de alta precisão, por gravimetria, e referência na padronização nacional da vazão de água, incluiu a automatização de vários aspectos do processo de calibração como a aquisição dos dados (balanças e condições ambientais), o acionamento de algumas partes do sistema 
(bombas e algumas válvulas), o controle da temperatura da água e o acompanhamento do efeito das vibrações causadas no ambiente pelas bombas. (Rainer E. et al.,2012)

O destaque para o uso de sistema de medição gravimétrico automatizado é também perceptível na comparação Inter laboratorial feita entre o PTB e o Bureau National de Metrologie-LaboratoireNational d'Essais (BNM-LNE). Nesta comparação, usaram sistemas de calibração gravimétricas com acionamento, controle de válvulas e aquisição de dados automatizadas. Porém, neste caso, se tratava de sistemas de calibração de medidores de vazão de gases. (Knopf, D. et al., 2001)

O sistema de de calibração de medidores de vazão de líquido do instituto de nacional de metrologia do Japão baseada no método gravimétrico foi automatizado parcialmente no seu desviador de fluxo a fim de possibilitar o uso de mais dois líquidos de trabalho. Os líquidos de trabalho originais eram querosene e óleo leve. A instalação de calibração foi modificada para calibrar os medidores de vazão com dois líquidos de trabalho adicionais, gasolina industrial e óleo de motor, possibilitando assim uma ampla faixa de viscosidade no mesmo sistema de calibração. (Cheong K-H, 2017)

O presente trabalho apresenta um processo que busca solucionar essa problemática através da automatização de um sistema de calibração de medidores de vazão. O sistema automatizado é a bancada de calibração de medidores de vazão de líquidos do Instituto Nacional em Metrologia Qualidade e Tecnologia (Inmetro), que é baseado no método gravimétrico e inicialmente era totalmente operado manualmente.

A metodologia adotada, os principais resultados obtidos e as conclusões são apresentados nas linhas a seguir.

\section{METODOLOGIA}

Foram realizados testes experimentais em paralela á pesquisa bibliográfica, com os quais se espera proporcionar ao sistema da Dinam o processo de funcionamento automatizado. Assim, o acionamento e desligamento das bombas, a aquisição e registros do dados das balanças como os do meio ambiente e o cálculos dos parâmetro necessários á calibração foram automatizados, em conformidade com o procedimento seguido por pelos outros institutos de Nacionais de Metrologia (INM) que realizaram a automatização de seus sistemas de calibração. (Kar-Hooi et al.,2018) Um programa foi desenvolvido e Labview para integrar e sincronizar todo o processo. Para avaliar o funcionamento do sistema automatizado, 18 corridas em 3 faixas de vazão foram realizados com o medidor de deslocamento positivo OI.

A figural abaixo mostra o diagrama de blocos que descreve o funcionamento do sistema.
Figura 1: Funcionamento do sistema de calibração

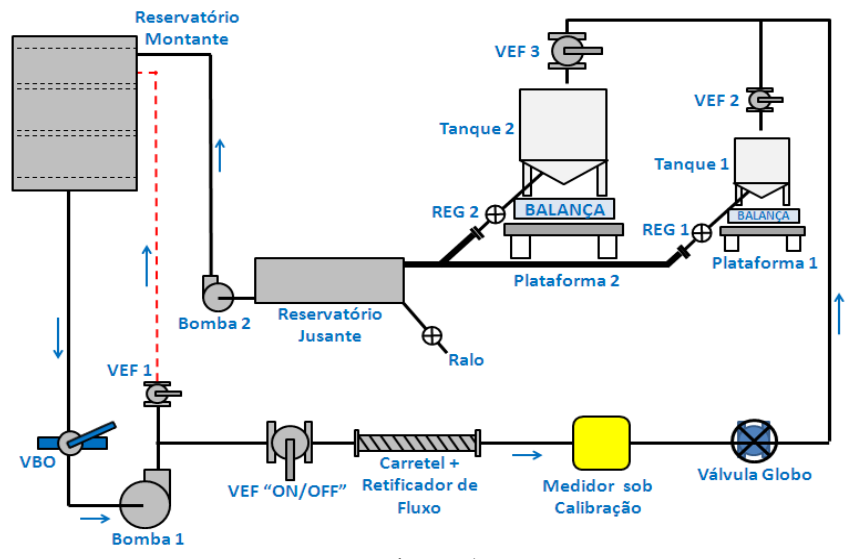

Fonte: Dinam/Inmetro

Foram realizadas as seguintes alterações no processo de controle e automatização da bancada de calibração do INMETRO:

- O processo de aquisição, registro e transferência em planilha dos valores de temperatura foi automatizado e ampliado para até oito (8) pontos.

- o processo de aquisição de dados das balanças das duas balanças do sistema foi também automatizado

- o controle da reinicialização das balanças a partir do computador também foi realizado.

- a aquisição de dados dos medidores: como o medidor sob calibração normalmente é do cliente, e com a variedade de medidores que existem no mercado optou-se em ler os dados dos medidores com câmera. Isso além de facilitar a leitura, fará com que qualquer medidor possa ter seus dados lidos durante o processo de calibração. Um código no Labview permite ao usuário ver esses dados no mesmo ambiente que os doutro dados. Como os dados do medidor são necessários só no início e no final do processo de calibração, uma opção para usuário digitar o valor no display foi acrescentada durante a integração dos diversos programas.

- O controle das bombas: a bancada do INMETRO possui duas bombas hidráulicas. Uma bomba 1 que realiza a vazão na tubulação. Esta bomba possui um inversor que foi controlado usando equipamentos de conexão da National instruments e um programa no Labview. Isso permite controlar a vazão desejada na tubulação durante a calibração. A bomba 2 que serve para enviar o líquido para o reservatório foi controlada através de dois relês conectores associados a um módulo de controle da National Instruments.

-foram desenvolvidos outros programas para outros aspectos do processo de automatização como a leitura dos dados da estação meteorológica, que foi por câmera como para o medidor, e a transferência dos dados em planilhas préprontas para calcular os parâmetros importantes da calibração (como a incerteza).

Após essas montagens e o desenvolvimento dos programas no Labview para o controle ou o acionamento dos diferentes componentes da bancada, esses programas foram integrados em um único programa no labview com uma interface que permita o manuseio fácil da bancada. $\mathrm{O}$ painel frontal do programa possui no total, oito abas permitindo ao usuário se mover entre eles em função da ação que deseja realizar. Essas abas foram organizadas de forma a corresponder às etapas da calibração manual a fim 
de facilitar o entendimento para o usuário. Mas como os dados são transferidos diretamente para a planilha, a primeira aba foi dedicada a isso. As diferentes partes do programa são apresentadas, a partir da interface de usuário.

\section{RESULTADOS}

Os pontos alcançados pela automatização são resumidos na tabela1 abaixo. A figura 2 apresenta o painel frontal do programa com a diferentes abas para o controle do sistema e registro dos dados.

Tabela 1: Resumo dos pontos alcançados pela automatização

\begin{tabular}{|l|l|l|}
\hline \multicolumn{1}{|c|}{ Foco da automatização } & Modo de operação & \multicolumn{1}{|c|}{ Material usado } \\
\hline $\begin{array}{l}\text { Registro das temperaturas } \\
\text { de entrada e saída do } \\
\text { medidor e do ambiente }\end{array}$ & $\begin{array}{l}\text { Automatizado / } \\
\text { com possibilidade } \\
\text { de usar o manual }\end{array}$ & $\begin{array}{l}\text { Termopares } \\
\text { módulo NI 921l } \\
\text { Programa "dissertacão,vi" }\end{array}$ \\
\hline $\begin{array}{l}\text { Controle da bomba l para } \\
\text { controle da vazão a } \\
\text { montante }\end{array}$ & $\begin{array}{l}\text { Automatizado / } \\
\text { com possibilidade } \\
\text { de usar o manual }\end{array}$ & $\begin{array}{l}\text { Inversor cfw09 } \\
\text { módulo NI 9263 } \\
\text { Programa "dissertacão,vi" }\end{array}$ \\
\hline $\begin{array}{l}\text { Acionamento da bomba 2 } \\
\text { para reabastecimento do } \\
\text { reservatório }\end{array}$ & $\begin{array}{l}\text { Automatizado / } \\
\text { com possibilidade } \\
\text { de usar o manual }\end{array}$ & $\begin{array}{l}\text { Relês acopladores } \\
\text { módulo NI 9274 } \\
\text { Programa "dissertacão,vi" }\end{array}$ \\
\hline $\begin{array}{l}\text { Aquisição de dados do } \\
\text { medidor }\end{array}$ & $\begin{array}{l}\text { Automatizado / } \\
\text { com possibilidade } \\
\text { de usar o manual }\end{array}$ & $\begin{array}{l}\text { Câmera } \\
\text { Cabo USB NI } \\
\text { Programa "dissertacão,vi" }\end{array}$ \\
\hline $\begin{array}{l}\text { Aquisição dos dados } \\
\text { medidos pelas balanças }\end{array}$ & $\begin{array}{l}\text { Automatizado / } \\
\text { com possibilidade } \\
\text { de usar o manual }\end{array}$ & $\begin{array}{l}\text { Balanças 300 kg e 35 kg } \\
\text { (saídas RS-232 } \\
\text { Cabo RS-232 NI } \\
\text { Programa "dissertação.vi" } \\
\text { - }\end{array}$ \\
\hline Cronômetro & $\begin{array}{l}\text { Acionado pelo } \\
\text { usuario }\end{array}$ & Programa "dissertacão,vi" \\
\hline $\begin{array}{l}\text { Aquisição e tratamento de } \\
\text { dados com o Labxieux }\end{array}$ & $\begin{array}{l}\text { Automatizado / } \\
\text { com possibilidade } \\
\text { fazer manualmente }\end{array}$ & $\begin{array}{l}\text { Computador (planilha Excel) } \\
\text { Programa "dissertacão,vi" }\end{array}$ \\
\hline
\end{tabular}

Figura 2: Painel de controle e aquisição de dados

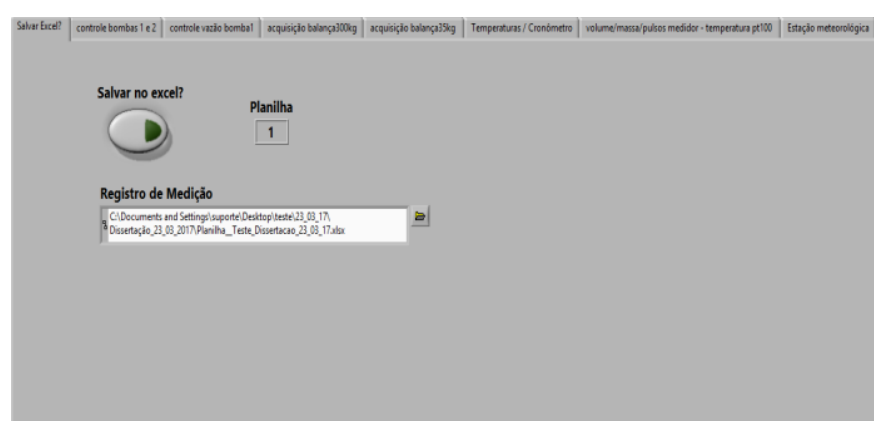

A figura 3 mostra os resultados da calibração do medidor de vazão de deslocamento tipo OI com e sem uso da bomba. Isso permitiu destacar a importância da automatização do controle da bomba no processo de calibração. O controle da bomba permite estabilizar a vazão nas faixas de vazão escolhidas, garantindo assim a calibração sem erros sistemáticos.
Figura 3: Efeito do controle da bomba na calibração

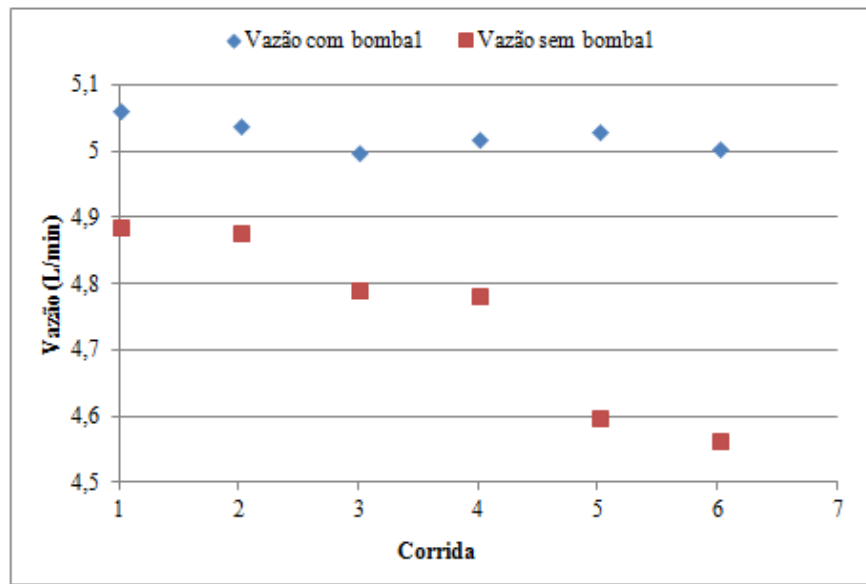

A tabela 2 mostra a consistência do sistema automatizado que possibilitou além da redução do número de operadores (de 3 para 1) e do tempo de calibração, a avaliação e melhor controle dos parâmetros que mais influenciam na calibração. São esses: a repetitividade, o volume totalizado pelo medidor de vazão e a massa totalizada na balança.

Tabela 2: Parâmetros mais influentes após teste de funcionamento

\begin{tabular}{|c|c|c|c|}
\hline \multirow{2}{*}{$\begin{array}{l}\text { Variáveis } \\
\text { de entrada } \\
(\boldsymbol{i})\end{array}$} & \multicolumn{3}{|c|}{ Vazão (L/min) } \\
\cline { 2 - 4 } & $\mathbf{3}$ & $\mathbf{1}$ & $\mathbf{1 0 0} \cdot \boldsymbol{c}_{\boldsymbol{i}} \cdot \boldsymbol{u}_{\boldsymbol{i}} / \mathbf{u}$ \\
\hline $\mathbf{\delta F}_{\mathrm{m}}$ & $15,10 \%$ & $59,04 \%$ & $\mathbf{1 0}$ \\
\hline $\mathbf{n}_{\mathrm{pm}}$ & $61,72 \%$ & $28,77 \%$ & $38,56 \%$ \\
\hline $\mathbf{M c}$ & $11,42 \%$ & $5,85 \%$ & $7,83 \%$ \\
\hline $\mathbf{M v}$ & $11,42 \%$ & $5,85 \%$ & $7,83 \%$ \\
\hline
\end{tabular}

A automatização do sistema possibilitou a redução efetiva do número de operadores necessários para os procedimentos de calibração. É possível realizar o processo com um operador, enquanto anteriormente precisava-se de dois a três operadores.

A aquisição de dados fundamentais para a calibração como os das balanças e da temperatura por serem realizados de forma automáticos não correm mais riscos de sofrer erros sistemáticos devidos a más anotações do operador agregando assim mais confiabilidade aos dados adquiridos.

O processo de aquisição de dados como um todo ficou mais ágil. Com as temperaturas e as balanças os valores são diretamente registrados na planilha. Para a vazão do medidor e os dados do higrômetro, o operador não precisa se movimentar para ter acesso a eles, pois já os tem na tela do computador através das câmeras. Basta digitar na aba correspondente da interface de usuário e salvar diretamente na planilha. $\mathrm{O}$ que constitui um ganho importante em tempo para o usuário, sendo que não é mais preciso anotar e depois digitar nenhum dado na planilha. $\mathrm{O}$ operador sai com seus dados registrados da forma e ordem que deseja.

O monitoramento contínuo da evolução das condições do fluido de trabalho e ambiental (temperatura, umidade), permite o refinamento dos resultados das medições e na determinação da influência desses fatores na qualidade dos resultados. Já com a temperatura do fluido, a automatização possibilitou a medição simultânea na linha de escoamento e 
nas balanças. A temperatura no medidor é assim melhor avaliada.

O acionamento das bombas a partir da mesa de controle evita que o operador tenha que se deslocar diversas vezes ou que seja preciso outro operador na busca da sincronização do acionamento de bomba com o início ou o final efetivo das medições. Com o sistema automatizado, um só operador pode fazer isso acionando as bombas e iniciando as medições que quer somente trocando de aba.

Com a integração dos programas, destacando as diferentes etapas da calibração, em um programa, fica mais fácil compreender o processo de calibração pela bancada. Isso facilitará a integração de operadores novos, que passaram a precisar de menos tempos de treinamento para realizar o procedimento de calibração com mais eficiência.

A automatização do sistema permite também realizar mais medições durante a calibração. Já que os dados são registrados em muito menos tempo que no registro manual, é possível realizar algumas medições a mais para ter resultados mais refinados.

Outro aspecto interessante é que a automatização além de melhorar o funcionamento do sistema não suprimiu os equipamentos de atuação manual. Assim, a bancada pode continuar funcionando com uma ou outra das opções, permitindo comparações diretas entre aspectos específicos dos dois procedimentos. Permite também que a bancada continue sendo operacional, mesmo que um ou outro elemento pare de funcionar. Uma disfunção na chave de acionamento manual da bomba1, por exemplo, não poderá mais ser motivo por não haver calibrações. Da mesma forma se algum elemento da automatização parar de funcionar, a parte manual pode ser acionada.

\section{CONCLUSÃO}

Redução do número de operadores e minimização do erro sistemático. Otimização do processo de aquisição e tratamento de dados com planilhas de cálculos prontas, bastando endereçar onde registrar os dados e obter os resultados no final da medição. Facilidade de realizar mais corridas melhorando a repetitividade e possibilidade de analisar de forma especifica o impacto de algumas variáveis de processo que não podem ser monitoradas de modo contínuo na operação manual...

\section{REFERÊNCIAS BIBLIOGRÁFICAS}

BERGMANN, G. Avaliação metrológico de sistemas de medição de vazão. Lajedo. 2011.

CÉSAR CASSIOLATO, E. O. A. Medição de Vazão.

Controle \& Instrumentação, n. 138, 2008.

ÇENGEL, Y. A.; CIMBALA, J. M. Mecânica dos fluidos: fundamentos e aplicações. São Paulo.: Mc Graw Hill, 2007.

CHEONG, K-H.; DOIHARA, R.; SHIMADA, T.; TERAO, $Y$. Development of a gravimetric system using a conical rotating double-wing diverter for low liquid flow rates, Flow Measurement and Instrumentation 56 1-13, 2017.

DELMÉ, G. J. MANUAL DE MEDIÇÃ̃ DE VAZÃO. $3^{a}$ EDIÇÃO. ed. [S.1.]: EDGARD BLÜCHER LTDA, 2003.
GERARD, N.; NIKOLA, P.; JIANRONG, L.; OLIVER, B.; KARINE, A.; KRISTER, S.; KURT, R.; JOHAN, K.; RÉMY, M.; MARKUS, R.; RAFAEL, L.; ALBERTO, P.; SIMONA, L.; ANDREW, B.; ARUL, M.; BJÖRN, G.; JORDAN, T.; PETER, E.; LENNART, K.; KAI, M.; ARNAS, L.; KIANOOSH, H., Metrology for LNG custody transfer and transport fuel applications, 18th International Congress of Metrology. Paris, 2017.

KAR-HOOI, C.; RYOUJI, D.; TAKASHI, S.; YOSHIYA, T., Static Gravimetric Method with Flying Start-andFinish using High Speed Switching Valves for Calibration of Low Liquid Flow, 10th Annual International Symposium on Fluid Flow Measurement (ISFM). Querétaro, Mexico, 2018.

KNOPF,D. ;BARBE, J.; RICHTER, W.; MARSCHAL, A., Comparison of the gas mass flow calibration systems of the BNM LNE and the PTB, Metrologia $N^{\circ} 38,2001$ p.197.

RAINER, E.; KARL HEINZ, B.; HANS-JOACHIM B. Design and realization of the high precision weighing systems as the gravimetric references in PTB's national water flow standard, Measurement. Science. Technology. $\mathrm{N}^{\mathrm{o}} 23,2012$.

RYHMING, I. L. Dynamique des fluides: um cours de base du deuxième cycle universitaire. Romande: Presse Polytechnique et Universitaire, 2004.

SOISSON, H. E. Instrumentação Industrial. Curitiba PR: Hemus, 2002.

\section{AGRADECIMENTOS}

Agradecimentos ao:

Inmetro: Instituto Nacional De Metrologia Qualidade e Tecnologia

Pronametro: Programa Nacional de Apoio ao Desenvolvimento da Metrologia, Qualidade e Tecnologia.

\section{COPYRIGHT}

Direitos autorais: O autor é o único responsável pelo material incluído no artigo. 
ESTUDO E DESENVOLVIMENTO DE UM MODELO MATEMÁTICO PARA UM MONOTRILHO ELÉTRICO DE ALTA VELOCIDADE MOVIDO A ENERGIA SUSTENTÁVEL, VISANDO A DIMINUIÇÃO DA EMISSÃO DE DIÓXIDO DE CARBONO NO DESLOCAMENTO ENTRE AS CIDADES DE SÃO PAULO E RIO DE JANEIRO

\author{
STUDY AND DEVELOPMENT OF A MATHEMATICAL MODEL FOR A \\ ELECTRIC HIGH SPEED MONORAIL POWERED BY RENEWABLE ENERGY, \\ LOOKING TO DECREASE THE DISPLACEMENT OF CARBON DIOXIDE IN \\ THE DISPLACEMENT BETWEEN THE CITIES OF SÃO PAULO AND RIO DE \\ JANEIRO
}

\author{
CARLOS AUGUSTO MARCONDES DOS SANTOS; TEÓFILO MIGUEL DE SOUZA
}

UNIVERSIDADE ESTADUAL PAULISTA - GUARATINGUETÁ

cmarcondessantos@gmail.com; teofilo.souza@unesp.br

\begin{abstract}
Resumo - Este estudo é focado na diminuição da emissão de dióxido de carbono por veículos a combustão no deslocamento de milhares de pessoas entre as duas maiores cidades do país, Rio de Janeiro $e$ São Paulo. Este trabalho propõe um modelo matemático que desenvolve pela primeira vez um monotrilho de alta velocidade que se desloca exclusivamente através de energia sustentável. $O$ estudo consiste na análise de equações e conceitos que são aplicados a um monotrilho de alta velocidade, que por sua vez utilizará como fonte de energia primária a energia elétrica limpa, solar e eólica.

Palavras-chave: Monotrilho. Sustentável. Alta Velocidade.
\end{abstract}

Abstract - This study is focused on reducing the emission of carbon dioxide by combustion vehicles in the displacement of thousands of people between the two largest cities in the country, Rio de Janeiro and São Paulo. This work proposes a mathematical model that develops, for the first time, a high-speed monorail that moves exclusively through renewable energy, which in the future may be totally powered by sustainable energies. The study consists in the analysis of equations and concepts that are applied to a high-speed monorail which will use clean electrical energy as the primary energy source, solar and wind.

Keywords: Monorail. Sustainable. High Speed.

\section{INTRODUÇÃO}

A Agência Nacional de Transportes Terrestres (ANTT, 2017) afirma que os setores de transportes no país têm se expandido e melhorado em diversos aspectos nas últimas décadas, mas faz a ressalva que ainda não se encontra em estado satisfatório. Para o Anuário Estatístico de Transportes (2017) do Governo Federal Brasileiro, o transporte de passageiros pelo mundo pode ser realizado por meio de corpos d'água, terrestre e aéreo. Sendo assim, os meios de transporte são classificados em ferroviário, rodoviário, marítimo, fluvial e aéreo.
O desenvolvimento das cidades, o aumento no número de empregos e o maior número de pessoas circulando diariamente ocasionam um aumento na demanda por bons sistemas de transporte público no mundo (NAZARI; CHOWDHURY; SHIFTAN, 2019). O Ministério do Desenvolvimento Regional (2018) reforça a idéia que as cidades têm como papel principal maximizar a troca de bens e serviços, cultura e conhecimentos entre seus habitantes, mas isso só é possível se houver condições de mobilidade adequadas para seus cidadãos. Neste sentido, a mobilidade é um atributo associado à cidade e corresponde à facilidade de deslocamento de pessoas e bens na área urbana.

A intenção deste trabalho é buscar a diminuição da emissão de dióxido de carbono por veículos a combustão no deslocamento diário de milhares de pessoas entre as cidades do Rio de Janeiro e São Paulo, incluindo as capitais. O trabalho tem caráter analítico, com o objetivo principal de desenvolver um modelo matemático para se criar um monotrilho de alta velocidade movido exclusivamente através de energias sustentáveis, algo inovador e ainda não existente ao redor do mundo.

\section{METODOLOGIA}

\section{1 - Mobilidade Urbana Sustentável}

A mobilidade sustentável no contexto sócio-econômico e ambiental da área urbana pode ser vista através de ações sobre o uso e ocupação do solo e sobre a gestão dos transportes visando proporcionar acesso aos bens e serviços de uma forma eficiente para todos os habitantes, melhorando a qualidade de vida da população atual sem prejudicar a geração futura e principalmente o meio ambiente. Um bom programa de políticas de atuação urbana visando à mobilidade sustentável consiste na coordenação 
de ações conjuntas para produzir efeitos acumulativos de longo prazo atrelados ao balanceamento de metas ambientais, econômicas e sociais da sustentabilidade (KIMIJIMA, 2009).

Quando se trata de mobilidade urbana e sustentabilidade se destacam as tecnologias de transporte que tem a contribuição com o menor impacto ao meio ambiente, podendo ser associado a fatores como o consumo de energia, a qualidade do ar, emissões de gases poluentes e a poluição sonora (MATHIESEN, et al., 2015).

As questões relacionadas com a mobilidade sustentável e os possíveis impactos e indicadores ambientais podem ser classificadas como: esgotamento de recursos devido ao aumento do consumo de energia, mudanças climáticas devido ao aumento das emissões de $\mathrm{CO}_{2}$, aumento da poluição do ar devido às emissões de $\mathrm{NOx}, \mathrm{CO}$, compostos orgânicos voláteis e outros poluentes, aumento da geração de lixo, poluição da água, aumento da infra-estrutura gerando perda de área verde e até mesmo a falta de segurança nas rodovias com o aumento nos acidentes (BUDDE; WELLS; CIPCIGAN, 2012).

\section{2 - Transportes através de energias renováveis}

Os meios de transporte são amplamente observados nos tempos atuais em termos de emissões dos gases de efeito estufa (GEE) devido a sua dependência de combustíveis fósseis, particularmente $\mathrm{o}$ petróleo. Globalmente, o transporte privado é $95 \%$ dependente do petróleo e é responsável por mais de $50 \%$ do que o mundo consome (IEA, 2016). Esta dependência, bem como o volume consumido durante a locomoção das pessoas, continua a crescer. Os combustíveis alternativos têm ganhado espaço e mais investimentos através de pesquisas e estudos, se tornando a melhor alternativa ao motor de combustão interna, fazendo com que a implantação e utilização dos veículos elétricos ganhassem força e relevância nos últimos anos, isto é o que afirma a International Energy Agency (IEA, 2016).

A integração de transporte e eletricidade, em combinação com veículos elétricos e novas energias, oferecem um potencial para se reduzir significativamente a dependência energética mundial de combustíveis fósseis e a consequente emissão dos gases de efeito estufa. Em um futuro próximo, sistemas de energia sustentável em larga escala serão necessários para a redução substancial de $\mathrm{CO}_{2}$. Contudo, a implementação em grande escala enfrenta dois grandes problemas: a substituição do petróleo no transporte do setor privado, que é relativamente barato, e, apesar de abundante, o sistema de geração de energia utilizando-se recursos energéticos renováveis ainda é expensivo, sendo assim, deve-se manter um equilíbrio entre demanda e oferta (LUND, 2008).

Desde a criação dos fóruns de aquecimento global, os meios de transporte têm a oportunidade de se tornar um dos líderes na redução da emissão dos gases de efeito estufa, diminuindo a dependência sobre o petróleo, implantando planos ambiciosos para se substituir os veículos à combustão por veículos elétricos (KÜHNE, 2010). Israel foi um dos primeiros países a adotar uma nova estratégia de eliminar a dependência do petróleo nos transportes privados, investindo em toda uma frota de ônibus elétrico para os transportes internos no país. Todos os aspectos são importantes em uma malha rodoviária totalmente sustentável, desde o tipo de bateria para armazenamento da carga elétrica até como estas baterias serão carregadas e que tipo de energia é utilizada para isto. A infra-estrutura das estações de carga e onde as baterias do transporte elétrico serão armazenadas também são muito relevantes para o projeto de transporte elétrico sustentável (ANDERSEN; MATHEWS; RASK, 2009).

Segundo Richardson (2012), os setores de transporte e geração de energia elétrica do mundo estão diretamente ligados a alguns dos principais problemas de condução deste século: o pico do petróleo, as mudanças climáticas e a dependência energética. A geração e o transporte de eletricidade correspondem por $60 \%$ da demanda global de energia primária, sendo que a maioria da demanda de carvão do mundo é devido à geração de eletricidade e a maior parte da demanda mundial de petróleo é devido ao transporte. Tecnologias alternativas de veículos, como veículos elétricos, estão sendo desenvolvidas para reduzir a dependência mundial de petróleo e limitar as emissões de $\mathrm{CO}_{2}$ relacionadas ao transporte.

De acordo com Mathiesen et al. (2015), o transporte será um dos principais desafios na sociedade para o futuro e deve-se receber atenção especial nas próximas décadas, sempre envolvendo cenários com energias renováveis. Os resultados esperados para um futuro próximo incluem maior desenvolvimento e integração das ferramentas e metodologias em energia, meio ambiente e transporte, bem como análises, projetos e implementações de sistemas de energias renováveis visando o transporte de pessoas.

\section{3 - Métodos}

A potência de tração que um motor desenvolve ao se movimentar, com velocidade constante sobre um trecho horizontal, está relacionada às resistências ao movimento do trem (BOSCH, 2005). De maneira inapropriada tais resistências são usualmente denominadas de atrito. Esta denominação é inadequada, prejudicando o entendimento da dinâmica de trens motorizados, pois as resistências a serem vencidas sobre um traçado horizontal são aquelas devidas ao movimento em relação ao ar - o arrasto aerodinâmico - e à resistência ao rolamento das rodas sobre $\mathrm{o}$ trilho (SILVEIRA, 2011).

A força externa a um trem que o impulsiona para frente é usualmente uma força de atrito estático, exceto quando rodas patinam ou deslizam sobre o trilho, quando então vale o atrito cinético, entre as rodas de tração e o trilho de rolamento (BOSCH, 2005). Desta forma a força de atrito nas rodas de tração, ao invés de se opor ao movimento do trem, desempenha o importante papel de força motora. A força de arrasto aerodinâmico se deve preponderantemente a efeitos inerciais do ar sobre o trem, sendo o atrito viscoso do ar com as superfícies do trem desprezível frente aos efeitos inerciais do ar. Portanto, é equivocado denominar os efeitos do ar sobre o trem de atrito já que o atrito viscoso não é relevante neste caso (SILVEIRA, 2011).

Segundo Silveira (2011) a equação (1) é a fórmula essencial da potência de tração que pode se tornar aplicável a qualquer meio de transporte com motor, movido através de rodas. Neste projeto, após o desenvolvimento desta equação, será possível aplicá-la a um monotrilho de alta velocidade. As equações a seguir são desenvolvidas através da relação entre a potência de tração com as intensidades da força de atrito, da força normal ao trilho de rolamento, neste caso os 
trilhos do monotrilho, nas rodas de tração do trem e considera quando o mesmo trafega com velocidade constante, sempre utilizando e se pautando nas leis de Newton para demonstrar seus cálculos.

$\mathrm{P}_{\text {tra ção }}=\tau_{\text {tra ção }} \times \omega=\left(\mathrm{A}_{\mathrm{t}}+\alpha \times \mathrm{N}_{\mathrm{t}}\right) \times \mathrm{v}$

Sendo:

$P_{\text {tra ção }}$ é a potência de tração das rodas do trem resultante do produto da intensidade do torque de tração pela velocidade angular;

$\tau_{\text {tra ção }}$ é o torque de tração das rodas do trem;

có a velocidade angular constante em torno do eixo da roda do trem;

$A_{t}$ é a força de atrito estático nas rodas do trem;

$\alpha$ é o coeficiente de resistência ao rolamento das rodas do trem;

$\mathrm{N}_{\mathrm{t}}$ é a força normal exercida pelos trilhos nas rodas do trem;

$v$ é a velocidade constante de deslocamento da roda do trem.

As forças de atrito estático nas rodas de tração de um meio de transporte em uma pista horizontal são as únicas forças externas que possuem a mesma orientação da velocidade em relação à pista, portanto, impulsionam o veículo para frente. A resistência ao avanço desse veículo é encontrada através das forcas de atrito nas rodas livres (nãotracionadas) e a força de arrasto do ar. Denomina-se de At a intensidade da resultante das forças de atrito nas rodas de tração, A a intensidade da resultante das forças de atrito nas rodas livres, Fa a força de arrasto do ar, e considerando que o veículo se desloque com velocidade $\mathrm{v}$ constante, então a condição da equação (2) é decorrente da primeira lei de Newton.

$A_{t}=A+F_{a}$

Sendo:

A é a intensidade da resultante das forças de atrito nas rodas livres;

$\mathrm{F}_{\mathrm{a}}$ é a força de arrasto do ar.

Através das equações (3) e (4) pode-se definir a intensidade da resultante das forças de atrito nas rodas livres e o coeficiente de resistência ao rolamento, respectivamente.

$\mathrm{A}=\alpha \times \mathrm{N}$

$\alpha=\frac{\mathrm{d}}{\mathrm{R}}$

Sendo:

$\mathrm{N}$ é a intensidade da resultante das forças normais nas rodas não tracionadas do trem;

d é região de contato da roda do trem com o trilho;

$\mathrm{R}$ é a dimensão do raio das rodas do trem.

A intensidade da força de arrasto inercial, $\mathrm{Fa}$, é demonstrada na equação (5) e depende da densidade do ar, $\rho$, da área frontal do trem, $S$ (área do trem na direção perpendicular ao movimento do ar em relação ao trem), do coeficiente de arrasto, C, (parâmetro adimensional que depende da forma aerodinâmica do trem) e da velocidade do ar, v, em relação ao trem de acordo com a seguinte expressão.
$\mathrm{F}_{\mathrm{a}}=\frac{1}{2} \times \rho \times \mathrm{C} \times \mathrm{S} \times \mathrm{v}^{2}$

Sendo:

P é a densidade do ar;

C é o coeficiente de arrasto, que é um parâmetro adimensional que depende da forma aerodinâmica do corpo, no caso, a forma do trem;

$\mathrm{S}$ é a área do trem na direção perpendicular ao movimento do ar em relação a ele.

Ressalta-se a importância de mencionar que a velocidade do trem em relação ao trilho é a mesma que em relação ao ar, admitindo-se neste estudo teórico que não haja vento, portanto considera-se que o ar esteja parado em relação ao trilho

Ao substituir as equações (3) e (5) na equação (2) é possível se obter a equação (6) para a força de atrito estático nas rodas do trem.

$A_{t}=\alpha \times N+\frac{1}{2} \times \rho \times C \times S \times v^{2}$

A substituição da equação (6) na equação (1) fornece a potência de tração ilustrada na equação (8).

$\mathrm{P}_{\text {tra ção }}=\left(\alpha \times \mathrm{N}+\frac{1}{2} \times \rho \times \mathrm{C} \times \mathrm{S} \times \mathrm{v}^{2}+\alpha \times \mathrm{N}_{\mathrm{t}}\right) \times \mathrm{v}$

$\mathrm{P}_{\text {tra ção }}=\frac{1}{2} \times \rho \times \mathrm{C} \times \mathrm{S} \times \mathrm{v}^{3}+\alpha \times\left(\mathrm{N}_{\mathrm{t}}+\mathrm{N}\right) \times \mathrm{v}$

A soma das intensidades das forças normais ao trilho em todas as rodas do trem é aproximadamente (pois a força que o ar faz sobre o trem pode ter uma componente na direção perpendicular ao trilho e não apenas na direção paralela ao trilho) igual ao valor do peso do trem, encontrase assim a equação final para a potência de tração do trem de alta velocidade através da equação (9).

$\mathrm{P}_{\text {tra ção }} \cong \frac{1}{2} \times \rho \times \mathrm{C} \times \mathrm{S} \times \mathrm{v}^{3}+\alpha \times \mathrm{M} \times \mathrm{g} \times \mathrm{v}$

Sendo:

M é a massa do trem;

g é a intensidade do campo gravitacional.

A equação (9) indica que a potência de tração do trem que se desloque na horizontal com velocidade constante possui duas componentes: a primeira, associada ao arrasto do ar, crescendo com o cubo da velocidade e a segunda, associada à resistência ao rolamento, crescendo linearmente com a velocidade.

A equação da potência de tração encontrada neste capítulo demonstra um importante resultado para o projeto do monotrilho que interliga Rio a São Paulo. É possível notar que em baixa velocidade (como em ambientes urbanos), a potência de tração é predominantemente destinada a vencer a resistência ao rolamento. Já nos regimes de velocidades maiores, a potência de tração cada vez mais se destina a vencer o arrasto do ar, de acordo com o aumento da velocidade do trem. A partir desta equação será possível calcular a velocidade do monotrilho de acordo com suas especificações, traçado, modelo e limitações. 


\section{RESULTADOS}

Através do desenvolvimento destas equações é possível se calcular a potência máxima necessária para que um monotrilho se mova por uma hora consecutiva. Sendo assim, neste projeto foram utilizadas as características de um modelo de monotrilho já existente, com a finalidade de auxiliar durante os cálculos e trazer o projeto para a realidade, ilustrando a tecnologia já existente atualmente. O modelo de monotrilho escolhido para fornecer as bases de informações é o Innovia 300, da empresa Bombardier, ilustrado nas figuras 1 e 2 .

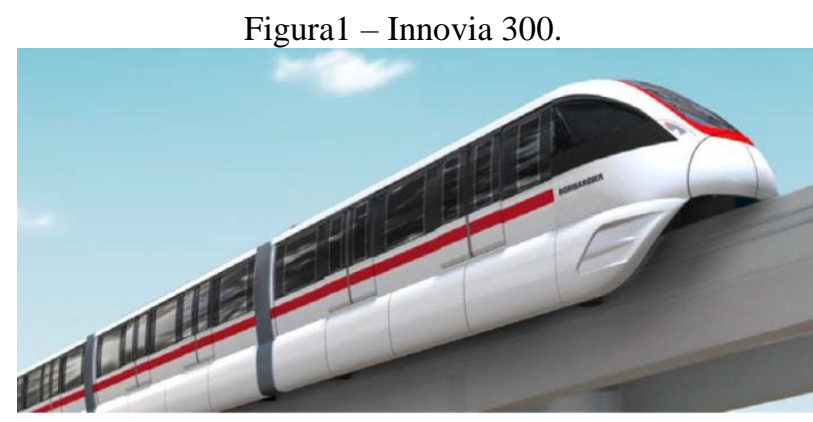

Fonte: Bombardier, 2010.

Figura 2 - Visão frontal do projeto de um Innovia 300.

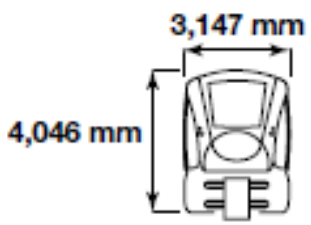

Fonte: Bombardier, 2010.

As informações que foram fornecidas pelo projeto da Bombardier do Innovia 300 (BOMBARDIER, 2010) são: dimensões das rodas do monotrilho, massa total do monotrilho considerando os carros com capacidade máxima de passageiros, coeficiente de arrasto aerodinâmico do monotrilho e a área frontal do monotrilho.

Os outros valores considerados neste projeto foram a velocidade de deslocamento do monotrilho que é de 200 $\mathrm{km} / \mathrm{h}$ ou seja, $55,55 \mathrm{~m} / \mathrm{s}$, totalizando 2 horas de percurso entre Rio e São Paulo (distância total de $402 \mathrm{~km}$ pela Rodovia Presidente Dutra), a gravidade da Terra de $9,8 \mathrm{~m} / \mathrm{s}^{2}$ e 103 pessoas, com massa de $90 \mathrm{~kg} /$ pessoa em média, por composição do monotrilho (total de 8 carros por composição).

Sendo assim, têm-se como valores de entrada as seguintes variáveis:

$\mathrm{R}: 0,685 \mathrm{~m}$

d: $0,148 \mathrm{~m}$

M: $23.279 \mathrm{~kg}$

g: $9,8 \mathrm{~m} / \mathrm{s}^{2}$

v: $55,55 \mathrm{~m} / \mathrm{s}$

$\rho: 0,8 \mathrm{~kg} / \mathrm{m}^{3}$

C: 0,08

S: $12,73 \mathrm{~m}^{2}$

Aplicando-se os valores de entrada na equação (9) tem-se o seguinte resultado para a potência do monotrilho durante uma hora de movimentação:
$\mathrm{P}_{\text {tra ção }} \cong \frac{1}{2} \times 0,8 \times 0,08 \times 12,73 \times 55,55^{3}+\frac{0,148}{0,685} \times$

$23.279 \times 9,8 \times 55,55$

$P_{\text {tração }} \times 8$ carros $=8 \times(2.730 .098)=21.840 \mathrm{MW}$

A partir do momento em que é encontrada a informação da potência máxima, em watt, necessária para se mover este monotrilho através de energia elétrica, durante uma hora, pode-se realizar a projeção do número de viagens diárias, para em fim ser projetado o quanto de energia limpa deve-se gerar para que este monotrilho se torne sustentável.

De acordo com o número de viagens dos ônibus rodoviários interestaduais, foi definido para este projeto um total de 32 viagens por dia, sendo elas dois trens partindo, simultaneamente, de hora em hora das duas estações iniciais (Rio de Janeiro e São Paulo), com horário de operação entre 06:00 e 22:00 horas, sete dias da semana.

A partir das informações do número de viagens que serão realizadas diariamente e a potência de tração de operação do monotrilho por uma hora, pode-se calcular a energia consumida mensalmente neste projeto em watt hora através da equação (10), que mostra a potência de tração durante uma hora sendo multiplicada por 2 horas de operação, 31 dias de um mês e 32 viagens diárias.

Econsumida $=$ Ptração $\times 2 \times 31 \times 32$

Econsumida $=21,840 \times 2 \times 31 \times 32=43.330,56 \mathrm{MWh}$

Portanto, a partir destes cálculos é conhecido que serão necessários se gerar 43.330,56 MWh durante todo o mês de operação do monotrilho, que neste projeto, serão produzidos através de energia solar e eólica.

Com a informação da energia consumida é possível calcular a energia solar gerada e a energia eólica gerada para atender este consumo, que neste projeto para uma maior ilustração da capacidade de cada sistema, serão divididos em $50 \%$ de cada modo energético, isso é possível devido às características da região Rio-São Paulo, com ventos médios de $16 \mathrm{~km} / \mathrm{h}$ (INPE, 2020) e 5,6 horas/pico de média anual de sol de pico a pelo menos $1.000 \mathrm{~W} / \mathrm{m}^{2}$ de irradiação solar diária (CEPEL, 2018).

Para se gerar $50 \%$ da energia consumida através de energia solar, aplica-se as informações da metade da energia consumida diária (1.397,76 MWh), Eq. (10), na Eq. (11) e o resultado deve ser inserido na Eq. (12) para se encontrar o número de painéis necessários neste estudo. Nestas equações o valor de Af representa o arranjo fotovoltaico necessário para suprir a demanda de energia diária, ou seja, a potência de todos os painéis necessários para se atender ao consumo de energia, o HSP representa as horas de sol de pico, referente ao tempo de exposição máxima dos painéis solares no plano horizontal na região do estudo a pelo menos $1.000 \mathrm{~W} / \mathrm{m}^{2}$ de irradiação solar diária, sendo a informação de 5,6 horas/pico de média anual de sol de pico fornecida pela CEPEL (2018) de acordo com as coordenadas de latitude e longitude da região e o Pps é a potência do painel solar que será utilizado neste estudo, sendo escolhido um painel de $2 \mathrm{~m}^{2}$ de $405 \mathrm{Wp}$ da Canadian Solar (2019), com o rendimento também fornecido pela empresa em seu datasheet. 
Consumo diário $50 \%=$ Consumo diário $\times$ 0,50

Consumo diário $50 \%=1.397,76 \mathrm{M} \times 0,50$

Consumo diário 50\% = 698,88 MWh

Af $=\frac{\text { Consumo diário } 50 \%}{\operatorname{HSP} \times(1-\text { rendimento })}$

$$
\text { Af }=\frac{698,88 \mathrm{MWh}}{5,6 \text { horas } / \text { pico } \times(1-0,20)}=156.000 .000 \mathrm{Wp}
$$

Número de painéis $=\frac{\mathrm{Af}}{\mathrm{Pps}}$

Número de painéis $=\frac{156.000 .000 \mathrm{Wp}}{405 \mathrm{Wp}}=385.185,18$

Número de painéis $=385.186$ painéis

Após o cálculo do número de painéis solares de $405 \mathrm{Wp}$ que serão necessários para fornecer os 698,88 MWh de energia e de posse da área de cada painel, $2 \mathrm{~m}^{2}$ de acordo com os catálogos dos fabricantes, pode-se afirmar que os painéis irão ocupar uma área de $770.372 \mathrm{~m}^{2}$, que é o equivalente a área de 71 campos de futebol.

O cálculo do número de turbinas eólicas para este projeto é mais simplificado, se baseando apenas no catálogo da turbina escolhida para o fornecimento de energia. A turbina eólica escolhida para este estudo é a Vestas V164 de três pás. Esta turbina eólica, segundo o fabricante, gera $98.742,85 \mathrm{kWh} /$ dia a um vento médio de $16 \mathrm{~km} / \mathrm{h}$. De posse desta informação e sabendo que as turbinas eólicas devem atender a geração de $698.880 \mathrm{kWh} /$ dia, pode-se afirmar que serão necessárias aproximadamente 7 turbinas eólicas para atender esta demanda energética.

Portanto, conclui-se que este projeto com 7 turbinas eólicas e 385.186 painéis solares instalados será suficiente para atender ao consumo de energia demandado pelas 32 composições de monotrilhos que se deslocarão entre São Paulo e Rio de Janeiro. Sendo assim, é possível afirmar a viabilidade deste projeto ser implantado através de energias sustentáveis e renováveis.

\section{CONCLUSÃO}

A preocupação dos líderes globais nos últimos encontros das Organizações das Nações Unidas, Grupo dos 7 e Grupos dos 20 foram pautadas nas mudanças climáticas e aquecimento global. Com estes assuntos sempre presentes, o desenvolvimento sustentável se tornou cada vez mais obrigatório e necessário nos últimos anos. A população global continua a crescer e o número de empregos e produção de insumos devem se manter alto durante o passar dos anos, com isso a ciência busca alternativas para a geração de energia sustentável, evitando cada vez mais a emissão dos gases que causam o efeito estufa.

Neste projeto foi tratado um assunto muito relevante para o Brasil como um todo, sendo que é de conhecimento de todos que um dos grandes responsáveis pelo efeito estufa é a emissão de dióxido de carbono pelos carros, motos e ônibus no deslocamento diário de pessoas. Sendo assim, este estudo escolheu duas das maiores cidades do Brasil para se basear e realizar um modelo matemático capaz de abranger outras cidades de mesmo porte ou até mesmo cidades menores, com a finalidade de reduzir o tráfego de pessoas neste trajeto, oferecendo um deslocamento mais viável, limpo e rápido, atraindo assim o maior número de pessoas para este meio de transporte, consequentemente, o número de pessoas que trafegam durante o dia através de outros modos irá diminuir e a poluição do ar e atmosfera também irão.

O resultado final do projeto apresentado se mostra muito coerente com o proposto e totalmente viável de se implantar, tendo como o maior contraponto para a sua realização o investimento inicial, já que a compra do monotrilho, painéis solares e turbinas eólicas ainda são considerado relativamente caros nos dias de hoje. Entretanto, este problema pode ser facilmente resolvido através de um contrato de concessão para exploração do trecho durante um longo período de tempo, por uma empresa privada, através de licitação promovida pelo governo federal.

\section{REFERÊNCIAS BIBLIOGRÁFICAS}

ANDERSEN, Poul; MATHEWS, John; RASK, Morten. Integrating private transport into renewable energy policy: The strategy of creating intelligent recharging grids for electric vehicles. Energy Policy. v. 37, p.6, 2009.

BOMBARDIER, Transportation. INNOVIA Monorail 300 Technology, Automated Monorail System. Official catalog. Berlim. v.1. p.2, 2010.

BRASIL. Agência Nacional de Transportes Terrestres. Relatório Anual. Brasília: MI, 2017. 151 p.

BRASIL. Ministério do Desenvolvimento Regional. Relatório de Gestão. Brasília: MDR, 2018. 119 p.

BOSCH, Robert. Manual de Tecnologia Automotiva. São Paulo, 2005.

BUDDE, T.; WELLS, P.; CIPCIGAN, L. Can innovative business models overcome resistance to electric vehicles? Better Place and battery electric cars in Denmark. Energy Policy, v. 48, p. 498-505, 2012.

CEPEL, Centro de Pesquisas de Energia Elétrica. SunData Potencial Solar. Centro de Referência para Energia Solar e Eólica Sérgio de Salvo Brito. Rio de Janeiro, 2018.

IEA. International Energy Agency. Key World Statistics. Paris Cedex 15, France, 2016. 80 p.

INPE, Instituto Nacional de Pesquisas Espaciais. Banco de dados do Centro de Previsão de Tempo e Estudos Climáticos. Banco de dados CPTEC, 2020. Disponível em: $<$ http://bancodedados.cptec.inpe.br/>. Acesso em: 02 de fev. de 2020.

KIMIJIMA, Nobuhiko. New Urban Transport System for Middle East Monorail System for Dubai Palm Jumeirah Transit System. Hitachi Review. v. 59, p.47, 2009.

KÜHNE, Reinhart. An energy efficient urban transportation means. Energy. v. 35, p.4, 2010.

LUND, Henrik. Renewable energy strategies for sustainable development. Energy Policy. v. 32, p. 8, 2008. 
MATHIESEN, B. V et al. Smart Energy Systems for coherent $100 \%$ renewable energy and transport solutions. Applied Energy, v. 145, p. 139-154, 2015.

NAZARI, S.; CHOWDHURY, S.; SHIFTAN, Y. Justice in public transport systems : A comparative study of Auckland , Brisbane, Perth and Vancouver. Cities, v. 90, n. January, p. 88-99, 2019.

RICHARDSON, David. Electric vehicles and the electric grid: Are view of modeling approaches, impacts, and renewable energy integration. Renewable and Sustainable Energy Reviews. v. 19, p.8, 2012.

SILVEIRA, Fernando. Potência de tração de um veículo automotor que se movimenta com velocidade constante. Revista Brasileira de Ensino de Física. v. 33, p.7, 2011.

SOLAR, Canadian. HiKu Super high power poly perc module. Official datasheet. Canada. v.1 p. 2, 2019.

\section{AGRADECIMENTOS}

O presente trabalho foi realizado com apoio da Coordenação de Aperfeiçoamento de Pessoal de Nível Superior- Brasil (CAPES), através do Programa de Demanda Social. O mais sincero agradecimento a todo o corpo de funcionários e professores da Pós-Graduação da UNESP.

\section{COPYRIGHT}

Direitos autorais: Os autores são os únicos responsáveis pelo material incluído no artigo. 